\title{
SET UP TO FAIL: THE IMPOSSIBILITY OF EMPLOYABILITY AS A SUBJECT POSITION FOR REINTEGRATING WOMEN
}

by

Anita Grace

A thesis submitted to the Faculty of Graduate and Postdoctoral Affairs in partial fulfillment of the requirements for the degree of

Doctor of Philosophy

in

Law and Legal Studies

Carleton University

Ottawa, Ontario

(C) 2020

Anita Grace 


\begin{abstract}
In this dissertation, I use critical discourse analysis to identify the material and conceptual barriers that prevent women who are reintegrating into the community after periods of incarceration from becoming 'employable'. Employability, as conceived within this dissertation, is a subject position toward which reintegrating women are directed. Yet while they are directed toward this, 'employability' is conceptually incompatible with the ways the needs and abilities of 'criminalized' women are characterized through correctional discourse. Drawing from in-depth interviews with twenty-one reintegrating women and thirteen service providers, I identify the contradictions within the discourses that describe reintegrating women, and which proscribe and constrain their possibilities for reintegration.
\end{abstract}

I offer a contribution to the scholarship of the past three decades that has queried, monitored and challenged practices and policies relating to women's corrections in Canada. Feminist efforts to identify women's pathways to crime, efforts which emphasize women's social, political, and cultural contexts, have been incorporated into correctional discourses that shift the emphasis from women's experiences, to the emotional and psychological impacts of those experiences. This serves to individualize structural problems. I probe the expressed rationales and practices of employment support for reintegrating women, and more importantly, examine how women navigate and respond to these supports and the discourses which sustain them. I find that the discourses which surround and support certain subject positions for women, discourses which are mobilized by adjectives such as 'criminalized', render elusive women's emancipation and redemption. I believe it is imperative to recognize the intersectional contexts of reintegrating women's lives and experiences. There is also a need to recognize the conceptual limitations of 
subject positions which are generated and mobilized through current discourses about women's criminalization, incarceration, and reintegration. 


\section{ACKNOWLEDGEMENTS}

First, I acknowledge and thank the twenty-one women, and thirteen service providers, who shared their experiences and insights with me. Many of them expressed willingness to help me advance my research, but also hoped to better address the multiple challenges women face in reintegration. My hope is that in sharing their narratives I have done justice to their stories and that my analysis can further efforts to support reintegrating women.

Thank you to my committee, Sheryl Hamilton, Diana Majury, and Aaron Doyle. Your comments and guidance throughout this project have been extremely valuable. You pushed me to deepen my analysis and pursue new ideas. I am so grateful for all your support. I also want to thank Kelly Hannah-Moffat and Jeff Monaghan, who were external and internal reviewers for my defence. Your insightful feedback was much appreciated and will inform my future work. To William Walters, who provided guidance and insight in the early stages of this research project, thank you. I am also grateful for support from other faculty members at Carleton, particularly Christiane Wilke, as well as for support from department staff, particularly Andrew Squires and Barb Higgins. I have also received extensive support and encouragement from members of the community, especially those who are active in supporting criminalized adults. They have been my sounding board and my motivation. In particular I would like to thank Samantha McAleese and other folks at CAJN, Yolande Knight and the CAC team, and Eileen Henderson.

I had several sources of financial support throughout my doctorate, without which I could not have completed my degree or done such an extensive project. I am grateful to SSHRC for awarding me the Joseph-Armand Bombardier Canada Graduate Scholarship. I would also like to acknowledge funding through Ontario Graduate Scholarships and Carleton University. This 
research was also made possible with permission from the Research Branch of Correctional Services Canada. 


\section{Table of Contents}

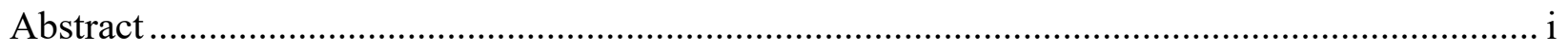

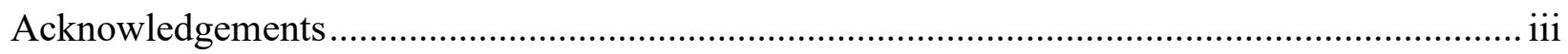

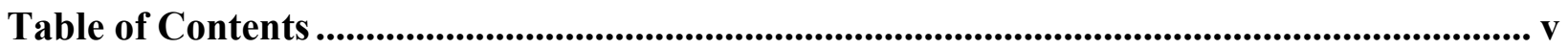

1. Conceptual Incompatibilities: Criminalized Women vs. Employable Women .................. 1

2. Make them work: The centrality of employability in corrections and reintegration ...... 10

Profile of incarcerated and reintegrating women in Canada.................................................... 11

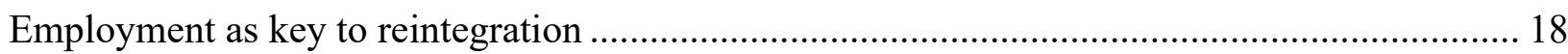

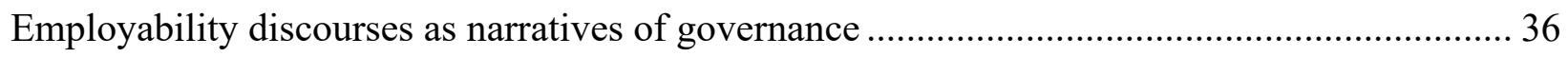

Research project: Discourses of employability............................................................. 43

3. 'I'm not ready for this': Employment supports for reintegrating women ....................... 63

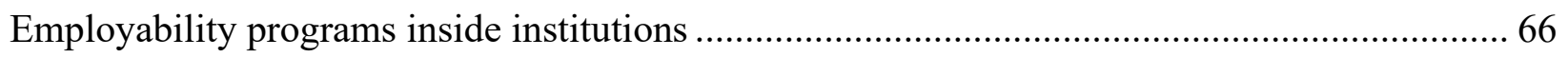

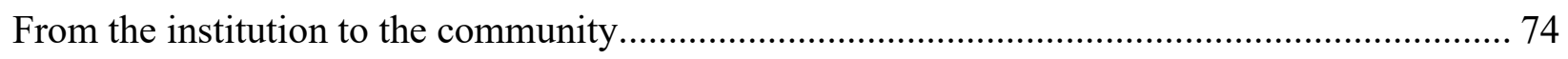

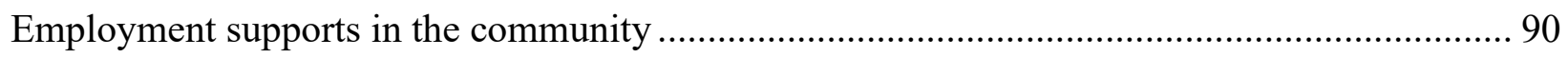

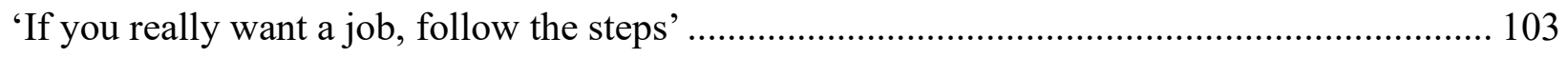

'It's not just the individual; it's not just the system. It has to be both.' Responsibility and

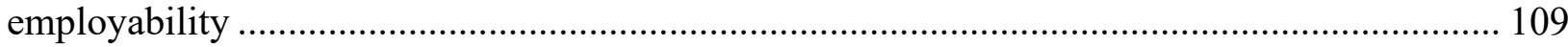

4. "It's your choice": Negotiating criminal records..................................................................... 112

"They can't do what they've done in the past" ............................................................... 114

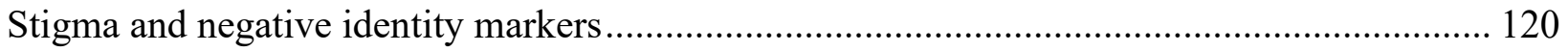

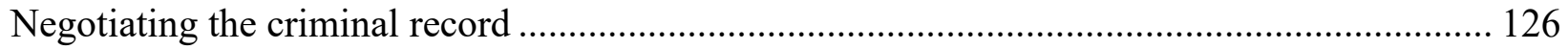

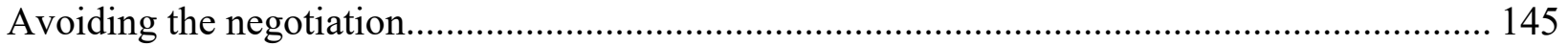

'It's your choice': The political becomes personal ............................................................. 158

5. Becoming work ready: Confidence \& mental health........................................................ 163

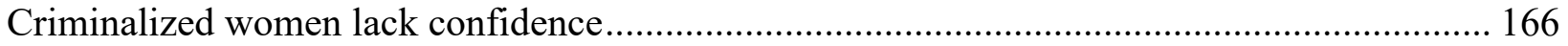

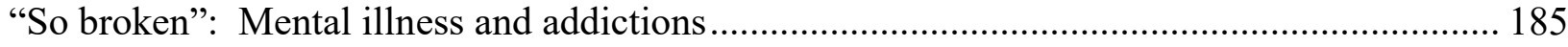

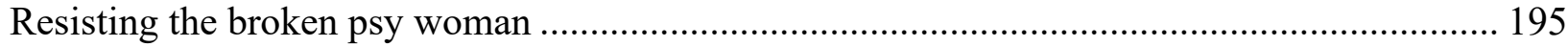

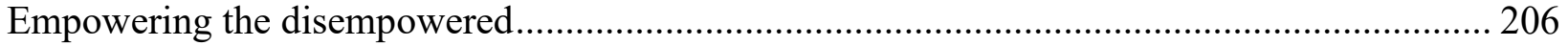

6. Work as 'soul craft' and redemption .....................................................................................208

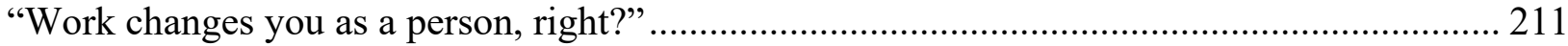

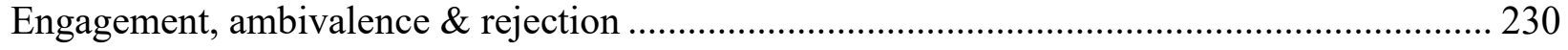

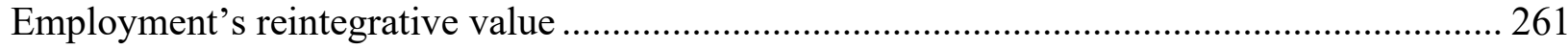

7. Irresponsible disempowerment.......................................................................................... 265 
'Don't give up': Advice from reintegrating women ..................................................... 272

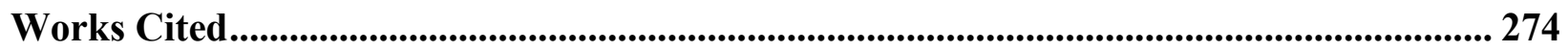

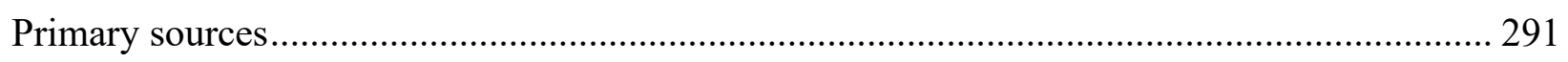

Appendix A - Recruitment Flyer.................................................................................. 293

Appendix B - Interview Guide - Service Providers ............................................................ 294

Appendix C - Interview Guide - Reintegrating Women .................................................. 295 


\section{Conceptual Incompatibilities: Criminalized Women vs. Employable Women}

Words matter when talking about women who are, or have been, incarcerated. Correctional Service Canada uses the term 'offender' to refer to anyone who is housed within a correctional facility, as well as anyone who is serving a sentence in the community. This word, offender, is widely resisted by academics and advocates alike. It ties individuals to their conviction, grants no other identity outside of that of having 'offended' criminal law. To replace this term, various others are adopted and used, and which indicate a particular critique or position. For example, Karlene Faith (1993) emphasizes the agency and resistance of the "unruly woman" in prison. Elizabeth Comack $(1996,2018)$ writes about "women in trouble", connecting the colonial and systemic abuses of women with their law violations. She, like many others, also refers to 'criminalized women', a term commonly used to draw attention to the governing apparatus that criminalizes women and to resist suggestions that women themselves are 'criminal' (see also Maidment 2006; Kilty 2012; Carlton and Segrave 2011). Indeed, the use of the term 'criminalized women' can signal one's feminist, critical position. Yet while I share that position, I have become hesitant to refer to women convicted of criminal offences as 'criminalized women'.

The apparatus that criminalizes women is repressive and colonial; evidence shows it is sexist and racist as well. As such, feminists have rightly pushed back against it by employing a term that focuses on, even responsibilizes, the institutions that ensnare and punish women. Feminist scholars and advocates have been instrumental in driving efforts to change criminal justice 
policies and practices in Canada. Robust, empirical research has informed what is known as 'pathways to crime' scholarship, a body of literature which illuminates how women's attempts to cope with victimization, trauma, and abuse propel them into situations in which they are at risk for being in conflict with the law (Comack 1996; Richie 1996; Simpson, Yahner, and Dugan 2008). This scholarship has been vital to challenging notions of 'mad' and 'bad' women who 'break the law' (Backhouse 1991). Indeed, it is vitally important to draw the connections between women's involvement with the criminal justice system and their experiences of trauma, poverty, abuse, gender-based violence, and other social and systemic wrongs. However, feminists scholars have noted that correctional discourse and practice adopt their contributions but use them to develop "individualistic and psychologized understandings of criminalized women" (Pollack 2007, 159; see also Hannah-Moffat 2001, 2000). The individualistic focus on women and their emotional needs informs the type of programming available to incarcerated and reintegrating women. CSC claims to offer 'gender-specific' programming that "reflect[s] an understanding of the psychological development of women" (Fortin 2004, 5). What this means in practice is that the feminist efforts to identify women's pathways to crime, efforts which emphasize women's social, political and cultural contexts, have been incorporated into correctional discourses that shift the emphasis from women's experiences, to the emotional and psychological impacts of those experiences. This individualizes structural and systemic problems.

Attuned to the ways in which the discourses of criminalization have been adopted, and adapted, by corrections, throughout this dissertation I use the term 'criminalized women' cautiously. I refer to the formerly incarcerated women who participated in this study as 'reintegrating women'. The verb 'reintegrating' emphasizes the process of transition and focuses 
on women's experiences of that process. ${ }^{1}$ There are those who would argue that 'reintegration' is disingenuous since many people who have been incarcerated were never 'integrated' into a community in the first place. Nonetheless, women who exit prison have no choice but to exist within a governing apparatus of reintegration that has legislated mandates (Corrections and Conditional Release Act 1992), physical infrastructure (halfway houses, parole offices, etc.), and a myriad of community-based organizations that provide various services and supports, some of which women are mandated to attend. Women leaving a carceral institution must become 'reintegrating women'. This is a subject position mandated, and shaped, by the correctional system. In this dissertation, I explore women's narratives about inhabiting this position.

'Criminalized' women are marked by their past; they were, at some point, convicted of a criminal offence. This identification of a woman with her criminalization forecloses discussion of her agency not only during her criminalization, but also in response to the apparatus of punishment and reform that is mobilized by a criminal conviction. 'Reintegration' is the present condition for the women I interviewed; it is on-going and indefinite. Reintegrating women are actively engaging in, negotiating, and even resisting their reintegration. Some women I met expressed trepidation and fear; others made bold claims of action and resilience. Some immediately dove into employment; others resisted the imperative to find work. I focus on women's reintegrating as an active engagement between women, those around them, and the governing technologies of reintegration. 'Employability' is the future subject position toward which women are directed.

\footnotetext{
${ }^{1}$ Here I am referencing Elizabeth Comack's (2018) use of the term 'prisoning of women' to emphasize the process and experience of incarceration.
} 
Employment is widely considered as key to, and a positive indicator of, successful reintegration (Davis, Bahr, and Ward 2013; Cobbina 2010; Pager 2007; Uggen, Wakefield, and Western 2005; Travis and Visher 2005; Petersilia 2003; Maruna 2001; Griffiths, Dandurand, and Murdoch 2007; Graffam et al. 2004; Ricciardelli, Evans, and Peters 2017). It is described as a way to reduce the likelihood of recidivism and to promote 'desistance' from crime (Delveaux, Blanchette, and Wickett 2005). Yet while employment may be important to reintegration, the apparatus of the reintegration system does not itself employ people (at least not the people coming out of prison). Reintegrating individuals must find employment in the private and public labour market, which means they must compete with other job seekers and successfully earn the opportunity to exchange their labour for wages. In other words, the reintegration apparatus does not make people employed; it aims to make them 'employable'. The production of incarcerated women as employable subjects can be traced back through the history of Canada's practices of governance through which 'wayward' and 'fallen' women are guided toward redemption (Hannah-Moffat 2001). It also reflects the reintegrative claims of the criminal justice system, such that the it not only punishes and deters crime, but provides for the welfare of 'lawbreakers' so they can lead productive lives and participate in the duties of citizenship (McKim 2017, 7). Women's prisons have historically emphasized 'honest labour' as key to women's 'reform' (Strange 1983). Women's correctional and reintegration programming claims to transform criminalized women into employable women.

This dissertation is titled Set Up to Fail: The Impossibility of Employability as a Subject Position for Reintegrating Women because while reintegrating women are directed toward becoming 'employable', that subject position is incompatible with current discourses about women's needs and abilities. This is not to say that reintegrating women are not, and cannot be, 
employed. Half of the women I interviewed had jobs. But when one considers how the discourse of employability creates a particular subject position for reintegrating women, it becomes apparent that this subjectivity is conceptually incompatible with the way 'criminalized' women are characterized through correctional discourse, both within institutions and in communities. My discursive project identifies the contradictions within these discourses by probing the expressed rationales and practices of employment support for reintegrating women, and more importantly, examining how women navigate and respond to these supports and the discourses which sustain them. I argue that the discourses which surround and support certain subject positions for women, discourses which are mobilized by adjectives such as 'criminalized', render elusive women's emancipation and redemption. I have come to believe that the employability of reintegrating women is conceptually impossible in current discourse.

The characteristics of a generic (even non-gendered) employable subject are expressed through programs and supports available to reintegrating women. In the discourses used within these programs, the employable woman is described as confident, driven, and focused on her future. She possesses an innate work ethic which she is ready and willing to demonstrate in any task, no matter how menial. Yet, in discourses addressing criminalized women, the reintegrating woman is broken, needy, and traumatized. She is incapable of knowing or acting in her own best interests, and cannot articulate or identify her own skills and abilities. These are the polarized characteristics of the two subject positions with which reintegrating women must constantly contend.

Reintegrating women encounter these discourses within the (somewhat adhoc) network of supports and services available to them 'in the community'. Service providers within this network assist women in various aspects of their reintegration, including employability. They 
draw upon a long history of feminist activism that seeks to improve women's labour opportunities and draw attention to the marginalization of individuals because of their gender, race, ability, sexuality, and class. Many of these service providers work within non-profit, community-based organizations whose mandates are to empower and support marginalized individuals and people involved in the criminal justice system. Like the correctional system, these organizations are informed by discourses of criminalization that emphasize women's experiences of trauma, poverty, and other abuses. As such, service providers mobilize the same incompatible discourses found within correctional institutions, discourses that construct criminalized women as broken and traumatized. Their efforts to 'empower' women presuppose that reintegrating women are 'disempowered'. When the efforts of community-based service providers to assist reintegrating women leave unchallenged, or even reify, the broken and needy subject position of the 'criminalized woman', the subjectivity of the employable woman remains impossible for reintegrating women to obtain as she cannot simultaneously inhabit these polarized subject positions.

\section{Outline}

Deviating somewhat from the traditional five-chapter structure of a dissertation, I explore the foundations and context of this project through two introductory chapters (Chapters Two and Three), and then provide three analytical chapters which probe the discourses of criminalization, reintegration, and employability. In Chapter Four, I focus on the criminal record and the surrounding discourses that reflect its associated stigma. The criminal record is the most obvious barrier to stable, well-paid employment. Employability programs cannot erase this barrier. Yet while the criminal record is recognized as a key exclusionary practice, its impact on reintegrating 
women has not been well examined in existing literature on reintegration and employment. Through this research, I indicate there are multiple uniquely gendered aspects of the criminal record as an employment barrier for women. One is that the record bars women from employment sectors in which they are most likely to have experience, and/or most likely to want to work. Closely related to this point is that sectors of the labour force that are more likely to accept or tolerate criminal records, such as construction, labour and trades, are male-dominated and not as accessible to women. Women often lack the experience and connections necessary for entry. They may also be intimidated, harassed, and feel uncomfortable on job sites. Additionally, the criminal record is not a barrier in and of itself, rather it becomes a barrier through its interpretation as a negative stigma signified by employers and other members of the public. Reintegrating women face heightened stigma, due to notions of dual-deviance relating to gender norms and expectations. My findings show that when service providers focus on how individual women negotiate the barrier of the criminal record, this serves to shift the location of the barrier of the record from the record itself to women's capacities for, and demonstrations of, ethical selfgovernance. How women interpret their responsibility for negotiating the criminal record demonstrates their awareness of the contradictory discourses, particularly around honesty, which govern their actions and morality.

Chapter Five delves more deeply into the subjectivity of reintegrating women, examining how the barriers to employment which are commonly identified by service providers and reintegrating women relate to internal aptitudes, attitudes, health, and well-being. I describe the internal locating of women's problems as the construction and mobilization of the subject position of the 'broken psy woman', offering this heuristic device to examine the impacts of psy interventions on criminalized women, of the heightened focus on women's mental and emotional 
'needs', and of the interpretation of women's experiences of distress and anger as symptoms of psychiatric disorder (Kilty 2012). Even while the broken psy woman is engendered through past experiences (trauma, abuse, violence, suffering, etc.), her subject position, as mobilized and expressed through narrative, affixes those experiences to her individual self, such as through the mobilization of psy diagnoses such as personality disorder. Such discourses construct women as broken, not women who were broken (in contrast to women who were convicted or criminalized). The broken psy woman is someone who is fundamentally disempowered; but the discourse about this subject position is powerful and pervasive. Reintegrating women must contend with the figuration of this broken psy woman as they seek to articulate their needs and experiences.

In Chapter Six, I explore the subject position of the employable woman through the narratives about work ethic and motivation. The production of employability is that of a particular subjectivity, one which is shaped by deeply-entrenched norms about gender, race, and class, and about assumptions governing the relationship between work and individual identity. The emphasis on the production of reintegrating women as employable subjects reifies work as the dominant model of social belonging, excluding other possibilities of productive social roles. The narrative of employable subject describes her as someone who is motivated to becoming a 'contributing member of society'. She is future-oriented, willing to embark upon the 'steps to success'. Given the pervasive association of employability with successful reintegration, reintegrating women are required to demonstrate the internalization of employability discourses, such as work ethic and 'drive to succeed'. Yet women are faced with the incompatibility of the subject positions of the criminalized, broken woman and the employable woman. Their 
descriptions of their relationship with work, and with the employable subject position, indicate the dynamic ways in which they navigate this incompatibility.

In the concluding chapter, I revisit the key claims of my dissertation, and indicate implications for future research and areas of exploration. While I echo the feminist call to recognize the intersectional contexts of women's lives and criminalization, I believe there is a need to think carefully about how such contexts are discussed and positioned in relation to women's identities. The figuration of the broken psy woman pathologizes women's responses to their lived experience. I invite consideration of how discourses of mental health and mental illness contribute to this figuration, and how we interpret women's responses to the experience of incarceration. 


\section{Make them work: The centrality of employability in corrections and reintegration}

Wherever you look in the development of modernist penality you will find labor. Exhort the offenders with religious tracts, but make them work. ... Educate them as citizens, but make them work. Treat their pathological features, but make them work. ${ }^{2}$

- JonATHAN SimOn, POOR DISCIPLINE

Reintegration is commonly understood as transition from the institution to the community. The associated implication is that individuals move from a space of constraint to one of freedom. Yet the 'freedom' of reintegration is somewhat illusory, and always contingent on the on-going compliance with various rules and duties. As noted in the introduction, this project focuses on 'reintegrating women', emphasizing reintegration as an active verb, as something located in the present and of indefinite duration. At what point can someone be said to have reintegrated? There is much emphasis in scholarship on criminalized women about women's pathways to crime and their experiences of incarceration. But what about their pathway from prison into the community? And what are the policy and program discourses that shape women's experiences of reintegration?

This chapter maps out the foundations of my dissertation project, beginning with a profile of incarcerated and reintegrating women in Canada and a description of some of the correctional programming available to them inside institutions. Next, I examine the discourse of employability in relation to reintegration. Throughout this work I will challenge these discourses of employment and employability, destabilizing their normative assumptions and redemptive

${ }^{2}$ Simon (1993, 39). 
claims. In this chapter, I also lay the foundations of the exploration in Chapter Four of the criminal record as an obstacle to employment by placing it within its political and legal context. In the third section, I introduce the theoretical discourses of responsibilization and empowerment which will be applied throughout this dissertation to examine the narratives of service providers and reintegrating women. While this project draws from, and builds upon, critical criminology scholarship and literature about governance and responsibilization, my focus throughout is on how reintegrating women are being responsibilized, and their narratives about how it feels to be responsibilized. What are women's experiences within the governing apparatus of reintegration? I probe the discourses and practices of responsibilization, opening them up to show how service providers and reintegrating women actively engage with them. Finally, I provide details about the research project, its methods and participants.

\section{ProfiLe OF INCARCERATED AND REINTEGRATING WOMEN IN CANADA}

Within Canada, imprisonment is a divided responsibility between federal and provincial governments, such that those who receive sentences less than two years serve their sentence in provincial institutions or jails (or the community), while those with sentences two years or more serve time in federal institutions. Within both federal and provincial corrections, women make up a fraction of those who are incarcerated. For example, in 2016-2017, the number of women admitted to federal prisons was less than ten percent of the number of men (402 women compared 4,407 men) (Public Safety Canada 2017, 38). Most women (over ninety percent) who receive custodial sentences are sent to provincial jails (Public Safety Canada 2017). Still, in Ontario, women make up only thirteen percent of the incarcerated population in provincial jails, and about nineteen percent of the population under community supervision (Malakieh 2018). 
These numbers are small in comparison to men (which has led to critiques of women being considered as "too few to count" (Adelberg and Currie 1987)), and has resulted in prisons, and correctional programming, being designed primarily for men (Comack 2018).

Yet in the last decade, women's rates of incarceration rose alarmingly. ${ }^{3}$ Changes to criminal justice policies resulted in a seventy-seven percent increase in the number of women federally incarcerated between 2005 and 2015 (Comack, Fabre, and Burgher 2015, 3), which had been partly attributed to the increase of mandatory minimum sentences (Mangat 2014). It is also extremely troubling that despite repeated calls to address the over-incarceration of Indigenous people (e.g. Royal Commission on Aboriginal Peoples 1996; Aboriginal Justice Implementation Committee 1999; Monchalin 2016), Indigenous women make up a disproportionate amount of the women who are incarcerated (36.6 percent), and are receiving federal sentences at increasing rates (up to 253 in 2016-17 from 177 in 2007-08) (Public Safety Canada 2017, 53 \& 63). Incarcerated women have generally been economically, socially, and racially marginalized (Comack and Balfour 2004; Hannah-Moffat 2013; Turnbull and Hannah-Moffat 2009; Maidment 2006). The vast majority of their convictions are related to 'poverty crimes', such that they reflect "systemic inequality, discrimination, and marginalization emanating from their class/race/gender locations" (Balfour and Comack 2014, 64).

Only 3.5 percent of those serving a life or indeterminate sentence in Canada are women (Public Safety Canada 2017, 57). This indicates that the majority of incarcerated women will be released back to the community, either in a graduated re-entry via residency in a halfway house,

\footnotetext{
${ }^{3}$ Recent trends suggest that Correctional Service Canada (CSC) is making effort to reduce women's incarceration, such as by increasing the number of women under community supervision (Kelly, Senate Standing Committee on Human Rights 2019). And with regard to provincially sentenced individuals, most sentenced to the Ontario correctional system are supervised in the community (Sapers 2017).
} 
after a portion of their sentence has been served (conditional release), or upon attainment of their statutory release date (stat). ${ }^{4}$ Prisoners in Canada, in both federal and provincial institutions, are eligible for conditional release after serving the lesser of either one-third of their sentence or seven years (unless they are serving a life sentence for murder). ${ }^{5}$ Conditional release means they are allowed to live in the community, but must abide by various conditions (such as not associating with certain people or being in certain geographic areas, being of 'good behaviour', and abstaining from drugs and alcohol). They are supervised by either parole (federal) or probation (provincial) officers, which may involve regular meetings and accounts of their activities, and urine analysis. Individuals who were not released on conditional release will be given statutory release after serving two-thirds of their sentence (unless their sentence is life or indefinite). ${ }^{6}$ They will also be required to abide by conditions and report to a parole or probation officer. Those on either conditional or statutory release may have a 'residential condition', meaning they must reside in a halfway house (or community-based residential facility in the parlance of corrections) for a prescribed amount of time. Given the relatively small number of women under supervision (in comparison to men), halfway houses for women provide residence to women under both federal and provincial supervision. In 2016-17 there were 628 women under the active community supervision of CSC across the country (Public Safety Canada 2017,

\footnotetext{
${ }^{4}$ Statutory release refers to a conditional release that is subject to supervision after an individual has served two thirds of their sentence (Public Safety Canada 2017, 73). Women have higher grant rates of federal day parole $(83.4 \%)$ and full parole (39.8\%) than men (69.3\% and $25.7 \%$ respectively) $(83)$.

${ }^{5}$ Conditional release of prisoners is governed by the Corrections and Conditional Release Act (1992) and administered by the Parole Board of Canada.

${ }^{6}$ Indigenous prisoners are more likely than non-Indigenous prisoners to be denied conditional release and serve their sentence up to statutory release, or even warrant expiry (Public Safety Canada 2019, 91)
} 
64), a number which is dwarfed by the 37,093 women on provincial probation ${ }^{7}$ (Mahony 2011, $31)$.

Incarcerated women hold poorer employment histories than women in the general population. Over seventy percent of incarcerated women were unemployed when taken into custody (Nolan and Power 2014, 1). ${ }^{8}$ More than half of federally incarcerated women in Canada do not have a skill, trade, or profession (Delveaux, Blanchette, and Wickett 2005, 25). In addition to a weak employment history, incarcerated women typically have low education levels. Less than half of incarcerated women in Canada have a high school diploma (Mahony 2011, 33). In particular, almost eighty percent of federally incarcerated Indigenous women were identified at intake as having the greatest need for education and employment programming (Wesley 2012). Notably, those working within and alongside the criminal justice system typically consider women less violent than men, but more psychologically troubled due to lived experiences of trauma and violence, as well as their socio-economic marginalization (McKim 2017; Wyse 2013; Greiner, Law, and Brown 2015).

\section{'Troubled' women: Psychological approaches to incarcerated women}

Incarcerated women are widely characterized as having higher levels of mental illness disorders compared to males, which includes higher rates of self-harm and attempted suicide (G. P. Brown, Hirdes, and Fries 2015; Moloughney 2004; Bodkin et al. 2019; Sapers 2016). Federally sentenced women under community supervision have been assessed as having

\footnotetext{
7 The most recent account of number of women on provincial probation is from $2008 / 2009$ data, which is problematic given the extensive changes to the Criminal Code and other criminal justice legislation in 2012, changes which have generally been understood to have significantly increased the number of women incarcerate due to increases in mandatory minimum sentences and removal of judicial discretion.

${ }^{8}$ Among the general population, in 2009 fifty-eight percent of Canadian women were employed (Ferrao 2010, 5).
} 
"considerable need in the personal and emotional domain as well as with substance abuse" (McConnell et al. 2014, iii). In these ways, psy authorities and criminal justice agencies "more frequently depict women offenders through the lens of pathology in comparison to their male equivalents" (Menzies, Chunn, and Chan 2005, 5; see also Backhouse 1991; Comack 1996; Hannah-Moffat 2001). There is a recognition that inequality, particularly in financial resources, status, and power, can impact mental health, and can determine access to resources to address these consequences (J. Williams, Scott, and Waterhouse 2001). Yet, efforts to give recognition to women's experiences of marginalization, violence, racism, trauma, etc. have resulted in increasing focus on women's mental and emotional states.

Within Canada, the regulation of and psy-interventions on incarcerated women have been documented for decades (Comack 1996; Hannah-Moffat and Shaw 2000; Hannah-Moffat 2001). A recent annual report from the Office of the Correctional Investigator notes that CSC considers eighty percent of incarcerated women as meeting the criteria for "some current mental disorder" (Zinger 2018). These include lifetime alcohol and substance use disorders (76 percent) and anxiety disorders (54 percent). Ivan Zinger reports that self-inflicted injuries have nearly quadrupled among federally sentenced women in the last decade. The tendency to 'recognize' high rates of mental illness among Canada's incarcerated women (see Kilty 2014a; Harner and Riley 2013; Kilty 2012) is indicative of the growing use of psy discourses to conceptualize women's needs and past experiences, which has in turn led to the rising use of psychotropics to 'manage' them (Pollack 2005; Kilty 2012). Within institutions, this can lead to the over-reliance on antipsychotic medications and sleep aids (Kilty 2014a; L. Haney 2010). Research from CSC indicates that psychotropics are the most common type of prescription medication for women in federal prisons, with 46 percent of women incarcerated in Ontario taking psychotropics (Langer 
et al. 2002; Sapers 2016). The former Correctional Investigator of Canada, Howard Sapers, also noted that this percentage of women with active psychotropic medication prescriptions was significantly higher for women than men, of whom only thirty percent were on psychotropics (Sapers 2016, 10).

Criminal justice discourses mobilize the deployment of psychological approaches, which locate problems and solutions within individual psyches and make individuals responsible for their own rehabilitation (March 2010). As Susan Starr Sered and Maureen Norton-Hawk argue, criminalized women "learn that their problems lie within themselves rather than outside in the real world, that their suffering is an expression of personal pathology rather than a manifestation of structural inequalities and violence" $(2014,12)$. In other words, the recognition of women's experiences of violence, trauma and oppression is operationalized through psychological and psychiatric discourses as 'mental health issues', locating experiences of trauma within the individual as a mental 'disease' or 'disorder' (Dobash and Dobash 1992; Comack 2018; Becker 2005).

In the late 1980s, the Task Force on Federally Sentenced Women (TFFSW) was established to examine and make recommendations on women's federal incarceration. ${ }^{9}$ Their investigation, culminating in a 1990 report titled Creating Choices, recognized the connection between women's criminalization and their historic and structural contexts, arguing that "issues such as poverty, racism, wife battering, and sexual abuse are central to women's crime" (TFFSW 1990, 83). The Task Force called for 'gender-responsive programming' and outlined a strategy for

\footnotetext{
${ }^{9}$ The work of the Task Force led to the closing of the Prison for Women (P4W) in Kingston and the construction of regional prisons and a healing lodge, as well as the development of new programs and strategies.
} 
reform based on five principles: empowerment; meaningful and responsible choices; respect and dignity; supportive environments; and shared responsibility. Gender-responsive programming, as interpreted and implemented by correctional services in other jurisdictions, has been found to focus on women's emotional desires (L. Haney 2010), needs (McKim 2017), and “problematic personal patterns" (Wyse 2013, 246). Such programming typically emphasizes women's relationships (wives, girlfriends, and mothers) over their economic and individual autonomy (Wyse 2013; McKim 2008, 2014; Morash 2010; Bouffard and Taxman 2000; Mullany 2002). The call to recognize women's experiences of violence, trauma and abuse was answered by a therapeutic focus on women's emotional and psychological needs.

'Therapeutic' approaches to correctional programming have been theorized as pastoralism or gentle coercion. For example, Barbara Cruikshank (1999) characterized the working of philanthropic organizations as first constituting subjects as deficient and then developing strategies to reshape individuals and their desires. Kelly Hannah-Moffat (2001), in examining Canadian penal techniques directed at incarcerated women, identifies the mix of disciplinary and pastoral strategies that were employed by community-based workers, and that these strategies frame women's subjectivity as child-like, in need of maternal direction and therapeutic governance. Indeed, CSC's programming for women emphasizes women's low self-esteem and their dependency, while also acknowledging other needs such as "poor educational and vocational achievement", childhood and parental instability, and substance abuse (Fortin 2004, 5). Additionally, in the past decade, there is a growing focus on women's substance abuse, while educational and employment interventions are downplayed (Wesley 2012). 


\section{EMPLOYMENT AS KEY TO REINTEGRATION}

In 1996, the Honourable Louise Arbour recommended that priority be given to vocational training for federally incarcerated women (133). However, ten years later, CSC admitted that federally incarcerated women still had few vocational programs and had "minimal access to meaningful work opportunities while incarcerated" (Correctional Service of Canada 2007, 48). This may be because a previous CSC report noted that "little evidence has generally been found for the effectiveness of employment interventions in decreasing recidivism for women offenders in particular" (Delveaux, Blanchette, and Wickett 2005, 5). What role should vocational training have in women's corrections? How do employment, and employability fit within the objectives, and priorities, of rehabilitative programming for incarcerated women? Given the power of the correctional agencies to require reintegrating women to participate in employability programs and demonstrate their 'employability', it is important to question and explore the apparent contradictions within the rationales and practices of employability programs. It is also important to explore women's lived experiences of receiving 'employability support' in order to understand how production of employability is not only practiced and justified, but also how it is inhabited. To begin, it is important to consider what 'employment' means.

Work is a broad term which can refer to "any expenditure of human effort" (Vallas 2012, 3), such that it is not simply an economic activity, but is a host of productive activities embedded in socio-legal and political settings which produce the subjectivities and subject positions of workers (Weeks 2011). While recognizing the conflation of the terms 'work' and 'employment' in everyday speech, in this research project, I purposely distinguish employment as a subcategory of work. I use the term employment the way others use the term 'waged work' (Weeks 2011), 'paid work' (Gatrell 2008), or 'job' (Armstrong and Armstrong 2010) in order to make 
clear the conceptual lines from employment to employability. ${ }^{10}$ Building upon Robert Rothman's (1987) understanding of learning to work as patterns of socialization, I consider employability training as a process of socialization both direct (such as formal job training and apprenticeship) and indirect (such as modeled performances of gender). Employability training involves developing 'human capital', and mobilizing trainees to invest in their productive capabilities through education, training, and work experience (Vallas 2012, 97). Employment support involves processes designed to motivate workers by factors other than payment and straight-up economic gain. Such socialization processes are particularly important given that the economic gains are likely to be quite limited in the types of low-wage, precarious work available to those with criminal records.

A sociological perspective of labour and class, informed by Max Weber (1922), refers to the social relations of production and positions within the labour process (Standing 2011, 8). Such a perspective is key to this project, since the social position of reintegrating women not only restricts their possibilities for employment, but shapes their perspectives about work's value and meaning. Conceptual categories relating to feelings about work have typically been developed over decades of research on men's work, particularly middle-class white men, and privilege their values and perspectives about how workers do, and should, feel about work (Johnson 2002, 66). A commonly expressed belief is that by working hard, you will get ahead in life (89). Another, exemplified in the Protestant work ethic, suggests that work is a moral imperative and will be

\footnotetext{
${ }^{10}$ More precise distinctions could be made between terms such as waged work, occupation, job, and employment, see for example Standing (2011). However, given that my focus is on the construct of employability and not on particular sites, structures or systems of employment, I think it is sufficient for my purposes to distinguish 'employment' from more general 'work' and display a certain "strategic imprecision" (DeVault 1999, 81) to employment itself.
} 
rewarded by riches in heaven. Work will also stave off "the doubts and temptations that preyed on idleness, [and open] the way to deserved wealth and status" (Rodgers 1978, 14). Another common belief, articulated by Arthur Kornhauser (1965), is that work is a stabilizing influence on a person's life, giving them a sense of purpose, meaning and achievement. These perspectives on work will be recognizable throughout this dissertation as they are expressed by both service providers and reintegrating women (see Chapter Six in particular).

Since criminal justice systems "teach and enforce a culture's agreed-upon values and mores" (Martel, Brassard, and Jaccoud 2011, 236), it is unsurprising that they direct reintegrating individuals toward labour market participation. Indeed, the "social role of waged work has been so naturalized as to seem necessary and inevitable" (Weeks 2011, 7). Rehabilitation is considered to involve the altering of behaviours and motivations such that 'offenders' become 'productive citizens' (Freeman 2008). Employment, in the context of reintegration, is described as providing structure, routine, a social network, and enhanced self-esteem (Graffam et al. 2004), as well as "social and economic value and a network of social supports" (Ricciardelli and Mooney 2017, 105). It is also seen to have a "normalizing effect" and to provide reintegrating individuals with a sense of personal dignity (O’Brien 2001, 290). Employment is thus held up as the key to success, a chance for reintegrating adults to redeem or 'reinvent' themselves. As such, employability programs are part of the process by which the correctional apparatus 'makes them work' (and historically are partly what physically made institutions) ${ }^{11}$ Such programs exist because employment, or 'labour market participation' is understood as a desirable and necessary

\footnotetext{
11 The Kingston Penitentiary was built in the 19th century through the use of inmate labour (https://www.cscscc.gc.ca/corcan/002005-0004-eng.shtml)
} 
goal (Usher 1990; MacKinnon 2015), particularly for those who must reintegrate into society after periods of incarceration. These programs are supported by research that correlates unemployment with crime and suggests that being unemployed increases one's chances of becoming criminally convicted (Hagan 1993). As such, employment is considered a way to reduce the likelihood of recidivism, or to promote 'desistance' from crime (Delveaux, Blanchette, and Wickett 2005). Employment is a way for 'ex-offenders' to acquire a 'stake in conformity' by finding employment and thus they will have 'more to lose' by reoffending compared to those who are unemployed (Davis, Bahr, and Ward 2013; Cobbina 2010; Uggen, Wakefield, and Western 2005; Petersilia 2003). Here it is important to recognize how certain assumptions about those who have been criminally charged have maintained influence in discourses and approaches to reintegrating individuals. For example, Daniel Glaser (1956) suggested that 'criminal offenders' are invested in deviant subcultures and unaffected by dominant culture standards. Such beliefs underpin claims about the value of employment as that which brings deviant individuals into contact with pro-social contacts and values (Graffam et al. 2004; Petersilia 2003).

Yet while correctional policies, programs and practices might aim to produce reformed subjects "whose reintegration will allow them to participate in the globalized marketplace" (Sim $2005,222)$, systemic divisions of gender, class, race, and ability will continue to exclude reintegrating women from the market place upon their release. Additionally, some analysis of post-carceral employment indicates that the perceived gains of employment may be linked more to the quality of the job than the simple fact of having a job (Maruna 2001; Uggen, Wakefield, and Western 2005). Other studies note the difficulty in separating the benefits of employment 
from those of other key aspects of reintegration, particularly housing (John Howard Society of Ontario, O’Grady, and Lafleur 2016; Fontaine and Biess 2012).

Indeed, the link between employment and reintegration success is not unanimously agreed upon by researchers, and definitive claims about employment's reintegrative potential are difficult to make, particularly in reference to reintegrating women. In part this may be because the bulk of research on reintegration and employment has been conducted on men, or refers to men and women as an aggregate population. Yet in addition, programs designed to enhance employability or other soft skills ('life' skills) can be difficult to capture in evaluative frameworks given variances between programs and between measures of success (Griffiths, Dandurand, and Murdoch 2007). Employability programs may be co-evaluated with educational ones (e.g. Dowden and Andrews 1999), further complicating precise evaluation.

Yet even if it is acknowledged that employment alone is not responsible for successful reintegration, making people employable aligns with social and political discourses and policies that focus on moral and cultural causes of poverty (Levitas 2005; MacKinnon 2015). Such an approach emphasizes work values which are rooted in classic theories on divisions of labour in society, the Protestant work ethic, and the liberal social contract (e.g. Weber 1958; A. Smith 1776). Michèle Lamont, in her study of working-class men of America and France, connects the emphasis placed upon being hardworking with discourses of personal dignity, yet notes that this drawing together of 'hard work' and 'dignity' occurs within the oppressive conditions of lowwage labour. Such labour is "often painful and time-consuming, yet underpaid, physically demanding, or psychologically challenging because repetitive" $(2000,26)$. Being able to persist in these conditions requires mental and physical fortitude. Shadd Maruna notes that adults with criminal records are often confined to low-status, repetitive work - "thankless, stinking work" 
(2001, 121). As such, being 'employable' may not only require that one is ready for a job, but that one is prepared to accept and persist in a thankless, stinking job. How does this complicate the construction of employable subjectivities within employment programs?

While the value of work is rooted in capitalist understandings of social belonging and productivity, feminists have long argued that 'work' is not limited to paid employment, and discourses of work should take into the account the unwaged, reproductive, and domestic labour which women are expected to perform (e.g. Friedan 1965; Oakley 1974; Hochschild 1989). Gendered divisions of labour have historically been based upon Victorian, paternalistic and patriarchal beliefs about the social and biological categories, and abilities, of women (Weeks 2011; Gatrell 2008). For example, a reflection on women's efforts to unionize in Canada notes that, historically, the "ideal of womanhood combined religious piety, moral purity, and first and foremost - a complete commitment to domesticity. A woman's primary role, her natural contribution, was as a wife and mother" (White 1980, 2). Yet despite apparent progress from such restrictive notions of women's roles, and the growth in women's waged labour over the last century, ${ }^{12}$ workplaces can serve to perpetuate, rather than free women from, entrenched gender norms and divisions.

Work, both waged and unwaged, serves to produce and reinforce gender performances, and workplaces are structured in relation to gender norms and productivities of gender-differentiated labour. Employers typically value and recompense traditionally 'masculine' skills more highly than those which are traditionally 'feminine'. Women's roles and contributions as workers are

\footnotetext{
${ }^{12}$ In Ontario, as in other Canadian provinces, women's labour force participation has risen dramatically since World War II, from about one-quarter of working-age women in the 1950s to sixty percent in the 1990s to over eighty percent in 2014 (Rinehart 1996, 5; Statistics Canada n.d.).
} 
less valued than men's, as is evident by the persistent gender-gap in earnings (McInturff 2014; Armstrong and Armstrong 2010). In particular, feminized areas of work (such as domestic work, health care, education, cleaning, and customer service) receive lower pay and are more vulnerable to precarity, such as through temporary contracts, part-time hours, and non-unionized work environments (Vosko and Clark 2009; Armstrong and Armstrong 2010; Glick 1991). In Ontario, more women than men work for minimum wage (twelve percent versus seven percent) and they are also more likely than men to work part-time (McInturff 2014, 6). Additionally, women are often expected to perform more caring, and emotionally-invested roles within the workplace (Leidner 1993; Berk 1985). Gendered divisions can also reflect arbitrarily constructed norms within specific industries, such as restaurant managers assigning women the role of serving and men the role of cooking (Leidner 1993).

Legislation such as the Ontario Human Rights Code, first adopted in 1962, ostensibly protects women from unequal pay and discrimination. Yet even into the $1980 \mathrm{~s}$, policies addressing matter such as workers' compensation virtually always portrayed employees as men (and their dependents as women) and focused more on accidents and injuries of the type men might experience in the workforce, rather than the diseases, repetitive strain injuries, and stress that impact women workers (Reasons, Ross, and Paterson 1981). Additionally, economic stimulus packages have benefited men more than women, such as by increasing jobs in maledominated areas like construction (ibid.). Since the 1980s, government policies addressing unemployment and other social problems have shifted from a Keynesian welfare approach toward an emphasis on market mechanisms, individual responsibilities, and short-term job training designed to meet labour market demands (MacKinnon 2015). Yet at the same time, there are government policies which restrict labour market participation; for example, people on social 
assistance will have their income deducted if they earn more than $\$ 200$ a month. This creates a disincentive for wage earning, while keeping individuals bound to the meagre supports from the state. (The challenges of navigating the constraints of ODSP benefits will be discussed in Chapter Six.)

Further complicating how the social constructs and understandings of work value might impact employability programs is the recognition that such programs are rooted in colonial projects that have undermined and negated Indigenous structures and systems of work, community, and education. As such, the widespread unemployment and underemployment of Indigenous peoples in Canada should be recognized as part of the human rights abuses characterizing settler relations (Settee 2011). Additionally, the entrenched economic marginalization of Indigenous people relates to the appropriation of Indigenous land and labour in the colonial project (Raibmon 2006; Lutz 1992). Indigenous wage labour has been vital to the development of regional and national economies in sectors such as agriculture and resource extraction. While the usurption of their hereditary land and resources has steadily narrowed their range of economic choices, since first contact, Indigenous people have developed myriad ways to simultaneously engage in traditional and capitalist economic activities. As Terry Wotherspoon argues, the general emphasis on unemployment and welfare among Aboriginal people obscures the fact that most Aboriginal people derive their income through wages, or, for example, that labour market participation rates for Métis people are higher than the national average (2007, 137). Nonetheless, Indigenous people experience profound socio-economic marginalization. Recently, the Truth and Reconciliation Commission recommended that the federal government “develop with Aboriginal groups a joint strategy to eliminate educational and employment gaps between Aboriginal and non-Aboriginal Canadians" (2015, 1-2). 
In the context of Canada's history of colonialism and oppression of Indigenous people, employability programs that fail to take into account the "substantial disparities in education, skills, and marketable credentials" serve to perpetuate these disparities (Wotherspoon 2007, 132; see also MacKinnon 2015). Yet how might employability programs be modified to address systemic and racial barriers to employment when these programs are discursively and theoretically generated through capitalist settler colonial projects? Since the socio-cultural contexts of incarcerated women are interpreted through the correctional lens as emotional and psychological needs, incarcerated Indigenous women are rated as having high needs levels and are disproportionately given high security classifications (Wesley 2012). Additionally, Aboriginal women's programming is often interrupted or unavailable (13). This suggests that Indigenous women do not have adequate access to training and programming that addresses their cultural, spiritual, and vocational needs. The report of the Task Force on Federally Sentenced Women (1990) argued that programming for Aboriginal women in federal institutions should focus on connections with communities and traditions, given the dislocation and disconnection experienced by incarcerated Indigenous women (see also Monture-Angus 2000). How do Indigenous women understand and navigate the complex and competing subject positions produced through employability programs? Does participation in employability programs then come at the expense of participating in traditional healing pathways? How are various subject positions (i.e. Indigenous, criminalized, employable) for incarcerated Indigenous women made (in)compatible by the criminal justice system?

It is not only Indigenous women who must navigate competing subject positions that are mobilized through correctional programming. Some research suggests disciplining women's performance of gender takes precedence over the production of their employability. For example, 
Jessica Wyse found that parole officers focus on "women's problematic personal patterns" $(2013,246)$ instead of on possibilities for employment. Indeed, as noted earlier, correctional programs for reintegrating women that emphasizes their relationships over their economic and individual autonomy illustrates how, for incarcerated and reintegrating women, relational and social roles are emphasized over independent and economic ones. Additionally, even policy makers and program administrators are dubious about the value of employment programs for reintegrating women. So, if courts mandate employability programs, but those supervising women or administering the programs question the efficacy or value of these programs, how do these service providers understand their own practices and rationalities of governance?

\section{Criminal records and other barriers to employment}

That reintegrating women face complex, systemic barriers to employment is clearly established in literature. As Sered and Norton-Hawk (2014) demonstrate in their research which followed reintegrating women over five years, precarious housing, poverty, addictions and violence are too often what await women upon release from institutions and halfway houses. What is less clear in existing research is which barriers preceded women's conflict with the law (such as socio-economic exclusion and systemic racism), and in what ways their involvement with the criminal justice system has impacted or augmented these barriers. More specifically, it is unclear from this data in what ways employment, or employment training, can successfully address the intersecting factors that produce and entrench the socio-economic marginalization of reintegrating women.

The challenge of navigating if, when, and how to reveal a criminal record does not occur in a vacuum, and neither is it unique to the women who participated in this study. Criminal record 
policies bind an individual to their criminal past, identifying them as risky and in need of surveillance. Yet as will be explored below, and in more detail in Chapter Four, the criminal record does not simply bar women from working with vulnerable sectors. It is used as a screening mechanism to bar individuals from many jobs, even where their 'riskiness' is less clearly defined. As such, it serves to extend the punishment of criminalization far beyond the sentence brought down in court by generating economic exclusion, especially for those who are only able to obtain precarious, poorly paid work. According to a 2016 report, approximately 3.8 million Canadians, or ten percent of the population, have criminal records (Public Safety 2016, 111). But what exactly is a criminal record, and how does it exclude women from employment? The term 'criminal record' is not expressly defined in any Canadian legislation, including the Criminal Records Act (1985). ${ }^{13}$ However, the British Columbia Supreme Court noted that the criminal record refers to the processes and policies by which the criminal justice system "identifies persons who have been criminally charged and convicted, creates records of their convictions, maintains databases and systems for the storage and retrieval of these records, and regulates disclosure to individuals and organizations" (Chu v. Canada 2017, para 17). In other words, the criminal record is generally understood to result from having been convicted of a criminal offence; a criminal record check reveals every criminal offence of which the individual has been convicted and for which a record suspension or pardon has not been issued or granted. The recognition that the criminal record is punitive was recently supported in the landmark case of Chu v. Canada (2017) which examined the constitutionality of retroactive changes to record

\footnotetext{
${ }^{13}$ Section 2 of the Criminal Records Act defines various terms, such as child, Commissioner, Executive Committee, pardon, period of probation, and record suspension, but does not actually define 'record'. Similarly, the Corrections and Conditional Release Act (1992) does not offer definition of 'criminal record'.
} 
suspensions. A key deciding factor in this case was the determination that the criminal record is a form of punishment, in part because it is designed to 'deter and denounce' crime (para 236).

Because of this determination, the court held that changing the length of time for which someone's record is maintained after they have already been sentenced violates Section Eleven of the Charter and cannot be justified under Section One.

Given that the criminal record can prevent people from accessing employment that offers a living wage, reintegrating individuals will often seek to have their record suspended. The process of record suspension is legislated through the Criminal Records Act and details how those convicted of criminal offences can apply to limit access to the disclosure of their conviction. It requires "the judicial record of the conviction be kept separate and apart from other criminal records and removes any disqualification or obligation to which the applicant is, by reason of conviction, subject under any Act of Parliament" (s. 2.3(b)). Additionally, section 3(1) of the Canadian Human Rights Act prohibits discrimination for the "conviction of an offence for which a pardon has been granted or in respect of which a record suspension has been ordered". Thus, a record suspension mobilizes certain human rights protections against discrimination. By the end of the 2011/12 fiscal year, 456,000 Canadians had received pardons since Parliament enacted the Criminal Records Act in 1970, and ninety-six percent of these were still in effect, indicating that only four percent had re-offended (Chuv. Canada, 2017 para 2). ${ }^{14}$ That same year there were 29,849 pardon applications (Crawford 2016). However, after the legislation came into effect making the process more difficult and expensive (and changed the terminology from 'pardon' to

\footnotetext{
${ }^{14}$ A record suspension is revoked by the Parole Board of Canada if a person is convicted of another indictable offence and certain summary offences, if the Board deems the person to no longer be of good conduct, and if the Board determines the application for suspension was knowingly false or deceptive (Criminal Records Act 1985 s 7).
} 
'record suspension'), ${ }^{15}$ the number of applications significantly declined; there were only 11,563 applications in 2016/17 (Public Safety Canada 2017). The lengthier, costlier, and more onerous process of obtaining a record suspension has been discouraging for reintegrating women, particularly those who have been living in the community for a long time.

The ubiquity of background checks means that histories of contact with the justice system can follow individuals for years, and even a lifetime (Ispa-Landa and Loeffler 2016). Research on employers' use of records checks in the United States has pointed to the ease and low cost of records checks in recent decades due to the proliferation of online databases (Holzer, Raphael, and Stoll 2007). The mobilization of a criminal record to screen and exclude certain individuals can be understood as a tool of social control (McKim 2017) and as producing structural stigma (McAleese 2017). The practices and policies associated with it can also be theorized as those of risk management. Risk management, as a strategy of crime control, mobilizes technologies and practices of banishment and coercion to subject certain individuals to intense surveillance and control (Hallsworth and Lea 2011; Garland 2001; Fox 2013; Feeley and Simon 1992). Mona Lynch (2000) suggests the growth in correctional practices of risk management is indicative of a shift away from rehabilitation and individual reform. By identifying individuals who have committed crimes in the past, the criminal record is intended to serve as an indicator of 'risky' individuals, those who are considered to be at greater risk of committing crime in the future. Despite that "over time knowledge that one committed an offence becomes less a predictor of

\footnotetext{
${ }^{15}$ Legislative changes implemented by the federal Conservative government in 2010 and 2011 made criminalized individuals wait longer before they could apply for a record suspension (formerly a pardon), increasing the time from five to ten years for indictable offences, and three to five years for summary offences. Applicants must also pay more, as the fee increased from $\$ 150$ to $\$ 640$. These changes have been the subject of much critique by advocates of criminalized and marginalized populations and those critical of punitive government policies (Murphy, Sprott, and Doob 2015; McAleese and Latimer 2017).
} 
whether offending will take place again in the future" (Murphy, Sprott, and Doob 2015, 211), the criminal record is consistently interpreted as a risk indicator.

In Ontario, provincial legislation indicates that a records check can be conducted for screening purposes to determine "suitability for employment, volunteer work, a licence, an office, membership in any body or to provide or receive goods or services" (Police Record Checks Reform Act, 2015, 2.1). The term 'suitability' indicates potential, and in this case, potential risk. An individual is not 'suitable' if they are too risky. Indeed, the criminal record is mobilized as a risk management practice in a variety of areas, such as in applications for apartment rentals, animal fostering, and other activities in which 'riskiness' invites exclusion (McAleese and Latimer 2017). With regard to employment, research in the United States has shown that more than a third of reintegrating adults indicate they have avoided disclosure of their criminal record to potential employers, seeking to avoid the anticipated discrimination and rejection (Lebel 2012, 102). In Ontario, the Human Rights Code (1990) does not prohibit employers from asking about a criminal record, or choosing not to hire someone who has a criminal record. ${ }^{16}$ However, advocates for reintegrating adults have mobilized campaigns such as 'ban the box' to take such questions off job applications in order to increase people's chances of making a favourable impression on employers who might then be willing to hire despite the record. Other recommendations include encouraging employers to consider the amount of time

\footnotetext{
${ }^{16}$ Ontario's Human Rights Code (1990) states: “Every person has a right to equal treatment with respect to employment without discrimination because of race, ancestry, place of origin, colour, ethnic origin, citizenship, creed, sex, sexual orientation, gender identity, gender expression, age, record of offences, marital status, family status or disability" (s. 5.1). These rights are not infringed when there is a "reasonable and bona fide qualification because of the nature of employment" (s 23.1.b) or when employment involves care of vulnerable sector members (s.23.1.c). Of note, 'record of offences' refers to offences for which a pardon or record suspension has been granted or the offence is related to a provincial law (s. 10.1.e).
} 
that has passed since conviction, since recidivism rates generally decrease with time, and/or deferring background checks till after the application process in order to increase chances that applicants can get an interview (Petersen 2015). Additionally, advocates of reintegrating adults seek to remind employers that while they are permitted to ask about criminal convictions, they are not allowed to ask about provincial offences (such as speeding or careless driving which are violations of the Ontario Highway Traffic Act).

Employers may not care a great deal about the particular offence an individual has committed, but the criminal record is viewed as a negative "indicator of general employability or trustworthiness" (Pager 2007, 5). Employers may assume that "past behavior predicts future behavior" (Harley et al. 2014, 9) and that those with criminal records are "likely to be less productive or [likely to be] more troublesome" (Freeman 2008, 407). Despite lack of data demonstrating that reintegrating adults are more or less likely to be fired than other employees (Petersen 2015, 187), employers are likely to err on the side of caution and choose not to hire someone with a record, using the record as "an easy screening mechanism" (Shivy et al. 2007, 37). Increasingly, “Canadian organizations - employers, volunteer managers, educational institutions, licensing bodies and governments - are incorporating police record checks into their hiring and management practices" (Canadian Civil Liberties Association 2014, 5). Similarly, a report from the John Howard Society of Ontario found that 60 percent of employers require a police record check for all employees $(2018,5)$. Fifteen percent of the employers surveyed would not be willing to take into consideration the type of offence, such as whether or not it is relevant to the requirements of the job (ibid.).

Risk-based governance has gendered impacts that have not been adequately acknowledged (Hannah-Moffat 2004). For example, people with criminal records are barred from working in 
positions of authority or trust over vulnerable persons (Criminal Records Act 1985, 6.3.1). ${ }^{17}$ This restriction has particular impacts on women since stereotypes about the types of work women are capable of and suited to doing have resulted in women's employment being clustered sectors that involve educating and caring for vulnerable individuals, such as children and seniors (Gatrell 2008). Leah Vosko and Lisa Clark note that in Canada "health care and social assistance" are the "most common industr[ies] of employment for prime working age women in all forms of paid employment except part-time temporary" (2009, 32-33). This corresponds with government data showing that women represent eighty-two percent of employees in the health care and social assistance industry (Statistics Canada 2015). Barring reintegrating women from these industries thus has a much more significant impact on them than the same limitation does on men, a finding which corresponds with a study for CSC that found fewer employment options for reintegrating women in comparison to men (Thompson, Lutfy, and Bertrand 2015).

Not only do legislative policies exclude reintegrating adults from certain professions, but the onus is also placed upon employers to manage the riskiness of individuals they employ. Christel Backman examined motives provided by employers in Sweden for their use of criminal record check and found that company security was often cited as a main reason since employers had to protect their assets $(2011,32)$. Employers not only seek to protect their material goods, but they must also consider the well-being of their other employees. For example, Ontario's Occupational Health and Safety Act (1990) requires employers to provide a safe working environment for all staff. This includes a provision that employers must inform staff if there is an

\footnotetext{
${ }^{17}$ Vulnerable persons are defined as those who, because of age, disability or other circumstances, are in positions of dependency on others and are at heightened risk of being harmed by persons in authority or trust to them (Criminal Records Act 6.3(1)) Individuals with convictions related to sexual and violent offences are permanently barred from working with vulnerable persons.
} 
employee who has a history of violent behaviour (section 32.05.3). In tort law, employers can be sued for 'negligence in employment' if it can be proven that the employer provided an employee with the ability to commit a harmful act. This can include a situation in which an employer hires someone without thoroughly considering that person's background. Employers are also further constrained by requirements of insurance companies. They can be insured against loss that comes as a direct result of fraudulent, dishonest or criminal activities by an employee, but only if they have conducted credit and background (criminal record) checks on their employees. Additionally, with increasing globalization, small businesses are bought up or replaced with large corporations. Large corporations are more likely to have blanket policies that prohibit the hiring of individuals with criminal records, removing discretion from local franchise owners. Such constraints indicate that risk management is not a practice limited to government; private businesses and corporations both choose and are legislated to adopt state technologies into the governance of their employees.

Women's barriers to employment also include prosaic concerns such as lack of fixed address, an interview 'outfit', or transportation (Delveaux, Blanchette, and Wickett 2005, 103). Another barrier to labour market participation that is commonly identified in literature on women's criminalization and reintegration refers to the inequitable division of domestic labour and child care responsibilities (Seabrook and Wyatt-Nichol 2015; Hughes Miller 2015). Women's positions within the sphere of waged work has historically been, and continues to be, complicated by conflicting gendered norms and expectations which pull women between the spheres of unwaged domestice labour and waged employment (Weeks 2011; Gatrell 2008; Slaughter 2015). Even when women live with a spouse or partner, they are likely to be responsible for the lion(ess)'s share of domestic responsibilities. Vosko and Clark (2009) refer to 
this division of domestic labour as the 'gender contract' that assigns men a "primary role in breadwinning and women central responsibility for (largely unpaid) care-giving" (Vosko and Clark 2009; Gatrell 2008; Glover and Kirton 2006). The majority of incarcerated women are mothers, and prior to their incarceration were sole-custody parents and primary caregivers for their children (Scobie and Gazso 2013; Withers and Folsom 2007; Vis-Dunbar 2008). Upon release, women regain, or seek to regain, custody of their children, and again will likely be the sole provider of support to them (Dodge and Pogrebin 2001). Given the absence of a national, affordable daycare program in Canada, women in minimum-wage jobs are often unable to pay for daycare. They are confined to the unpaid roles of providing care for their own children, ironically unable to afford to work.

Feminist critics of women's prisons have pointed to the adoption of discourses around empowerment, gender-sensitive care, and choice. After the closing of the Prison for Women (P4W) in Kingston and the opening of new prisons for women across Canada, Kelly-Hannah Moffat and Margaret Shaw (2000) aptly warned that even 'women-centered' penal techniques would still reproduce existing power relationships and would be inherently disempowering to women. To combat such dynamics, women's advocates in Canada and beyond have typically proposed community corrections which, they assert, could better provide for women's needs, particularly with regard to substance abuse and vocational training (Hannah-Moffat and Shaw 2000; O'Brien 2001). However, McKim (2008) points out that in the United States there has been little research on community corrections for women, with important exceptions being her own work $(2014,2017)$ and that of Lynne Haney $(2010)$. Here in Canada, Amanda Nelund (2015) examined the role of community organizations in supporting criminalized women in Winnipeg, but there is a lack of in-depth qualitative research on community-based support for 
reintegrating women, particularly for women who are reintegrating into the community after periods of incarceration.

\section{EMPLOYABILITY DISCOURSES AS NARRATIVES OF GOVERNANCE}

Critiques of women's penal reform that employ Foucauldian analyses of power and discipline have been important for drawing attention to the technologies and practices of governance, showing the gendered ways in which women are governed (Hannah-Moffat 2001). As noted above, correctional policies, programs and practices mobilize governance discourses to make women responsible for becoming reformed subjects capable of participating in the labour market. The responsibilization model of corrections, the Risk-Need-Responsivity Model (Bonta and Andrews 1977), identifies 'criminogenic' needs (such as employment, substance abuse, and marital/family relations) that incarcerated and reintegrating individuals must address. Such principles of risk, and practices of risk assessment, have roots in rational choice theories of criminal activity, theories which assume individuals weigh risks and benefits before choosing to commit an offence (Boudon 2003; c.f. De Haan and Loader 2002). The emphasis on individual choice in activities leading to criminalization has been challenged by research showing that decision-making processes relating to crime may be subject to cognitive limitations, influences of drugs and alcohol, and lack of awareness of risks or consequences (Tunnell 1992; Burnett 2004). But additionally, the emphasis on individual choice is challenged by those who point to how it obscures broader power dynamics and structural constraints. As Dana Becker argues,

the notion of choice can be quite deceptive. The options available to women all exist within the prevailing social order. What is lost in psychological translation is the reality that within a culture some choices are more costly than others, and that 
none is 'free'. ... For women, choices must be understood as socially constructed and, as a result, affected by power inequities $(2005,162-63)$

Additionally, critics of the risk assessment model have pointed out that it fails to account for gendered oppressions, colonialism, and other experiences of oppressed groups (Hannah-Moffat 2001, 2004; Turnbull and Hannah-Moffat 2009; McKim 2008; Pollack 2005; Monture-Angus 1999). Feminists have insisted that 'criminalized' women are more likely to be at risk than to be a risk to public safety (Comack 1996; Hannah-Moffat 2005, 2008; Comack 2018). Yet within the framework of 'criminogenic risks', women's experiences of violence, trauma and abuse, their struggles to provide for their children, or their problems with self-medication, drug and alcohol use, are framed as risks for which women must take responsibility and work to address through correctional programming. The discourse of risk is used to legitimate accredited programs through which women are expected to acquire the skills to address their riskiness (Sim 2005). Risk management trends in criminal justice interventions "make offenders responsible for their own reform" (Hannah-Moffat 2013, 137). The combination of governance with risk management brings to bear here the notion of 'responsibilization', a key theoretical concept which indicates the dual process of disciplinary governance and recruitment of the self. As the term suggests, responsibilization is the process by which individuals are recruited into, and made responsible for, their own self-governance (Foucault 1991; Dean 2010; Gordon 1991; N. Rose 1999b, 2000; O’Malley 1996). Responsibilization practices are evident in references to a woman's need to make good choices and engage in self-transformation (Nelund 2015). Responsibilization is also evident in employment programs that focus on individualized development of 'human capital' through education and training (MacKinnon 2015). As such, the ways in which women are encouraged, trained and instructed to perceive themselves as 
employable are understood in this project as specific practices of governance. This theoretical framing ties my project to broader questions around the governance of women, such as how and by whom they are governed (e.g. Hannah-Moffat 2001; Comack and Balfour 2004). Sarah Turnbull and Hannah-Moffat conceive of parole conditions as a form of "targeted governance" comprised of particular and individualized techniques of surveillance that are employed to "police the boundaries of acceptable conduct" - that is, conduct that is determined 'acceptable' along normative, gendered lines (2009, 533; see also Hannah-Moffat 2004, 2001). The targeting of governing practices is combined with the mobilization of 'risk' into strategies of governance.

As noted above, work is a social as well as an economic practice. Kathi Weeks describes the expectation that most people work for wages as a "social convention and disciplinary apparatus" (2011, 7-8). It is helpful here to understand discipline as a form of governance, a "type of power, a modality for its exercise, comprising a whole set of instruments, techniques, procedures, levels of application, targets" (Foucault 1977, 215). It "concerns the exercise of power over and through the individual, the body and its forces and capacities, and the composition of aggregates of human individuals" (Dean 2010, 29). A disciplined subject is required to reform or conform, to be corrected. Thus, there is a constitutive aspect of governance. It does not simply involve teaching individuals what not to do, but training them in what they should do and how they should be. Examining employability discourses as narratives of governance facilitates an examination of power as that which "operates to invest the citizen with a set of goals and selfunderstandings, and gives the citizen-subject an investment in participating voluntarily in programs, projects, and institutions set up to 'help' them” (Cruikshank 1999, 41). In other words, a governmentality framework allows me to examine how reintegrating women are recruited into 
their own self-governance and become invested in constructing concepts of being employable selves.

Responsibilization is a key aspect of governance-at-a-distance, which Foucauldian theorists recognize as "intensely moral in that it seeks to engage with how both the 'governed' and the 'governors' regulate themselves" and how the choices, desires and aspirations of individuals are shaped (Dean 2010, 19; see also N. Rose 2000). Responsibilization aims to instill pro-social selfgovernment and self-scrutiny, affiliating women with dominant social and cultural norms (N. Rose 2000). This can clearly be seen when we look at how the language of responsibility and choice relate to employment and success. Indeed, the individual responsibilization of success is well articulated by Clare Hemmings and Amal Treacher Kabesh.

To succeed is to have made good choices and acted independently to achieve one's goals; to fail is to have made worse choices, not chosen at all, or acted counter to one's own interests. The interests of states and institutions are nowhere visible in this schema and their real and continued presence might instead be said to manifest individual desires that seem uncannily to follow what we might term 'the interests of power' itself $(2013,39)$.

This analysis points to how individual desires are shaped to align with the interests of power, even while masking the pervasive presence of that power.

Responsibilization emphasizes self-governance strategies which rely on constructions of individuals as "rational, free, responsible, and prudent consumers who are capable of minimizing and managing risk" (Hannah-Moffat 2001, 164; see also N. Rose 1996). Responsibilization also reflects the influence of dispositional theories of behaviour, such that individuals as autonomous beings are responsible for their own actions (C. Haney 1982), and behaviours reflect individual 
character (Ross and Nisbett 1991). In her research on parole practices, Mona Lynch (2000) notes the emphasis on human nature, attitude, character and personality to explain behaviours of reintegrating adults, and the de-emphasis on structures and situations. In discussing the responsibilizing strategies and practices of governance, Simon (1994) notes that governance includes creating, and circumscribing, the conditions for responsible choices. Hannah-Moffat (2001) adds that for criminalized women, choices are severely constrained such that their opportunities to perform responsibility and reform are predetermined to correspond with state goals.

\section{Empowerment as self-directive and coercive}

The emphasis on women's choice exists within the context of women's criminalization and incarceration, in which 'taking responsibility' for one's crimes is also part of the broader discourse of empowerment. Empowerment is a term extensively used in discourses of welfare, social programs, and therapeutic interventions and is associated with other abilities or attributes such as self-esteem, competence, assertiveness, and confidence (Becker 2005; Boehm and Staples 2002). Empowerment strategies were originally associated with social movements that sought to place women's experiences in wider social, political and economic contexts, and which evolved from "ideals of participatory democracy, critical self-reflection, and collective action" (I. M. Young 1994, 50). Yet Dana Becker (2005) describes empowerment as relationships of power and notes how empowerment strategies focus on women's individual, medical, and personal problems - the ways in which they cope with inequality, rather than inequality itself (see also Kendall 2002; McKim 2017). The process of empowerment is often considered to be the responsibility of the individual, such that "[p]eople empower themselves" (Lee 2001, 60; see 
also Beaulaurier and Taylor 1999). In contrast, Barbara Cruikshank argues empowerment is “a democratically unaccountable exercise of power in that the relationship is typically initiated by one party seeking to empower another. ... relationships of empowerment are simultaneously voluntary and coercive $(1999,70)$.

This tension between conceptions of empowerment as self-directive or coercive runs throughout the discourses surrounding women's criminalization and reintegration. The final report of the TFFSW emphasizes how contexts of violence and trauma had eroded women's selfesteem such that they are unable to 'cope' $(1990,106)$, and prioritizes empowerment and 'meaningful and responsible choices.' Such framing of women's experiences and their way forward shores up governing discourses that require women to 'take responsibility' for their past, present, and future actions through self-governing strategies of empowerment (Garland 1997; Hannah-Moffat 1999; Kendall 2002; Lynch 2000). Such discourses mobilize a concept of individual agency, which relates to responsibilization and empowerment. Recognizing the varied conditions and circumstances in which women exercise agency allows space for a robust examination of responsibilization and the numerous ways in which it is inhabited. I avoid calling out binaries such as coercion and resistance, but seek to understand the social structures that frame the possibilities for agency and responsibility, as well as the social relationships and activities through which they are exercised and inhabited (e.g. Madhok, Phillips, and Wilson 2013).

The rationalities behind particular subjectivities toward which women are directed can vary depending upon those who are promoting them. I noticed variance in how service providers discussed the importance of employment for reintegrating women, which impacted not only how service providers support women, but what discourses they draw upon to explain their work. 
Amanda Nelund (2015) found that some community workers assist women in finding employment as a means of expanding the women's options and helping them support their families. Such direction toward employment "aligns with the interest that neoliberal governance has of citizens" (171). Yet it also aligns with feminist projects that seek to expand women's possibilities and provide economic security for women. With "very different motivations and goals, the same strategies make sense for both feminism and neoliberalism" (171). In other words, a particular practice of responsibilization, such as directing women toward becoming employable subjects, might have different supporting mentalities even while it serves as means of responsibilization.

Subjects are constituted in multiple ways and each has a history; each is suffused with norms and values of the society and culture within which they are located (N. Rose and Valverde 1998, 575). The subject position of the employable reintegrating woman is steeped in norms about gender roles and abilities, and about the connection between employment and social belonging. Understanding this position requires a recognition of the "complex social formations that constitute and constrain subjects" (Weeks 1998, 4). I am interested not only in understanding the discursive foundations of employability, but in exploring how women inhabit this subject position. Given the restrictive context of reintegration, I do not want to overestimate reintegrating women's capacities for self-creation and self-transformation by under-emphasizing the forces constraining women and making difficult the imagination and realization of alternative subjectivities. Informed by feminist standpoint perspectives that foster 'projects of totality' (Weeks 1998; Harstock 1987; Devault 1990), I attempt to locate some of the specific conditions and practices that impact the possibilities for employment for reintegrating women, and position these within the larger frameworks of social structures, correctional and labour practices, while 
not suggesting that such frameworks determine women's subjectivities. There are tensions within governing discourses and rationales around employment and employability, as well as a disconnect between the production of the perception of self as an employable subject, and the actual employment possibilities for reintegrating women. These points of tension indicate the need for careful analysis of how service providers navigate and inhabit these tensions, and how reintegrating women describe their experiences in employability programs and in their search for employment. Laboring practices available to reintegrating women suggest certain ways of being in the world. Women's laboring practices are both constraining and enabling. These alternatives "are located not in some natural or metaphysical essence, but in our practices; more specifically, these possibilities of feminist subjectivity, of feminist political agency, are grounded in an ontology of laboring practices" (Weeks 1998, 7). My research highlights the necessity of bringing a feminist, intersectional lens to women's integration into the labour market after periods of incarceration.

\section{RESEARCH PROJECT: DISCOURSES OF EMPLOYABILITY}

Through this research project, I explore what makes reintegrating women 'employable'. I understand 'employability' as a subject position toward which reintegrating women are directed, a subject position which is shaped by norms and beliefs about gender and work. By examining the narratives of reintegrating women, and the service providers who assist them, I identify descriptions of the barriers that women face, not only to employment, but to being employable. Current conceptual framings of incarcerated and reintegrating women limit women's reintegrative possibilities, even while correctional discourses demand individual responsibility. Women's narratives form the foundation of this work, and detail the ways in which reintegrating 
women experience and interpret the governing practices related to the production of employability. In particular, this project prioritizes the narratives of reintegrating women as part of the feminist effort to address the invisibilization of women in correctional policies and practices.

I draw upon Foucauldian poststructuralist recognitions of the power that resides within dominant discourses (L. J. Miller 2003; S. Mills 2004). I understand social reality as articulated through discourse, and reality as interpreted through the discourses made available to us (Phillips and Hardy 2002; Chase 1995; Josselson 1995) In other words, throughout this work, discourses are positioned and referenced as articulations of social contexts and contributions to the way these contexts exist and evolve (S. Mills 2004). By focusing my analysis on discourses of reintegration and employability, particularly key terms such as honesty, choice, empowerment, confidence, and motivation, I explore understandings of 'successful' reintegration. I ask how service providers seek to assist (or produce) reintegrating women as employable subjects. What mentalities of governance are referenced and mobilized through their narratives? How do reintegrating women experience being governed and produced as employable subjects? Certainly, I was interested to know what kinds of jobs reintegrating women could obtain, and what both service providers and reintegrating women consider to be effective employment programming. ${ }^{18}$ However, more importantly, I sought to understand the constitution of employability and reintegration success by using discourse as point of inquiry.

\footnotetext{
${ }^{18}$ In addition to producing this dissertation, I am producing a report for service providers, community partners, and criminalized women that maps out a critical path to employment; explains key barriers; identifies the types of employment most often available to women; suggests possibilities for employment supports; and shares some of the advice given by reintegrating women to their peers. This reflects how this project is grounded within, and accountable to, the community and how much of my motivation guiding this project relates to how to improve supports for reintegrating women.
} 
Merry Morash (2010) notes that the experiences of criminalized women differ greatly due to the intersection of factors such as race, ethnicity, class, sexual orientation and other markers of social location, as well as their criminal involvement. Much of my work takes inspiration from socialist feminist standpoint theory that is committed both to understanding the relationships between social structures and subjectivities, and fostering social transformation (Harstock 1987; Devault 1990), I chose a grounded, qualitative research process because I saw potential to generate rich data and theories through rigorous process designed to amass and analyze empirical data (Corbin and Strauss 2008; Sarantakos 2005; B. G. Glaser and Strauss 1967). I was interested in "understanding social phenomena from the actors' own perspectives", or at least the expressed perspectives and experiences (Brinkman and Kvale 2015). As such, I focused on the narratives of experiences and beliefs, with the goal being to derive general understandings of the shared characteristics of these narratives (Moustakas 1994, 13). Recognizing that one person's description and interpretation of events could be significantly different from someone else's was important to this process. I reminded myself that my aim was not to find the 'truth' about these women - the programs they did or did not participate in, the services they do or do not have access to, the barriers they do or do not face. As Comack notes, "[d]iscourses are neither 'true' nor 'false' - but their effects can be very real”' (1993a, 9; see also Josselson 1995; Doucet 2008).

The data for this project are interviews with service providers and reintegrating women. I approached interviews as guided conversations through which "knowledge is created 'inter' the points of view of the interviewer and the interviewee" (Kvale and Brinkmann 2008, 149). In other words, I understand knowledge and meaning as generated through this research project, and as being co-created or constructed with myself and my research respondents and as an aspect of our interaction (Corbin and Strauss 2008, 6). Each interview was a conversation with an 
individual who had a unique experience and socio-cultural location. The narrative approach invited research participants to interpret themselves and their experiences for me (Josselson and Lieblich 1995). I also believe that as a researcher and interviewer, I was actively involved with my respondents so that together we constructed "fuller answers" to the research questions (DeVault 1999, 65). Marjorie DeVault encourages researchers to take responsibility for recognizing how concepts learned as academics may “distort women's accounts" (1999, 66). As I conducted interviews, I tested concepts I was identifying and solicited feedback on theories I was generating (Ezzy 2002). For example, after hearing from several service providers that 'confidence' was key to women's employment success, I began putting this question to reintegrating women - telling them what I had been told, and asking for their opinion. How certain women answered this and other questions informed subsequent interviews, enriching my interviews along the way.

\section{Research methods: Interviews}

I conducted my research within Ontario, a region of Canada with a long history of criminalizing and incarcerating women. Until 1995, all federally sentenced women were imprisoned in Kingston's notorious P4W, and prior to that in Toronto's Andrew Mercer Reformatory for Females (1874-1927). Although federally sentenced women are now incarcerated in institutions across CSC's five regions, Grand Valley Institution (GVI) in Kitchener is the largest women's prison in the country, holding approximately 200 women. All of the federally incarcerated women interviewed had served time at GVI (although some also served time in other federal institutions). There are also seven halfway houses for women across the province. 
I conducted preliminary research in $2015,{ }^{19}$ and began my full field research in 2017. I began by contacting Elizabeth Fry (E. Fry) Societies in urban areas across Ontario. E. Fry Societies are community-based, women-centered organizations that support criminalized women and girls. Programs they offer include court support, Shoplifting Alternative Rehabilitation Programs, transitional housing, anger management, and mother-child programs. Through communications with staff from various E. Fry offices, I identified other community organizations, which I then contacted. I also conducted Internet searches to identify other agencies serving reintegrating women in urban areas of southern Ontario, and I began reaching out to these agencies. This process yielded seven community-based agencies, and ten interviews with service providers. Data in this dissertation reflect interviews with thirteen service providers and twenty-one reintegrating women. Six of the interviews with service providers were conducted during my preliminary research in 2015; the remaining seven were conducted over a 20-month span (2017-2018). ${ }^{20}$ Saturation is a measure of data quality and refers to "collecting data until no new information is obtained" (Morse 1995, 147). While I continued to find conversations with service providers and reintegrating women interesting and insightful, by the fall of 2018 I felt that I had achieved saturation and no new themes were emerging.

\footnotetext{
${ }^{19}$ In 2015, I conducted 10 interviews with service providers in Ottawa and Winnipeg. These service providers were currently or formerly employed in community-based organizations that provide services to criminalized women. They were recruited from my network of contacts and through snowballing.

${ }^{20}$ There were three interviews from 2015 which have been excluded from analysis here, one because it was done with a service provider in Winnipeg. The other two because they were early in my research and my questions were still in development. Additionally, both individuals did not want to be audio-recorded. Other 2015 interviews had been audio-recorded, and while my questions were not exactly the same, the breadth of discussion during our conversation provide rich details that significantly contribute to this project.
} 


\section{Service providers}

The only sampling criteria for service provider inclusion was that they provide employmentrelated support to reintegrating women. Of the thirteen service providers interviewed, twelve were women; ten were affiliated with a community-based organization; and ten were White. Service providers had an average of six and half years of experience, with the most being twenty-three and the least one year. Their educational training varied significantly. The educational and professional training of other service providers included criminology (four service providers), psychology, occupational therapy, business, information technology (IT), education, and political science. Their roles, and role titles, also varied, which is indicative of variances in ways in which employment supports are positioned within community organizations. Roles included Reintegration Coordinator, Employment Consultant, Employment Advisor, Community Employment Coordinator, Case Worker, and Executive Director. Most interviews were conducted in the service provider's office, although three were held in coffee shops. All except one were audio-recorded. Each participant was assigned a pseudonym, which was chosen with intention, such that I chose names common to the woman's generation, ethnic, and socio-cultural context. ${ }^{21}$ The pseudonyms of service providers in this study are: Donna, Elena, Heather, Patricia, Natasha, Jessica, Sarah, Sheila, Kim, Maria, Helen, Jeff, and Susan.

\footnotetext{
${ }^{21}$ Assigning pseudonyms to women of socio-cultural and ethnic contexts involved Internet searches and exploration of relevant literature. In other words, if I interviewed a woman with a common anglo-Saxon, name, I would pick another similar name shared by others of her generation. If she had a name that was slightly uncommon, or with atypical spelling, I tried do likewise for her pseudonym. If I interviewed a woman with a name that reflected her ethnic background, I chose a similar name. For example, 'Chantell' is a name I found in searching for common Jamaican names in order to reflect her Jamaican descent. Care was also taken to not assign as a pseudonym a name of another participant, which meant that in one case I had to change a pseudonym initially chosen after conducting an interview with a woman of that name.
} 
All of the service providers interviewed worked in organizations that provided services to reintegrating women, but only five were with organizations that provided services exclusively to women..$^{22}$ One of these provided services for women who had experienced violence, including but not limited to women who had been criminalized. Four other service providers worked for organizations that provided services to adults involved in the justice system, services which included but were not limited to employment support. Another service provider worked with an organization that was mandated to provide employment support to those with barriers, which may or may not relate to criminalization. The remaining three service providers interviewed worked for CSC in capacities relating to parole or employment support.

Similar to the variances in roles, service providers had varying degrees of authority over the women they assisted. For example, Maria, who worked with the organization offering support to women who had experienced violence, had little to no formal governing capacity over her 'clients'. The women she worked with could choose whether or not to avail themselves of the services offered, services that included counselling, employment-related support, and educational upgrading. These programs were not court-mandated, nor related to federal and provincial correctional systems. Maria suggested there could be points of tension in their work when it came to meeting women's needs if there were parole conditions or court-imposed constraints because her organization's "mandate and the law don't correspond."

Service providers working in community-based organizations providing support to reintegrating adults also indicated points of tension and frustration with the differing mandates

\footnotetext{
${ }^{22}$ One of the service providers, counted among these five, had worked with an organization that worked exclusively with criminalized women but at the time of our interview was working with an organization that provided services for men and women who had challenges relating to mental illness. Where relevant, I note in this work if her comments relate to her time spent with the women's organization.
} 
between their own organizations and that of corrections. Donna had been with an organization assisting women in conflict with the law for several years. She said her organization did not receive any funding to specifically address women's employment needs. "If a woman expresses a desire in finding employment, we might be lucky in being able to help them," she said, adding that this would likely be the responsibility of the individual case worker. "But really, there's no core employment program here. We've attempted to get them going. We've been denied funding." She was extremely critical of CSC and CORCAN ${ }^{23}$ for not supporting women's employment. "I find it absolutely abhorrent and appalling that more attention isn't paid to women's employment," she said. "To me it's criminal, that CORCAN puts the majority of resources into, into men and virtually ignores women. You know, I can't understand the justification for that." This speaks to constraints faced by non-profit, community-based organizations that are heavily, or even completely, dependent on program funding. If employment for women is not identified as a key intervention for reintegrating women, such as by government and corrections, then it is difficult for community-based organizations to receive funding to invest in employment programs.

Community-based organizations offer a variety of court-mandated and voluntary-access programs. Participation in, and successful completion of these programs can be part of women's reintegration requirements. Staff within these organizations may work closely with correctional staff, such as having meetings with parole officers and sharing information about women under supervision. Some service providers like Heather and Elena also had disciplinary roles, such as

\footnotetext{
${ }^{23}$ CORCAN is the employment and employability program of CSC. It is a special operating agency whose name is
} always written in all-capitals, although it does not seem to be an acronym. 
for those who managed or worked in halfway houses. In addition to offering individual counselling and both voluntary and mandated programs, these service providers enforce curfews, monitor women's whereabouts, and test for drug and alcohol use. They report on women who violate parole conditions and can recommend that women be sent back to prison. Finally, parole officers like Sheila and Kim have the authority to decide whether or not a woman can apply for or accept certain jobs, and can also make decisions about the application of curfews and other conditions. They apply the guidelines set out by the Parole Board of Canada, but have a significant amount of individual discretion on how to interpret these guidelines.

\section{Reintegrating women}

The participation criteria for reintegrating women in my study was that they had been incarcerated in either a provincial or federal institution. ${ }^{24}$ Participants were recruited through flyers distributed at halfway houses and community-based organizations, but more frequently by word of mouth or by my presence at a halfway house. Several women said they participated because by doing so they received two ten-dollar gift certificates. (They had a choice of cards from Tim Hortons or a grocery store). Some interviews were arranged days or even weeks in advance, such as when I was put in contact with a reintegrating woman whom I then emailed or texted to inquire about arranging an interview. On these occasions, I would drive to our prearranged location for the single interview. However, the majority of my interviews were conducted in halfway houses. For these interviews, I obtained permission from halfway house

\footnotetext{
${ }^{24}$ I conducted an interview with one other criminalized woman who heard about my project and approached me. During our interview I realized that she had not been incarcerated, but had been on house-arrest during which time she was able to continue with her education and employment. While our conversation was rich, I decided to exclude it from this current analysis as there were multiple factors which made her experience quite different from other reintegrating women.
} 
staff and arranged a time to come to the house. Staff and/or I would then approach women to explain the project and ask if they were interested in being interviewed. As such, I was often able to interview multiple women on the same day. At one location, I came back for a second day as there were still women interested in talking to me. Following the interviews, I would write summaries and record my reflections. These notes were transcribed and treated as data. In total, sixteen women were interviewed in their halfway house ${ }^{25}$ or bail house, three at Tim Hortons, one in her own home, and one outside her place of work. Interviews were audio-recorded, except for one, for which I took hand-written notes. During all interviews, I made note of aspects of speech that would not be captured in text, jotting these down in the margins of my notebooks and expanding upon them later in my reflections. ${ }^{26}$ Audio recordings were transcribed in full and the quotes provided in the following pages are presented without significant modification. ${ }^{27} \mathrm{I}$ am aware that much is lost in transcription, such as facial and tonal expressions. As much as I try to convey some of the characteristics of a conversation or the individual, words often fail me. I also am cautious about being too descriptive as I want to preserve participants' anonymity.

\footnotetext{
${ }^{25}$ There are 7 halfway houses for women in Ontario. I conducted interviews in 3 of these houses; another woman I interviewed lived in a fourth house, but our interview was done off-site.

${ }^{26}$ As part of my analytic and writing process, I developed a pattern of beginning my writing day by listening to the audio recordings of interviews. Initially this was because I was finishing up my transcriptions while beginning to write up findings. Even after transcription was complete, I sometimes continued to start my day this way (either listening to segments of audio or re-reading an interview transcript) in order to remain grounded in my research. Through this process I developed a familiarity with my data that has been useful as I sought to delve deeper into certain themes. Of course, I also feel this dissertation can capture but a part of the rich data I collected and that each time I plunge back into a woman's story, I am aware of the potential of other avenues of inquiry.

${ }^{27}$ As I was participating in a two-way conversation with women, I engaged in gestures and expressions such as nods, smiles and shared laughter, expressions of sympathy or concern, and gestures or words of agreement. As I transcribed my interviews, I was struck by how often women punctuated the comments with 'right?' or 'you know?' My response was usually an affirmative murmur or a spoken 'yes/yeah/right'. In my transcriptions I have omitted these responses unless they were questions or comments to which women responded, or which altered the flow of conversation.
} 
Of the twenty-one reintegrating women, nine women were White, five were Indigenous, three were Black, and four were Asian. Their average age was thirty-eight, with the youngest (Donisha) who was twenty-three and the oldest (Tina) who was sixty. At the time of our interview, eleven women were employed. Just over half of the women (12) had children, and Becky was pregnant with her first. Of the women who had children, for eight of them, their children were grown up and were not economically dependent on them. Of the other four, only Lin currently had her children living with her. The other three women were living in a halfway house, but two of them indicated they would be living with their children upon their release. I purposely recruited those who identify as women for this study, but have included Andy, who contacted me about participating and was in the process of transitioning from female to male. ${ }^{28}$ Five women had come out of provincial jail; sixteen out of federal prison. The length of time since their release varied significantly, from one week to five years; the average was ten months. All except one were still under supervision. When asked if they had any disabilities, only two women identified physical injuries, although others mentioned physical limitations during our conversation (such as back pain that prevented them from standing for long periods). Eight women identified a disability relating to mental illness, such as being 'bi-polar' or having learning disabilities, depression, anxiety, or just general 'mental illness' (see Chapter Five). As with service providers, pseudonyms were chosen with careful intention. They are: Alexa, Tina,

\footnotetext{
${ }^{28}$ I recognize that including Andy, who was beginning to identify as a male, marks them an outlier in this project. However, I feel their contribution is still important, particularly as they are one of the few participants who had been incarcerated in a women's provincial jail. Additionally, Andy's presence in this project is an acknowledgement of the current context of corrections in Canada, such that there is uncertainty about where to 'place' those who are nonbinary or transitioning in our correctional institutions that classify gender as distinct categories of either male or female.
} 
Chantell, Andy, Becky, Elaine, Ashley, Donisha, Zahra, Malone, Srila, Theresa, Carla, Holly, Janessa, Nicole, Lori, Joan, Melody, Lin, and Tara.

In my interviews with reintegrating women, I did not ask about their criminal charge, or probe into their past beyond asking about employment experience prior to their incarceration. However, I learned early on that it was important to ask if they had served a federal or provincial sentence, as this made a significant difference in terms of the types of employment programming that had been available to them. Otherwise, I did not ask much about their sentence unless it was to clarify something they were telling me about their institutional time. However, many women talked extensively about their time inside, not just in terms of employment programs, but their interactions with guards, other women, prison programs, etc. Some women also indicated the type of charge they had, particularly those who had fraud related charges since such charges significantly impact their employment prospects.

At times I had the impression that the interview served almost a therapeutic role for my participants. For example, Jeff, a service provider, said, "I can be so candid with you. It's like psychotherapy for me. It's like here I get to tell you all this stuff." Several reintegrating women thanked me at the end of the interview and said they had enjoyed talking with me. Nicole noted that she had not known what to expect coming in.

Like what is this lady going to ask me? What's going on? What am I doing? But you know what? Actually, I'm really happy I did this. I'm really, really happy I did this. Because like if it helps one person, it's more than, it's more than I could say for something I haven't done, right?

By 'helping someone else', Nicole is referring not only to helping me as a researcher (which she, like several others, seemed quite willing to do), but also to the hope that this research could 
improve employment supports for reintegrating women. Indeed, part of this research project involves producing a report for community partners in which I will report back on my findings.

\section{Analysis}

Drawing from insights from feminist linguistics, my process of analysis included attention to what it means to talk and listen 'as women' (DeVault 1999; D. E. Smith 1987). I am not suggesting that as a woman I necessarily understand other women's perspectives, but rather that my experiences as a woman informed the questions I ask, how I responded during interviews, and how I analyzed interviews. Additionally, as a woman interviewing women, there were many times when respondents "signal a request for understanding... on the woman-to-woman level" (DeVault 1999, 69). As I transcribed interviews, I was aware of the frequency with which women signaled requests for my agreement or understanding, such as by asking 'right?' or 'do you know what I mean?' As DeVault $(1999,69)$ point out, the phrase 'you know' can be read as simply incidental features of speech, but can also indicate "the joint production of talk" and an appeal for understanding. Women appealed to my understanding and shared experience, but also sought to 'educate' me on what they considered to be experiences I did not share.

I was often humbled by the extent to which women demonstrated trust in me by sharing their stories and personal struggles. At the same time, I never assumed they told me everything, or that through the course of one interview, I would 'know' these women. I could only "hear and know something about their stories" (Doucet 2008, 80 emphasis in original). There are likely parts of their stories that they did not share with me. For example, very few women talked about drug and alcohol addiction, even though statistics on incarcerated women would suggest that this was relevant to more than half of them. 
Since I was focusing on the narratives of individuals as expressed to me during the interviews, and my purpose was hearing their stories, I decided from the outset that I would not 'Google' the women I interviewed. I will admit that there were times I was curious, such as after interviewing women who told me that if someone conducts an online search with their name, they would find multiple stories about their past. But I accepted from these women what they wanted to tell me, and respected their privacy by not trying to find out more. Another reason I did not search for women's pasts is because I knew that what I would find might influence how I interpreted their narratives. Certainly, one could argue that 'knowing more' might enable me to read their narratives more critically and identify where they were obscuring or omitting certain details. However, reading media accounts of women's crimes would be reading other people's stories about these women, narratives that were constructed for purposes much different than mine. Such narratives might influence my impression of certain women, particularly those who had been convicted of violent crimes or sexual offences. I was also aware that the extent of information I might find online about some individuals would be inconsistent across the women I interviewed. Women who had been convicted of summary offences are unlikely to make the news; thus for some women I might find multiple pages of salacious details, while for others I might find next to nothing. Again, this might impact how I interpreted their stories when I reviewed the transcripts and field notes. Reintegrating women face stigma, judgment or prejudice from many people they meet. I did not want to be one of those in whose eyes they saw fear, distrust, or skepticism.

Consistent with how I approached women's narratives about themselves, their past experiences, and their barriers, I took the same approach to descriptions of employment services. Different women at the same halfway house gave different accounts of the supports available to 
them. Some told me there was nothing available, others told me there was plenty of support around. I interpreted these discrepancies as indicative of both the ad hoc nature of employment support for women in the community, and of the perceptions individual women have about the type of support that is meaningful to them. In brief, programs both are and are not available. Both are valid perceptions. I also knew that a woman might tell me about her future plans and convincingly describe how close she is to success and independence. The next day, she may be back behind bars. Her ambitions and hopes were not less valid because they were thwarted.

As previously noted, this research is a grounded, qualitative project informed by feminist standpoints and methodologies (Devault 1996; Francis 2002; Weeks 1998; Ahmed 2017; Harstock 1987; D. E. Smith 1987). Yet while identifying myself as a feminist and emphasizing gender in this project, I do not assume some all-encompassing or homogenous category of 'women' (Smart 1992) who share the same experiences in employability training or in accessing employment. Building upon anlyses of intersections of biography, history, social structures, race, class and other structural and human factors (C. W. Mills 1959; Crenshaw 1991), I understand that other factors "may sometimes be equal to or more important than gender in the marginalization of individuals and groups" (Chunn and Menzies 2014, 117; see also Comack 1996). I have sought to retain a sense of unity with other feminist projects and concerns, yet respect and acknowledge the varying needs of different groups (hooks 1991). I believe this is especially important in research on women involved in the justice system, where criminalization, gender, race, and class intersect in compounding and complex ways.

Even as I seek to emphasize the differences in women's positions and experiences, I am aware of the warning from feminist researchers of the "serious danger of romanticizing and/or appropriating the vision of the less powerful while claiming to see from their positions" 
(Haraway 1996, 584). Additionally, I am also aware of the debates among feminist and other critical researchers as to how to hear and present the 'voices' of subaltern others (Mazzei and Jackson 2009; Chunn and Menzies 2014). While working within the research traditions that prioritize the voices of others (Corbin and Strauss 2008), I recognize that throughout the research process (study design, interviews, coding, theorizing), I am interpreting others, or as Andrea Doucet (2008) explains, I am interpreting their narrations of self. I assume accountability for my own position and do not assume to speak on behalf all women, yet maintain that I am able to critically engage "with the forms of authority and expertise that circumscribe women's control over their lives" (Code 1991, 180).

\section{My location as researcher}

Reflexivity and acknowledgement of personal standpoint are key aspects of feminist research methodology (Harstock 1987; Devault 1990; Comack 1993). I have sought to engage reflexively with the theories and methods I employ to make sense of the phenomenon I explore, as well as about my own politics, values and position, my relationships with research respondents, and my situation within the communities in which I was conducting research. As noted above, I draw from the concept of 'women's standpoint' (Harstock 1987; DeVault 1999) to both reflect on my own standpoint, and to maintain that women do not share a single position but are located in various socially organized activities, places and spaces and make effort to identify some of these spaces. Throughout my project, I practiced reflexivity in several ways, such as checking my interpretations of data by directly asking other interview participants. I also sought out opportunities to check both my process and my interpretation with other scholars, 
such as through conference presentations and through informal conversation. ${ }^{29}$ Additionally, as a feminist researcher, I firmly believe in acknowledging my position - not only as a researcher, but in the various other aspects of my identity. Fittingly, standpoint theory such as developed and explored by Dorothy Smith (1987), Hilary Rose (1983), and Weeks (1998) emphasizes the gender divisions of labour and its consequences on women's lives, and I am particularly indebted to these authors for guiding my exploration of women's employment and reintegration.

My position with regard to this research project, and more specifically my engagement with social transformative efforts, has evolved over the course of this work. When I began this research, I had already been connected with community criminal justice organizations for several years, and my work and volunteer efforts have continued. I have come to know in greater detail some women's stories and have met some women on multiple occasions outside of the formal research interview. Since men make up more than ninety percent of individuals incarcerated in Canada, the number of reintegrating women is relatively small, especially federally sentenced women. In the process of analyzing transcripts, it was not uncommon for me to realize that the woman being referred to by a service provider was one that I had also interviewed. ${ }^{30}$ There are only a handful of women in the province with long-term supervision orders, and they become known to parole officers and service providers.

\footnotetext{
${ }^{29}$ For example, a colleague in the Department of Sociology and Anthropology conducted field work on 'Ban the Box' campaigns which seek to remove questions about criminal records from employment applications. She and I met several times during the course of our respective periods of data collection and analysis in order to discuss findings, interpretations, and nascent theories. These discussions not only provided important emotional support in the long process of writing up a dissertation, but they stimulated ideas about meaning and significance, and helped to identify additional complexities within my research data (Ezzy 2002; Strauss 1987).

${ }^{30}$ Because there are few halfway houses for women in Ontario, and not very many federally sentenced women, it is not uncommon that service providers in one location have worked with women who later reside in another location, especially in the Greater Toronto Area.
} 
As Chair of the Citizen Advisory Committee of the Ottawa Parole Office I have sought to find ways to support employment for individuals on parole in Ottawa, particularly women. I was able to obtain project funding through CORCAN and CSC, and partner with the local Elizabeth Fry Society, to implement employment workshops for women at the halfway house.

Additionally, we were able to engage, and remunerate, a woman who had been federally incarcerated to develop and lead these workshops. This has been very meaningful for me as an opportunity to put my research into action. Jennifer Kilty $(2014 b, 139)$ encourages feminist researchers to "remember our roots, our communities, the issues that drive us". By engaging with the community, and finding ways to put research into action, I have felt both enriched and challenged. While this dissertation focuses on the research interviews I conducted, those for which I have signed consent forms and ethics clearance, part of being reflexive in my analysis is acknowledging that I am unable to fully separate out what I learned through this research project from what I have learned through on-going participation in supporting and working with reintegrating women and agencies involved with them.

I have also been very aware of my own position and of relations with myself and 'ghosts' of my past (Doucet 2008). In many ways, I have been fortunate in my life. However, I have also experienced poverty on several occasions and have done the kind of menial, tedious jobs that only those most desperate will accept. While I did not disclose this to the women I interviewed, these experiences shaped my conversations and my understanding of what it means to do manual labour and minimum-wage work. Additionally, during my research period, my own marriage ended and for several months I was unsure where my children and I would live, or how I could support them. I struggled to find housing I could afford, yet was aware that my budget far exceeded that of women on social assistance or those working for minimum wage. As I dealt 
with lawyers and studied rules and regulations dealing with child custody and separation, I noticed that I listened with heightened awareness to women's accounts of the interim custody arrangements they scrambled to make when they were arrested, or the negotiations they were undertaking with the fathers of their children or child service agencies.

While my personal concerns about my children and my living arrangements made me keenly aware of these aspects of our conversations, I also found my awareness of employment-related supports shifted with my personal experiences. As I plan for what will happen after I complete this dissertation, and as I looked for ways to support myself and my children, I attended employment workshops, consulted resources, and spent hours on job sites. I noticed that I was approaching these efforts with a new awareness of my own privilege, noting how some of the resources available to me would not be available for women who do not share my level of education, mobility, location, etc. I was also aware of how much employment opportunities still emphasize networking and cultural capital, and how my access to individuals in positions of power were starkly different from the reintegrating women with whom I spoke. These personal experiences shaped not only my interactions with women, but informed my reading of the interview transcripts and the literature on employment and employability.

\section{Other issues and future work}

My research project examines narratives about women's reintegration and employment. As such, the interview questions I asked focused primarily on women's experiences with employment applications, training, support, etc. With most research participants, I had the impression our discussion was relevant to their concerns and interests. However, as I will explore in the discussion of honesty in Chapter Three, and as was remarked on by Susan Starr Sered and 
Maureen Norton-Hawk (2014) in their research with reintegrating women, research participants may have been telling me what they thought I wanted to hear. There were also a few interviews for which I felt like my questions were not all that relevant to women's primary or immediate concerns. As will be explored in Chapter Six, some women expressed ambivalence or resistance to employment. For some it was of interest, but not a priority. Future research projects with reintegrating women that are structured around another aspect of reintegration, such as housing or family connections, could provide a nice counterpart to this project.

This research is much like a snapshot, a temporally limited view of women's perspectives on reintegration and employment. While there have been a few reintegrating women with whom I have remained in contact, for the most part I do not know what happened to these women after I met with them. Are they still in the community, or have they been sent back to jail? Were they able to find a keep a job? An extended project, such as that which was done by Sered and Norton-Hawk (2014) would be beneficial for exploring the arc of women's reintegration and employment. In this project, there is a blurring of the narratives about the skills and aptitudes required to find employment and those required to maintain employment. The focus of the study was on the former, but discussions of the latter often came up in conversations, both with reintegrating women and with service providers. For the purposes of this project, I do not think this is significant since my intention was to examine narratives of governance relating to women's employment and employability. However, future research that explored and compared women's experiences of finding work with those of maintaining work could provide important insights in the sustained practice of employability and possibly open way so further explore if, when and how women come to adopt their employment within their narratives of self and descriptions of individual identity. 


\section{3. 'I'm not ready for this': Employment supports for reintegrating women}

The prisoning of women, especially in these neo-liberal times, is another source of trauma. The provision of gender-responsive programming and other resources in prison is essentially designed to empower the women to become responsible, self-reliant, and conforming neo-liberal citizens. ${ }^{31}$

- $\quad$ ElizaBeth COMACK, COMING BACK TO JAIL

Soon after her release from federal prison, Malone enrolled in a community-based employment program. Like many other such programs in which reintegrating women participate, this one was not designed specifically for reintegrating women, rather it was non gender specific, and non barrier specific (although Malone said a lot of the other participants were also coming out of jail). Over the course of three weeks, she and the other participants were taught a variety of employability 'soft skills', such as job searching, work 'etiquette', and time management, the "skills to help you find employment," she explained. Program participants were paid for their time and were expected to treat the program like a job. Similarly, Donisha had also found a community-based employment program; in her case it was targeted at youth. The two-week instructional program was followed by a four-week job placement. Like Malone, Donisha had been paid to participate in her program. In fact, she laughingly said that a service provider had

${ }^{31}$ Comack $(2018,29)$ 
encouraged her to enroll by telling her, "you'll get paid just to sit and look pretty." ${ }^{32}$ But Donisha insisted she did more than that, describing the training she had received such as workplace safety and use of power tools. She was subsequently given a work placement. "It's helping me get to where I want to be, right?” she said about her new job. “So, yeah, I'm, I'm planning on staying there for awhile."

Yet while women like Malone and Donisha described the programs in which they had participated, and spoke positively about the support they received, other women said there was actually little help available to reintegrating women. "There's no help offered, no, no, no," Joan said emphatically. "There's nothing, nowhere. No.” Certainly the availability of employment programs for reintegrating women is not consistent across urban Ontario. When I began this research, I had expected to find employability programming that perpetuated narrow, gendered employment options for incarcerated and reintegrating women, such as sewing and hairdressing. Instead, I found a general lack of any employment training for women, gendered or otherwise. When it comes to employment programs, women seem to still be considered 'too few to count' (Adelberg and Currie 1987). Of the thirteen service providers interviewed, only four worked exclusively with women, which is indicative of the nature of employment support in the community such that programs exclusively for reintegrating women are extremely rare. The nine other service providers often indicated they had only a handful of women among those they supported. The result is a patchwork of options which each individual woman must navigate in order to obtain the support she requires to find employment.

\footnotetext{
${ }^{32}$ Hearing that Donisha was told she could (or should?) 'sit and look pretty' was certainly troubling to me. It relates to the discussion about discipline of women's performances of gender found in this chapter's section 'Employment supports in the community'.
} 
Some criminologists have suggested that community organizations working with reintegrating adults are an extension of the punitive and surveillant arm of the state (Cohen 1985; Garland 2001; Feeley and Simon 1992). As such, community organizations have been portrayed in literature as rhizomatic and non-hierarchical networks mobilized in practices of crime control. David Garland suggests penal and community organizations share "the same assumptions, harbor the same anxieties, deploy the same stereotypes, and utilize the same recipes for the identification of risk and the allocation of blame" $(2001,201)$. Malcolm Feeley and Jonathan Simon (1992) portray them as being invested and involved in risk-management, such as through sharing of information, keeping of records, and establishing networks of surveillance. However, others suggest that analysis which merges institutional and community-based systems together obscures important differences in origins, discursive frameworks, foundational beliefs and focal concerns (McCorkel 2004; Nelund 2015). My research indicates that service providers in the community do engage in surveillant and disciplinary practices, such as monitoring women's comings and goings from halfway houses, as well as their drug and alcohol consumption. Such surveillance may be a requirement of their funding, particularly if they are housing women serving their sentences in the community. However, the service providers I interviewed expressed narratives of trauma-informed care, therapeutic support, and benevolence that sit uneasily with discourses and practices of governance and risk management (see Hannah-Moffat and Maurutto 2012).

This chapter provides a descriptive account of the employment supports available to reintegrating women in order to provide context for the following chapters which engage more analytically with how women negotiate various aspects of employability. In other words, subsequent chapters will explore the subject position of the 'employable woman'; here I map out 
the material and practical aspects of finding employment upon release from prison. To begin, I touch upon the employment supports available to women inside carceral institutions, since such programs can impact women's job access upon release. This is followed by an overview of the employment supports available to women in the community, and the types of jobs toward which

reintegrating women are directed. Women transitioning from the institution to employment in the community generally follow certain steps, such as writing résumés, submitting job applications, preparing for interviews, and responding to offers of employment. Some key challenges in these initial stages include prosaic concerns such as obtaining identification (ID) and the material assets required for work (clothes, boots, etc.). Reintegrating women must also navigate barriers relating to their status as parolees or probationers, such as adhering to curfews and parole conditions. Finally, women who obtain a job must then negotiate various challenges in the maintenance of this job, such as their relationships with bosses and co-workers.

\section{EMPLOYABILITY PROGRAMS INSIDE INSTITUTIONS}

"Basically, jail is like one of the hardest, the lowest points in someone's life," Donisha said. Like eight other reintegrating women I interviewed, Donisha had been out of prison for less than three months. Climbing out of this 'lowest point' was clearly an on-going process, not one which is done easily or quickly. Women struggle with anxiety and uncertainty, and with fear of being re-apprehended. They also need to re-learn how to navigate life on the outside. "You've been in one geographical location for how many years?” said Ashley. "I think it's a psychological process that, the depth of how it changes you as a person." This recalls Foucault's reflection that "space is fundamental in any exercise of power" $(1984,252)$. Clearly, incarceration is an oppressive and punitive space in which women's mobility and agency are severely constrained 
(Hannah-Moffat 2001). Within this constrained space, women are made responsible for their own governance and self-improvement, but given limited choice and control over the conditions in which they can act (Comack 2018, 206; Hayman 2006, 239). Indigenous women in particular are impacted by the lack of sufficient access to culturally appropriate programming and services which could help them navigate their carceral environment (Wesley 2012).

The recommendations of the Task Force on Federally Sentenced Women, discussed in Chapter Two, that would see a women-centred vision of corrections rooted in feminist and Indigenous principles have not been implemented to the extent or in the ways they were intended (Hannah-Moffat and Shaw 2000; Hayman 2006; Monture-Angus 2000; Hannah-Moffat 2001). The language of 'choice' and 'empowerment' has been mobilized by CSC to "stress responsibility and accountability, not structural relations of power or inequality" (Hannah-Moffat 2002, 207). The language of choice is also pervasive in the programs offered inside and outside institutions. For example, Heather described the programs her organization offers inside a women's provincial jail. "We have two staff [at the prison] full time that do 'Skills for Better Living', which is life skills, and 'Change is a Choice', working on things anywhere from addiction to helping with assertiveness or helping with self-esteem.” The program name, 'Change is a Choice' recalls the 1990 Task Force report (Creating Choices) and discourses of responsibility and empowerment.

Federal prisons are mandated to provide employability training to those who are incarcerated (Commissioner's Directive 735, 2017). Of the sixteen women coming out federal prison, all but two had participated in employment programs offered inside. Tara said she chose not to because she was hoping "to go right back on ODSP" after her release. Tina, who was sixty-years-old at the time of our interview, said she did not participate in employment 
programming. "That's not for me," she said. "That's for the young ones." The other fourteen women all participated in at least some employment programs, although Holly and Lori only did WHIMIS training, which seemed to be the most readily accessible program, but also the one with the least value. "You're asking one of the women, like one of the prisoners, to put the $\mathrm{CD}$ in the DVD player and project it on the screen, and facilitate the program," Ashley explained. "That's your WHIMIS training inside." She added that she had taken WHIMIS training five times, suggesting that participating in such programs may be a way to relieve boredom rather than gain knowledge or competency development. "WHIMIS certification isn't really going to change what you can earn," echoed Melody.

However, women who had been at GVI described other programs and certifications they received, such as Safe Food Handling, First Aid, Skills for Employment, and Ready to Work. Janessa got her 'fork lift ticket'. Ashley participated in a 'textiles' or sewing employment program. "It's like slave labour," she said. Similarly, Joan indicated that she participated in a work program that was "something silly" but was "a way to kill time and put money in the canteen." She said the job itself did little to provide her with employable skills. "It doesn't qualify you for anything really," she said, and described her job as "watching [men] pour concrete.' She would mostly stand around, but sometimes do small things to assist those who were doing the actual labour. "Whatever little things, fetch and carry shit, they wanted me to do, I'm willing to do it," she said. For this 'job' she was paid five dollars a day. Such accounts of training suggest that some programs contribute little more than a distraction and a line on a résumé to the women who participate. Service providers also expressed concerns about the lack of employment support for women inside prison, especially in comparison to what is available in men's prisons. Since there are fewer incarcerated women in Canada, fewer programs exist for 
them. Heather described federal programs as 'illusory'. She also suggested that even if women come out of an institution having completed employment programs, they still have immediate and practical barriers that eclipse the benefits of such training.

Yet participation in employment programs during periods of incarceration is one of the ways in which incarcerated women are expected, by prison and parole staff, to demonstrate their 'commitment' to reform. Lin was frustrated that the employment programs offered at GVI focused on skills she was not interested in acquiring, such as manual labour, but she still participated in all the programming that was available.

The only reason why I took it all is because that's what they're looking at, to see if you're participating. Because if you're not participating, they're going to say, 'Why are you not participating? You're not adjusting well. You're not ready.' So, that phrase fake it 'til you make it'? It's prevalent. Everybody does it.

Melody confirmed that many women at GVI just participate in programs in order to satisfy their correctional officers, but her comments were made in the context of speaking critically of women's lack of effort. "Their big thing is do you get a certificate for it?" she said. "Okay, so you're just going through the motions to it make it look good on paper." She suggested women did not make much effort to actually benefit from the programs.

Melody was one of the federal women who said that the programming available inside was beneficial. When she was telling me about how hard she worked to find a job, and to hold on to that job, I asked her where she gained those skills. "Inside," she replied quickly. She spoke highly of the employment programs she received. 
We had another one, it was called Ready to Work. ... It was fifteen days, Monday

to Friday, from eight to four. And it was like, we got five different certifications, so we got our Smart Serve, our Safe Food Handling, WHIMIS, ... Work Place Essentials and Service Essentials. Right? So, and it was, that was really good intense program... So, we, we went through an interview process in order to get into this program. They only took ten people at a time. And, you had to take it when you were getting ready to leave, so, you'd have all these certifications. Interviewer: So you did find that helpful then?

Oh, big time. Yes. Because, even like at my place, it's a grocery store, but we sell alcohol. So it's like, okay, I can sit here and I've got my Smart Serve. ... It was like, that was another plus, in order for me to get this job right?

Melody's account indicates that some of the practical skills, such as certification in Smart Serve, can assist women in the job market. Srila also said she got her Food Handling Certificate while at GVI, which helped her get her current job at a company making edible arrangements.

While some women indicated they came out of prison with some certifications to list on their résumés, others used their time inside to focus on their education. Lori said that when she was incarcerated, she did a grade-score equivalency test which resulted in a Grade Four assessment. So, during her years at GVI, she took academic upgrading classes and said, in a tone that suggested both pride and self-mockery, "I graduated Grade Ten while I was in the pen, at what, forty-years-old or something." She added that not having had her Grade Ten may have been one of the reasons she had always struggled to find work. Joan also indicated that she had focused on obtaining her Grade Ten while she was incarcerated. Both women expressed some 
pride in this accomplishment, but it was not clear that for either of them it had afforded any new opportunities upon release. Indeed, research suggests that those with high school equivalency do not achieve the same employment success as those who completed high school, which is attributed to low levels of noncognitive skills that are not overcome through participation in equivalency programs (Heckman, Stixrud, and Urzua 2006, 413).

\section{Nothing for provincials}

As noted in the previous chapter, the majority of incarcerated women serve time in provincial, not federal, institutions. Those who receive provincial sentences, the 'provincials', have been convicted of 'summary offences', meaning offences that can be dealt with summarily or promptly. The crimes for which they are convicted are considered less serious than 'indictable offences' which have sentences of at least two years in federal prisons. Yet although the amount of time provincials served behind bars may be shorter ${ }^{33}$ than that which was served by federals, their experiences seemed to be much worse. In other words, it is ironic that women whose sentences are short are in some ways are more disadvantaged by their experience of incarceration than are those women serving longer sentences. "Provincials have a high turnover rate" said Heather, who managed a halfway house. She said that ninety percent of the women from provincial jails had substance abuse issues. Research in the United States has associated the 'revolving door' of prisons with psychiatric disorders (Baillargeon et al. 2009) and addictions (Warner and Kramer 2009; Harrison 2001). Several service providers, like Heather, attributed

\footnotetext{
${ }^{33}$ In theory, women convicted of summary offences serve less time behind bars than those who receive federal sentences, however, my research indicates this is not always the case. I met with federal women who served a third of their time ( 8 months of two years) in federal prison and then were released to a halfway house. In contrast, Crystal spent 15 months in a provincial jail before being released to a halfway house.
} 
women's re-incarceration to addiction, noting that drug-addicted women may not be able to resist the temptations they face when they are back in the community. Using drugs again, or more precisely, being caught for using drugs while on probation or parole, will often send women back to jail. Yet recidivism for drug use must be looked at in the context of a severe shortage of addiction treatment facilities for women in the community, and other supports (such as safe housing) that can help women maintain sobriety. Unable to get the support they need inside jail, and struggling to find it in the community, many of these women end up back in jail, or, Heather said, they "end up in bad situations, homeless, on the street, and then they end up prostituting because that's how they have to afford their habit." As Comack (2018) found in her research on provincially incarcerated women in Manitoba, over seventy percent of her respondents had prior experiences of incarceration, and for many of them coming back to jail was a "defining feature" of their lives.

Provincials were unanimous in casting their jail-time as, at best, a 'waste of time'. But some also described their experiences as traumatic. "The food is crap. They treat us like crap. The guards are sexual predators or they're violent with us or threaten us," said Andy. "They say like, 'you'll be leaving in a body bag.' Shit like that." While women in federal institutions are housed in minimum, medium or maximum-security units, depending on their risk assessment, almost all provincially sentenced inmates are placed in maximum security by default and there is no standardized security risk assessment tool (Sapers 2017). Additionally, with regard to rehabilitative and employment programming, there is a stark difference between what is available to women in federal and provincial institutions. Women who had served time in provincial jails and detention centres consistently told me there were no employment programs available to them. What little programming exists is notoriously under-funded and unsupported, 
generally run by community service providers and volunteers, and lacking in facilitation space and supplies (Sapers 2017). Carla said she received "nothing" in provincial jail. Becky said, "there might be someone that might come in once every like blue moon to give like a talk or something", but added that there was not really much support. "There's no programming for employment," said Andy. "No AA meetings, no counselling, no discharge planning." Nicole indicated that she was able to access some programming, but noted that it was very limited.

They give you anger management or they give you like, oh, how to cope with addictions, you know? Those are all great things to learn, but like, some of us aren't addicts and some of us are in there just because we made stupid choices. And um, you know, like we, we're going to come back out to real life eventually, right?

Nicole was the only provincial woman I interviewed who said she had participated in an employment program inside, but she spoke of it with derision. She was part of a small group of women who helped in the kitchen with the preparation of meals for her own prison and the neighbouring men's correctional complex. Like Ashley's description of the CORCAN textile program, Nicole described the work as "slave labor". She added that she and other workers did not actually get monetary remuneration. "I know it's awful to say, but we get paid in chocolate bars and chips and pop." She added that instead of boosting self-esteem, this job made her feel like she was being "treated like a kid", and did not help with trying to maintain a healthy diet or weight. Thus, women coming out of provincial jails are much less likely than federally sentenced women to have been given meaningful programming, and are more likely to feel unprepared to enter the job market. 


\section{FROM THE INSTITUTION TO THE COMMUNITY}

Upon release from prison or jail, women often experience "disorientation and trepidation" in negotiating all the demands of adjustment and resettlement (Maidment 2006, 102). They are also likely to experience a "stigmatizing social shame from the community" (Dodge and Pogrebin 2001, 44). Data on federally incarcerated women indicate that sixty percent of reintegrating women have no credit history, sixty-three percent have financial debt, and almost half cannot afford a residence (Zinger 2017). Additionally, women released from federal prisons take, on average, eighty-two days to find work, almost twice that of reintegrating men's average of fortyfive. ${ }^{34}$ Heather expressed it more starkly, noting that many women come out of institutions with "nothing, absolutely nothing". They likely have no money; they lack weather-appropriate clothing; and they have nowhere to go. As noted above, prison, especially provincial jail, is often described as a revolving door. Andy, who spent twenty years in and out of jail, attributed this phenomenon to lack of support for women both inside jail and in the community.

If you don't have the safety net in place, you don't have someone to drive you to a safe destination, where are you gonna go? You're gonna go back to that old place right away, like that...Because that's why you get people continuously going back and forth in the system. It's because you don't have any, they don't have any support for those people.

Andy is identifying some of the basic needs that women have when coming out jail: a safe place to stay and a means to get there. Indeed, upon reentry women often need immediate support for

\footnotetext{
34 These numbers about the average length of time for those released from federal institutions was obtained via email conversations with CORCAN management.
} 
housing, and sustained support for other concerns like addictions, health, and a source of income (O'Brien 2001). Reintegration literature presents basic and immediate concerns as 'stabilization needs', but notes that due to a 'poverty of social capital', most reintegrating adults are unlikely to have supportive contacts in the community who will help them securing housing and employment (Maruna 2001; Ricciardelli, Evans, and Peters 2017). Chapter Four explores how some 'fall back' on informal and illegal ways of making money when they perceive there are no other viable options.

For those who do not transition from the institution to the community via a halfway house, their immediate concern is for shelter. Jeff told me about a reintegrating woman who died four months after her release from the halfway house, a loss which he said was because she "didn't have the housing support she needed." She was living in a place that "was just really not appropriate for anyone actually." She was doing well in the employment program. "She loved coming to work," he said. "She did not love going home." In Toronto, where this woman lived, studio apartments rent for over \$1,500 a month, while monthly shelter allowance for someone on Ontario Works is $\$ 368 .^{35}$ Lack of financial means to secure adequate housing is a very real concern for reintegrating women. Awareness of the risks faced by inadequately housed women may fuel the efforts of service providers to encourage women to find and maintain a job. Nonprofit, community-based organizations like the Elizabeth Fry and John Howard Societies, and the Salvation Army often step in and offer some assistance to reintegrating adults. Parole and probation officers will also make efforts to direct individuals to locally available resources, such

\footnotetext{
${ }^{35} \mathrm{CBC}$, 'What Toronto’s average monthly rent of $\$ 1,800$ gets you in cities Canada-wide," CBC Toronto 1 Mar 2017, https://www.cbc.ca/news/canada/toronto/rent-toronto-canada-1.4002899. Stats on OW: Homes First, "Info and Stats", https://homesfirst.on.ca/info-stats.
} 
as shelters and employment services. But it is widely recognized that supports for reintegrating adults in the community are consistently under-funded and under-staffed (Maidment 2006; Ricciardelli, Evans, and Peters 2017).

Reintegrating women face the immediate challenge of providing for their most basic needs. While incarceration is undeniably difficult and oppressive, it does remove women from the various quotidian concerns and responsibilities, such as paying rent, and making meals. Nicole described her experience of incarceration as debilitating in that women forget how to provide for their own basic needs outside of the institutional walls.

We forget too when we go to jail and whatever you know just like away from this all, like whether it's rehab or like you know just like real life, you know? Like things are given to us, right? Like we have three meals a day given to us, or provided. We have a bed time. We have a bed. Like, you don't think of rent. You don't think of, so you know, when you come out, you don't really have, you don't think of those things.... Like we, we're going to come back out to real life eventually, right? So like, and you forget. You forget when you're in there, when someone's feeding you, when someone's clothing you, when someone's like, how much things are gonna affect you if you don't have clothes to go to a job interview or like you don't have money to buy food and you're like starving throughout the day, you know?

Nicole described this process as becoming 'institutionalized'. She gave an example of how, in the early days after her release, she was unaccustomed to anticipating her daily needs: she left the halfway house for a day of training and only realized later that she had not packed a lunch, nor did she have any money to buy food. Patricia O'Brien notes that the controlling prison 
culture can reinforce a "lack of planning for future responsibilities" $(2001,290)$, so upon release many women must re-learn how to plan for the future and re-learn how to provide for their own needs. Similarly, Elena noted that because life inside an institution is highly regulated, for some women it is a struggle to find ways to develop their own routines.

Donisha also used the word 'institutionalized' to describe what happened to women who were incarcerated. "A lot of females, a lot of people, um coming out of prison, jail, whatever the case is, they're institutionalized," she said. "They don't know how to act, like they don't even know how to talk to somebody, right?" She indicated that she felt overwhelmed, nervous, and excited about all the change she was seeing around her. "When we come out, like it's even, it's a new world now," she said. "Like it's a new place. It's a whole new system, like, you know? Everything is different, you know?" She described at times being almost giddy with the realization that she could talk to strangers. "It's like, hi!" she said, pretending to wave excitedly at someone. "Hi! Hi! What's your name? Hi! It's good to see ya! Good to see ya!" Donisha gave a hearty laugh. "Like people look at me, what's wrong with her?" Though she made her point with humor, Donisha was speaking to the very real challenges reintegrating women face in relearning how to navigate relationships with those on the outside, whether with strangers on the bus, co-workers, or bosses. Heather suggested that incarcerated women have been in "yes ma'am, no ma'am" situations in which they must toe the line. They have to rediscover how to assert themselves in socially-acceptable ways. As Craig Haney notes, "[a]dapting to the realities of prison life may change a prisoner's habits of thinking and acting in ways that will persist long after his or her incarceration has ended" $(2006,162)$.

Joan indicated that it was not just the shift from the institution to community that was challenging, but also a need to find a social network that was different from what she had pre- 
incarceration. "I had no friends, no family, no nothing," she said. "I had one friend who wanted to use me for cheap labour." She ended the comment about her 'friend', a woman who paid her small amounts of cash to clean bathrooms, with a gruff laugh, then continued.

My daughter wasn't speaking to me. My son wasn't speaking to me. Nobody was speaking to me. Um, I had to fit back in to society. Cuz depression is bad without having anybody to reach out to. You can't afford a psychologist. ...I was having problems fitting back into community. I didn't know any straight people. All I knew was drugs and shit. So, it was really hard to fit back in.

The social aspects of reintegration, though beyond the scope of this dissertation, clearly impact women's approach to employment.

In addition to the social needs, women often have immediate, practical needs, particularly for clothing. "There's some girls that are in here right now who have nothing," said Malone about her fellow residents at a halfway house. "So it's like we're just kind of helping each other. You know? We'll give her some shoes if she needs them or whatever, you know what I mean?" Later that day a large donation of used clothing was delivered to the house. Some residents immediately began looking through it to find items in their size, but also flagged items for other women. At another halfway house, the manager also told me she receives donations from a local consignment store, and noted that clothing was an immediate and pressing concern for many of her residents. "A lot of them gain a lot of weight in the institution," Kim said about women parolees. "So yeah, so they're coming out they don't even have clothes for to go to work." 36

\footnotetext{
${ }^{36}$ Comack's (2018) research on incarcerated women in Manitoba also notes that many women gain weight while inside due to the poor quality of food, much of which is deep-fried, and the lack of opportunities for exercise.
} 
Another challenge for women who are reintegrating is learning about and navigating technological, political, and socio-cultural changes that have happened 'on the outside'. Depending on the length of their sentence, women might be unprepared for how people now communicate with each other (smartphones; texting instead of calling). They may be unfamiliar with new ways to get around the city (Uber and Presto cards), or feel uncertain about changes to banking (web banking and e-transfers). Kim noted that women who have served long sentences are "quite out of touch with a lot of things" which puts them "behind the eight ball" in terms of navigating the outside world. Donisha gave the example of not knowing how to get or use a bus pass when she first came out. Heather said her residence had a seventy-three-year-old woman who had been incarcerated for over thirty years. "So it's like okay, where do you start?" she asked rhetorically. Those who have not experienced the disconnect of incarceration and prolonged removal from the community may have difficulty anticipating the needs of reintegrating women, some of which may not be obvious even to women themselves until they try to board a bus or submit a pdf attachment with their on-line job application.

\section{Surveillance and support: Halfway houses and parole conditions}

For some, especially those who served long sentences, the transition back to the community and the return to daily responsibilities can be overwhelming. Several reintegrating women expressed appreciation for the buffer of the halfway house, a residence that exists in what Robert Werth describes as the "liminal position" between incarceration and freedom $(2012,329)$. Of the women I interviewed, fourteen were living in a halfway house, and an additional three were in 
the comparable environment of a bail house. ${ }^{37}$ Halfway houses are designed as intermediate spaces, between institution and community, wherein women do not have to worry about paying for shelter, and where they can begin to build connections in the community, look for work, etc. Yet while they may offer a buffer zone, they are also sites of surveillance. Madonna Maidment describes such spaces as "another layer of enforcement and urged compliance" $(2006,18)$. Additionally, women residing in halfway houses are supervised by a variety of individuals, such as their parole or probation officers, managers, and staff at the house, as well as the facilitators of any programs they attend. These various individuals may have different ideas about a woman's abilities or readiness to find employment. When there is disagreement, reintegrating women are caught in the middle, pulled in multiple directions.

Donna described how gaps within the redemptive narrative for reintegrating women result in the cross-mobilization of competing directives.

There have been instances of [reintegrating women] finding employment and then being asked to cut back hours because they're spending too much time working and not enough time focusing on their internal growth.

Interviewer: So mixed messages.

Very, very definitely mixed messages. Um and you know women themselves find it confusing. They say well, obviously I need to find a job in order to be selfsufficient and yet you're telling me I have to cut back that job now.

\footnotetext{
${ }^{37}$ Bail houses are residences for those awaiting sentencing. The participants I interviewed in these houses had been previously incarcerated and were currently in the process of waiting to find out if they would be serving another period of time in jail.
} 
It falls upon women to navigate any competing messages, ever aware that their freedom may be at stake. Yet as Donna's quote illustrates, service providers also experience the tension of having different perspectives or goals relative to other service providers. This tension was particularly apparent between non-profit community organizations and CSC. Additionally, as will be discussed in Chapter Five, service providers did not discuss or acknowledge to me their own power and position in constraining women's choices - even while emphasizing the fundamental importance of women making the right ones.

As noted in Chapter Two, women on conditional or statutory release are often subject to restrictive parole or probation conditions. These conditions can prevent women from returning to their families and communities, and can cut them off from the life they knew prior to their incarceration. Conditions also set women up for further entanglement in the justice system if they are charged with breaches (Comack 2018). Women whose conditions require residence in a halfway house experience close supervision. They have curfews that generally require them to be inside all night, and they must report where they are going each time they leave the house. Kim, a parole officer, showed me the log sheet of women at the halfway house in her jurisdiction. She could see when each woman left the house, where she went, and when she returned. Running her finger down the list, Kim remarked, "She's going to work. And this [next name] is the one that's looking for a job." But she looked at the places this woman had gone, such as a grocery store, a community centre where she participates in programs, and Tim Hortons. "It's not looking like she's looking for a job," Kim concluded. "So, I'll have to question her on that."

Some women I spoke with chafed at the constraints of living in a halfway house (curfews, chores, etc.), while others, like Donisha, expressed an appreciation for the time to adjust and find their footing. 
Cuz you don't pay rent here, right? So it's not like you have very big responsibility being here. It's actually better being here when you're trying to find a job, cuz you don't have to pay rent, you don't have to pay for groceries. You don't have to pay cable. Like you don't have to pay any of that. So you just work, make your money, come back.

Similarly, as indicated by Nicole's comments above about acquired dependency during incarceration, many reintegrating women are unaccustomed to providing for all their daily needs. They are also unlikely to have the financial means to do so (Sapers 2017; Wesley 2012). While residing at the halfway house, women receive a small allowance with which they can purchase groceries and a few necessities. Some expressed appreciation for this support; others pointed out that it did not go far enough. "We only get twenty-eight dollars a week and two [transit] tokens," Malone said. "Two tokens is only one trip. So, you know, it's like, it's hard to try and have money to like go to all these places, drop off résumés, or go meet with like my past managers or whatever, you know what I mean?"

There seemed to be a general consensus among service providers that upon release, women need some time to get settled and address their immediate concerns. "I usually tell them to decompress a little bit from being in the institution," said Kim. "Like, if they've served a longer sentence, I'll say, you know, you've got two weeks. But um, once two weeks comes and goes, you're gonna be looking for a job." In other words, it is not long before women are expected to pursue either education or employment. Unless they can get an exemption (such as by proving disability or having aged out of the job market), this expectation is enforced by those who are in positions of authority, such as parole and probation officers and halfway house managers. Most 
women choose to pursue employment, even if that 'choice' is not entirely their preference (see Chapter Six).

Heather managed a women's halfway house. She suggested the emphasis on employment often comes from probation and parole officers who “don't want [women] sitting here doing nothing. So the first objective is to find employment." Employment, or the search for employment, is part of the technologies of discipline. Parole officers can also require individuals under their supervision to keep a log of all jobs applied for. For example, Sarah described the strict surveillance some CSC staff require.

If you don't have a job then you'd better be looking and you'd better be showing me that you're looking by like printing off emails that you sent in order to show that you sent emails to employers, or showing me your phone, showing me you've called, like reporting where you've handed out your résumé.

Sarah's experience was that of a community member who worked and volunteered with reintegrating adults (the majority of which were men). Her narrative is indicative of the tension that was sometimes expressed on the part of some service providers toward correctional staff. It also described a degree of surveillance which none of the reintegrating women reported experiencing. Though no one said it directly to me, I was often given the impression that women were seen to be treated less severely than men, or given more leeway when it came to the requirement to find employment. It is unclear whether this is because service providers did not expect women to be employable (see Chapter Five), or because they recognized the increased challenges that women face (see Chapter Four). Kim, a parole officer, said that asking 'clients' to keep a 'job log' was within her mandate, but she indicated that this is not something she typically 
did with women. However, as noted above, she could use log books and other surveillant technologies to keep close tabs on women under her supervision.

Women whose criminalization was linked to their substance use and addictions were most chronically disadvantaged, and violence-involved women faced particular challenges. Similarly, the ways in which women are governed will depend upon intersecting factors. Kim indicated that she encouraged her clients to pursue employment upon release, but she also indicated that she was willing to make concessions for women who identified needs other than education and employment.

That's often a need for them to you know, really work on themselves to be, you know, the mom that they want to be, or uh the partner that they want to be. So, I give them that opportunity, like if that's gonna increase your self-esteem? Then, okay we'll delay work a little bit. We'll get you into this program. We'll get you, you know, maintain your sobriety. Get you set up so you have a home group, NA or AA group that you can tap into. Cuz in the long run, I think that's gonna be better than jumping in to a job that they're not prepared [for].

The recognition that women may not be ready to start working immediately upon release suggests that while employment is considered important, it is not necessarily the first priority for reintegration. Indeed, Elena noted that women who are seen as a risk for drug use may be discouraged from finding employment since those supervising them do not trust that income brought in won't be used for drugs.

The more money they start collecting, the more that it goes to use for other things, as opposed to saving it. And a lot of it too has to go with if you have financial 
disclosure and they're making money, and it could be a few dollars here and there, and it's all coming in cash-wise, we don't know. We don't know where it's going to. So it's making sure that if they do get a job, that we know all the information, where they are, what they're doing. So they usually start focusing on staying clean first, and then the job comes later.

Elena's account indicates the surveillance extended over women residing in a halfway house, such that they may be required to account for all their money and how they spend it. Residents are also required to submit to drug tests and prove their sobriety.

\section{Conditions}

Reintegrating women are severely limited in their employment options. As will be discussed in the next chapter, legislation and hiring practices relating to the criminal record mean that many jobs are simply off the table. This is particularly the case for jobs dealing with the vulnerable sector, such as children or seniors. But restrictions on employment for reintegrating women can also include prohibitions against jobs handling money (particularly for those whose charges related to fraud) or serving alcohol (for those whose convictions were associated with addiction, or operating a vehicle (for those with convictions related to dangerous or impaired driving). Women comprise a small minority of those convicted of sexual offences; those with such convictions are severely restricted in their mobility in the community and in the types of jobs they can have. Thus, the context and duties of a job can mobilize particular exclusions (Petersen 2015). Restrictions placed upon women, such as where they can and cannot live, the kind of job they cannot do, with whom they cannot associate, these decisions are made based upon knowledge not only of each individual woman, but also of aggregate 'risk factors' of criminalized women in general (Turnbull and Hannah-Moffat 2009). This use of knowledge to 
target practices of discipline is identified by Mariana Valverde and Mike Mopas $(2004,239)$ as 'targeted governance' and illustrates the use of information (knowledge) to direct disciplinary practices and strategies. The Parole Board of Canada (PBC), when granting release, details conditions placed upon women according the risk and needs assessments conducted during her period of incarceration. In research on PBC decisions about women's parole between 2000 and 2001, Hannah-Moffat and Turnbull (2009) found that seventy-four percent of women released on parole were released with specific conditions. All but one of the women I interviewed were still under supervision, and obliged to comply with their supervisory conditions.

Restrictions imposed upon women can be geographical, such that a woman must reside within a certain area and not return to others. For example, a woman who committed crimes in one part of the Greater Toronto Area, and whose victims are still living in that region, will likely not be allowed to return there. This can pose multiple challenges for women whose families and support system members reside in the same community as their victims. Women who have been convicted of sexual offences against minors have particularly stringent conditions. For example, Tara listed her restrictions, "No schools, no malls, no libraries, no community centers, no parks, no beaches, no camp grounds, no bike paths," she said. "Like there's a huge list of places I can't go." With regard to employment, geographic and physical conditions can clearly restrict someone's options for employment. Additionally, being barred from former communities can mean that she is unable to access employment-related networks or return to previous jobs.

Another common restriction, particularly for women living in halfway houses, is a curfew which limits both how late a woman can return to the house at night, and how early she can leave. "I'd get up at like 5:30 in the morning," Joan said. "And the halfway house would say 'Oh, you can't leave till 6:00'.' She pinched her voice as she imitated the staff, indicating how 
she felt their response was unreasonable. She added that by making her wait till six, she arrived late at the job site and lost that work opportunity. However, those I interviewed who were in positions to enforce curfews (house managers and staff, and indirectly the parole officers) all told me they would extend curfews to accommodate women's employment, and a couple of women indicated their curfews had been extended to allow them to work. "My curfew's technically eleven o'clock," Zahra said, "but they extended it because I work till whenever I get in.” Indeed, halfway house staff and parole officers have some discretion in how they enforce certain conditions, particularly curfews. Reintegrating women indicated some houses had reputations as being particularly strict and even eager to send women back. The discretion with which halfway house staff and parole officers could be strict or lax about a curfew was hinted at both by reintegrating women and by service providers, implying that often such barriers come down to personal relationships and individual attitudes. "I may have had just one shitty staff that day," Joan said. "Who knows? Either way, they didn't let me out on time for me to make it to that job."

Women may also need to phone their supervisors to check in, and in some cases are required to do so from a landline, which can be a challenge given that landlines are increasingly being replaced by cell phones. Their parole or probation officers might stop by women's places of work to check on them, which can be anxiety-producing for those who do not want co-workers or employers to know they are under supervision. Kim described accommodations she makes with women under her supervision so as to not make her visits obvious. She does not approach their place of work, but rather parks nearby and phones her parolees, who then come out and meet with her in the car. 
Chantell, who had been convicted of fraud charges, described getting mixed messages from her parole officer and the parole supervisor about the interpretation of the restriction on 'managing finance'. When Chantell was looking for work, she would take job descriptions to her parole officer and ask if she could apply. She was annoyed at being told by her parole officer that she could apply, but by the parole supervisor she could not.

So one understood it to be nothing at all to do with finance, and one understood it to be manage. So petty cash, for example, is that part of it? Like most reception duties have some element of petty cash or whatever, like seriously? ... So that was frustrating for me.

Realizing that the issue of finance management was going to be on-going, and a source of frustration, Chantell decided to walk away from administrative work completely, although she notes that, even in her new field of event management, she has run into questions around ticket sales, event budgets, and other financial matters. As long as she is under supervision, she has to disclose all of these duties to her parole officer and says she has been put in awkward positions where she is unable to perform all the tasks required with a job because someone in the parole office thinks the duties fall under her restriction category. Chantell indicated she always complied with the demands of the parole office, even when she felt they were unreasonable. "I was like, you know what? This is my freedom at stake."

Chantell was in the process of building a new career, one that while different from financial management, still allowed her to apply her skills in organization, management, and strategic planning. Most other reintegrating women I interviewed did not have such an extensive skill set from which they could build a fresh start. Kim noted that some of the women who had fraud 
charges were extremely discouraged about no longer being able to stay in their chosen profession.

I have to be realistic with them and say listen, you know there's too many barriers. You have special conditions that says you can't be in charge of any kind of finances. So you have to think about career change. And difficulty with that is I mean sometimes they're fifty, they're forty.

Kim said one woman struggled for over two years trying to get back into her profession before finally moving to a different field. During the extended stretch of trying to find work, this woman was forced to declare bankruptcy and then worked long hours as a waitress to try to make ends meet.

Jessica said she had seen some women at the halfway house she managed who were strong and resilient, but were held back by parole conditions and restrictions. "Adhering to their probation or parole orders always came first," she said. "So that would limit them, like the restrictions." Indeed, Tina insisted the correctional system sets women up for failure.

They want failure. They want people to fail so they can say, oh yeah, we'll make it tough for them so they'll always come back. You know? That's the mentality. And I'm not a paranoid person, you know, I'm pretty straight up. I know, I see it. I lived it.

The dominant rhetoric of corrections is that of empowerment and responsibilization. As will be explored in this dissertation, such rhetoric does not acknowledge the practices of discipline and risk management that persist within institutions and in the community. Additionally, the discourses of empowerment reinforce a subject position of women as broken subjects incapable 
of knowing and doing what is best for themselves. As Tina's quote demonstrates, all theory aside, women experience the practices of corrections and surveillance in the community as punitive and even malicious.

\section{EMPLOYMENT SUPPORTS IN THE COMMUNITY}

As noted in the previous chapter, while all of the service providers interviewed for this project provided employment-related support to reintegrating women, the ways in which they did this varied significantly. Only four of the service providers interviewed worked exclusively with criminalized and/or reintegrating women; only five service providers had roles which were primarily related to employment support. The rest provided support to women which included, but was not limited to, employment. Jenny Roberts (2002) in examining community-based programs for reintegrating women in the UK, notes the importance of securing access to relevant community resources. All service providers I interviewed, and those to whom I reached out in the initial stages of the research project, mentioned numerous community-based services and resources to which they referred women. Referrals often related to assessments of women's needs or to women's identity groups, such that Indigenous women were referred to Native Women's centres, and young women were directed to programs for youth. It was not uncommon for me to find a community-based organization that provides support to women who have been in conflict with the law, but which does not have an employment program. Staff at these organizations refer women to other local organizations for employment support, such as the local Employment Ontario office, ${ }^{38}$ a YWCA Employment Centre, employment centres for

\footnotetext{
${ }^{38}$ The Ontario Ministry of Labour, Training and Skills Development has offices across the province which offer free training and job support.
} 
immigrants, or resource centres for marginalized women. Most of the programs to which women were directed would offer support with résumés, job searches, and interview preparation, which corresponds with reintegration literature that indicates that pre-employment programs in the community typically focus on those skills (Ricciardelli, Evans, and Peters 2017).

The most frequently cited community-based resource to which service providers referred women was Dress for Success, which is an international not-for-profit organization that provides women with professional clothing at no cost. Dress for Success has sites across Ontario, and indeed several reintegrating women I interviewed had received clothing from them. Additionally, many community organizations, and even parole offices, can provide requisite clothing and equipment for jobs, particularly work boots. I interviewed Donisha in a halfway house and she mentioned that staff had provided her with the boots she needed for her construction job. She pointed to a near-by closet "Right here, in this closet," she said, indicating that was where the boots were stored. "Yeah, they just gave me work boots." Heather also noted that her organization had been able to provide chef knives for a resident who enrolled in a local culinary program. "We try to gain our own charitable funds to put towards cutting down the costs and make it that much easier for them not to have those barriers," she explained.

Some employment-related programs are run out of homeless shelters, others in community centres and non-profit agencies. Some are attached to colleges, adult high schools, or provincial employment support centres. The variety of locations and programs was described by some as indicative of the diversity, and adequacy, of support available to women, but by others as an indication of the lack of coherency. As Kim noted, reintegrating women "always kind of get lost in the shuffle." Given the lack of programming specifically available to reintegrating women, 
women must seek employment support in a disparate array of resources and supports, which may not directly address their needs and barriers.

Community organizations working with marginalized individuals draw connections between poverty, unemployment and lack of education. Elena noted that many reintegrating women cannot afford to pay tuition, or take time away from earning an income, in order to complete an educational program. Kim estimated that about twenty-five percent of women under her supervision had not completed high school. But, she said, even if they had indicated that getting their Grade Twelve would be their priority upon release, once they got back into the community, priorities shifted toward finding a way to earn an income. "I've had little success in getting them to continue high school on the outside," Kim said. "All the other variables come in to play. I need money. I need money. I have to find a job. I can't go to school because I'm not gonna get paid. So I'll go work at Tim Hortons. And that's gonna take away from going to school." She added that being around other women who are working and earning money can influence their decision to pursue employment over education. "And then next thing you know, school's out the window."

Recognizing the challenges that marginalized adults have in upgrading their education, many community organizations offer educational programs such as high school equivalency or skills training (e.g. computer skills) in evening classes or on flexible schedules. Patricia runs such a program for a community organization providing services to adults involved in the criminal justice system. She described how the program allows for the various ways in which students can complete the requirements, such that they may be allowed to complete a one-year program over two or more years, and be permitted to drop out and re-enroll without losing 
credits. Indeed, she did not expect that students would complete the program through continuous participation.

Let's put it this way, people don't just like stay for the two years and get it done. I would say that on an average they're on and off the program for four years or so, or even three years. But very few people are able to really just get it done within the two years.

Patricia listed some of the challenges her students encounter in completing this and other similar programs: drug and alcohol addictions, instability in housing (often related to poverty), and recidivism. To accommodate such challenges, Patricia noted that it was important to be accommodating, yet at the same time, she saw her role as preparing students for a work place environment.

Even in terms of coming on a regular basis, coming on time. I always say, you know, yes, we're a flexible program here, but what we are doing is we're getting you ready for when you go to college or when you get employed, to be on time, come on a regular basis, and dress appropriately. And speak in an appropriate manner too.

Service providers are thus working to balance the disciplinary aspects of their programs with the accommodation they recognize their students require. Malone described this balance of discipline and accommodation that she saw demonstrated in the employment program in which she was a participant.

They are very strict about like, like they try to push dress code. Um, and they're strict with like punctuality and stuff. They're only strict about it though because 
they really want to kind of teach you because they want it to be like a real work, like they're trying to get you in the swing of things, like as a real job. But they're not gonna go to the extent of like kicking you out, because their whole point is they're trying to help you, you know what I mean?

Clearly service providers must navigate the tension of being supportive and strict. But it is not only punctuality that is being disciplined. As the quotes from both Patricia and Malone indicate, women's performances of what is acceptable dress and speech are also being disciplined. “They'll send you home like if you're, you know, if you're wearing a short little skirt or something," Malone said, "just because they really kind of want to teach you the lesson." Similarly, Patricia said that part of teaching participants to 'dress appropriately' meant no "little tank tops or little shorts or anything like that." She said that she would give "feedback" to women such as "Don't wear that top; it's a bit too low at the front." Elena noted that women "come in their tank tops and their track pants and their shorts, or they put on a pair of long leggings and a tank top that you know, isn't long enough, and they think they're presentable." She said that she had to "start from the basics" and teach them what was 'appropriate'. In other words, reintegrating women are chastised for dressing in clothes considered too 'sexy' or revealing. Clearly, 'employability training' extends beyond employment skills to include instruction on manners, dress, and comportment. Such instruction draws upon genderappropriate norms about women's sexuality and performances of gender.

Susan said that she and other employment support workers "address those interview characteristics and presentations and behaviours and attitudes" because she recognized that there are widespread perceptions that "women should be, you know, mannered in such a way." Though not defining this 'way' in which women should be mannered, her narrative suggested 
that it needed to include docility, politeness and no overt sexuality. Allison McKim notes in her study of penal rehab in the United States that targets of women's reform include performances of gender through appearance, clothing, and mannerisms $(2017,91)$. In preparing women for work, society, and its gendered expectations (Weeks 2011), service providers may anticipate that by disciplining women's gender performances they are increasing women's chances of being successful in job interviews and gaining employment opportunities. Yet through such 'supports' and 'guidance', the dominant, normative scripts of how gender should be performed remain unchallenged and are even further entrenched. Given the disciplinary context in which such instruction is being given (such that women could be sent home from class for wearing a skirt that was too short), women are clearly being told that their successful reintegration depends upon their 'appropriate' performances of gender and compliance with entrenched norms of sexual respectability which, along with norms of domesticity and motherhood, have long governed reintegrating women (Sim 2005).

Overt performances of gender are disciplined through employability programs; women's internal characteristics are also shaped and governed through the variety of reintegration programs that encourage ethical self-reformulation (N. Rose 1999a). When I asked service providers about the programs they offered, I was struck by how many of these programs seemed to have little do to with employable skills. Instead, the emphasis seemed to be on women's emotional, social, and interpersonal needs. Employability programs were often intermingled with other programs such as healthy living, healthy management, healthy relationships, anger management, grief and loss, creative writing, and pride. As will be discussed in Chapter Five, these programs reflect a governing approach which positions criminalized women as broken subjects needing therapeutic support. 
While the resources available to reintegrating women are not cohesively laid out, and are rarely designed specifically for women's particular needs or concerns, Melody insisted there were adequate resources available in the community. "I don't agree with the idea that there's nothing out there," she said. "There is, if you want it... You have to look for it." Yet the perception of what is available, and the utility of these resources, varied significantly among women I interviewed. Nicole said there were several programs and resources available in her local Indigenous community centre of which she could 'take advantage', noting "because I am Aboriginal, I can grab on to them." She recognized that non-Indigenous women at the halfway house did not have access to these same programs. In other words, certain identity characteristics, such as age or ethnicity, could offer inclusion or exclusion in various programs. As many community organizations depend on program-specific funding, target populations may be determined by funding agendas and government priorities and may not necessarily reflect the demographics of the populations in need. Additionally, as these various community programs are not specifically geared to women with criminal records, some reintegrating women who participated in community-based employment programs told me they did not feel comfortable disclosing to the group, or even the instructor, that they had a criminal record.

Thirteen of the women had not participated in any community-based employment programs. Six women indicated this was because they did not feel they needed extra support, or at least not the type of support available through programs offered to them. For example, Zahra had already used an online job site to find her current position in a restaurant. Lin, who prior to her incarceration worked as an independent consultant, said she was encouraged to take an employment course upon her release. "I said, do you think that I'm going to get anything out of it?" she replied. "I could teach the course." Another six women had not participated in programs 
because they did not know what was available to them, or when they had made forays to explore their options, had found the resources unappealing or not suited to their needs. Alexa said she was referred to a local community organization that provides support to reintegrating adults, but she found it "too sketchy". She went to an employment support centre but was frustrated with the advice she was given. "They told me, oh, you need to make friends because you get work through friends, you know word of mouth and social media," she said. "And I was like, no. Last I heard, that's not how you look for work." Nicole had not participated in any programs, but she had only been out for a week and indicated that she was planning to participate in programs targeted at Indigenous women.

Only seven women had participated in the type of employment program in which participants enroll and, upon completion, receive a certificate, diploma, and/or apprenticeship. Malone and Donisha had both participated in community programs targeted at youth with barriers to employment; Holly joined an employment program at a local Native women's centre; Ashely participated in an employment program designed to give marginalized people access to trades; and Joan received her fork lift operation certification through a community program. Chantell and Andy both enrolled at their local college in programs that offered skills and apprenticeships. Finally, Melody received some individual support through a local non-profit organization and was then able to get a job.

\section{Jobs available to reintegrating women}

Nicole said that being incarcerated was one of the first times in her life she found herself sitting and taking stock of her situation. 
I'm like, where do want your life to go? Right? And how are you gonna make it get there? Like you know? This [question] is for anybody. Everybody. They ask you when you're five, you know, like what are you gonna be when you grow up, right? You don't think of it that much. You're, 'I'm gonna be an astronaut' or 'I'm gonna be this.' And like you're twenty-five and you're in jail and you're like, holy fuck! I was gonna be an astronaut! You know? That's not happening. NASA's not calling you next week. So like you gotta get out there and you gotta find something else.

Vocational psychologists could likely offer several explanations for why Nicole did not end up working for NASA. Linda Gottfredson (1981) combines psychological theories about occupational choice with social systems perspectives to demonstrate that as children grow, they adjust their occupational aspirations to fit their gender, abilities, and interests, but also, importantly, their socio-economic class. Nicole grew up in an impoverished downtown neighbourhood in Toronto. While she might have thought she could be an astronaut when she was five, as she grew up, she would have narrowed her aspirations to the perceived accessibility of a more limited set of occupations. In other words, what kind of work people choose is shaped by what Pierre Bourdieu (1977) described as habitus, the class-structured ways of thinking and being in the world. The ways of seeing the world, or more precisely the world in which we live, become 'common sense', informing what is real and what is fantasy. Nicole expressed her own 'reality check' when she said, "that's not happening. NASA's not calling you this week." Those childhood dreams of outer space were clearly expressed as fantastical, bearing little resemblance with the actual career she held prior to incarceration - working as a self-employed esthetician. 
All of the reintegrating women interviewed had previous job experience, experience which informed their perceptions of the type of jobs which they could again pursue. The following quote from Holly is a typical account.

I did telemarketing. I worked at a pizza shop. I worked at, uh, a Rogers store. I worked um, at a pizza place, oh I did say that, at a pizza place. I worked at a couple pizza places. I worked at, um, other things that would put on my résumé like I did um, you know like places like Kmart and stuff when you have to count stock, I did stuff like that. Um, the bakery.

Most women listed a similar array of jobs, the majority of which paid minimum wage. "I worked at Wal-Mart, Good Life, Food Basics, um, TransCon, Petro, Sears," said Carla. Joan said she took "just any minimum wage thing I could get." She also interspersed her 'legitimate' work with 'illegitimate' work, such as selling sex or drugs. Similarly, Holly said she took breaks between jobs, saying she "didn't always work, work, work, work" in formal jobs, but earned an income for several years as an escort.

Given that most women's job experience was limited to minimum-wage jobs, these were the types of jobs to which they were applying or to which they were encouraged to apply by service providers. At the time of our interview, eleven women were employed. Their jobs included working in restaurants, food service or food production (Zahra, Lin, Theresa and Srila), environmental cleaning (Andy), construction (Donisha), and housekeeping (Holly). Melody had a full-time position in a grocery store; Joan worked the overnight shift in a men's shelter; Alexa had a job in a warehouse. Chantell had finished a college program in event management and was working in a placement; prior to this she was briefly employed at a call centre. Similarly, when I asked service providers what types of jobs they had seen reintegrating women obtain, they listed 
positions such as packing, catering, food preparation, asbestos removal, and customer service, and that women might find work in grocery stores, warehouses, call centres, and restaurants. Thus, my findings correspond with literature on reintegration and employment which indicates that jobs available to those with criminal records are likely to be precarious, low-paying, lowskilled, temporary and/or seasonal (Western 2002; Ricciardelli, Evans, and Peters 2017).

Jobs that have irregular hours, such as those typically associated with the types of casual and seasonal work that is available to people with criminal records, can be difficult to manage for women living in residences with curfews. They can also be challenging for women who have, or will have, children in their care. While the challenge of balancing demands of motherhood and employment is by no means unique to reintegrating women, the lack of support for reintegrating women as mothers (Maidment 2006) leaves them particularly vulnerable. Reintegrating women who are struggling to provide and care for their children face profound challenges in securing employment that is safe and provides a living wage. Since reintegrating women are much more likely than reintegrating men to be sole caregivers of their children (Cahn 2000; Brennan 2014), they are more likely than men to have to consider how to negotiate these competing demands upon release. Patricia described some of the questions mothers need to consider when looking at potential jobs. "They are thinking about, okay, how many hours is this going to be? Is it going to be nights, is it going to be weekends?" she said. "How are they going to deal with that?" Natasha knew of a local cleaning company that would hire women with criminal records, but only for overnight shifts in corporate buildings. Such schedules are particularly prohibitive to single mothers and those who do not have a trusted partner or family member who would look after their children during their absense, and who also face heightened scrutiny from child protection services (Maidment 2006, 136-39). Susan noted that few reintegrating women are able to find 
support form a social network in looking after their children during employment hours since many have "burnt their bridges" with family members and cannot turn to them for assistance.

Additionally, service providers like Donna noted that the lack of affordable daycare means that women's wages are mostly, if not wholly, spent on paying someone else to look after their children.

The costs of childcare mean that if all that is available to you is a minimum wage job, then you are not financially any further ahead by working than you would be by being on [welfare or disability support]. So there's just the very realistic economic barrier for women who are parenting.

The lack of affordable childcare, and of supportive social networks, can place both women and their children at risk. Natasha noted that some women might leave their children home alone at night when they went to work, placing at risk both her children's safety and her continued custody of them should the situation be made known to child services. "One woman had just had a baby and she would bring her baby to work [at a cleaning job] when it was at night," Natasha said. Bringing an infant to a work site where it might be exposed to noxious chemicals is a stark indication of the risks women and their children face in trying to satisfy the demands of employment and childcare. Several service providers noted that women who are unable to provide for their children through legitimate employment may turn to illegitimate work that puts them at risk of reincarceration or victimization (see also Allan, Bennett, and Chettiar 2014; van der Meulen 2010).

Interestingly, while nine of the thirteen service providers discussed or at least mentioned challenges posed by competing demands of childcare and employment, few reintegrating women identified their children as a barrier to their employability. This may be due to the fact that few 
of the women in my study had young children who were or would be in their care, but it may also indicate how those supporting women may emphasize women's relationships and personal needs over their economic needs. For example, Nicole expressed frustration with the lack of employment programming available to reintegrating women in comparison to that which is available to men. She has twice served sentences in provincial jails and said that almost all the programming for women focused on addictions, anger-management or mothering. I asked her if she also thought women's programming didn’t emphasize employment. She responded, “I agree a thousand percent with that." She described how the expectations seem to be different for men and women.

Like I see someone telling me to take a parenting course and go take care of my kids. Like, I don't see someone saying, 'hey listen, you can get a six-figure job if you do this course.' Like you know? You know, six months you're gonna be on your way to like success. Like I don't see that. And it sucks. Because you know, women, as women we do a lot, we do a whole lot.

Though she has two children who will be living with her after she leaves the halfway house, Nicole insisted that women are capable of "more than being mom". In the section 'Ambivalence' in Chapter Six I will explore further how some women discussed their dual roles of mothers and workers. It is clear that in assessing the jobs available to reintegrating women, there are variances in the ways in which gendered barriers, such exclusion from male-dominated trades or the responsibilities as mothers, are identified, positioned, and experienced. 


\section{'IF YOU REALLY WANT A JOB, FOLLOW THE STEPS'}

Nicole said that women are not "equipped" for employment when they are released to the community. "They just kind of like throw you out, right?" she said. "Like they don't tell you like go here, here's what you're gonna do for money and here's how you're gonna do it. They don't give you those steps." Nicole was not alone in likening release from prison to being thrown or tossed out. Like other women, she indicated that release can be experienced as a sudden lack of support, almost an abandonment. Several women indicated they were met with "nothing" upon release. They had no money, nowhere to go. As Nicole said, they do not even know the 'steps' they can take to meet their basic needs. The metaphor of 'steps' came up frequently in the narratives of both service providers and reintegrating women as they described the process of transition from the institution to employment, and indeed this metaphor can be found in other literature on reintegration (Fox 2013; Pavao 2011; Graffam et al. 2004; Shivy et al. 2007). Andy suggested reintegrating women need to take things "one step at a time," indicating the process is gradual and requires patience. Theresa warned that women should not try to 'skip steps' along the way. She suggested that for those who had addictions, they must address these before they tried to take on employment, suggesting that otherwise women would "miss all of the steps." She added, "Like it's not just all of a sudden you get out and I'm gonna go look for a job." Not only do women need to take things in steps, but these steps might be incremental. "I just think that, for me, ever since I got out of prison, everything comes in little baby steps," said Holly. "I needed to move up the little steps till I was ready." Similarly, Nicole indicated that women should be willing to do the "small little things", the "little steps that like will better yourself." But what are these little steps that women need to take to find employment? Though they will certainly not be the same for everyone, there are several key elements, or steps, that were fairly 
consistently identified by service providers and reintegrating women. "So my advice would be actually if you really want a job," said Srila, "follow the steps."

Service providers also indicated that women need to follow the steps. "We always tell them, like take things one step at a time, as opposed to just jumping in to a full-time job and looking at the money aspect of it," Elena said. "Cuz a lot of them aren’t ready." Like Nicole, Elena saw women exiting prison as not being ready for fulltime work, and as needing more support to identify and follow the steps to employment. Helen also used the metaphor of steps, indicating that she referenced this to encourage people to accept jobs that may not be in themselves appealing, but could open other possibilities. "They have to find something," she said. "And often times it's not the most meaningful position for them, um, but at least it's a start. And that's what we talk about, just getting back into the routine and uh, it's a first step towards your longterm goal." The identification of long-term goals was something several service providers identified as challenging for reintegrating women, and indeed personal goal-setting is in many ways incompatible with the constraints of carceral environments that prescribe and mandate particular pursuits (see Hannah-Moffat 2001, and Chapter Six, section Success). Service providers also recognized that women's basic needs, such as housing, food, and safety, will take priority over goals that might relate to education or employment. Yet they noted that women are caught in a chicken and egg quandary with no clear solution: women need to have their basic needs met in order to be able to obtain and maintain a job, but they need a job in order to be able to pay for these same needs. Nonetheless, service providers often articulated the various steps women needed to follow in order to find employment. The first step was to get some official proof of identity. 


\section{Get your ID}

An immediate, practical concern for most reintegrating women is their lack identification (ID). Indeed, Joan summarized what her experience was like when she would be released from another stint in jail. "No ID. No housing. No people. No family. No job. No ID to get welfare," she said. "No way to get ID cuz when you come out of provincial, they don't give you nothing." The obstacle of lack of ID is the result of the technologies of governance relating to the provision of ID that require material artefacts such as birth certificates, passports, and drivers' licenses, objects that women coming from precarious lives of poverty and marginalization are unlikely to have. Obstacles to the provision of ID also reflect the lack of coordination between government institutions, ${ }^{39}$ and shortcomings in the management of personal belongings for those who are reintegrating. Upon intake into an institution, most personal belongings are taken from an individual and stored until their release. Given that many people's experiences of arrest come at a chaotic time in their lives, there may not be any proper ID in those belongings. While individuals are incarcerated, particularly if they are held in provincial jails or detention centres, they are typically not provided with opportunities to apply for ID. Lack of ID can also complicate other aspects of reintegration, such as applications for housing and opening bank accounts. "You get out and you get your life back together," Ashley said, "but it's not that easy, especially when you need to get your ID, you need to, you know, figure, there's so many components of your life."

\footnotetext{
${ }^{39}$ For the Ontario health card (OHIP), the Ministry of Ontario requires original copies of three documents, such as certificate of birth or citizenship, and a passport. They also require a proof of residency and do not accept residency in carceral institutions. In other words, prisoners who do not have an OHIP card are not able to begin the process of applying for one until they have a residence in the community, which creates a gap during which access to healthcare is made difficult.
} 
Some ID, such as passports, require a guarantor, which can be difficult to find for women whose lives prior to incarceration were marked by poverty and marginalization. Service providers like Heather and Elena described the time and effort they had invested to help women at their residence obtain ID. They indicated a fatigue not only with the system (the bureaucracy, the delays, the paper work), but also with women who fall back into addiction, disappear, or are re-incarcerated. "They're so transient," Heather said, adding it could be hard to find someone who could verify a woman's identity. As will be explored in Chapter Five, several service providers expressed a mix of frustration and sympathy toward the women they sought to help; some suggested that women are so 'broken' it can be difficult to know where to begin.

\section{Make a résumé}

As noted above, there are few employment programs designed specifically for reintegrating women, and women are typically directed to a variety of organizations and services in the community as they follow the steps toward employability. The most widely available support seemed to be assistance with creating a résumé. "If you need help building a résumé," Srila said, "there's people to do that." Kim echoed this saying, "there doesn't seem to be gaps" with regard to résumé development, and she rattled off several community resources to which she could refer women. "People are always willing to print them off." Certainly, being 'work-ready' is not as straight-forward as having a résumé in hand, however, a résumé is a practical and tangible tool, and is required for most formal job applications. It can also be produced within a relatively short period of time, which may be partly why it was most easily accessible employment support available to reintegrating women. 
Five of the reintegrating women interviewed said they had received support in the community in developing their résumés, and Carla and Elaine both indicated they were planning to get help with theirs in the near future. Zahra and Srila both mentioned that they had received help with their résumés while at GVI, and then had used these to get jobs upon their release. Résumés are, of course, constrained and constructed narratives which are purposefully filled with idealized half-truths. We hide certain things and make others perhaps shine more brightly than is warranted. For women coming out of prison, there is much they wish to hide, and they may struggle to articulate the skills and competencies they possess.

Elena, a staff member at a halfway house in the GTA, runs workshops with reintegrating women to help them develop their résumés. She indicated that many women did not know how to craft a résumé, suggesting that they would often just provide a bullet point list of jobs they had done. Through her workshops and individualized support, she guided women on how to fit their experiences into the appropriate framework and narrative. "Are you able to talk to people?" Elena would ask, and then translate this into 'communication skills', indicating to women how they could frame their competencies as employable skills. However, Elena noted that despite such measures, crafting even the most rudimentary résumé was challenging when women did not have any employment history and lacked their high school diploma. Indeed, Joan received help in building her résumé, but noted that the service provider "struggled to make it look good," since Joan lacked the credentials one would typically include. Even for women who had some education or previous job experience, Elena said most were anxious about how to explain the gaps in their employment history. She would help them 'hide' these gaps by using the employment programs women did while incarcerated to fill in time. However, she also noted that even if women are able to craft a résumé that hid the period of incarceration, many were still 
afraid that employers would see through the narrative and know that they had been incarcerated. "A lot of them, they'll say, 'Oh yeah, looks good on paper," she said, but they were still fearful of how to answer questions an employer might ask. The fear that someone will see through the idealized narrative of a résumé is by no means limited to reintegrating women. However, service providers consistently expressed the perception that reintegrating women were particularly vulnerable to anxiety about how to explain their past.

\section{Apply for a job}

Applying for a job can be intimidating for anyone, but as Holly noted, this is especially true “for women who never had a job before, who's coming out of prison all of a sudden they want you to get a job as part of your parole." She said that women who have not held formal jobs before “don't even know what jobs are, what jobs entail." Even women who had previous job experience reported feeling anxious and ill-prepared to start applying for jobs. Melody said she had been out of prison for about three weeks when a caseworker told her about a place that was hiring people with barriers. "She says, I'd like you to go,” Melody relayed. “And I'm like, I'm not ready for this." Thus, while some reintegrating women said halfway houses and community organizations needed to do better at providing job boards, information about job fairs, and notices of companies that were hiring, others said women need to be more supported, such as through mentorship and individual guidance. "I think it takes people who are willing to take time, willing to go with you to a place, help you through that whole process and hold your hand through the process," said Ashley. "I know, like you're adult, you're supposed to be able to do that," she added, but noted that the process of transitioning from the institution was challenging and hard to navigate alone. 
Maria commented that women may not be familiar with changes to job application processes, such as the ubiquity of online applications. She said they will ask her, "Why can't I just walk over and drop it off?" As such, assisting women with job applications often requires helping them navigate changes in technology. Joan said she needed someone who would 'sit with her' at the computer and help her navigate an application. Other women indicated they were capable of using a computer to search for jobs, but complained about the lack of access. "They should have a computer here," Tina said, referring to the halfway house. "You should write that down: a computer with Internet." She said women had to 'parade' around town to find computers they could use at the public library or other community organizations. While one halfway house I visited had a computer with Internet access which was available to women, other houses did not have any accessible computers and women relied on public libraries or used their cell phones to connect to the Internet. As such, what might be considered by many to be a straight-forward process of applying for a job, can be intimidating and anxiety-provoking to reintegrating women.

\section{'IT'S NOT JUST THE INDIVIDUAL; IT'S NOT JUST THE SYSTEM. IT HAS TO BE BOTH.'}

\section{RESPONSIBILITY AND EMPLOYABILITY}

Part of the process of becoming employable, beyond the technologies of the résumé and the application itself, is the positioning of oneself to be a worker. As Mary Gatta found in her exploration of employment services for marginalized women, service providers "report that they understand the challenges of the economy and social structures, but in practice have internalized a very individualistic approach to the clients - specifically, that the clients need to be realistic about their options, take personal responsibility for their situation, and do whatever it takes to get a job" $(2014,32)$. Similarly, service providers I interviewed expressed both an appreciation for 
the structural challenges women face, but also an emphasis on individual responsibility. Jeff articulated this tension.

I don't think people with a criminal record are fundamentally any different than anyone else. There's often a lot of history, time, place and circumstance, and reasons for that. And I'm not putting it all onto the system. It's person, it's, it's a big mess. But ultimately, I think there's a way out. There's always a better way of being and doing and I have a lot of hope and, and, uh, motivation for people, anyone, to change to their circumstance. But there has to be, it's not just the individual. It's not just the system. It has to be both.

The recognition that 'it has to be both' the system and the individual is one that can get lost in the implementation of employment programming and discussions about specific steps to employability. There is a risk that the focus will shift from identifying structural barriers and systemic processes that restrict women's possibilities for socio-economic integration, and emphasize women's personal aptitudes and efforts. Indeed, while Jeff acknowledged structural constraints, throughout the interview he expressed views such that people have it "within themselves' to make change, that change is all about 'choice', and that people should start with the 'simple things' such as "sit up straight; smile more." 40 The tension between identification of structural barriers and emphasis on individual responsibility runs throughout this dissertation and will be explored in greater depth in the chapters ahead. As will be discussed, perceptions of job readiness and employability include possession of material things such as work boots and clothes

\footnotetext{
40 The admonition to 'smile more' has long been directed toward women and intricately bound with gendered expectations about women's performance of both labour and domestic roles (Kwan and Trautner 2009).
} 
that fit, appropriation of culturally-defined technologies such as résumés, demonstration of practical skills such as time management as well as personal attributes such as confidence, motivation and a work ethic. 


\section{4. "It's your choice": Negotiating criminal records}

Dealing with parole, looking for work and trying to explain a large gap in your résumé, or trying to get back into school with a felony conviction are some of the features that make the prison tantamount to permanent social excommunication. ${ }^{41}$

- Joshua Price, Prison AND SOCIAL DEATH

A couple of months after being released from prison, Lin managed to secure a job interview. She was nervous about being asked about her criminal record and the two-year gap in her résumé, so she called up a woman who was part of her support network, a volunteer she had met her during her time at GVI. "I really just want to be transparent," Lin told her. "Do you think I should say it right out before I even start?" By 'it' she meant the fact of her criminal record. However, Lin's contact advised her against this, suggesting she wait to see if she were asked. Lin heeded the advice and decided to only talk about her record if she was directly asked. "I' $\mathrm{d}$ really like to disclose," she told me. "But there's no point."

Lin was describing the mix of desires, fears, and uncertainty that accompanies the negotiation almost all reintegrating women must make when seeking employment: if, when, and how to disclose her criminal record. This negotiation is shaped by discourses of choice, empowerment and individual responsibility. For Lin, as for many other reintegrating women, it is paradoxically the fear having her criminal record discovered which prompts her to want to reveal it. But as she said, there is 'no point' to this strategy. Her forthrightness is unlikely to be rewarded with increased trust; instead it would likely preempt any chance she had at securing the job. The advice Lin received, to 'wait and see' is therefore quite common. 'Don't foreclose your

${ }^{41}$ Price $(2015,12)$ 
chances,' service providers advise. 'Maybe this time you'll get lucky.' The problem with the advice of 'if they don't ask, don't tell' is that it leaves women underneath the shadow of being 'found out' and offers no guidance for what women should do if employers $d o$ ask. It also communicates to reintegrating women that disclosing a criminal record renders remote their chances of securing employment, particularly secure, well-paid employment. More importantly, it places emphasis on women's individual choice about how they negotiate their record and leaves unchallenged the stigma women will face upon disclosure, namely the widespread belief that a previously criminalized self is a fundamentally risky self.

That the criminal record is a barrier to employment is obvious. Indeed, when asked about the barriers that reintegrating women faced in finding employment, the criminal record was usually the first thing mentioned by service providers and reintegrating women. But how does the criminal record function as a barrier, and how is it experienced? For reintegrating women, the criminal record is almost a tangible construct which they must carry with them. Afraid that others can see this burden, or will discover its presence, they might acknowledge it from the outset, such as Lin wanted to do in her job interview. But, knowing it will not be well-received, most seek other ways to manage it, or distance themselves from it. Key to this distancing is a negotiation of honesty. As will be explored in this chapter, women are often told they do not have to disclose their record if they are not directly asked about it, yet they are also told that they cannot lie if they are asked. As such, honesty does not require transparency, but it does require truthfulness. How is such somewhat contradictory advice experienced, and how do women respond to the call to honesty as they inhabit the disciplinary norms which surround them?

"It sucks that you can't get a job with that [the record]," Becky said. "What are you supposed to do? Like usually you just go back to crime, cuz you can't get a job." The concern 
that reintegrating women will return to/engage in illicit activity seemed to be a primary motivating factor for service providers who offer employment support to reintegrating women (see Chapter Six). Yet employability programs that provide services such as skills training, résumé building, and interview skills cannot erase the barrier of the criminal record, particularly since management of the criminal record is determined by legislated policies and its interpretation influenced by entrenched stereotypes and social stigma. In this chapter, I explore how reintegrating women approach accessing the labour-market by examining their negotiation of the criminal record. I also consider women's engagement with experiences of stigma and performances of honesty and examine how women's negotiation of the record is framed within discourses of choice, empowerment, and individual responsibilization.

\section{“THEY CAN'T DO WHAT THEY'VE DONE IN THE PAST"}

The criminal record is a key exclusionary practice that prevents reintegrating adults from gaining meaningful and stable employment. Indeed, service providers described it as the 'the most significant' or the 'biggest' barrier to legitimate employment for reintegrating women. Thus, they make concerted efforts to address this barrier, working on behalf of reintegrating women to advocate with employers, and connecting women with resources available in the community that can provide employment support to those with criminal records. As noted in Chapter Two, the criminal record restricts possibilities for women to obtain employment in industries typically most available to them, and in professions which women are more likely to have experience. This reality was clearly articulated by the service providers I interviewed. "The kinds of employment women may have had previously require a records check more often than the kinds of employment males may have had," Donna said. She added that "anything to do with 
childcare or the helping sector" was no longer an option. Similarly, Natasha pointed out that "if you wanted to be a personal support worker, work in a group home or institutional group setting, [there's] absolutely no way if you have a criminal record." Patricia echoed this comment by noting that for "a lot of the women that I've dealt with, they can't do what they've done in the past." She also added that any of their employment related contacts might not only be "from fifteen or twenty years ago", but are in industries from which women are now barred.

The desire to turn one's troubled past into positive contributions to society (such as counselling youth at risk or providing victim support) is common among reintegrating adults (Maruna 2001). Service providers noted that reintegrating women often express interest in pursuing employment in the care and service sectors, such as in jobs working with seniors, children, and people with disabilities. Jessica said that in her experience, some women had taken on caring and supportive roles while in prison, which was "super rewarding for them." She added that in doing this therapeutic work, women discovered "they may be really good at that." Patricia echoed the assessment that reintegrating women wanted to work in roles in which they could apply skills they had in caring for others. "For a lot of these women, the whole caring and nurturing thing, that's what they want to do," she said. Yet Donna, who works in a community organization assisting reintegrating women (who are considered vulnerable), admitted that even her own organization requires a records check from its employees. Despite any personal desire she might have to hire women with 'lived experience' of incarceration, policies such as those laid out in the Criminal Records Act restrict her ability to do so. Similarly, Natasha said a criminal record could bar people from participating in employment programs within her organization. She gave the example of their social enterprise that provides catering services to local businesses and organizations. The enterprise depends on fostering positive relationships 
with its customers, but found that some customers were asking if the servers coming into their establishments had criminal records. This put the enterprise in a tough position. If they hired individuals with criminal records, they could lose contracts in the community, jeopardizing the whole operation. Natasha remarked that as a staff member trying to help adults who wanted to work, she found such barriers "a little bit disheartening". As she explained, "Cuz we were like if these individuals can't work here and get experience, and you know, like a reference letter or recommendation, how are they going to take that next step into the community?" Women's criminal convictions, as noted in Chapter Two, are often related to their experiences of poverty. The economic impacts of the criminal record indicate that criminalization not only stems from but also produces poverty and marginalization.

Sarah is a service provider who, among her other employment support roles, would assist adults with their applications for record suspensions (formerly pardons). She said that women with criminal records would ask for help with the pardon application "so they could go into fields like nursing or social work, or to be able to work with children, like daycare, or be a teacher, youth worker, personal support worker." All such jobs require a 'clean' records check in order to exclude those who are considered a risk to the vulnerable population being served. That schools, hospitals, and seniors' centres would employ techniques of risk management in hiring practices is not unexpected. Their duty of care requires diligence and caution. Yet the criminal records check is a flawed tool of risk management since it cannot actually predict who will commit crime; it is simply a record of past conviction.

Service providers who had been working with reintegrating adults for several years noted that they had seen the job market becoming increasingly difficult to access for those with records. Jobs to which they could direct women five or ten years ago now require background 
checks. Donna gave the example of cleaning as an industry that has recently become more difficult to access. Natasha noted that even positions in grocery or clothing stores often require a criminal record check. However, there were also regional differences in terms of franchises willing to hire people with records. For example, Kim noted that "at one point I had three or four clients all working at Tim Hortons, cuz Tim Hortons didn’t ask about criminal records." Yet in another urban area, service providers reported that their local Tim Hortons franchises required a criminal record check. Such inconsistencies can be frustrating to both service providers and reintegrating women. Indeed, service providers expressed a great deal of frustration relating to criminal records. "It's hard. It's really, really hard," said Heather. "And some of these women have great opportunities, but just because of that criminal record, it changes everything." The frustration was clearly felt, but its target was not so easily identified. Only one service provider mentioned politically-directed advocacy efforts such as 'Ban the Box' campaigns (McAleese 2017). For others, their frustration seemed to be directed generally at employers who were unwilling to make concessions for individual cases, or even more broadly at the shifting, globalized job market in which large companies with blanket policies are replacing smaller businesses that might have been more accommodating in the past. But frustration was also expressed toward reintegrating women, such as for failing to recognize the limitations of their employment options and being unwilling to accept the types of jobs available to them.

Reintegrating women also indicated that their aspirations were thwarted by their records, but few said they wanted to work in therapeutic or caring roles. Ashley said, "I've also been very passionate about like naturopath, homeopath, organic, like healing" but did not have previous employment experience in this area, or a clear goal of doing such work. Andy was hoping to get a peer-support role working with people living on the streets who are struggling with addiction, 
since this was Andy's previous life experience. But Becky was the only woman I interviewed who indicated that she had a specific goal to work in a sector now closed to her. "I always wanted to be a paramedic," she said. "But I have a criminal record now, so I can't." She added that she was not even able to enroll in a paramedic program until she had received a record suspension, which she said was "so stupid, cuz I would have done the schooling" while waiting out the period of time before which she could apply. Zahra also indicidated that she was planning to apply for a record suspension. Unlike Becky, she was able to begin training her now since her plan was to be a chef, and she hoped that by the time her five years of training was complete, she would be eligible to apply. "I'm ninety-five percent sure I'll get it," she said. "I haven't been in trouble again since then. It was a one-time thing. It was so long ago. And I've proven myself that I'm changed and I'm moving on. I don't see why they wouldn't give it to me." But while Zahra may be able to get a pardon if she does not get "in trouble" again, she seemed to believe that changes had been made to the record suspension process. "It used to be ten years when Harper was on [as Prime Minister]," she said. "I heard they changed it to three years now, but that's what a person said." While the current Liberal government has indicated that changes are underway to the process and cost of record suspension, these changes have not yet been implemented, meaning a ten-year wait is still a ten-year wait. Zahra's confidence that a pardon was not going to "be a problem" could be based on inaccurate information and she is likely to be discouraged when she realizes that she has a long wait ahead. Indeed, Natasha relayed a story about a woman she worked with who was deeply impacted by the 2012 legislative changes that lengthened the time before someone could apply for a pardon. ${ }^{42}$ "That just completely sucked the

\footnotetext{
${ }^{42}$ See Chapter Two, 'Challenges to becoming work ready'.
} 
life out of that woman," she said. "Like she had been holding on to this date for years. She had saved up for it." Natasha added that given that most people with criminal records are only able to access minimum wage jobs "at best", saving up the $\$ 640$ to apply for a suspension is extremely difficult. "It takes them so long to build up to this." Natasha noted that she saw people become so discouraged that they just gave up.

Service providers invited and encouraged reintegrating women to resist not only their criminal record but the implied 'criminal identity'. Indeed, the criminal record and its associated stigma were often referred to something 'carried' by women, even tangibly described as a 'backpack'. Such narratives frame the criminal record as external to women, as a burden to, not characteristic of, their subjectivity. Indeed, with the exception of those working directly for CSC who refer to reintegrating women as 'offenders' or 'parolees', service providers consistently referred to reintegrating women as 'clients' or simply 'women'. They rejected terms that would suggest a women's conviction is part of her identity.

"The government effectively makes you unemployable when they make it so that you have to get a criminal check," said Joan, a woman who was unable to find work for four years after her release from a federal prison. She clearly recognized that the government has a key role in determining the policies and practices barring reintegrating people from employment. Yet in order to understand how the criminal record functions as a tool of exclusion, it is important to look beyond these policies and explore the associated stigma of the criminal record and how this stigma is experienced and negotiated by reintegrating women. 


\section{STIGMA AND NEGATIVE IDENTITY MARKERS}

Hannah-Moffat argues that in governing practice, the concept of risk is ambiguous and flexible $(1999,2005)$. In the mobilization of risk management practices in women's reintegration and employment it seems that the 'risk' that needs management is the woman herself, a woman whose criminalized and stigmatized past incites curiosity and exclusion. In the descriptions of the stigma borne by reintegrating women, not only is her apparent 'riskiness' made clear, but also the ways in which she herself is at risk. Clearly, the possession of a criminal record invites multiple legislated exclusions from the labour market. However, the barriers posed by the criminal record also result from negative repercussions relating to social stigma (Pager 2007; Hagan and Dinovitzer 1999; Murray 2005; Dodge and Pogrebin 2001). It is interpreted not only as an indicator of a risky character, but also a morally corrupt one. Stigma can be understood as the relationship between an attribute and a stereotype wherein one is perceived as having "blemishes of individual character" (Goffman 1963, 4). This type of stigma is commonly imputed to reintegrating adults (Ricciardelli and Mooney 2017, 106), and is appropriate in this context since the attribute of the criminal record is almost irrevocably associated with stereotypes of criminals and criminality. But since the majority of criminal offenders are male, androcentric notions of criminality are the norm (Menzies and Chunn 2014). Stereotypes of criminals are thus highly gendered, associated with violent, hyper-masculinity, and women's criminality is considered a dual deviance, violating both legal and gender norms (Hannah-Moffat 2004; Smart 1995; Steffensmeier and Allan 1996; Backhouse 1991; Eljdupovic and Bromwich 2013). For example, after interviewing 125 probationers in Virginia about the effects of social bonds and drug use on criminal activities, Spencer De Li and Doris Mackenzie found that females "often carry heavier stigmas than male offenders even if they are involved in similar 
offenses" $(2003,282)$. They found that, compared to males, women on probation were less likely to find employment and considered this an indication that the stigma of the criminal record can be a more significant impediment for women in obtaining employment. Indeed, Patricia, a reintegration coordinator, described the impacts of the criminal record as "two-fold" such that the criminal stigma was compounded by a woman's perceived lack of conformity to gender norms. Similarly, Natasha indicated that reintegrating women face an "almost exotic idea of a criminal woman" which incites an interest not typically seen in response to men's criminality.

I think often when women have a criminal record there's this sort of large curiosity that follows them. Sort of like, I wonder what she did? And why was she there for? And I think it carries with it this sort of larger more like secretive component to it.

Donisha described the reaction she and other women get when people find out they have criminal records. "They're like, whoa! Whoa!," she said, mimicing how they back away defensively. She explained that they automatically assume the worst. "When people hear oh, like she just came out of prison, like she has a criminal record, or she just came out of jail, like, like they just feel like it's a violent crime, you know?"

The perception of reintegrating women as violators of gendered norms extends into other aspects of women's lives, even if these aspects are completely unrelated to the crime of which a woman has been convicted (Eljdupovic and Bromwich 2013). For example, some service providers noted that the stigma women face for their criminal past extends to their perceived (in)abilities as mothers. As Sarah said, "I think the thing with criminalized women is there's that an assumption that they must be bad mothers." Reintegrating women are thus at risk of heightened scrutiny, even into areas of their lives unrelated to their conviction. Of particular 
interest here is how the criminal record, interpreted as a negative stigma, severely restricts employment possibilities (Maruna 2001; Harding 2003). Yet while the stigma of the criminal record can have a powerful effect on employers' hiring decisions, other factors such as race and class can have an equal or greater impact. As Devah Pager (2007) revealed in her Wisconsinbased experiment of sending out identically qualified 'candidates' whose only differences were minor convictions and race, white men with criminal records were more likely to get call backs than black men with no criminal records. ${ }^{43}$

Several service providers noted that employers are increasingly unwilling to hire adults with criminal records. They described their efforts to address the stigma of a criminal record and to disrupt associations of past convictions with current risk. Part of this work involved building connections and trust with employers in the community. "We seek out connections, linkages," Heather said, adding that she and other staff members spend significant amounts of time in the community, meeting with potential employers. "I do a lot of like lateral engagement with businesses. Um, what do, who do you employ? What would that look like?" She and other service providers described asking employers probing questions to gauge if they might be willing to overlook a woman's record. They might point out that the majority of women's crimes are related to property and drug offences, not to violence (Savage 2019). They may also try to convince employers past offences are unrelated to the tasks required for a specific job. For example, Helen told me about a woman who was hired with a cleaning company because the

\footnotetext{
${ }^{43}$ Pager hired two pairs of actors, one black and one white, to apply for advertised, entry-level jobs. The fake résumés she created were identical except that one included a minor, nonviolent drug felony and 18-month prison sentence. White nonoffender-applicants received callbacks on $34 \%$ of their applications, those with criminal records got callbacks $17 \%$ of the time. Black applicants with no criminal record had a $14 \%$ callback rate, while those with records had only $5 \%$ callbacks.
} 
employer considered her offence (drug trafficking) to not be as risky as other offences (robbery and fraud). Patricia also indicated that advocacy efforts can be successful, saying that if a woman's charge "has nothing to do with what they're going into, you know it might be okay." Indeed, several service providers told stories about employers they had convinced to give women a chance. Kim told me about one manager who not only hired a woman with a record, but recognized that this woman's parole officer had to visit her at work each month as part of the required monitoring. He just asked that Kim be subtle about it so that business clients would not know there was a parolee on staff. "So, we do have some employers that are willing to work with us," Kim said, "which is great." In another example, Donna described one of her organization's success stories.

In one instance we actually found an employer willing to take women with a criminal record and then matched women who were living at [the halfway house] to that employer. And it was very successful. That woman, one of the women is still employed there, who was a lifer. So she hadn't had a job in, you know, twenty years. And it worked out incredibly well.

However, despite that this particular situation worked out well, Donna added that such success is "on a case-by-case basis; very, very piecemeal." Indeed, Jeff indicated that organizations advocating for justice-involved adults encounter not only indifference, but contempt. "If it's an adult coming out of prison with a criminal record, fuck them," he said. "I don't think that way, but that's how the market, the market's like why would I wanna, why would I wanna help that person?"

Donileen Loseke suggests that the public generally believes "people who are not responsible for the harm they experience are worthy of sympathy" (2003, 78 emphasis in original). She calls 
these 'feeling rules' which dictate emotional responses to narratives (see also Dunn and PowellWilliams 2007). Criminalized adults are considered responsible for the harms they have experienced, and as Jeff suggests, they are often unable to elicit sympathy from employers. When one considers these feeling rules, it clear that women are in a catch-22 position. If they admit their criminal past and express full responsibility, they may not gain sympathy due to the feeling rules that withhold it from those who are culpable. Yet if they offer up explanations for their past, they risk appearing to be making excuses and as being unwilling to accept responsibility, and thus morally corrupt. Natasha found that women were more likely than men to volunteer explanations about their criminal record and saw how this could backfire and further stigmatize them. She attributed women's desire to explain to “a very large sense of feeling insubordinate or unqualified or that kind of thing" and indicated these feelings related not only to their traumatic experience of incarceration, but also to interpersonal relationships that may have got them involved in criminal activity in the first place. But in her experience, women's voluntary disclosure or explanation made them "more vulnerable" to being perceived negatively.

Negative perceptions of those with criminal pasts are particularly acute for certain crimes. Certainly the stigma asociated with sex offenders is well-documented (i.e. Rickard 2016; Cubellis, Evans, and Fera 2019). But Heather suggested that fraud charges are "probably the hardest" to deal with, because once a woman has committed fraud, she is "blacklisted" in her profession. Women who committed high-stakes fraud are also more likely to have a conviction that drew media attention. As Elena remarked, "What jobs can they get when you can Google them and the amount of money is on the news, especially if [they] fraud the government." Theresa, a woman whose fraud case had been extremely high profile, said she was considering changing her name. Although she had managed to find employment, she knew that coworkers 
and business contacts could easily find her past on the Internet, which could put her employment in jeopardy. Lin, another woman who had a fraud conviction, said she was forced to completely abandon the career in which she had spent many years. She described having "huge stigma" following her. Indeed, the criminal record was often talked about by reintegrating women and service providers as a quasi-tangible thing that 'follows' women or which they 'carry'. For example, Natasha said there is "a huge backpack of stigma that they drag around." Such metaphors are interesting in that they invite consideration of reintegrating women as something other than their stigma. The stigma is something women bear, or which follows them. It is not inherently who they are. As such, these metaphors and discourses allow space for imagining women without the burden of past conviction.

Ashley expressed resistance to the stigma of the criminal record when she described her frustration with those who are unwilling to see past the 'black and white' of a criminal record and consider the person as an individual.

Why is it such a criteria if someone has a record or not? Why is that such a trust, you know, foundation? 'Well if you're a criminal, I can't trust you.' Why don't you just give the person a chance? Why don't you meet the person face to face first? ... Take the person for who they are.

By asking that people take the person for who they are, Ashley is insisting that she is not the corrupt and deviant figuration associated with the record. Yet despite such expressions of resistance, like other reintegrating women, Ashley was well aware that she still must contend with this figuration. It may be this deviant figure of the 'criminalized woman' that employers do not want to hire, but as Ashley expressed, individual women struggle to find ways to make employers see them and not the figure conjured up through stereotypes about those with criminal 
records. The following section explores how reintegrating women negotiate the criminal record and resist the figuration of the criminal woman.

\section{NEGOTIATING THE CRIMINAL RECORD}

Since coming out of prison, Chantell is highly motivated to present herself as morally upright and demonstrate a reformed character. Initially, she thought this could be done by voluntarily disclosing her criminalization, thereby indicating a transparent and honest self. She repeatedly told me that she is working hard to be known as a 'woman of her word', suggesting that building a reputation as being reliable, trustworthy and honest is key to her personal redemption. Yet as she recognizes, when your story involves criminalization, transparency is not likely to be rewarded with increased trust. By telling someone about her criminal record, Chantell could unburden herself of her secret and feel proud of acting in what she considers a morally upright manner. Yet the secret she has to tell is so bound up in stigma and shame, entry to the domain of the included is likely to remain barred. Erving Goffman (1963) suggests that stigmatized individuals have a heightened interest in projecting positive self-images and desirable identities to others. Chantell has recognized that it is her responsibility to figure out how and when to disclose her criminal record, but even after living in the community for two years, this process is still fraught with challenges and set-backs, such as were discussed in Chapter Two.

Similarly, when Donisha was released to a halfway house in Toronto after spending three years at GVI, her worries about how she would find a job were closely tied to how she would negotiate disclosure of her criminal record. 
It's like okay, I don't know who's gonna hire me, right? I've a big huge [time] gap, like it's crazy. And I'm not sure what jobs I can apply for. I don't wanna waste my time doing criminal record checks and, you know, not get the job. Go to interviews, wasting my time, like you know? Worried about what they're gonna, how they're gonna ask, what they're gonna ask me, how to answer these questions.

Donisha described what she anticipated an employer's response would be, "They're just like, Oh! She's a criminal. Can't hire her." Anticipating questions about her criminalization, Donisha is demonstrating what Goffman (1963) identifies as a stigmatized person's self-consciousness and calculation about her impression on others, and management of information. Individuals with criminal records use various strategies to overcome the negative consequences of its stigma. These may include attempts at 'passing', which is the "management of undisclosed discrediting information about the self" (Goffman 1963, 42), such as by crafting personal narratives that conceal a criminal past and display positive information (Harding 2003). Those with criminal records may also seek to manage its associated stigma by withdrawing from interactions in which disclosure might result, openly disclosing their status, or keeping their status a secret (Winnick and Bodkin 2008, 300). They may also eventually seek to have their record suspended, pardoned, or expunged (Ispa-Landa and Loeffler 2016). Women must negotiate how to manage their disclosure of their record in multiple arenas including housing, child and social services, mental health, addictions treatment, and support groups (Maidment 2006). Service providers, who are in positions of guidance, authority, and supervision over reintegrating women, advise women about this negotiation, but leave the 'choice' up to each woman. 
Broadly speaking, women indicated they have three options when it comes to negotiating their criminal record with potential employers: they can tell the truth, lie, or try to avoid the question. In determining their approach to these choices, women engage in the types of questions stigmatized individuals grapple with: "to tell or not to tell; to let on or not to let on; to lie or not to lie; and in each case, to whom, how, when, and where" (Goffman 1963, 42). For each woman, and in each negotiation, the stakes are high: disclosing a criminal record to an employer may mean that employer is unable or unwilling to offer her the position. Not disclosing risks being found out and rejected, both for being a 'criminal' and for being dishonest. Reintegrating women were significantly varied in how they responded to such questions, and also indicated that they were likely to try to read the context in which they make their negotiations. This suggested there is not one hard and fast rule to apply in all situations. For example, as we talked, Holly seemed to be considering various options for how to respond to the question about her record. "I think starting up a relationship with an employer it's not good to lie, but, and even withholding information is lying as well, it's kind of like a lie," Holly said, signaling recognition of the imperative to be honest, and suggesting this even includes not withholding information. However, she went on to express possibilities that she might not tell unless asked, or that she would choose to lie. "I would still go that way where I wouldn't mention it unless it was asked. And even yet, I might not even be truthful about that part if I felt like I was somebody that could do the job." Thus, in exploring the various ways women negotiate their criminal record, each category is not exclusive of the others, and women may choose different responses at different times. Women may try to anticipate the response of the employer (does this seem like a person who would care about a record?) and the place of employment (is this the kind of company that is likely to have a blanket policy?). They might try to figure out how much the employer already 
knows. For example, if they were referred to this employer by someone else, did that contact already disclose the woman's 'situation'. If so, it may be in her best interest to be up-front about the record. But if the employer does not know, or suspect, then it may be in her best interest to keep quiet. Research on recidivism indicates that lack of money is a key factor in return to crime (Burnett 2004). So women might also take a chance in order to earn an income for a brief period, even if they know they will likely be fired once human resources check into their background. As their varied responses indicate, the challenges are many, and as clearly expressed throughout my interviews, the solutions are few.

\section{'If they don't ask, don't tell'}

As noted at the outset of this chapter, reintegrating women are frequently told 'if they don't ask, don't tell'. Service providers are aware that women are in a very difficult position and are likely to face heightened stigma about their criminalized past. So they indicated that they advise women that they don't have to tell. For example, Helen is an employment coordinator at a parole office. She said sometimes disclosing a criminal record is just a matter of "ticking a box" beside the question about whether one has a criminal conviction for which a record suspension has not been granted. "Like, you don't want to have to tick the box, right?" she asked. She suggested that if people don't tick it, the employer could assume it is because they have a criminal record, or simply that "attention to detail wasn't there, right?" By indicating to parolees that they can simply leave the box unmarked, Helen is not only suggesting ways to avoid disclosure, but implicitly condoning it as well. Heather, a manager of a halfway house, was also one of the service providers who encouraged women to try to avoid disclosure. She said she would advise women, "if they don't ask you, then take a chance." 
When service providers tell reintegrating women that they do not have to disclose, their intention is to help women avoid the stigma and constraints of the criminal record. However, they know this strategy can backfire. Heather told me about a woman who had managed to get a decent job with benefits, something "you never see". But even after three months, she was still anxious that at any moment human resources would run a criminal record check on her and she would lose her job. Another example she gave was about a woman who had managed to get a job as a personal support worker without being asked about her record. She worked for three years, then was fired when a change in placement prompted a check. "That just killed her," Heather said. "And then things just went south." While she did not go into detail about what 'going south' meant, the implication was that losing the job was devasting to this woman and precipitated a downward spiral. Similarly, Chantell said that the first job she found was at a call center where employees were not asked about their criminal record, so she did not volunteer the information. However, she believes that someone 'outed' her to her manager. She said one day her manager was telling her 'you're doing great', the next day she was fired. These stories indicate the risks women assume when they 'take a chance' on accepting a job without disclosing their criminal record.

Dissimulation about the criminal record can leave women feeling ill at ease in their employment. Indeed, several women who had been able to find employment by following the 'if they don't ask, don't tell' advice felt anxious about their record being discovered. Melody was keenly aware of the prejudice that exists against reintegrating women. She expressed an almost 
crippling fear that her current employers will find out about her past and fire her. ${ }^{44}$ She described fantasies of walking into her manager's office and unburdening herself of her heavy secret. Melody did not describe experiences of discrimination at her workplace, indeed she talked about being supported and encouraged by her direct supervisors. However, she knew she was passing as a non-criminalized person. She said she felt like she was living a "double-life". Yet despite the relief that disclosure might bring emotionally, it could cost her the job she had worked so hard to not only acquire, but at which she excels. "In October, I'll get my raise," she said, and down the road she said she will get "one-hundred percent benefits too, and a dental plan and everything." It's been over a decade since she has seen a dentist. With so much at stake, Melody felt she could not risk disclosure.

Holly also indicated that she was 'passing' at work and living a double-life. She said none of her co-workers knew about her past. "I have this like little, yeah, it's like fake, it's not a fake life, but I'm just leaving certain parts out." She constructed a story that is partially true about her life, but which purposefully leaves certain details out. "I don't want them to know anything about me cuz, I don't want them to judge me as that, right?' Being judged as 'that' suggests a fear of being judged as a criminal, an inmate. Additionally, most of Holly's adult working life had been spent as an escort and a drug addict, following which was a period of time spent in federal prison. The stigmas associated with inmate, escort, and addict are each significant on their own; each suggests a figuration that is morally corrupt, risky, and destructive. Holly's hesitant suggestion that she was crafting a 'fake life' indicates the desire to present to co-workers an alternative

\footnotetext{
${ }^{44}$ When Melody applied for this job, she said the application form asked 'is there a criminal offence for which you have not been pardoned?' Melody said she put 'no' and told me, "I'm not lying because I wasn't pardoned, right?" The result was that Melody got a job without disclosing her criminal record.
} 
identity, yet her discussion of passing indicated that she was not sure how to construct this alternative identity and her efforts were still tentative. The use of a 'working person' as a new and alternative identity is a possibility that will be explored in Chapter Five.

Donisha, despite her concerns about job applications being a 'waste of time' erroneously suggested that employers do not have the right to ask her about her criminal record. It is perhaps this belief which lead her to say she was well within her rights to withhold information about her past. She told me that if she is asked whether or not she has a record, she will not answer directly. Instead, she will tell them they can run a criminal record check. She said she would do this so that the "conversation can keep going," rather than ending as soon as they find out about the record.

They don't just write you off right away, right [if they don't know]? So they're like, okay. Well, I guess we're gonna have to do a criminal record check if we really want to know. We're gonna have to do a criminal record check. So, and then, then that gives you a better opportunity to get the job too because, like they don't know. They don't know if you do or if you don't.

This approach seems to have worked for her, since she managed to get a job in construction through an employment program placement. What is striking though is that despite her views that employers do not have the right to ask, and her fears that no one would hire her if they knew about her record, a chance occurrence (the loss of her phone) prompted her to voluntarily disclose. Each evening her boss would text her and other crew members to let them know where and when to show up for work. But when she lost her phone, she was unable to get these messages, or communicate with him to let him know what had happened. Concerned that she was going to be fired for missing work and not being touch, as soon as she got a new phone she 
messaged him with her apologies. His response was sympathetic, which perhaps made her feel comfortable enough to tell him the rest of her story.

He's just like, being very sympathetic. And I just felt bad. And I'm like you know what, I feel like I need to tell you this because there's gonna be another time when I can't come to work. And you're gonna think I'm just playing hooky or something, right? So, I need to let you know this is what's going on.

By 'other times when I can't come to work', Donisha was referring to mandatory house meetings and appointments with her parole officer. Her anxiety about losing her job over missing work had prompted her to consider that these meetings could also impact her job. So Donisha told him her situation, and again his response was supportive. He told her to let him know if she was going to have to miss work for a meeting, and he kept her on with the crew. "Clearly I'm very valuable to the team," she said with a chuckle.

Donisha had received her job through a placement with an employment agency that offers support to youth with barriers, so she recognized that it is possible that the employer already knew or suspected she had a criminal record. Yet I find interesting how his sympathetic response to her having lost her phone and missed work prompted her to 'feel bad', suggesting that she felt guilty about her lack of transparency with him. But Donisha was also acting pre-emptively, anticipating that there would be more times where her supervision-related obligations could interfere with her work, and that non-disclosure created a burden of anxiety she no longer wanted to bear. Her choice to voluntarily disclose also suggests that even when women are able to secure work by non-disclosure, in time they may choose to reveal their record.

Chantell told me that when she came out of the federal institution, one of her biggest fears was how to talk about her criminal record. "I was sort of wrestling with, oh my gosh I have to 
tell everybody everything, right off the bat. Like just sort of clear the air, this is it," she said. But a service provider told her she did not have to disclose unless she wanted to. "She just helped me to see no, that's your information. You get to choose who you share that with. And that was a really powerful piece for me, because that's one of the biggest hurdles I had to get over." Chantell described this non-disclosure advice as empowering, but indicated that her negotiation of the stigma of criminalization was an ongoing struggle, and one which was not confined to employment. In examining perceptions of stigma among parolees in the United States, Thomas LeBel (2012) noted that individuals with more formal education were more sensitive to public opinion, and more likely to perceive stigma. Chantell was one of the few respondents who had a professional degree. During the interview, she gave numerous examples of her efforts to rebuild her social network and establish a positive reputation for herself, efforts which may reflect her heightened awareness of the stigma of criminalization. Yet while she felt like she was more in control about who would know about her past, as her story about being fired from her call centre job indicates, she was still vulnerable to people finding out before she was ready to tell them, or when she had not wanted them to know. It illustrates the emotional ups and downs of finding work and then being let go, as well as the precarity of gaining employment through nondisclosure.

\section{'Just be honest'}

As discussed above, acquiring a job without having disclosed the criminal record can generate anxiety and can result in women being fired once the record is discovered. Yet it does allow women to earn an income, even if just for a short time. Such opportunities are not widely available. Many reintegrating women told me that it was hard to find places where they had a 
choice about whether or not to disclose. Alexa applied for over 50 jobs before she finally was able to get some warehouse work through a staffing agency. "I had to fill out an application for employment and then when you put like 'do you have a criminal record' and you gotta check yes, right?" she said. "I never got a call back." She was describing a common experience applying for a job and having to answer yes or no to the question about having a criminal record. Many job applications include the question 'Have you been convicted of a crime for which you have not received a record suspension?' This question is followed by Yes and No boxes, and in some cases by a text box in which applicants can provide comments or details. Alexa suggested she had to check yes. But as she found out, by admitting to her record, she was not invited for an interview. As Heather said, "You're damned if you do. You're damned if you don't."

Lin relayed a recent experience she had when applying online for a job. She had uploaded her résumé and completed the whole application form, until she got to the end where she saw the question: “'have you been convicted of an offence for which you have not received pardon?' Yes or No". There was nowhere on the form where Lin could provide additional information to explain how her conviction would not prevent her from performing well at this particular job. "So, I didn't even pursue it." She abandoned the application. Like most reintegrating women, she anticipated that if she checked 'yes', her application would not move forward so she decided there was no point in submitting it, which suggests she felt obligated to be honest in her response. Lin and other women who had been incarcerated at GVI had been told that they should never try to lie on application forms. "I'm gonna be honest with them," Lori told me when asked how she would respond if employers asked. "You can't lie about it. Cuz I did programs in uh, in um GVI that told [us] don't be, don't lie about it. You have to tell the truth. Cuz they're gonna find out eventually anyways. So then it's just gonna be worse for you in the end." The threat that 
employers would find out and make things worse for her seemed to have impacted Lori. Despite her fears that the record will prevent her from getting the dishwashing job she had recently applied for, she said she felt bound to tell the truth. As noted above, Heather and Helen both encourage women to 'take their chances' with job applications and dodge the question if they could. Yet if forced to respond, they said women must tell the truth. "If someone asks you, then tell the truth," Heather said. "You have to be honest," Helen said. "You can't lie." This unequivocal insistence on 'telling the truth' corresponds to Goffman's assessment of professionals assisting stigmatizing individuals who generally warn stigmatized individuals "against attempting to pass completely" $(1963,109)$. In other words, while most service providers implicitly and explicitly encouraged reintegrating women to evade answering the question about their record, most did not go so far as to directly encourage women to lie. In this way, they prioritized performing honesty over performing employability. However, as will be discussed below, some service providers were more equivocal about disclosure, hinting that they condoned deception.

Yet even if reintegrating women decide they will 'tell the truth', how women interpret and enact the call to 'be honest' is a matter of individual negotiation, both with what honesty is and how it should be performed. Malone, a 25-year-old woman with several years of experience in fashion retail prior to a year spent at GVI, seems to have accepted the indictment to be honest. However, she indicated that honesty is a negotiation. Her comments are worth quoting at length.

The way like I was advised to kind of play it up, just you know, if it comes up, just kind of say, you know, I was away. I was just dealing with a little bit of a situation. Um, and then if, obviously they're gonna do a record check, most places 
do, if it comes to it, just be honest. You know, just listen, this happened. I got into a little situation. ...

Don't lay all the facts on the table. Don't be like, oh I was, you know, I was robbing a store or something, you know. But just kind of, just be honest about it but still keep it professional, you know. Just, yeah, I was in this situation, I had to go away and deal with it for a little bit. Um, I'm back I'm trying to build back my you know, my, what's the word, credibility? Or yeah, just, just be honest with it. Um, try not to just lay it on the table.

Don't you know, don't go there and be, 'Hi, I have a criminal record.' Like, no. Cuz they're not gonna give you a chance, you know? Try to, try to play it off the, you can let them get to know you personally first, cuz you want them to know you, not know the inmate, you know what I mean? So that's definitely key, I would say. Yeah. Just try to let them get to know you personally first before you kinda. But also, be honest about it, don't be like 'Oh no, I don't have a criminal record'. Cuz you know, cuz then they're gonna go searching, they're gonna find it. And then you lied to them, so then that ruins your credibility there too, right? So. Interviewer: So if they don't ask, you wouldn't volunteer that information? No. No. I wouldn't. Um and then if it comes up, you know if it, then I would just say, yeah, you know, this did happen, um, however I feel I have the skills to fill the position. 
While Malone repeatedly states that women should 'be honest', her interpretation of honesty is clearly not straightforward. She would not volunteer the fact of her criminal record; so she is not suggesting that an honest approach requires someone to initiate disclosure, rather that she would not lie about her record. Her decision not to lie seems based on the awareness that she would likely be found out anyway, not on a need to unburden herself of the secret (such as expressed by others like Chantell, Melody, and Lin). In other words, for Malone, being honest can be understood as not lying when directly asked. In contrast, Chantell talked about her desire to disclose her criminal record as part of what she identified as a need to enact moral uprightness. Lori, who was ready to be honest about her record knew it could cost her the job but suggested she would maintain a personal integrity. "You might not get the job from being truthful," she said, "but at least you're being honest and telling the truth." This suggests women can have different ideas about what it means to be honest, and different methods and motives for performing honesty.

Natasha connected the desire of women to overcome their "shame" of conviction and incarceration with the impulse to disclose not only their record, but even to provide details about their criminal charge. In her experience, women were more likely than men to voluntarily disclose the facts of their case. Yet she said this could negatively impact women as employers may be less likely to hire them after hearing the specifics, perhaps because as Loseke suggests, such frank disclosure might violate the feelings rules of sympathy, and also because women's criminality is, as previously discussed, seen as violation of gender norms. However, Patricia suggested that it may be to women's benefit to disclose their criminal record, particularly if their crime is not violent or fraud related. In contrast, Malone is advocating for a more tight-lipped approach to honesty. Being honest for Malone does not mean telling everything, or 'laying all 
the facts on the table'. If asked, don't lie about the record, but don't go into any details. She is evincing a commitment to honesty and ethical self-governance while determining the nature and performance of honesty (cf. Werth 2012).

In the above excerpt, as throughout the interview, Malone referred to her criminalization as 'being in a situation', or even as a "little situation". Her time at Grand Valley was time spent 'away' 'dealing with the situation'. Similarly, Theresa described what she said when she reconnected with a former business partner. "I said, without going into details, I got myself, I disappeared for a couple years because I got myself in some legal matters that, you know, kind of changed my life. I didn't go into detail. And that was my choice. And I felt like at least I had opened it up." Theresa indicated that she had said enough to suggest she had been 'honest' about her past, but like Malone she used euphemisms for criminalization and downplayed the severity of her charges. This suggests that honesty can be performed in multiple ways, and can include evasive and distancing language.

Although the idea was incompletely expressed, in the excerpt above Malone says, 'try to play it off'. What she would play it off against is unclear, but the suggestion is that if one needs to disclose, downplay the gravity of the charge, use euphemisms for incarceration, and try to play off something else, perhaps to deflect attention from the record itself. Her twice-used metaphor of 'laying the cards on the table' and of the word 'play' also suggests a game. This game metaphor for negotiating reintegration, was also present in Helen's narrative. She suggested there were ways that parolees can "play it" when it comes to disclosure. She gave an example of those whose parole conditions stipulated that they cannot be around schools and parks with children, even for jobs like snow removal. "I would play it based around availability," she said, describing how she would advise them to indicate they were only available for evening shifts, something 
which might even be attractive to employers looking to fill less popular shifts. This notion of 'play' is not uncommon among reintegrating adults, for whom it suggests performing compliance (Werth 2012). For example, when Ashley talked about institutional therapy she said, "I know how to play that. It's a game." For Malone, 'playing off' might also mean deflection. In her example of how she would answer the question about her record, she would switch the focus away from her past to her professional skills. Similarly, Lin said, "If it ever comes up, that's when I'm going to say, well I am switching directions at this point in my life." She laughed and added, "being creative I think." By being creative, she was indicating that she could direct the conversation to where she was going in the future. But the term 'creative' also suggests an element of playfulness and malleability. Clearly the stakes are high and the use of game-related metaphors should not be interpreted as insouciance. However, the call to playfulness expressed by these women invites consideration of reintegrating women as not simply resisting the constraints of their criminal record, but actively and adaptively crafting an imaginative subject position that is future-oriented rather than constrained by errors of the past.

Reintegrating women may also seek to differentiate themselves from a 'previous' (criminalized) identity by signaling a temporal distinction by pointing to the passage of time (Moran 2012). Helen pointed to temporal distance as another way in which women can be honest, but can distance themselves from their criminalization. She would tell people that if they had to disclose their record, simply say, "yes, I've made mistakes in the past. It's just not going to affect how I do the job." Similarly, Tara said that even if she had to disclose her record, she would say, "I'd rather not talk about that. It's part of my past. It's not who I am today and it won't affect how I'm going to do the job for you." Philosophical discussion of the ontological distinction between being and becoming (i.e. Nietzsche 1954; Foucault 1983; Weeks 1998) is 
beyond the scope of this work. Yet we are never not who we once were, and at the same time, we are never exactly who we once were. Part of the negotiation of the criminal record is an attempt to indicate that despite the record, which is interpreted as an indication of criminal identity, an individual is not actively and presently a criminal. As such, they may leave off challenging that they ever actually were 'a criminal' by focusing on the temporal as an ontological distinction. ${ }^{45}$ Indeed, Malone's comment that she wants employers to get to know her personally, not as 'the inmate' is striking. Like Tara, she is indicating that the inmate is something, or someone, other than herself, someone from her past. The inmate is someone the employer does not need to meet. As philosophers like Catriona Mackenzie (2009) might suggest, Tara and Malone are distinguishing aspects of their history that while attributable to them, are not central to their selfconception or ones with which they identify. Perhaps it is because she does not self-identify with 'the inmate', Malone does not feel a need to reveal this to an employer. Her interpretation of the 'be honest' approach is a complicated negotiation with facts, impressions and performance.

In addition to pointing to the passage of time to claim a reformed identity, Malone, Lin and Helen suggest that women should steer the interview to focus on their skills. This approach might be described as 'normification' by Goffman, such that it is the "effort on the part of a stigmatized individual to present himself [sic] as an ordinary person, although not necessarily making a secret of his failings" $(1963,31)$. The emphasis on skills also allows women to draw attention to aspects of their identity that are not associated with the criminalized woman figuration. Theresa indicated that she thought her criminalized self was not relevant to her

\footnotetext{
${ }^{45}$ Feminist criminology has made important contributions to challenging the ontological associations of a criminal conviction with a criminal identity (e.g. Comack 1996; Hannah-Moffat 2001; L. Haney 2010). By discussing women's strategies of distancing themselves from their prior convictions, I am not suggesting these women were formerly criminal selves, but rather I am seeking to present the strategies they use to manage criminal stigma.
} 
'working' self. "Does anyone have a right to really know my past?" she asked. "Especially in work, I feel like okay, like when you're working, they should judge you for what, your performance, you know?" Theresa's resistance against who should know about her past indicates that even if honesty must be performed with certain people, such as the employer, it does not need to be performed with everyone, or performed to the same extent. Again, this indicates the malleability of performances of honesty, and how for reintegrating women their choices about if, when, how, and to whom they disclose, will be on-going for an indefinite period of time.

\section{'I would put no'}

Service providers were generally consistent in indicating that they would advise women not to disclose unless directly asked, and they might even encourage women to be evasive about their past. However, none of them told me they would advocate actually lying. This may be because they recognize that women who lied to get a job are at a high risk of being fired if their record is found out. However, as a researcher asking questions with a notepad in hand and a recording device between us, I recognize that I was not creating an environment conducive to admissions of practices such as lying, and perhaps I elicited an ideal version of events and participants may have told me what they thought I wanted to hear (Sered and Norton-Hawk 2014). That said, some service providers said they knew women had lied to get work, and indicated they had not chastised these women or told them they must disclose. "Some of them had said, 'well I was overseas working as a nanny'," Kim said. "Sometimes that works." That what seemed to me a rather improbable excuse was used by some women made me wonder if Kim shared this tip with women she supervised, relaying lies that had worked for others and thereby implicitly condoning them. However, Sheila, a supervisor of women's parole officers, 
said, "Maybe [women] don't want to lie. It feels wrong, so they don't want to go out there and do that." She did not condemn lying, or even insist that women always tell the truth, but she suggested that lying would feel wrong, pointing to an emotional affect as a motive for performing honesty.

As always with awareness of the recording device between us and my role as an outsider and a researcher, it is not surprising that most of the reintegrating women I interviewed told me they would not lie. "To lie, and try to like, fool [your employer], you're not going to get far," said Ashley. "It's going to come to a point where you're just going to have to reveal yourself anyway." Like other women, Ashley figured the record would eventually come out. She suggested women might spend years looking over their shoulders, afraid that at any moment their past would be found out and they would lose everything. While Srila was the only participant who told me she had lied on her job application, others indicated that lying was an option they were considering. Holly suggested she might lie if she thought it would help her get a job for which she was qualified. Carla had been out of jail for less than a month when we talked, and she had not yet applied for any jobs. However, she was already mulling over how she would respond to the question about her record. "I think I would put no, just so they wouldn't look into it any further," she said. "I don't know if that's good to do that, but whatever gets the job, right? Some people do." Carla's ambivalence about the morality of this decision seemed influenced by her awareness that others do it as well. Certainly lying on job applications is not uncommon, although in most cases people's lies involve exaggerations of their qualifications and experience (Wood, Schmidtke, and Decker 2007; Robinson, Shepherd, and Heywood 1998).

Srila told me that in her current food prep job, she had checked the 'No' box for the question about a criminal record. "Do I want to tell my boss that I have record?" she asked. "No. I don't.". 
Srila justified her decision to lie by saying that everyone makes mistakes in life and had she told the truth about her record, she would not have been able to get the job. She is not afraid that her boss will run a record check on her as she said the two of them "have a great relationship, you know what I mean? Like where she's talking about her family and kids and this and that." This lack of concern about being found out was strikingly different from the anxiety expressed by some women who had been able to find work by not disclosing (but not actually lying). When I asked Srila if she was worried that her record might be found out, she said she was and that she had considered telling her boss, but quickly added, "she's seen the good side of me, so there's no need to bring up that." Similar to Malone's comments about an employer not needing to know 'the inmate', Srila suggested that the employer knew her 'good side', so there was no need to introduce her to another aspect of herself. She valued the relationship she has with her boss and does not want to jeopardize that by disclosing her past. However, Srila also considered this job temporary and one that she planned to leave as soon as she found a better paying replacement. Her fear of disclosure was not the same as for women like Melody who hoped to stay in their job for a long time. Additionally, Srila's previous job experience included working at her brother's bar and cleaning houses with a friend, both of which had been acquired through informal processes of hiring in which she had not been asked about a criminal record. This may explain in part why Srila stands out from other respondents by not seeing the criminal record as a significant barrier. "I know I could get another job," she said. "I'm not worried." As with Zahra's previously noted comments that the criminal record would not be a 'problem' for her, I wondered if Srila's stated assurance that she could easily find another job was an indication of a bravado (Goffman 1963) that some stigmatized individuals express. 


\section{AVOIDING THE NEGotiation}

As discussed above, women have three broad choices to make when it comes to if, when, and how they will disclose their criminal record to potential or actual employers. Each of these options has pitfalls, and it is not hard to understand the anxiety several of them expressed when weighing them. Yet women who do not want to put themselves in a position where they have to disclose their record have limited opportunities to earn an income. An ideal option is to find work with employers and/or companies that knowingly or purposefully hire reintegrating adults. Yet given that such employers are few and far between, another option is to seek income through informal work which may be illegitimate or illegal. Additionally, as will be explored in the section on engagement and ambivalence in Chapter Six, some women disengage from the 'working world', relying on social assistance and/or disability support payments. Although distinctions between these options are rather vague, as they are between these options and those discussed above, exploring how women discuss them further reveals ways in which they manage the stigma of their criminalization.

\section{Ideal to find places that know and still hire}

Reintegrating women repeatedly told me that what they most needed was a list of companies willing to hire people with criminal records. "The only way that I could see [community organizations] being helpful is just get like a list of places that are hiring that don't require a criminal record [check] and stuff," said Becky. Certainly, as noted above, most service providers discussed their efforts to network with local businesses and find those willing to hire individuals who have criminal records. Heather explained, "We try to seek employers that the women feel comfortable telling them up front, this is my criminal record, I've done $\mathrm{x}, \mathrm{y}$, and $\mathrm{z}$, but I'm still 
employable." Clearly, having an employer to whom women can disclose their record relates to the call to honesty discussed above, but the hope is that transparency about the record will be rewarded with trust, and possibly a job offer. However, some women expressed skepticism about the suggestion that employers might still accept them after they knew their past. Elena recounted that she has found employers in the community who said they were willing to hire women with records, but then when she directed women to apply there, the employer would turn around and ask for a background check. She said in such cases, women felt like they had been 'set up'. Similarly, Tina described her experience with employers, saying that even if there are those who had agreed to accept candidates with criminal records, they were still likely to choose to hire someone else. It was early in the summer when we talked, and she said that university students were proving stiff competition to women at her halfway house. "You see somebody, Jane here with a criminal record and Sally here with none," she said, pointing to another halfway house resident and then to me. "I'm gonna hire you [Sally] as opposed to her [Jane]." In other words, having an employer willing to hire someone with a criminal record does not mean they will.

Labour market sectors typically available to those with criminal records are those which are male-dominated and relate to construction, trades, and manual labour. One parole manager jokingly told me that if you get your roof repaired, half the guys up there have records. Similarly, Patricia noted that a lot of men can say, "Oh, I know this one construction guy." She made this point not only to differentiate between the informal contacts men are likely to have compared to those women might have, but also that areas like construction are unlikely to do background checks. However, even though most women recognized that jobs in construction were accessible to those with records, they may not want to take on such work, due in part to the physical 
demands of the job but also to the (potentially hostile) male-dominated environment. ${ }^{46}$ Indeed, Elena relayed a story of a woman who had successfully completed a welding program but who faced such discrimination on job sites that she quit during the apprenticeship stage of the program. "The biggest problem she had was being a woman," Elena said. "Wherever she went basically she was brought down and compared to the men that were working there." Elena said this woman gave up and never went back, despite having enjoyed the program and the skills she acquired.

Yet, while construction and manual labour jobs are not appealing to all women, some participants indicated they would be willing to work there if given the chance. Holly expressed frustration that men had access to more jobs that were forgiving of the record.

Like a man who comes out of prison, there's the construction jobs. There could be construction jobs for myself as well if I had somebody to like allow my foot in the door, right? And I find for men it's just that way. ... A man might come out with less or equal amount of, um, education as me and still have more opportunities for a better paying job, right? Longer jobs or whatever, right?

Her comments indicate that even if all reintegrating adults face precarious employment opportunities, men's work is generally better paid, and more readily accessible. Women also noted that most of the employment programs for reintegrating adults were targeted at men. "I'm like, wait, why they don't have like something, specific to like, you know, for me?" Nicole asked. "Why can't I jump on that program that he's doing?" Both she and Holly were clearly aware of the gendered differences in accessing employment for those who been criminalized.

\footnotetext{
${ }^{46}$ Women make up only $6.4 \%$ of people employed in transportation, trades and construction work (Ferrao 2010, 23).
} 
Becky was one of the few respondents who had experience working in male-dominated sectors. She had spent 10 years as a heavy equipment operator, some of which was done after her first conviction. She believed only about half of the companies hiring for this kind of work would check if she had a criminal record. "Biggest companies generally they want like a clean record and stuff," she explained. "But I think they're getting more lenient now a little bit cuz a lot of people are just, they have records for tickets and stupid stuff.” By suggesting that a lot of people have records for minor infractions, Becky indicated that in certain contexts, criminalization does not carry the same stigma as it does in situations where criminalization is atypical. Construction and heavy equipment operation are not the only areas in which a criminal record may not be barrier. Zahra was hired in a restaurant within weeks of being released from federal prison. She laughingly said that a lot of 'back of house' staff in restaurants have been in trouble with the law. "Majority of cook, chef positions like, they're criminals," she said. "A lot of them, right? So it's like, it's okay. They [employers] don't really care. As long as you do your job and you don't screw up too much, they're good." Indeed, Zahra was not asked if she had a criminal record when she applied for the job. While she did not voluntarily disclose it, the only reference letter she could provide was from her employment program manager inside GVI, a letter which was on CSC letterhead. She said the restaurant manager looked at the letter and said, “That's perfect. You're good.” She was hired.

Joan also found work with an organization that accepted her background, a place which even recognized the skills and strengths she had developed during her many years of dealing with addiction and incarceration. Joan worked the night shift at a men's homeless shelter where her "nerves of steel" and life experience were an asset in dealing with shelter clientele, and the associated drugs, fights, etc. "Nobody can distract me with nonsense while something else is 
going on," Joan said with a chuckle of pride. "I've been through it all. None of it fazes me." Unlike the temporal disassociation indicated by women like Malone and Tara, Joan clearly drew on her past to deal with the present challenges of her job. Her position is noteworthy in that it allowed her to transparently mobilize aspects of her criminalized background in the sociallyacceptable role of a 'worker'. Two other participants, Andy and Ashley, expressed longing for a job that would allow them to use their experiences to help others. Yet as noted earlier, even community organizations working with reintegrating adults can be constrained by legislation such that they cannot offer jobs to those with criminal records. Kim told me about one woman who, after job searching for more than two years, was finally able to find a position with an organization working with reintegrating adults. This organization had created a peer-support position, one which allowed and even welcomed individuals with experience of criminalization. But again, such opportunities are rare. It is more likely that if an employer knows about the record and still offers a position, it is despite, not because. Jessica explained, sometimes you may find "an agency willing to work with you because they know your skills and abilities and strengths and you're good at what you do and you have all this certification, and they're willing to waive the criminal records check." However, not only is finding such opportunities infrequent, it requires that women have managed to secure education, certification, and/or employment experience that makes them well-qualified for the position. Theresa was the only reintegrating woman interviewed who had an extensive skill-set for which her employer was willing to overlook the criminal record.

Clearly, obtaining a job in which one's experience with the criminal justice system is valued is ideal, and exceptional. Melody had participated in a program that provided general 'job readiness' training (see Chapter Three for more on job readiness training). After completing the 
classroom training, she was referred to the owner of a Tim Hortons franchise who had agreed to offer employment to program participants. She successfully passed a group interview and an individual interview, and was then invited to meet with the store manager. As they were talking, the manager mentioned that she had partnered with the training program because she wanted to assist people struggling to access employment, but she was unclear about the nature of Melody's barrier. Melody, a petite, soft-spoken woman who wears a small gold cross around her neck, presents herself very professionally. She likely did not appear to fit to any of stereotypes the employer might have had about those with employment barriers (Pager 2007, 101). In response to the question, Melody said she sighed, then told the manager that she had a criminal record. The manager seemed surprised, then asked Melody if she would like to talk about it.

So then I just sat there and I said, listen, if I don't tell you about it, I could walk out this door and you can sit here and you can Google my name and you can see all the negative stuff that was said about me. And, I said, or, we can sit here, and I can tell you everything, the good, the bad, everything. Sat there for about a half an hour, telling her my whole story.

And then she stood up. She's right where you are [sitting across from her at a Tim Hortons table]. And she stood up and she came over to me and I'm kind of like, I thought she was going to say, get out of my store. And she came over and she's just standing there. So then I get up thinking, I better leave, right? She just put her arms around me and hugged me and she said, I want to welcome you to our family. 
Like Joan's experience of finding an employer who valued her diverse skills, Melody's story of acceptance is an outlier among research participants. It indicates another ideal scenario. Although this job did not end up working out for Melody, she had found employer to whom she could unburden her secret and she was still literally welcomed with open arms. Yet it is also important to acknowledge what Melody alluded to - the indefinite sentence of Internet search engines. There is no pardon process for Google. If Melody had not known that her past was so accessible to anyone who wanted to search, would she have disclosed to the hiring manager? Her story ended well, but she had expected it to go the other way. She did not expect acceptance through transparency.

Additionally, finding an employer who is willing to hire someone with a criminal record does not necessarily mean you have found an employer for whom reintegrating women want to work. Sarah suggested that "the jobs that are out there that you can get with a record are not necessarily the jobs that women want to do." Natasha told me that women with records had some success in finding work doing overnight cleaning shifts in commercial buildings when nobody was around. But these jobs made her "nervous" for the women placed there, a recognition that night work has been established as a risk factor for workplace violence and aggression (Hurtado et al. 2018). "Sadly," Natasha added, "I think some of them get to a point that they want to work so badly that they just accept these positions." Susan also demonstrated some wariness of employers willing to hire women with records, noting that women are "often exploited in those jobs as well because of their limited options" and telling me about women she had placed in jobs who had subsequently experienced sexual harassment. "They've been so conditioned to cower and to submit, right?" she said. "And then the fear factor. I'll let that go, because I can't lose my job." Coming from a punitive and hostile carceral environment, reintegrating women may find it 
difficult to assert themselves, or know in whom they can trust to confide their experience. While most of the service providers described the struggles they had in trying to find employers willing to hire people with criminal records, Susan stands out in that she knew of places that would hire people with records, but would not send her female clients to them. She considered these job sites as too risky to women's safety.

Throughout the interviews, service providers expressed concern about women's vulnerabilities. Even when discussing specific conditions women had, such as those with fraud charges being unable to work with money, or those with addiction not being allowed to work in bars, their concerns were expressed as more relating to women's vulnerabilities than their risk toward others. As such, even while the technology of the criminal record can be viewed as a legislated practice of risk management, service providers assisting women who hold criminal records emphasized the risks these women faced far more than their supposed riskiness. This reflects how service providers are continuing the long-standing efforts by feminist correctional reformers who have argued that women do not represent a threat to public safety, but are themselves at risk of being victimized (Hannah-Moffat 2001; TFFSW 1990).

Indeed, when considering the types of employment available to reintegrating women, the juxtaposition of women's riskiness and risk becomes apparent. As discussed above, criminal records mobilize strategies and practices of risk management, but clearly the 'risk' being managed is that which is perceived to come from criminalized individuals. But reintegrating women are themselves at risk in the community. As Susan and Natasha demonstrate, jobs available to reintegrating women can be risky to their health and safety. Susan's assessment of reintegrating women as being 'conditioned to cower' indicates how experiences of incarceration and criminalization can increase risks to women's safety. As many feminists have argued, the 
prisoning of women, despite mandated goals of rehabilitation and empowerment, is inherently punitive and repressive (Maidment 2006; Hannah-Moffat 2001; Comack 2018). As will be discussed in the next chapter, carceral governance mobilizes and entrenches a broken and disempowered subject position for women. The risks of exploitation and workplace harassment in the precarious job market are already acute for women (Johnson 2002), even more so for those who have been criminalized. Women are especially at risk when they engage in informal and illicit ways of earning income.

\section{'Falling back': Informal and alternative options}

The criminal record is clearly a significant barrier to most well-paid, stable employment. Some reintegrating women indicated they had little expectation of being able to obtain such employment, and they were considering informal work as a way of earning some money. For example, Nicole said that prior to her most recent stint in jail, she had worked independently as a hair stylist/esthetician, often out of her own apartment. She said in this type of work, a criminal record "really doesn't interfere." Though she did not currently have the resources to invest in supplies, she felt confident that if she pursued this again, her record would not interfere. When considering informal work, it is important to recognize the blurred lines between informal and illegal work. Distinctions between 'legitimate' and 'illegitimate', or 'legal' and 'illegal' work contribute to and perpetuate women's criminalization (van der Meulen 2010; Hannem and Bruckert 2014; Jeffrey and MacDonald 2006; Grant 2014; Gatrell 2008). A primary example is the sex industry, which encompasses a wide range of 'illegitimate' labour practices. While prostitution itself has never been illegal in Canada, under the Criminal Code (1985), and more specifically the Protection of Communities and Exploited Persons Act (2014), various aspects of 
sex work were made illegal, such as communicating for purposes of selling sex and gaining material benefit from sex. Such legislation makes it very difficult for sex workers to engage in their trade without contravening the law in some way (Hannem and Bruckert 2014). In other words, while sex work can provide a source of income (and in some cases a better source of income than that which is available otherwise), it carries a risk of further criminalization. It also, as Nicole describes, offers few protections. She narrated a hypothetical line of reasoning, and regret, for persisting in illegitimate work.

I'm just gonna be a prostitute for the rest of my life, or I'm just gonna sell drugs. That's your prerogative, obviously. Like, you're gonna be 56-years-old one day and think like, what did I do with my life? You know, why am I trying now only to work? Why am I not qualified for unemployment? Why don't I have a pension? Like you know?

Nicole laughed when she commented on unemployment and pensions, as if pointing out how farcical it was to think that one could have any hopes of long-term security by continuing as a prostitute or drug dealer.

Yet for those who are discouraged about negotiating their criminal records with potential employers, who have faced too many rejections, or who have only been able to find poorly-paid, difficult jobs, the illegal market is an alluring option. Service providers indicated that women can make 'good money' selling drugs and engaging in the sex trade, particularly if they have experience in these areas. Jessica explained, women often do not see many other viable options and 'fall back' on previous methods of earning a living 
[They are] looking at our system and seeing like okay what jobs are available to somebody with a criminal record? And there's very small jobs, or, sorry, smallpaying jobs. And so the natural tendency for some of these women are to fall back on options that worked for them in the past, and maybe didn't work for them in terms of like, it helped them stay out of conflict with the law, but it helped them day-to-day get by, right? And it helped their families. And that's like sex work and like selling drugs, essentially.

Similarly, Natasha indicated that desperation and poverty could lead women into, or back into, prostitution and drug sales. Significantly, as both Jessica and Natasha pointed out, the need to earn money was most acute for women with dependent children. Indeed, Nicole said having children gave her a sense of "urgency" about finding employment because "there's always a time where they need something, right? ... If it's not lunch money it's gonna be something else."

Several service providers and reintegrating women referred to illegal income as 'easy money'. Lin described how she interpreted return to illegal work, saying that a lot of women are “just doing a lot of hustling you know, easy, easy money. That's something that they will, if they could easily fall back into if they don't have any viable means of living, you know?' Her comments were made in the context of criticizing CSC for their lack of employment support for women. She expressed sympathy for women who had few options, but also indicated that she was not one of those who fall back into 'easy money'. As will be explored in Chapter Six, reintegrating women often expressed claims to their own redemption by distinguishing themselves from others, such as those who just went for the 'easy' money. However, Joan's account of her old patterns upon release from jail illustrate the constraints within which some women make the 'choice' about a return to illegal work. 
Like you come out in the middle of winter with summer clothes on. And they give you a bus token. To go where? To do what? There's nowhere to go. No clothes. No nothing. You go out in the snow. All you have to do is go back to crack. So you pick up a trick on the way back to Scarborough and pick up dope with the money you get from doing it, right?

This description of being dumped out of jail with nothing but a bus token demonstrates how vulnerable reintegrating women are, and even puts into question the notion of 'reintegration'. What are women expected to reintegrate into when they have nowhere to go? Research on sex trade workers in Winnipeg found that women typically do this work out of economic necessity and due to past experiences of poverty, homelessness, childhood victimization, and sexual exploitation (J. Brown et al. 2006; Seshia 2005). Thus, the engagement in illegal work must be understood in its context of the very limited options and resources. While there may be a certain 'ease' with which cash can be made relatively quickly (Jeffrey and MacDonald 2006), that does not mean this work is 'easy', particularly since it carries significant risk, including high risks of violent victimization (Farley, Lynne, and Cotton 2005). Additionally, given that sex workers are disproportionately Indigenous, engagement in this work must be considered in the context of historical and current practices of racism and colonialism (Farley, Lynne, and Cotton 2005; Comack 2018).

While the decision to return to or engage in criminalized labour may be a choice, it is a constrained choice "in the face of few other viable options within the formal labour market" (Gatrell 2008, 8). For example, Janessa, a former drug dealer, also expressed her frustration with the lack of options available to herself and other women at the halfway house. 
Like you just leave people stuck in things and you give them nothing and no resources, no nothing, what do you expect them to do? You know what I mean? They're gonna sell drugs. They're gonna do what they have to do to feed their kids, you know what I mean? To do what they have to do.

As a result of her frustration, and in anticipation of rejection, Janessa was withdrawing from interactions in which disclosure might result. In other words, she had stopped trying to find work. As will be explored in Chapter Six, Janessa was one of the women who said she was stepping away from the 'employment world'.

Service providers are aware of the risks women face if they return to illegal sources of income. For example, Kim acknowledged that reintegrating women can make more money selling drugs or sex than they can by working at a minimum-wage job. She tries to convince parolees under her supervision that the risks are too great by reminding them of all they stand to lose.

You're gonna be caught. You're gonna go back to jail. You're gonna lose your kids. You're gonna lose your dog. You're gonna lose your apartment, everything you've worked for. That's a choice. At the end of the day it's a choice they're making cuz they're adults. I can only try to encourage and motivate them.

Kim's tough talk recognizes that having an apartment, kids, and a dog are things for which women have to work extremely hard, particularly if they rely on income from legal sources. For many reintegrating women, no matter how hard they work, these things will always be out of reach. Still, Kim suggested that not only can women gain these things through hard work, they can lose them through bad choices. She described this speech and other similar messages as 
'motivational interviewing'. In trying to motivate her clients to make the right choices, Kim tried to remind them of what was at stake if they made the wrong ones. As a parole officer, Kim would likely know that a not insignificant number of women have their parole revoked (approximately forty percent in 2002/03 and 2003/04 in the two years after release), although only a quarter of these revocations were due to conviction for a new offence (Gobeil and Barrett 2007, 9). Kim, like other service providers, repeatedly suggested that if women did not find employment, they would fall back on illegal jobs. This discourse of legitimate versus illegitimate work was prevalent in the interviews with service providers. It serves to support broader narratives about the inherent value of (legitimate) employment, about reintegration as a transition from illegal and illegitimate activities to becoming law-abiding members of the community, and about the centrality of employment as an identity marker. Such discourses also place a great deal of emphasis on individual choice and responsibility.

\section{'IT'S YOUR CHOICE': THE POLITICAL BECOMES PERSONAL}

Service providers are keenly aware of the catch-twenty-two position women face when it comes to disclosing information about their criminal record. They expressed sympathy for the difficult position women are in, yet emphasized the individual responsibility women have for figuring out what to do, and how to do it. Yet by focusing on how individual women negotiate the barrier of the criminal record, the location of the problem shifts from an external burden of the record to women's capacities for, and demonstrations of, ethical self-governance. Sheila, who has been working both directly and indirectly with incarcerated and reintegrating women for over fifteen years, indicated that it was up to each woman to decide how she would manage the presentation of her criminal record. She said she does not tell women they have to disclose, but 
neither does she encourage them to lie. Such ambivalence was expressed even more clearly by Kim, a parole officer with over twenty years of experience working with reintegrating adults. She told me she did not know what to tell women about disclosing their records. "So yes, the whole criminal record, you know how they answer that, I don't know. I never know the proper answer." Kim has seen women struggle with the barrier of the criminal record throughout her career. Yet she repeatedly insisted that she 'doesn't know the answer' to if/how they should disclose. By insisting that she doesn't know, Kim places responsibility for navigating the criminal record solely on the shoulders of reintegrating women. Women are thus made individually responsible for the constructed barrier of a criminal record, called to independently navigate the decision about disclosure, and to do so in an ethical way that demonstrates their agency and reformed subjectivity.

In telling women they must decide for themselves how to negotiate disclosure of their record, service providers can be understood as seeking to encourage women to advocate for themselves, drawing upon discourses of agency and empowerment to emphasize autonomy and individual choice. For example, Maria works in a non-profit, community-based organization with services for women who have experienced violence. She provides employment support and training, and describes the program as operating on a model of 'stages of change', a 'strengthsbased' approach. "We try not to tell them what to do," she said. If a woman asks Maria for advice about disclosing a criminal record or something else like the need for accommodation to use medical marijuana, Maria will say these decisions are not hers to make. While she said that the hardest part of her job was not telling women what to do, her organization's approach requires that she keep her 'opinions' to herself. “All I can do is give them both sides, what studies have shown," she said. So she tells the women, "It's your choice." This approach is 
consistent with much of the support work around victimized women, such that she encourages women's independence while suspending her own judgment and biases (Dunn and PowellWilliams 2007, 996) and promoting a position of self as other than victim. It can also be recognized as part of feminist practice that aims to approach other women without judgment and to reject paternalistic presumptions that women lack the capacity to know, and choose, what is best for themselves (Madhok, Phillips, and Wilson 2013). By telling women that they must choose how to negotiate their criminal record, service providers can be said to be mobilizing women's agency.

However, the mobilization of agency discourses makes it more difficult to address the "hostilities and ambivalences that also structure our relations to one another" (Hemmings and Treacher Kabesh 2013). Reintegrating women face systematic exclusions from many of the most basic supports necessary to rebuild their lives post-incarceration. There is an implied promise in the narratives of agency mobilization that excluded citizens will be able to enter the domains of the included by demonstrating positive moral standards, making the right choices, and proving themselves to be ethically reconstructed (Werth 2012; Bosworth and Kaufman 2013). However, when faced with the no-win choice such as disclosure of the criminal record, there is no right choice that fosters inclusion. Although telling women 'it is your choice' may be an encouragement to self-govern and to adopt productive goals of self-promotion, individual choice does not, and cannot, address or dismantle the structures of discrimination and stigma attached to the criminal record. Reintegrating women expect, and indeed encounter, hostility and rejection when people learn of their past. Despite empowering and inclusionary objectives of agency mobilization, broader conditions for inclusion are not in place (Lynch 2000). The emphasis on individual choice de-responsibilizes carceral and correctional systems, as well as those who 
enact and enforce policy decisions relating to criminal records. The political is collapsed into the personal.

In the context of ethical responsibility, women who insist on their own innocence, or who try to downplay the gravity of their misdeeds, are seen as not only as failing to demonstrate responsibility, but also as lacking the maturity and moral uprightness necessary for being considered trustworthy. Women like Chantell acknowledged this when they said their conviction exaggerated their offence, but that there was no point in fighting this. Ironically, Chantell found that trying to get people to recognize that her crimes were not as bad as depicted could actually result in those people thinking less, not more, of her, since she was viewed as failing to take full responsibility for her actions. Ashley has repeatedly fought against and appealed her convictions. Because of this, she has faced repeated pressure from correctional staff, parole officers and others to 'take responsibility' for what she has done. She was told by prison staff, "Don't ask for nothing or you'll get no. Because you're not taking responsibility." When she responded by telling them she was appealing her conviction and sentence, she said they would reply, "Doesn't matter, in our eyes, you're guilty cuz you're here.” Ashley's resistance against her conviction, and against those involved in her punishment, was met with increasingly punitive responses. While the legitimacy of the criminal justice system depends upon the right of an accused to resist wrongful accusation, Ashley's account of her experience in prison indicates that in carceral spaces, resistance to the subject position of the 'offender' is an unacceptable form of agency 
mobilization. How reintegrating women are expected to perform agency must comply with the objectives of those governing them, and only such expressions of agency will be tolerated. ${ }^{47}$

Reintegrating women are directed to perform their responsibilization in compliance with the dominant normative frameworks that govern socio-political and economic structures within society. Waged work is fundamental to the operation of these structures. Indeed, work is not just an economic practice, but a social convention and disciplinary apparatus that shapes and constrains the possibilities for social belonging (Weeks 2011). As such, what is most important to those who govern reintegrating women is not if, when, or how women disclose their record, but whether or not they pursue employment. This may explain the ambivalence demonstrated by some service providers about how individual women negotiate the barrier of the criminal record. Service providers are more concerned that women pursue and obtain employment than they are with how women manage this negotiation. Failing to make the 'right choice' about how to disclose one's criminal record could be excused as an understandable struggle in addressing the imposed barrier of the criminal record. Even lying about one's record, which could morally be considered a 'wrong choice', can be a 'right choice' if the intent or result is employment. Yet it is unmistakably a 'wrong choice' to not pursue employment. The discourses of agency, responsibility, and empowerment require reintegrating women to act toward their own success. Women are viewed as failing in this regard if they do not pursue independence and personal growth, and key to such pursuit is the redemptive production of the formerly incarcerated self into the employable self.

\footnotetext{
${ }^{47}$ Rebecca Bromwich (2015) examines how Ashley Smith's resistance to her imprisonment can be understood as assertion of her own agency, but also how her agency was denied through correctional practices and through the mobilization of various discourses that recast her as mentally ill, childlike and passive.
} 


\section{Becoming work ready: Confidence \& mental health}

Remember, no more effort is required to aim high in life, to demand abundance and prosperity, than is required to accept misery and poverty. ${ }^{48}$

- NAPOLEON HiLl, THINK AND GROW RICH

I interviewed Holly at the dining table in the large kitchen of the halfway house where she lived. She sat with her back straight; her hands folded in her lap. Her soft voice was hard to hear at times over the hum of the two large fridges that stood behind us. Her answers were tentative, cautious. She had been out of prison for about nine months, but had only recently found employment. We discussed things like résumés and certifications, but then I asked her what it 'takes', besides those kinds of things, to actually get a job. Holly paused, then said, "I think it takes what I was lacking for a little bit, is confidence." She raised her voice at the last syllable in word 'confidence', expressing this more as a question than an answer. Patricia O'Brien, who interviewed reintegrating women in the United States, remarked that women expressed insights during the interviews which they had not articulated before $(2001,289)$. Sometimes when I asked women questions, they would pause, repeat the question under their breath, or gaze to the side, as if mulling over how best to respond. Holly seemed to be testing out the idea of confidence. After another pause, she elaborated on her line of thinking.

Um, I think confidence is really important cuz I didn't have that coming out of prison. Um, and um, like a really good attitude, just um, being able to you know come up with the words you need to use to, to get your point across, so that, you

${ }^{48}$ Hill [1937] 2003, 31. 
know, you sound intelligent, um trustworthy and all that kind of stuff. Um, and I think you also have to be not afraid to look for the job, like to put the work in, the effort in, to get the job.

Again, she ended with her voice raised, adding a note of hesitation. Yet her faltering explanation of the role of confidence in employment success suggested it could serve as a foundation of, or gateway to, other attributes or presentations of self. As the interview continued, Holly circled back several times to the idea of confidence. "Confidence building is really, really important," she said when asked about beneficial supports. "Some people aren’t afraid to be turned down, but I was. Cuz I was afraid that if I got turned down and turned down, that it was going to just, where some people might be feisty about it, I was afraid that it might, like, hurt me.” Holly paused before she said 'hurt me', as if she was not sure how to describe what might happen if she was repeatedly turned down. Later she mentioned that she was learning to deal with "anxiety and, you know, panic attacks and stuff like that," indicating that she had experience with mental and emotional struggles. She also talked about learning to recognize triggers that might lead to a relapse in her addiction. Holly was not the only woman I interviewed who suggested that being turned down from a job could be emotionally devastating. Lori said that if she did not get the job she was interviewing for the next day, she would likely be too discouraged to try again. When Holly said that she thought confidence was the "biggest thing" impacting her reintegration, might it allow her to perform employability, such as by appearing trustworthy, intelligent, and work ready, and thereby prevent rejection? Could it also help protect her from hurtful emotions?

Service providers also suggested that confidence was fundamental to employment readiness, and that it was something reintegrating women widely lacked. Of the thirteen service providers interviewed, ten mentioned lack of confidence as a significant or even the most significant 
challenge facing reintegrating women. "I can't tell you the number of conversations I've had with women who say, well I don't have any skills," Donna said. When I met to interview her in her homey office at a downtown community-centre, she had been working with justice-involved women for the past seven years. "They have no, no idea how to market themselves, or that they in fact do possess skills. They see their deficits more than they see their, what they do bring to the table." Due to their lack of confidence, Donna said, reintegrating women would not try for jobs in construction and trades, where employers 'do not run record checks' and people can "make a good living". Lack of confidence, Donna went on, kept women from believing they could develop the skill set to work in this industry. Construction jobs frequently came up in discussions with service providers and reintegrating women. Through these conversations I identified numerous barriers women face in integrating into this environment, which can include lack of training and experience in manual labour; a male-dominated work-environment in which many women do not feel comfortable; long hours and early morning start times that are difficult to manage for women with child-care responsibilities; job sites that often require access to a car; and a network of contacts to open doors. Given these numerous barriers to employment in construction, I found it interesting that Donna identified lack of confidence as the "biggest barrier' keeping women from finding success in this sector. And yet, Holly had also indicated that lack of confidence was a key factor that was holding her back. What does it really mean to have confidence, and why is it so important for employability?

As noted in the previous chapter, the criminal record is a significant barrier to employment, and women need to negotiate if, when, and how they will disclose that record. Service providers emphasized that women have to 'choose' what to do, drawing upon the discourses of choice and empowerment that dominate correctional policies and practices. I interpret this emphasis on 
individual choice as a practice of responsibilization, one that emphasizes self-governance strategies and de-emphasizes structural and contextual constraints. Such practices open the door to blame, or self-blame, of reintegrating women for failing to make correct choices or to failing to minimize and manage their own vulnerabilities and risks. Yet while service providers expressed frustration with reintegrating women for repeating risky behaviours or for not pursuing prescribed goals of reintegration, they suggested this was due to women's inability, not moral or ethical shortcomings. Direct blame is avoided through reference to lack of ability, or skills, awareness, and fortitude. In explaining perceived inabilities of reintegrating women, the narratives of service providers constitute them as mentally and emotionally unwell, and as dealing with past experiences of trauma and on-going struggles with addiction. As such, the figuration of 'criminalized women' which emerges through their narrative is not that of a rational, free and responsible individual capable of her own empowerment. In this chapter I explore the figuration of the reintegrating woman which is constructed through narratives about women's perceived inabilities to achieve employability, a figuration I name the 'broken psy woman'. There are three categories of attributes and characteristics that get coded as indicators of what I have identified as this figuration of the broken psy woman: her lack of confidence, her 'affliction' with mental illness, and her struggles with trauma and addiction. Finally, I explore what (limited) options are available to women who seek to resist the constraints of this subject position.

\section{CRIMINALIZED WOMEN LACK CONFIDENCE}

"I find that that is one big thing is that the confidence level in terms of getting employment," Sheila said. "On top of having minimal employment experience and maybe skills, they don't 
have the confidence to move forward." She said that lacking employment skills can contribute to low self-esteem, but even if women have the skills, "I can imagine the confidence isn't there." In other words, a key characteristic of the reintegrating woman, as described by service providers, is their lack of confidence. Sheila suggested that a supportive employer would give women the chance to "develop the confidence to use the skills". Like Donna, quoted above, Sheila implied that while women may possess some employable skills and are capable of acquiring more, they are held back by their lack of confidence. Confidence, by its absence, serves to negate and inhibit other attributes. Paradoxically, by not existing, it exists as a barrier.

Kim also described confidence as something that could be possessed, but could also be eroded through traumatic and challenging experiences. "I mean, they're sober for the first time in their lives," she said. "They don't have their children. They want to get their children back. They're living in a halfway house. They don't want people to know they're on parole, coworkers and such. So that whole self-esteem bit is, is difficult." Kim, like some other service providers, used terms such as 'self-esteem' and 'confidence' interchangeably. Yet her narrative suggests that even something like sobriety, which is supposedly a positive step toward which addicted women should aspire, is associated with lack of confidence. Kim said that women, compared to men, "tend to internalize the things a little bit more sometimes." She suggested this internalization erodes confidence and self-esteem. As discussed in the previous chapter, Kim told me she did not know what to tell women when it came to how to navigate the criminal record. But with regard to self-esteem, she expressed no hesitation in knowing what to say. "We try to build up her self-esteem and you know, encourage her," she explained. "Today, yes, you got up, you got out of bed, you got dressed, you had a shower, and you're gonna go look for a job. That's fantastic, you know. So, keep doing that." Kim described this process of affirming 
women's minor accomplishments (getting dressed and showering) as "motivational interviewing", which is a therapeutic practice developed to address addiction but also used in other social work and counselling contexts (Barber 1995; Hettema, Steele, and Miller 2004).

Kim, who has a degree in psychology, was the only service provider I interviewed who used the term 'motivational interviewing'. However, other service providers also discussed their efforts to affirm women and build up their confidence. "I think you have to work a little more in terms of the self and like building that up so that they're able and ready to work," Natasha said. Jeff noted that when participants began their placement with his social enterprise, he would purposefully compliment their skills and personal attributes, often telling them that they had "leadership potential". He said they would respond with disbelief, saying, "No one's ever told me that before." Jeff said he would reinforce messages of potential with participants throughout their placement. "Sometimes," he explained, "you need to be told something again and again for you to actually start to believe it." He believed this positive reinforcement led to improved confidence. He told me about a woman who completed the program and went on to find employment. "She had the confidence she needed through our entrepreneur program." He went on to say that in addition to confidence, she gained the 'language' to talk about things like returns on investment, which she was able to use during job interviews to demonstrate her knowledge. "She's gotten four promotions of this major brand, global brand. She works in Toronto. She's got new clothes, got a place of her own." Confidence and language are both elusive, unquantifiable traits, yet according to Jeff's account, are vital to success. Having confidence and a new style of discourse enabled this woman to gain entry to the business world, membership into which enabled her to acquire outwardly recognizable indicators of success. Since Jeff perceived this woman's barriers to employment as the result of a lack of confidence 
and business 'know-how', he attributed her post-program success to having gained these skills and abilities. While this is a possibility, the emphasis on confidence and language downplays other factors which may have contributed to this woman's success, such as previous job experience and education. Indeed, later in the interview Jeff indicated that participants who did best in the program were young people who had education and previous employment experience.

Jeff's description of his program participants and his efforts to develop their confidence suggest that participants did not think they had confidence, but he fostered their self-esteem by telling them they had attributes like leadership skills. In contrast, Maria and Kim suggested that women do not recognize their own lack of this key attribute, indicating that women were in fact less confident (or competent) than they thought themselves to be. Maria told me women would tell her they were ready to work, but she insisted they were not. "They have this beautiful résumé," she said. "But they are not ready." I asked her what would make them work-ready. She quickly replied, “confidence.” Since her role was to assist women with their employment-related goals, I asked her how she assisted women in developing confidence. "By not focusing on what you have to do but on what you can do," she said. She also said her organization offers women classes like yoga, arts and crafts which "boost confidence”.

Clearly, how service providers assess women's confidence and belief in self can vary significantly. Their perceptions of women's possession or lack of confidence influences the ways in which they approach the women they assist, and the programming they offer. There is no measurement by which one could rate the levels of confidence different approaches might foster. Few service providers I interviewed indicated that they evaluated the success of their program or approach based upon the number of women successfully able to obtain and maintain employment. Instead, service providers "produce scripts to relay their definition of the situation 
and to explain why they do what they do" (L. Haney 2010, 5). The script commonly adopted by service providers is that reintegrating women lack confidence, whether they know it or not. Mobilization of this script shores up approaches adopted in working with women, whether this is advocating for trades-skills training, offering yoga classes, or conducting motivational interviewing.

\section{A tautological fallacy: Empowered to be empowered}

Although confidence was repeatedly referenced by the service providers I interviewed, its essence remained obscure. Sheila referred to "the confidence level", as if it is measurable, something which can rise or fall like mercury in a thermometer. Jeff said his program participant "had the confidence she needed" because she completed the program. Here, confidence is a possession, a determinate object the program participant acquired along with a reference letter. Yet more frequently, confidence is described as a characteristic, something which reintegrating women lack, but which could be developed through supportive programming and employment. Natasha described programs as functioning as a "holding stage to see how the individual does, to give them a chance to sort of you know get a little self-esteem and self-confidence in their abilities and opportunities." Jessica said women "gain" confidence by working. Heather said that women got a "boost of confidence" by getting complimentary hair styling from a local esthetician school. These presentations of confidence as something to be developed, acquired, and fostered among those who are marginalized relate to feminist literature about empowerment, such as the call from Gutiérrez and Lewis (1999) for consciousness, connection and confidence in order to empower women of color and other oppressed groups. The confident self becomes a model of empowerment (Cruikshank 1999). Similarly, reintegration literature draws upon such 
empowerment discourses when positive characteristics such as 'confidence in self' are associated with successful integration (O’Brien 2001), and, inversely, disempowerment is associated with lack of self-esteem (McKim 2017; L. Haney 2010). Yet the language of empowerment used by service providers codes "the subjective substrate of exclusion as lack of self-esteem, self-worth and the skills of self-management necessary to steer oneself as an active individual in the empire of choice" (N. Rose 2000, 334 emphasis added). This demonstrates how the discourses of empowerment, evidenced through narratives of confidence, relate to individual responsibilization. Empowerment is the technique to mobilize individual responsibility. Yet by lacking self-esteem and confidence, women are incapable of the self-management needed to achieve empowerment. Clearly there is a tautological fallacy if women are responsible for becoming empowered even while empowerment is a subject position which is required to in order to be capable of assuming responsibility.

Narratives about the need to foster confidence are not limited to the empowerment efforts directed toward reintegrating women and other marginalized groups. Lack of confidence is presented in self-help books as an affliction common to all women and a contributor to gender inequality. For example, Katty Kay and Claire Shipman (2014) suggest lack of confidence is pervasive among women, including female undergraduates at Ivy League schools, athletes in the Women's National Basketball Association, and professionals of all ages and backgrounds. Their book, The Confidence Code, is one among many which claim that by increasing confidence, women will achieve success (professional and otherwise). Other examples include the pinkcovered book titled The Confidence Kit: Your Bullsh*t-Free Guide to Owning Your Fear (Foran 2019), which claims to be the 'ultimate guide to confidence' and Confidence: Finding It and Living It (De Angelis 1995), which shows readers the confidence 'deep within' themselves. In 
the international best-seller Lean In: Women, Work, and the Will to Lead (Sandberg 2013), the former Facebook CEO writes that, as women, we hold ourselves back by "lacking selfconfidence, by not raising our hands, and by pulling back when we should be leaning in" (8). In perusing these books, I notice a similar framework of individual responsibilization that I heard in the narratives of service providers. Conversations about pay equity are re-framed in terms of women's lack of confidence which inhibits them from asking for a raise. Lack of female representation at the top of corporations and political office is similarly framed as women's selfinflicted failure to put themselves forward and believe in their own abilities. The focus is on individual characteristics, attributes, and responses to exclusionary practices and structures, rather than the ways in which those practices and structures are systemic, racial, political, and classed.

While confidence (or lack thereof) is blamed for a myriad of social and economic problems relating to gender inequality, as with the narratives of service providers, the term 'confidence' remains nebulous. It is described as "the purity of action produced by a mind free of doubt" (Kay and Shipman 2014, 3) or as the "stuff that turns thoughts into action" (50, emphasis added). Confidence is portrayed as having an ephemeral quality; it is something which women lack but it also can be developed through various techniques such as adopting powerful postures, taking risks, and recognizing negative thought patterns. My point here is not to debate the merits of such techniques or conduct an examination of popular texts on confidence, but rather to recognize the vernacular resources (Ibarra and Kitsuse 2003) which are drawn upon the claimsmaking processes of service providers, and the context in which their narratives can be understood. These books, as well as popular women's magazines and talk shows, promote a narrative of self-empowerment that emphasizes personal fulfillment and individual self- 
expression. Such narratives are mobilized within biopolitical governing strategies that shape and guide people's capacities to act upon themselves (N. Rose 1990; Foucault 1980; Cruikshank 1999). Individuals, not social or governmental institutions, are responsible for well-being (including economic success).

Interestingly, while the majority of service providers discussed the lack of confidence in reintegrating women, Susan stands out by describing performance of confidence as a problem for reintegrating women.

Women, too, do come across as a little more assertive or seem to present with a little more, some arrogance or confidence, it can be over-confidence cuz they're kind of you know, um, making, you know, compensating right? ... If they came across as more sure of themselves, cocksure, that would be perceived as fearful. She would be a risk of upsetting, or a threat in the workplace towards other, to other women.

The double-bind faced by women in leadership has long been recognized, such that stereotypes about successful leadership traits (confidence, competence, and assertiveness) are seen as conflicting with those of appropriate feminine traits (nurturing, emotional sensitivity, and politeness), so that women who demonstrate attributes such as assertiveness can face backlash for violating feminine stereotypes (Rudman et al. 2012; Eagly and Karau 2002; Glick 1991). Additionally, employers in low-skill labour markets often value "docility, dependability, and persistence more than cognitive ability or independent thought" (Heckman, Stixrud, and Urzua 2006, 412), suggesting that confidence or assertiveness may not be rewarded in low-skill labour markets as they might be in professional markets. Susan's comments indicate the particular challenge reintegrating women face in demonstrating or performing confidence. Women who 
appear too confident may be deemed risky, a threat to other women and to the workplace.

(Although Susan used the word 'fearful', she was suggesting that women elicit fear.) This relates to observations that women are judged for violating normative feminine behaviours such as mildness of manner and speech which themselves are based upon white, middle-class norms of femininity (Malloch 1999). As noted in previous chapters, reintegrating women are particularly at risk of being judged for violating feminine norms (Hannah-Moffat 2004; Smart 1995;

Steffensmeier and Allan 1996; Backhouse 1991). Susan posited that reintegrating women overcompensate for what is actually a lack of confidence, but in doing so they come across as 'cocksure'. Her use of this gendered term linking confidence with the male phallus is noteworthy given the stereotypes about masculine confidence and recognition that within the workplace men can be rewarded for assertiveness (Rudman et al. 2012).

If women's failure to possess or demonstrate confidence can hold them back from employment opportunities, performances of confidence can also limit their opportunities as these performances can be interpreted as aggression and risk. Such challenges lead to the question of how reintegrating women engage with the discourses of confidence and negotiate its performances. While I cannot assess how reintegrating women are perceived by employers or coworkers, their discussions of confidence and stories of employment-related experiences illustrate the challenges they face and the pervasiveness of concerns about internal attributes and self-esteem.

\section{"It comes back to self-esteem and confidence": Narratives of inner abilities}

Srila found a part-time job within one week of being released. She said women just need to put themselves out there. "I think it's just the confidence," she said to explain what was 
necessary to find a job. Like the service providers I interviewed, and like many other reintegrating women, Srila identified confidence as a key factor in women's ability to find employment. But while the service providers suggested that the vast majority of reintegrating women lack confidence, of the twenty-two reintegrating women I interviewed, seventeen expressed confidence in their skills and/or in their abilities to find work. How they expressed this confidence varied significantly, and I recognize that I met these women for brief periods of time and they may have chosen to share with me positive narratives that cast their experiences and prospects in a rosy glow (see Sered and Norton-Hawk 2014). Also, I made sure that a significant portion of the interview focused on women's strengths, not just their barriers to employment. I encouraged them to articulate employable skills acquired through unconventional means, such as the entrepreneurial skills Holly gained by running an escort agency, which included paying for advertisements, hiring women and "taking care of them". Yet even if my interviews elicited more positive responses than women might have expressed without prompting, the impression I had after talking to them was that most of them felt they had the skills and abilities to be employed, and if given half a chance, they could find a job.

Janessa stood out as an example of a woman who presented as extremely confident. Her assertive body language, strong tone of voice, and frequent outbursts of laughter certainly gave me an impression of a woman who knew her own abilities and was not afraid to pursue what she wanted. She told me she has never had trouble finding work, despite her lengthy criminal record. “I know how to like, you know, represent myself and how to appear, right?" she said. I asked her to explain further what she meant. "I don't know really," she shrugged. "Just confidence really, right? So, just gotta have the confidence." This recalls Holly's suggestion that having confidence enables one to appear to possess other attributes. Confidence again is the foundation of other 
intangible skills. Janessa also suggested that internalized fears and doubts were more of a barrier than the criminal record.

Because at the end of the day it's not the card that's stopping you, ... it's that feeling of yourself, of, you know what I mean, I can't do it because of this, you know what I mean? I can't do it because of that. It's just about encouraging yourself, right? So it comes back to self-esteem and confidence, right?

As I have noted before, a transcript cannot adequately relay all that is conveyed in a spoken narrative. Janessa interspersed her comments with rhetorical queries such as 'right?' and 'you know what I mean?' in a tone that suggested I should be agreeing with her, that the points she was making were obvious. In interviews with other women, such queries were often expressed hesitantly, such as when Holly tested her ideas about confidence and seemed to cautiously look to me for confirmation. In contrast, Janessa said that if she was trying to sell me something, "you'll take it because you like me." She seemed accustomed to getting people to see things her way. Her stories suggested she had leveraged her confidence and out-going personality to find the jobs she'd had. She told me she had never had a "legit job" prior to her incarceration. "I'm a drug dealer," she said with a loud laugh. But she was able to recognize that she had skills from this previous line of work, such as her ability to convince people and bring them onside. She also said she had no trouble approaching strangers or walking into some place and asking for something, including a job. She described herself as sociable, talkative, and approachable. "I talk to people and laugh with them, you know what I mean?" Additionally, Janessa said it was because of her confident attitude that some employers did not even ask her about her criminal record. This suggests there is some truth to the claim made by service providers like Helen that reintegrating women are less likely than men to be asked if they have a criminal record, that is, if 
they know how to present themselves. Confidence, as an attribute or performance, can be a mask for hiding other aspects of self you do not want to show.

Donisha, a twenty-three-year old woman of Jamaican descent, did not use the word 'confident' to describe herself, but her account of landing a job with a construction company illustrated that she was self-assured in her skills and knowledge after having done all the employment-related training she could at GVI and, subsequently, a youth employment program in the community. She was proud to have her knowledge recognized, especially in the maledominated world of construction.

When I came out now and I met the contractor, he was like, do you have your [certification in working at] high levels, I was like yeah! And I even have this, I even have this, and I have this, and I have this. He's like, 'whoa! None of my guys have that.' I was like, really!? He's like, 'yeah. I'm going to make you head of security, like of head of um, safety.' I was like okaaaay! Yes! So like, now I'm this tiny girl, right, amongst all these big men, and I'm in charge of safety. It's crazy... It's cool. Like I love it. I love it. I love it.

Again, a transcript cannot do justice to Donisha's expressive tone and manner of speaking. When she relayed this story, she drew words out for emphasis or punctuated her speech with clapping or slapping her hands against her thighs. When she said 'I'm in charge' she drew out her words I'm.... in... charge, the word 'charge' emphatic and triumphant. When she said 'okay!' the word danced and her face lit up.

As I listened to women like Donisha and Janessa, I could not help but think about how so many service providers had told me women had no confidence or belief in their own abilities. Their articulations of strength and accomplishments stand in strong contrast to the 
characterization of criminalized women as broken and submissive. Even other women who did not speak with the same power or enthusiasm expressed confidence in the skills they possessed, such as in ability to style hair (Nicole), understand high-end fashion (Malone), or provide good customer service (Melody). Andy talked about being the "star" in the bail house they lived in. "I'm strong. I get the job done as fast as possible." Although Andy discussed struggles with addiction, depression, gender-transition, and a lengthy criminal record, they repeatedly returned to claims of strength and survival skills. When describing their landscaping work, Andy proudly said, "I'm stronger than most of the dudes [my boss has] got working for him." Lack of confidence did not seem to be holding Andy back; indeed, I had the impression that Andy was so confident in their abilities that they were frustrated that others around did not recognize all they had to offer. Given their physical strength and the work ethic they had demonstrated, Andy insisted they should be given more opportunities to work. "I'm more than qualified for enough stuff, you know?"

Such presentations of self are strikingly different from the descriptions of reintegrating women suggested by service providers like Donna and Sheila who had insisted that women did not recognize the skills they had or seek out opportunities to prove (and improve) themselves. I also do not think reintegrating women would have needed to read my notes from these interviews to know that they were presenting me with a different subject position than what I was hearing from staff at their halfway house and community centres. The figure of the broken psy woman lurks in every hallway and programming room. The discourses embedded in programs like 'change is a choice' and 'stages of growth' that the women participate in continually remind them that they are damaged and disordered. By telling me stories about their successes, their 
positive attitudes, and their fighting spirits, reintegrating women were resisting the dark figure of the broken woman. They insisted they were something other.

I am not suggesting that the majority of the reintegrating women I interviewed spoke with Andy's bravado or Donisha's pride. Women like Holly and Melody expressed a confidence in almost hesitant tones, almost as if it was something they had recently acquired and were still developing. Holly said she had been, "learning about myself and how come I feel the way I do about things." She added that "confidence" was key to this new-found ability to manage. "I find it a lot easier to just brush things off now," she added. "I don’t take things too personally." Melody said that in her life prior to her incarceration, she lacked self-confidence. "I was afraid, you know?" she said, "I had no confidence in myself or anything else." But while she was incarcerated, Melody said she did a lot of work on herself. "So I'm a much more confident type of person." Similarly, Holly said, "I've really, really worked on myself a lot." She said because of this work, she knows herself better and can regulate her emotions. While the phrase to 'work on oneself' is not uncommon in popular discourse about self-improvement, it is noteworthy here in the context of the responsibilization discourses so prevalent in approaches to criminalized individuals. It was also a phrase I heard from service providers like Elena, who said that when women come out of the institution to the halfway house, they are encouraged to start with 'working on themselves' before trying to take on other things like finding employment.

Working on oneself reflects the narrative of being responsible for personal growth. Melody further demonstrated the association of choice, responsibility and work on self.

I've made the choice. It's all about a choice. I've made the choice to sit there and to heal and to do the work on myself. Because, I don't want to be there anymore. I don't want to go back to that, you know what I mean? ...I have no regrets because 
it got me to where I am today. You know? And it's like everything is a learning experience.

Melody said she has 'no regrets', which seems counter to the enforced obligation incarcerated and reintegrating women face to demonstrate remorse for their crime. Yet Melody suggested that she has used her past to create a new and better identity. She was one of six women who chose to disclose her offence to me; her conviction was for killing her abusive husband. During another part of our conversation she said she regretted having left both her kids "parentless", and the claim noted above that she has 'no regrets' should be placed in the context of what she indicated was a situation of domestic violence in which she had "no self-esteem whatsoever" (see Browne 1987; S. L. Miller and Meloy 2006). For Melody, her articulation of a desire to change relates to what she identified as a need to develop self-confidence and personal strength.

Like Melody, it was in learning to reframe her past experiences that Holly seems to have begun to build confidence. She was not the only one to suggest that confidence is something to be built. Chantell and Malone also spoke of the need to 'build' confidence. As noted with some of the descriptions of the criminal record, some of the concepts developed through this research have a quasi-materiality. There is a sense of something tangible and concrete in the notion of 'building' confidence. As a verb, building suggests effort and progress. As a noun, 'a building' is the evidence of that, a structure that has been created. The discourse of 'building confidence' can be understood as one that implies effort must be exerted, which relates to the not-infrequent mention of 'working' on oneself. Holly could have said the program gave her confidence, which is another verb commonly associated with confidence, but the fact that she did not, and chose instead a word that indicates her own agency, suggests an internalization of the responsibility to exert effort herself. In saying the employment program she participated in was 'about building 
confidence', Holly implies that she constructed her confidence, it was not something handed to her.

In such narratives, confidence is an attitude that accompanies or indicates resilience and knowledge of self; it is something produced through effort. Certainly, such narratives support the view articulated by service providers that confidence could be developed through therapeutic programming, and that it would serve to usher in new abilities and skills. However, even if programming can foster confidence, it also serves to perpetuate the location of women's problems within themselves. When problems are constructed in a particular way (women lack confidence), interventions are constructed to respond to that formulation (programs should increase confidence). Such formulations, supported by the popular vernacular of confidence and the psy discourses of disorder and mental health, indicate not only that women are made responsible for their own empowerment, but how such responsibilization is operationalized. As Dana Becker argues in her powerful book The Myth of Empowerment, women's problems are commonly located in the "medical and psychological context rather than in the sociopolitical domain" $(2005,4)$. This locating of problems, and the solutions, curtails approaches that would address the structural and systemic oppressions women face.

While most women I spoke with expressed such stories of self-awareness and selfassurance, there were five women who exhibited very little confidence or hope. Within these women I could recognize that figure of the broken psy woman presented to me in the narratives of service providers. For example, I met with Lori at the halfway house she was living in. She looked much older than her thirty-six years and either cast her eyes downward or squinted warily at me and at the audio recorder on the table. Although she had an appointment the next day to meet with an employer about a job as a dishwasher, she did not express much hope about her 
chances of getting the job. When I asked her what she would say her strengths were if the employer asked, she physically curled up her body and said she would be "speechless", not knowing what to say. I tried to encourage her to 'practice' the interview with me, but that just made her retreat further into herself, so I apologized and changed the subject. I was reminded of a comment made by Elena, a service provider at a halfway house, who told me that when she asked reintegrating women about their skills, "they can barely answer that."

Tara also demonstrated a lack of confidence, but in a way that differed from Lori. Like Lori, she expressed little hope that she would find work, but she was able to come up with some things she would say about herself to a potential employer, such as 'I'm reliable. I'm on time. Available anytime." After a pause she added that she was a "quick learner". She said she had applied for a hundred jobs already, but with limitations due to a physical disability and conditions relating to her supervision order, she said trying to find work was discouraging and frustrating. Yet while Tara did not express much confidence about finding work, she suggested that her inability to get a job was due to what could be seen as imposed factors - disability and parole conditions. She suggested that she had attributes that made her employable, but she was being denied the opportunity to prove this. As noted above, the nature of confidence is nebulous, and is not likely something one either has or has not. Tara may express confidence in employability skills, but remain doubtful about her chances of finding a job.

As noted above with regard to Susan's concerns about women's over-confidence, how women demonstrate confidence is not straightforward, or without risks. Ashley and Nicole both suggested that over-confidence can get in the way of being willing to learn and to make necessary changes. Both said that women needed to "humble" themselves. "It's about are you willing to learn," said Ashley. "Are you willing to humble yourself and actually be a good 
worker, you know?" Similarly, Nicole said that women need to 'humble themselves to the situation'. She explained that lack of humility prevents collaboration, which she identified as essential too, yet lacking, in women's reintegration success.

I find especially with women we don't really like, you know, because we don't want to be wrong. We don't want to show that weakness because again, in a way, men are stronger than I am, right? There's a lot of, and it sounds very stereotypical, but there's a lot of stereotypes when it comes to that, but yeah, we don't want to be that weaker sex. So like, we end up hurting each other and hurting ourselves in the process, right? It sucks.

Nicole's suggestion that women do not want to show weakness resonates with Susan's assessment of women over-compensating for insecurities and appearing too brash. Nicole recognized that her references to women as the 'weaker sex' draw upon harmful stereotypes, but she implied that such stereotypes still inform the world around her. A petite woman with a soft voice, Nicole grew up with a single mom in an impoverished, rough neighbourhood of Toronto. Her reflections on women's fear of showing weakness is likely deeply rooted in her personal experiences. Yet she suggested that women's fear of being weak, or showing weakness, leads them to tear one another down. The interview with Nicole stood out as being one that most directly called for women's solidarity and collective action. While many women articulated their own strengths and skills, and often claimed to be different from other women at the halfway house who were 'lazy', Nicole called on women to be willing to show weakness and support one another.

Reintegrating women are consistently exposed to narratives that emphasize the moral imperative to strengthen their internal aptitudes. They are encouraged to participate in various 
programs or activities in order to improve their confidence. Through these programs, and in the dominant psy discourses propagated through women's magazines, books, and talk shows, they are presented with certain terms, such as confidence and self-esteem, with which to articulate and make sense of their experience. However, even if reintegrating women and service providers both express narratives of confidence, these narratives may serve different purposes. For service providers, such narratives support the responsibilization of women for their own empowerment. Reintegration programming and services seek to promote and bolster women's confidence so they will be empowered to assume the roles prescribed to them, roles which would demonstrate they are 'productive' members of society. Confidence building and empowerment are a means toward an end, an end which is firmly rooted in capitalist conceptions of social belonging. Some reintegrating women, like Srila and Chantell, also suggested that confidence, as a capacity to persist against the odds and withstand the inevitable setbacks, is important in finding employment and can be a means toward a reintegration goal. However, for other women, the role of confidence, as an ability to stand in the face of adversity, may be less about persisting toward goals of employability and success, and more about protecting themselves from pain and rejection, and resisting the subject position of a broken woman. As Holly suggested, confidence may be able to protect her from the 'hurt' of being turned down. ${ }^{49}$ Similarly, Janessa's boisterous claims to confidence were not done to tell me that she should be employed (as will be explored in the next chapter, she did not want a job right now), but rather to demonstrate that she was not

\footnotetext{
${ }^{49}$ This interpretation, of confidence being for service providers a means toward the tangible goal of employment and successful reintegration, and for criminalized women as an increased capacity to withstand adversity, is in direct contrast to Amnon Boehm and Lee Staples' (2002) comparative investigation of empowerment by social workers and consumers in which they found that consumers emphasized direct outcomes, such as economic independence, while social workers emphasized behavioural and attitudinal change.
} 
incapable. Her expressions of confidence can be read as a claim to being un-broken, like Andy's claim to be a survivor. As will be explored below, the dominant psy discourses of mental illness, disorder and addiction communicate to reintegrating women that they lack the very qualities needed to resist and persist. Claims to confidence may thus be an important part of the resistance to this narrative.

\section{"SO BROKEN": MENTAL ILLNESS AND ADDICTIONS}

"Other than the basic criminal record and lack of motivation and criminal history," said Sheila, "the mental illness, that piece is pretty high." This comment is representative of the perspective frequently expressed by service providers. Mental illness was not the first barrier mentioned in the interviews, but it inevitably came up, sometimes in a tone that suggested 'of course' there is mental illness, as if it were a given that all reintegrating women have some form of such illness. There was also the suggestion that those with mental illness are unable to manage the demands of obtaining and maintaining employment (F. Williams et al. 2008; Hartwell 2001). The frequent references to women's emotional and mental 'illnesses', and 'challenges' also fits into the narrative of reintegrating women not being work 'ready'. As noted above, this was attributed in part to a lack of confidence. But as service providers discussed women's mental, emotional, and addiction-related challenges, a figuration of a broken psy woman emerges. Is such a figure ever really employable? How does the characterization of this figure complicate the work that service providers are trying to do in providing reintegrating women with employment support?

Heather described women's mental health as "a whole other can of worms", a metaphor that suggests something tangled and unappealing. She said a lot of the women at her house have 
"mental health issues", with everything from "simple social anxieties versus, uh, schizophrenia, personality disorders. Like we have them all." She asked, "How do you manage that? How do you help them?" She did not directly answer these questions, but followed them by resignedly stating that "mental health is huge,", suggesting it has no obvious solution. Jessica, who also had experience managing a halfway house for women, mentioned diagnoses common to residents included Fetal Alcohol Syndrome and Attention Deficit Hyperactivity Disorder (ADHD). "These women are so broken half the time that they end up really not having a future oriented outlook on life," she said, implying that mental illness has severely incapacitated reintegrating women. The figure of the broken psy woman is clearly discouraging to these service providers. Similarly, Susan suggested that reintegrating women were often difficult to help. She described women as "needy" and said, in her experience, women focus on their "sexuality" and they "tend to hook into relationships quite quickly." They spent more effort on trying to find a male partner or retuning to "toxic relationships" than they did in finding employment. She attributed this to their "co-dependent type of mentality." Women's emphasis on finding a partner could be framed as part of the dominant 'heterosexual matrix' (Butler 1990) within which men are providers and women are in need of their protection and support. It can also be framed as a practical response to the high cost of living in Ontario's urban centres. Indeed, Susan acknowledged that it is next to impossible to find a place to rent on a single-earner, minimum-wage income. Yet framing women's pursuit of a relationship as an indicator of mental unwellness disengages the narrative of women's reintegration from these gendered and structural constraints, while reifying narratives of individual pathology. It also suggests that the mentally healthy woman is an independent woman, a woman unfettered by romantic ties and dependency upon others, especially men (McKim 2017). 
Susan's reference to co-dependence is indicative of the use of psy terms to characterize reintegrating women, and to explain their actions, or lack of (appropriate) agency. Similarly, Sheila suggested reintegrating women were dealing with "mental health issues that may or may not have been diagnosed, but it impacts their ability to hold a job." For her, these issues were evidenced by women's lack of "that whole community-functioning skill." In other words, women's behaviours are presented as evidence of a psy diagnosis, even if that diagnosis was never made. Diagnoses of mental illness have been criticized as being based on androcentric, middle-class norms (Ussher 2005) and gendered psychiatric theories, practices, and discourses (Chesler 1972). Yet what is notable here is that women's struggles to reintegrate after periods of incarceration, which could be characterized in a variety of ways, are described within the script of psy disorders. Sered and Norton-Shaw $(2014,95)$ draw attention to the influence of 'poppsychology' on narratives directed toward reintegrating women. Such narratives connect suffering with unresolved trauma, emotional weakness and character flaws, individual deficits which should be addressed through therapy and medication. The dominant message of such narratives is that "a person who experiences abuse, poverty, homelessness, incarceration, or even illness is likely to feel that there is something wrong with her, not with society" (ibid.). In other words, the focus on women's mental health/illness bolsters the responsibilizing technologies of governance that work on the individual self, while obscuring structural, racial, gendered, and class inequalities and injustices. As Kendall points out, "by insisting that the problem of crime inheres in cognitive deficits, the focus of intervention remains at the level of the individual. Thus social inequalities and oppressions need not be addressed" (2002, 197; see also McKim 2017).

Jessica indicated the impacts of poverty and marginalization at the level of the individual when she referenced the "social determinants of health". The social determinants of health are 
conditions in which people live that affect their quality of health, including life expectancy and their likelihood of developing cardiovascular disease, experiencing affliction and injuries, and obtaining educational and employment success (Mikkonen and Raphael 2010). Jessica also explained that those experiencing poverty and lack of stable employment, are "more likely to suffer from a mental health issue." She added that mental illness and criminalization ages people. "A person with a mental health issue or who has come in contact with the law and is actually forty [years-old] is like a fifty-year-old in terms of their physical nature." Haggard skin, limp hair, missing teeth, stained fingers, and faded tattoos were some of the markers visible on reintegrating women that made them seem older than their years and that could be read as negative 'stigma symbols' (Goffman 1963). In other words, social determinants of health have bodily and material manifestations. Yet consistent with the pervasive discourse of mental illness, Jessica emphasized how these determinants manifest in 'mental health issues.'

Jeff's narrative about reintegrating adults stood out from other service providers I interviewed because he referenced a type of discourse that differed from the psy and therapeutic language the others employed. Throughout the interview, he described his views on meditation, enlightenment and other alternative approaches to self-development. For example, he advocated for a 'shifting of consciousness' achieved by adopting positive behaviours and mindsets and using 'other technologies.' These technologies, which he said were more effective than cognitive behavioral therapy (the model employed by CSC), included using 'plants' to assist in cognitive shifts. "We're all suffering," he said. "Everyone suffers." He went on to argue that helping others begins with one's own enlightenment. "We're asking what's the solution for someone else? We should be really asking like what am I doing to become enlightened?” After achieving selfunderstanding, Jeff said then "you'll be able to really help people, others, the ocean, the dolphin, 
the homeless child, the refugee, the person with a criminal record." Jeff noted that he had not come into his role of working with reintegrating adults through the same route that most others take. Over half of the service providers I interviewed had degrees in criminology, psychology, or education. They also worked primarily with those trained in sociology and social work. These are fields in which the psy narratives of mental health/illness are well-established. Jeff's background was business and sales, but his perspectives on personal development were influenced from his studies in yoga, meditation and alternative philosophies. While his narrative is an outlier in terms of the lack of engagement with psy discourses, it serves here to illustrate that there are other possible discourses that service providers could draw upon to articulate the internal challenges reintegrating women face, and the proposed solutions to these challenges. Reflecting on Jeff's views prompted me to wonder what narratives I might have heard if, for example, I had interviewed prison chaplains. They may have articulated a spiritual dimension of women's experiences and possibilities that was absent in the narratives of service providers. Or what if the service providers I had interviewed were from non-Western countries and had experience with narratives that emphasized familial and communal connections, or Indigenous healers who might have used notions of the 'soul wound' to include colonial and collective trauma (Duran, Duran, and Yellow Horse Brave Heart 1999). ${ }^{50}$ Imagining alternative characterizations of women's internal challenges can be a reminder that the dominant psy discourse is politically, culturally, and historically located.

\footnotetext{
${ }^{50}$ One of the gaps in my project is that I was unable to interview a service provider from an Indigenous women's organization. Although I reached out to several such organizations, I was unsuccessful in finding someone willing to be interviewed. This is unfortunate since an Indigenous service provider may have offered some alternative discourses, such as regarding connections to cultural and spiritual traditions, which was lacking among in the interviews I conducted.
} 
When service providers critically engaged with the discourse of women as mentally ill, it was in reference to the connection between 'mental illness' and past experiences of trauma, which is consistent with the feminist approach to women's mental and emotional needs that was noted above. "Most of these women are victims," Heather said. Similarly, Jessica noted that among reintegrating women, there were "extensive histories of physical, sexual, and emotional violence that have happened in their lifetimes or they've seen it happen to their family members or their parents." Indeed, a recent report based on analysis of thirty years of studies about the prevalence of childhood abuse and neglect reported among Canada's incarcerated population found that women experienced significant levels of child abuse (65.7 percent) and sexual abuse (50.4 percent), as well as neglect, physical and emotional abuse (Bodkin et al. 2019, e1).

Service providers also recognized that women's experiences of trauma have deep roots. Jessica mentioned inter-generational trauma, such as for those whose parents had experienced Residential Schools. Others talked about negative childhood experiences. "They were very often abused and neglected themselves," Susan said. "So they didn't have the nurturing, the parenting, that would have set them up for success." She also referenced more recent experiences relating to incarceration and separation from children, something she poignantly described as "the disappointment, the anguish, dealing with the unknown, the uncertainty and the loss of control and power, as a result of their children being given over to the system." As such, service providers emphasized women's lived experience over their psy diagnoses, or at least suggested that the latter stemmed from the former. This contrasts with accounts of the 'medicalization' of women's conditions and behaviour described by researchers in other contexts, such as Kilty's (2014a, 2012) examination of federal institutions. It also suggests that even if service providers accept and contribute to the characterization of reintegrating women as broken psy subjects, they 
seek to place this subjectivity within its socio-structural context. Yet even though they reference women's social problems, their focus comes back to the individual's experience of these problems, and their "present-day symptomatology" (Duran, Duran, and Yellow Horse Brave Heart 1999). Central to this symptomatology is addiction and drug use.

\section{Addiction comes from inside}

It is difficult to talk about reintegrating women without addressing addictions. Patricia told me most of the women she worked with got involved in the criminal justice system "because of addictions". Canadian research suggests approximately eight of ten women in federal custody have histories of drug and alcohol abuse (Sapers 2014, 46) and almost one third of federally sentenced women have a drug-related conviction (McConnell et al. 2014, 12). As Joan wryly remarked, when you get too old to sell your body, you turn to selling drugs. While statistics on provincially incarcerated women are much harder to find, service providers indicate that most provincially sentenced women have crimes related to addictions. Their crimes may be for theft under $\$ 5,000$, break and enter, possession, or other charges that may relate to the purchase and use of drugs.

The dominant model of addiction treatment views addiction as a disease (Reinarman 2013). As such, addiction should be 'treated'. Yet when it comes to the treatment of reintegrating, addicted women, Allison McKim (2017) suggests there is a melding of discourses referencing disease with those suggesting addiction is an individual responsibility. She found that staff at American penal addictions treatment centers considered women to be suffering primarily from low self-esteem, drawing the addiction treatment focus away from 'disease' and back to internal characteristics and personal responsibility. Kate McCoy, a researcher of access to health care by 
those who use drugs, also notes that addiction is commonly framed as "essentially a selfindulgent, voluntary behavior for which individuals should take personal responsibility" (McCoy 2010). Service providers I interviewed did not suggest women's drug use was indulgent, rather they linked it to efforts to cope with past experiences of trauma and the challenges of reintegration. "Because of the trauma, um they have a tendency to not be able to cope with emotions that are really strong," Jessica said. "So like what ends up happening is they bury it down and then they use drugs to cope with it." Susan also referred to drug use as 'selfmedication' and suggested incarceration and loss of children were some of the triggers. "What's driving it is very often lifestyle, addictions, so that's a big mess," she said. Like Heather's metaphor of mental illness as a can of worms, service providers described addiction as a 'mess' that was impossible to untangle.

Heather estimated that ninety percent of the women in her halfway house had "some sort of substance issue." She said that not only do women with addictions often end up back in prison for violations, but employment moves to the "back burner" as they focus either on fighting or feeding their addiction. Elena echoed Heather's representation of most of the women coming out of provincial custody to the halfway house as struggling with addiction. "I find with the provincials, jobs are not necessarily number one on the [priority] list because they're trying to get them to stay clean and focus on their relapse prevention plan." Obtaining and maintaining employment while actively using drugs is a challenge not many women can manage. Lin relayed a story of a woman she had met on the inside who died of an overdose in the community after her release. "She left the halfway house after six months. Within two weeks, um, she OD'd at a hotel room. She was twenty-four." Lin said this woman had "done all the programs" inside, but Lin saw her death as one of the "failures of the system because she wasn't ready." By placing 
responsibility for this young woman's death on the correctional system that failed to adequately prepare her for release, Lin was echoing critiques, such as from Indigenous feminists, who call for greater accountability for responsibilities of CSC and other governing institutions (MontureAngus 2000).

When I asked Elena and Heather for stories about women who had been able to find work, some of their 'success stories' ended with women relapsing and being sent back to prison. Elena added that women who are still struggling with addiction will be tempted to spend any new income on drugs, which can quickly derail their employment and lead to re-incarceration. Jessica was one of the few service providers who talked about drug and alcohol addiction in terms that suggested lack of judgment and criticism (such as referring to 'substance use' and 'selfmedication' rather than 'drug abuse'). However, she still noted that "organizing your life enough to get to a job and keep it while, when you're a substance user is particularly hard." She added that some people are able to manage it, but that it certainly adds to their challenges.

The ability of reintegrating women to handle the challenge of over-coming addiction and finding and maintaining employment seemed to be considered by service providers like Elena and Heather as more than most women could handle. Elena talked about one of the women staying at the halfway house.

I've had her working on programming, like relapse prevention plans and the things that she needs to do to get herself basically committed to staying clean and on the right track before she is able to go look for a job. And I wouldn't say that she should go out and get a job now. And those are the things that she needs to work towards so that when she does go out, she's ready. As opposed to saying, yeah, yeah sure, go. And then something happens in the meantime and now you 
can't take those back. And that could basically you know send her out for a job now. She's not stable enough, put her right back into Vanier, right? So it's those things we want to avoid."

One of the driving questions for this research project was what makes reintegrating women 'employable'. Elena's discussion of this women illustrates a perception that substance addicted women are not employable. Elena insisted that this woman needs to learn to manage her addiction and be 'committed' to living without drugs. Hannah-Moffat and Turnbull have described parole conditions (such as not using drugs) as being designed to help prepare individuals for 'freedom' by mobilizing particular techniques of self-governance (such as resisting the temptation to buy and use drugs), while simultaneously serving as modes of surveillance $(2009,533)$. As such, conditions such as abstaining from drugs and also demonstrating a 'commitment' to staying clean, can be understood as targeted governance of risk (Hannah-Moffat 2004; Valverde and Mopas 2004; Werth 2012). Women are expected to demonstrate a commitment to responsible, autonomous self-governance, and must do so before they will be recognized as capable of setting out on the path to social and economic participation.

While service providers generally described women as broken and needy, emotionally and mentally unwell, there were occasional references to women's internal strengths. For example, Susan said "they're survivors, right?" using a term associated with women's experience of sexual abuse and intimate partner violence (Hoff 1990; Bass and Davis 1994). Jeff also indicated that women had survived adversity. "I think we need to recognize the skills that they have," he said. "If they've survived, given the fact that they've been abused and criminalized, and the fact that they're still living is like a miracle. It shows how gritty and resilient they are." Maria described the women she worked with as strong, resourceful, and able to handle extremely stressful 
situations. Similarly, Jessica said, "There were women who were very strong, resilient." While these articulations of women's strength and resilience were encouraging to hear, as I will explore in the next chapter, such discussions of women's success still emphasized individual responsibility. However, it does indicate that while the broken psy figure is omnipresent in discourses about reintegrating women, service providers expressed varying degrees of resistance to this characterization. As might be expected, it is in the narratives of reintegrating women that resistance is expressed more clearly and urgently.

\section{RESISTING THE BROKEN PSY WOMAN}

One of the last questions in my interviews with reintegrating women was whether they had any disabilities. Eight women identified a disability relating to mental illness, such as being 'bipolar' or having learning disabilities, depression, anxiety, or just general 'mental illness'. Ashley hedged her answer, saying, "Not really. No, just like overcoming like the transition process, you know?" She explained that she had so much fear when she came out, and dealing with this fear has been an on-going struggle. She did not use psy words such as 'depression' and 'anxiety' during our conversation, but instead chose words such as being 'overwhelmed' and 'afraid'. The choice of vocabulary to describe emotions can be seen as resistance to dominant psy discourses and to the carceral context in which women are quickly labeled with various 'mental illnesses.' Zahra said she had PTSD, anxiety and depression, but added that she did not consider any of these to be disabilities. Similarly, Nicole, who was one of two who identified having a bi-polar diagnosis, resisted the label of disability. "Mental health issues or any type of disability or obstacle, they're all obstacles," she said. "I mean it's how you're gonna take care of them." By replacing disability with obstacle, Nicole's choice of terms suggests a shift in the location of this 
'issue', focusing less on how it characterizes the self and more on how it is external to the self. It is, as Nicole indicates, something that can be overcome. As noted, psy discourses are pervasive in characterizations of criminalized women, and pop-psychology is the vernacular which women have learned to make sense of the emotional and mental experiences. Yet as their narratives suggest, even while they employ such language to discuss their experiences, they find ways to push against the ways in which narratives of disability and disorder are wedded to their identities.

Kilty notes how the 'distress' incarcerated women experience due to experiences like homelessness, poverty, violence, and drug and alcohol use are "conceptualized by psy vocabulary as depression and anxiety" $(2012,164)$. Yet the use of these terms is indicative of one of the "conundrums facing feminist critics" of psy discourses and pathologies, namely how to critique social constructions of pathology and inappropriate interpretations of women's symptomatology while recognizing that individual women find significant meaning, reassurance, and benefit in mental health 'treatments' (Ussher 2005, 30). As Mary Brown Parlee notes, "what is strategically difficult for feminists, is that many women now derive genuine benefits in their personal lives from an ideology that functions to explain and obscure social contradictions in their lives and those of other women" $(1989,20)$. Indeed, the vocabulary of depression and anxiety was frequently used by reintegrating women in describing their emotions and their experiences inside prison and after their release. Several indicated that they had benefitted by learning what these terms mean, and how they relate to their own experiences.

Andy and Joan told me about periods of time during which they were unable to get out of bed for days or weeks on end. "I stayed in bed, didn't shower, didn't brush my teeth. It was horrifying" said Joan, "That was depression." Naming this period as depression is perhaps 
explanatory for Joan, a way to make sense of what she was experiencing in the language available to her. Indeed, other women indicated that exposure to terms such as 'depression' and 'anxiety' was helpful in gaining insight and coping strategies. Donisha said that until recently, she did not know what 'anxiety' meant, or how this term could be used to describe her postcarceral experiences. She described the panic she felt whenever she heard a police siren. She talked about waking up covered in sweat, her heart racing. Confused by what she was experiencing, Donisha went to a doctor and described her symptoms. When she was told she was experiencing anxiety, Donisha replied, "What the hell is that?" But based upon the information her doctor gave her, and the reading she had subsequently done to inform herself, Donisha indicated she is not only more informed, but aware of the impact anxiety can have.

Anxiety is a big thing. I did not know it was this real until, until jail, right? Until prison, like I did not know it was this serious. I didn't know it was like, that big. So, that's another thing. Anxiety. I don't even know what to call that. I don't know if that's a disability, or a mental illness, or like, cuz it just does so much to you, right?

Like Nicole, Donisha was hesitant to say if this is a disability but, in a way, she suggested it does not matter what we call it. It just needs to be recognized for its impacts. She also insisted that more should be done to help reintegrating women, especially in terms of helping them understand what they are experiencing.

It really needs to be addressed. It really does. That's a big, and a lot of people don't even know it's anxiety, right? They just think they're crazy. They just think, oh my gosh, jail just did me dirty. And like now I can't move on with my life cuz 
I'm just so, um, you know, scarred, right? But, it's anxiety. And it can be helped.

It could be you know, it can, you can work with it, right?

Donisha's experience suggests that by receiving a 'diagnosis' from a doctor, a label to give to her physical, mental, and emotional symptoms, she felt empowered to act. Without this language, Donisha suggested that she might have just thought she was irreparably 'crazy', permanently broken. But by framing her experience as anxiety, it became a problem with a name, something that could be addressed and overcome. She found ways to 'work with it' and described strategies such as positive thinking and checking negative thought patterns.

Holly also suggested she had benefited from learning about her emotions. "So I do know the anxiety right now is, is, um worrying about the future, about things that haven't happened yet," she said. "Depression is about things that have already happened, and anxiety is about things that haven't happened. So that's something that I learned." She gave me an example of how this new understanding helped with her job. She had recently started work as a housekeeper in a small inn. She found out one evening that the next day she would be working alone. Nervous about her abilities to perform unfamiliar tasks without the guidance of her experienced co-worker, Holly felt herself starting to panic. But she was able to calm herself, "I said to myself, ah, just you know, it's not that big of a thing. Just go do it." Despite her anxiety keeping her awake most of the night, Holly still showed up at work in the morning, where she was relieved to discover that she had a co-worker on her shift after all. "Before I wouldn't have went," she said. "I would have called in sick, or I would have quit my job." This clearly illustrates not only how anxiety impacts women's attempts to start fresh in new and unfamiliar environments, but also how Holly had benefited from the self-understanding she had gained in treatment, and ways she had learned to acknowledge, and manage, her fear. She credited the recovery program she had completed for 
this new ability to cope. Yet the 'insights' Holly gained through her recovery programs seem to have encouraged her to focus on the internal experience and emotions as the source of her problems. "There's everything inside us that makes us addicts, right?” she said. This is consistent with analysis of penal rehabilitation programs which, unable to change the structures and situations that disadvantage reintegrating women, focus on changing "women's flawed selves" (McKim 2017, 169).

Holly's narrative differs from others like Nicole and Donisha who suggested emotional and mental struggles were imposed or quasi-external. Indeed, while it is clear that learning about psy vocabulary can provide women with tools to frame and address their experiences, reintegrating women also expressed resistance to the ways in which their troubles were diagnosed and addressed. For example, Tina's critique of the management of women through medication touches upon several key criticisms of psy interventions.

A lot of the women inside shouldn't be under that criteria of mental health, you know? They, you know one day you see them and they're good to go, you know, spunky and then two weeks later they're either they're on methadone or they're on prescription meds that the psychiatrist prescribes. Okay. So, I said I'm totally against that. and because that kills your spirit. Anything that you put in your body, minimizes your spirit to motivate. And that, it's a control thing. You know?

Not only does Tina poignantly describe the dulling effect of prescribed addiction and psychiatric medication, but she draws the link to the control and governance of women. She also suggested that CSC was quick to put a label on everyone, casting women either as "mental health" or "addict". The use of psychiatric medication is the dominant form of psy intervention in prisons, due to various factors including shortage of resources for other interventions (such as 
counselling, group programming) and the medicalization of carceral responses to 'deviance' (Kilty 2012; Ussher 2005). Donisha gave a vivid description of how prison staff respond to women's self-identified needs with medication.

And there [in prison], they only want to give you drugs! Right? They only want to give you like sleeping pills and like anti-depressants. And like, like, that stuff does not help. Cuz it has nothing to do with, it's not a sickness. It's not a sickness. It's not like, it's not like um, like a cold, like you know, that's how they treat it. ... Like it's crazy. Like they just want to give you, oh you have anxiety, oh here take anti-depressants. And then since you take anti-depressants, you need to take this. But now since you take that, you need to take sleeping pills, because it's not gonna make you sleep. Now you take sleeping pills, you have to be on. You know, they just want to keep giving you more drugs, and more drugs, and more drugs.

Donisha went on to say that if she told staff she had a headache or menstrual cramps, she would be offered a Percocet. "Whoa!" she said with a laugh, acting out her reaction. "I just need Tylenol or something. You know what? I don't need it. You know what? I'm fine. I'm fine. I'm fine. I'm fine. I'll just go drink some chamomile and put like a hot rag or something. I'm fine, I don't need that stuff." Both Donisha and Tina describe their resistance to being encouraged to take medication, and both suggest that CSC has it wrong when they attempt to treat women's complex problems with pills. Donisha's account also corresponds with research showing that in federal prison, women are prescribed on average 4.4 different medications (Langer et al. 2002). It is also notable how Donisha pushed back against medicalization by insisting that the emotions she was experiencing were not "a sickness". Just as she expressed hesitation about whether 
anxiety was a disability or mental illness, she was resisting ways in which experiences were framed as characteristics of the self, as illness and disorder.

\section{"Do it on your own. But you're messed up."}

Nicole also expressed frustration with the emphasis within prisons on addictions and mental illness. "There's all this big huff over like, you know, drugs and addiction," she said. She noted how the limited programming available to incarcerated women, and to women in the community, focuses primarily on addictions, anger management, and therapeutic care. Such emphases are shored up by the characterization of criminalized women as broken psy figures, angry and depressed addicts. "We could benefit from more than just what triggers us," she said. Not many reintegrating women discussed their drug and alcohol addiction with me, although a few indicated that they had recently been sent back for a short stint in jail because they had been caught using drugs. Tina said there had been drugs in her past, but that now she was living clean. Holly told me she had "gotten into drugs" in the past, but now was finding new things to focus on, such as healthy eating. "When I went to prison, I wasn't doing drugs anymore and [nutrition] was a new part of my life," she said. "So it's, my diet has become my thing I think a lot of about." Holly said nutrition, work, and family were her new priorities. This identification of new, healthy priorities can be understood as part of the "redemption script" that former inmates construct as part of their post-carceral identity (Maruna 2001, 86).

Andy was an exception among my research participants in that they spoke frankly of their struggles with drugs. But Andy also framed this struggle as a story of redemption and success. Andy spent more than half of their thirty-seven years addicted to drugs, living on the streets and 
cycling in and out of jail. Now, living sober for close to a year, Andy is trying to turn their life around and find employment.

I'm trying to kind of rebuild myself so I don't fall back in those patterns of behaviour. I'm trying to acknowledge like my struggles, my triggers, my issues so I can attack them, and one at a time. And I'm trying to be successful and for me this and that is like okay, I've been, 'scuse the language, but a fuck up all my life.

Andy was proud of how far they had come, but repeatedly referenced having struggled very hard to get to the place they were. As noted above in the discussion of 'working on self', Andy mentioned the 'work' they had done to address addiction. Holly also said that that she had "worked on" herself as part of her recovery. This mobilization of the language of work, particularly in relation to addressing addiction, indicates not only the individual responsibilization, but also the mobilization of work's associated characteristics such as effort and diligence. Andy's emphasis on personal effort and strength may also be indicative of the discourse available to describe the process for dealing with addiction. But Andy's emphasis on 'work' and 'strength' was also reflected in their choice of the word 'survivor'. "I broke free," Andy said, referring to their drug addiction and street life. "I was in too deep, I climbed out and here I am. I'm a survivor and now I'm trying to survive, just trying to heal inside, you know, spiritually, mentally, physically, just trying to heal and push myself forward." Similarly, Tina used the term survivor to describe herself, and to tie her survival to resistance to colonial oppression. "I'm a survivor," she said. "I'm not a victim. I said you could make it your choice. Either you want to be a victim and stay there, or you want to survive. You're a survivor. Hey, I'm Native. You know? And I said, it's really resilience, you know?' 
Words like 'survivor' celebrate strength and resilience, but also personal responsibility and effort. By talking about the work they did on themselves, women indicated that they were acting out the responsibility to improve themselves. Assuming responsibility can also involve recognizing past experiences and influences, the 'triggers', and the trauma. As indicated in the narratives of service providers, the use of drugs and alcohol is often framed as a response to experiences of violence and abuse. In other words, the women who must assume responsibility for their actions, and their emotions, are also the victimized, broken women who have developed psychologically dependent selves (McKim 2017). I did not ask women about their past experiences of trauma, just as I did not ask them to tell me about their convictions or their 'pathways to crime'. But some participants mentioned past experiences, such as in the context of describing the lifetime of struggles from which they were now seeking alternatives. For example, Andy said their father had 'beat her up' for most of her young life. "He kicked me in the head at seven-years-old with steel-toed boots. He caused some permanent damage," Andy said. "I've had many blows to my head." Research indicates that childhood-acquired brain injury causes severe cognitive and behavioural disorders, and is associated with violent behaviours (LefèvreDognin et al. 2015) and a study of prisoners in Ontario found that thirty-eight percent of women had experienced a traumatic brain injury (Colantonio et al. 2014). Research also indicates that childhood trauma contributes to mental and physical illness (Everett and Gallop 2001; Mock and Arai 2011) as well as depression, risky behaviours, substance abuse, and other self-harming patterns (Sered and Norton-Hawk 2014).

Zahra also mentioned that she grew up with "a lot of abuse." She said that her dad "had a really bad anger issues and he would take it out on us." A daughter of immigrants, she was engaged at the age of fifteen and was married at eighteen. Her husband also controlled and 
abused her. When she tried to go back to school after having kids, he beat her so badly that he broke her nose. She spent years trapped in this marriage, taking care of her husband and her kids. It was only after she was incarcerated that she sought psychiatric help for what she began to identify as "depression, anxiety, PTSD". Zahra told me about anxiety she felt about her children and the loss of control she had over their well-being, grief over death of family members, and other emotions and circumstances she struggled to deal with while confined at GVI. "I actually got a razor blade, broke it. Two, three times I did that," she said. "I was just dying inside. I couldn't, I was, I so wanted to slash myself so bad." Zahra recognized that she was a risk to herself. "I went to the guard station and said I need help right now," she said. "I'm like I need to see somebody right now. I'm gonna do something to myself." She was taken to a closely supervised unit and was able to talk with a therapist for several hours. She said this calmed her down and allowed her to 'vent'. She also recognized that this willingness to seek help, and then talk about what she was experiencing, was very different from her previous patterns where said she would have 'locked herself up with her misery'.

Zahra's story indicates the tension mentioned above. While it is important to critically examine governance and treatment of reintegrating women, and to challenge discourses that label women as disordered, deviant and ill, the alternative is not to do nothing, or to suggest all treatment is harmful and that interventions are not at time necessary. Zahra's story also recalled for me Donisha's description of prison as "one of the hardest, the lowest points in someone's life," a time during which she saw other inmates self-harming and not knowing how to "deal with' overwhelming pain and anxiety. Yet while Zahra said that she was helped by the prison staff, she pushed back against the diagnosis she was given. As noted above, she rejected the suggestion that depression, anxiety and PTSD were disabilities. She also pushed back against 
internalization of these diagnoses. "I don't think of myself as crazy," she said. "I just think I needed help at the time. I just needed to vent and take stuff out of my system.”

Reintegrating women were often quite frank about the help they needed, not just for practical employment related supports, but also in terms of coping with the challenges of transitioning from prison. Ashley said several times that she needed someone to 'hold her hand' and accompany her through difficult times. She was vehement in her rejection of the individual responsibilization discourse which, she insisted, does nothing to actually help women.

You're a number. You're an inmate. You're a prisoner. Like they're very negative words that is not rehabilitative at all. So that bullshit word [rehabilitation], in court when they sentence you or convict you, whatever, there's no rehabilitation in prison, okay? The only rehabilitation that you may find is what you give yourself... Like it's hard to get someone to understand what being locked up behind walls, to not see civilization day after day, month after month, year after year, does to a person, okay? It's messed up. Psychologically, it changes you as a person. It's really sad.

Ashley went on to express her frustration with the call to fix herself, and the pressure she felt from family to put her past behind her. "You really need to get your life together," she said they tell her. But when she asks for help, she says she is told "No, do it on your own. But you're messed up." Ashley identified the dual message of 'do it on your own' (fix yourself, heal yourself) and 'you're messed up' (you're broken, beyond saving). It is this irreconcilable duality, the mobilization of responsibilizing governance strategies upon the subjectivity of the broken, disempowered woman, that I believe frustrates both reintegrating women and service providers. 


\section{EMPOWERING THE DISEMPOWERED}

The mobilization of empowerment discourses, which had been intended to address the unique needs of incarcerated women (see TFFSW 1990), has served to construct and then entrench a subjectivity of criminalized women as needy and emotional, a broken woman. Service providers were willing and ready to acknowledge women's past experiences of trauma and marginalization, and their on-going emotional and mental struggles, yet the empowerment discourses and disciplinary practices of responsibilization through which these needs and experiences are understood create a subject position for women that seems incapable of the autonomy, self-control and confidence to be empowered. As such, the persistent figuration of criminalized women is that of broken psy subjects who lack the ability to act in their own best interests. Trends in responsibilization have been associated with increased self-doubt and cynicism among criminal justice practitioners (Garland 1990, 1996), which corresponds with some of the pessimism and frustration I heard in the narratives of service providers. Repeated claims that reintegrating women lack motivation indicate the tenacity of the constructed broken psy subjectivity of criminalized women which paradoxically constructs women as both incapable of, yet responsible for, their own empowerment.

Within the narrative of empowerment and individual responsibility, it is up to individual reintegrating women to motivate themselves to overcome their past and make the right choices toward becoming a productive, contributing member of society. As noted in the previous chapter, service providers recognize that there is no simple 'right choice' to make when it comes to how and when to disclose the criminal record, but they insist that women must act toward their 'best interests', as empowered, independent and responsible women. But due to the dominance and persistence of the subjectivity of the broken psy woman, service providers consider reintegrating 
women as lacking the confidence, and mental and emotional wellness, to make this transition. Thus, their support for women is targeted at women's internal selves. Yet the context in which women receive this support, either within prisons through correctional programming or in the community after their release, is situated within a context of oppression and marginalization. Even while women are encouraged to take more control of their emotions and behaviours, their ability to influence others, and to influence the outcome of decisions that affect their lives, remains severely limited. Are not the promises of empowerment therefore illusory? Yet in keeping with the discourses of individual responsibilization, women are responsible for participating in - and even benefiting from - such support. How then are women to be motivated to actively participate in such supports, particularly if they realize it can offer few tangible rewards? What discourses are mobilized to encourage women to continue to exert effort to overcome both external and internal barriers to reintegration? In the following chapter I explore how work is positioned as a potential for identity formation and redemption. What are the possibilities, and limitations, of mobilizing employability as the alternative to the broken psy subjectivity? 


\section{Work as 'soul craft' and redemption}

In general, it is not the police or the threat of violence that force us to work, but rather a social system that ensures that working is the only way that most of us can meet our basic needs. ${ }^{51}$

- KATHI WeEKS, THE PROBLEM WITH WORK

Sheila is a senior parole officer with close to twenty years of experience in Corrections. When I interviewed her in her sunny, downtown office, she told me she was passionate about helping reintegrating women. She spoke confidently and rapidly, often referring to papers on her desk which had details such as logs of women's comings and goings from the local halfway house, or tables with statistics from the OMS (Offender Management System). She knew the research, having studied criminology, and worked in CSC national headquarters. She knew the multiple barriers reintegrating women face in finding employment; yet throughout our conversation, Sheila kept insisting that women were unable to find work because they lacked motivation. "When it comes to women and employment," she said, "sometimes you just can't make them motivated, instill that motivation." She linked lack of motivation to lack of confidence, self-esteem, job skills, and 'community functioning skills'. But she also attributed lack of motivation to a pattern of dependence on men and/or social assistance. She suggested reintegrating women just don't know "how good it actually feels to be able to work sometimes" because they have never done it. In general, Sheila suggested that more than skills, women need to learn the value of work. She most frequently used the word 'motivation', but used other terms such as 'work ethic', and even 'personality' to indicate this internal drive to succeed. Several times she suggested that employment programs are not all that valuable since women do not gain

${ }^{51}$ Weeks $(2002,7)$. 
motivation through them. In fact, as we discussed the nature of work ethic, she suggested it is not something that can be taught. All the reintegrating women who she identified as having found work, she also identified as having a 'work ethic', apparently something which they possessed before they got the job and which led them to seek employment.

Sheila's perspective, that reintegrating women generally lack motivation to find and maintain employment, was not uncommon among service providers. Yet I met reintegrating women who described themselves as highly motivated to find work. Like Sheila, Andy also had twenty years of experience in corrections, although for Andy, it was as someone who had cycled in and out of the provincial jails, halfway houses, and bail houses. Andy, who was in the process of gender transitioning from being Andrea, presented with a brash confidence. When we began talking in the immaculately-tidy living room of a bail house, Andy flopped back onto the couch and propped sneaker-clad feet up on the armrest. They immediately described themself as a gogetter, a survivor.

I'm going to make things happen. Not everybody has the same outlook or strength as me, or the wisdom or you know cuz, cuz like I'm from a hard place. And not many people have the strength to get out of that hard place. And I do.

Andy said that each day they worked to become a better person. They described themself as physically strong and not afraid to get their hands dirty, joking about past experience shoveling manure as testament that they will do just about any kind of job. "And I'm successful today, just for getting out of [my past]," Andy said. "Um, yes, all the things I've done have been amazing, that's great. And I want to continue to be successful, but I deserve a break too." I found poignant this comment that they 'deserves a break'. It recalled the title of Sered and Norton-Hawk's book, Can't Catch a Break: Gender, Jail, Drugs and the Limits of Personal Responsibility (2014), 
which documents the lives and struggles of forty women who had been incarcerated. Sered and Norton-Hawk critique the pervasive message of personal responsibility directed toward reintegrating women. Like them, I am concerned that the emphasis on individual choice, personality, and responsibility, which I heard frequently in the narratives of service providers, obscures structural and systemic marginalization. Yet as reintegrating women talked about the barriers they faced, they also emphasized the choices they made and their personal drive, as will be discussed, such as doggedly continuing to apply for jobs (Alexa), or putting up with unfulfilling manual labour (Andy) and a hazardous work environment (Joan). While they identified structural barriers such as the criminal record, and challenges such as a lack of employers willing to give them a chance, they clearly claimed their success as due to their own drive and work ethic. And yet, as Andy said, they "deserve a break too." This is an acknowledgement that personal drive is not enough, not when the odds are stacked so highly against them.

Both service providers and reintegrating women repeatedly spoke of the importance of motivation, work ethic, and drive. To understand this tension between structural constraints and personal responsibility, in this chapter I examine perspectives on work, first exploring how service providers describe employment success and failure, then how reintegrating women discuss work in relation to narratives of self and personal motivation. What does it mean to value work? Does work have the same value for service providers and reintegrating women? How do narratives about success, failure, drive, and work ethic, offer insight to the available subjectivities for reintegrating women? Work is held up through the discourses of service providers, and to some extent of reintegrating women, as a chance to craft a new soul and identity. Employment, and employability, are the means by which reintegrating women are 
expected to perform a certain redemption which would demonstrate their willingness and readiness to live in the community. But what does redemption look like? How does it act? How do you know if you have been redeemed?

\section{"WORK CHANGES YOU AS A PERSON, RIGHT?"}

Weeks has noted that labour is "often presented as the equivalent of a human essence, a universal creative potential from which we are estranged and to which we should be restored" $(1998,10)$. Similarly, André Gorz argues that labour exists in dominant discourses as a source of “'social ties', 'social cohesion', 'integration', 'socialization', 'personalization', 'personal identity' and meaning" $(1999,57)$. Yet Weeks and Gorz both point out that such claims of labour's value are being made at a time when people experience employment as insecure, intermittent, and unreliable. There are no guarantees that employment will integrate the worker into a community, or provide a foundation of stability from which individuals can economically, and socially, integrate into their communities. Similarly, Jock Young describes the supposed redemptive qualities of work as being able to "transform the underclass" by changing their attitudes, dependencies and "criminal tendencies", thereby transporting them into conventional, law abiding society $(2007,18)$. Yet he questions normative assumptions about employment by drawing attention to the low-wage, menial-employment sector within which the lower classes are caught. Women leaving prison typically "return (integrate) to the very same socially and economically disadvantaged locations that had brought them into 'conflict with the law' in the first place" (Maidment 2006, 10; see also Maruna 2011; Reynolds 2010). Upon leaving prison, women face systemic and gendered inequalities that have, and will continue, to exclude them from social integration. Yet they also face a normative script that places value upon labour and 
its pursuit. They are expected to exert exceptional effort to overcome multiple barriers to the labour market.

Upon release from prison, there are limited choices available to women about how they will demonstrate successful reintegration into their communities (Hannah-Moffat 2001). As mentioned in Chapter Three, women who return to the community after incarceration typically have two choices: get a job or go back to school (the aim of the latter also being employment). Some women may be allowed to apply for ODSP and social assistance, such as if they have a severely-limiting physical disability or if they are past the age of retirement. However, the average age of reintegrating women in this study was thirty-eight, which is similar to another Canadian study of women under federal supervision whose average age was thirty-nine (Delveaux, Blanchette, and Wickett 2005, 12), which suggests the majority of reintegrating women are considered to be of 'working age'. Since most cannot afford to pursue education, particularly full-time education, and since they require some source of income, they will choose employment. But this choice must be understood within the constrained context of parole obligations and financial need.

Working, or being trained to work, involves learning and embodying the 'sociological dimensions' of work roles, which include systems of belief and opinion organizing interpersonal relationships, worker subculture, and organizational contexts (Rothman 1987, 2). As already noted, most jobs available to reintegrating women are precarious and poorly-paid. This is a wellknown fact among both reintegrating women and the service providers who assist them. Yet most service providers I interviewed still expressed the expectation that women should find meaning and even a sense of identity through their work. They did not go so far as to suggest the actual labour that women perform (stocking shelves, washing dishes, changing bed linens, etc.) 
would be meaningful; rather, they mobilized broader narratives about independence, success markers, and contributions to the public good to indicate that by working, women would find meaning and fulfillment. As such, service providers side-stepped discussions about employment tasks in order to focus on employment's value. Work becomes a virtuous abstraction, bestowing blessings of meaning and purpose. Service providers under-emphasized practical activities of labour, while emphasizing work as its production of a particular subjectivity, namely that of a legally-employed, economically-independent woman.

Helen, an employment coordinator for reintegrating adults, suggested that even if a job was "not the most meaningful position for them... at least it's a start." She said she focuses on this long-term approach in her discussions about employment with reintegrating women. "We talk about just getting back into the routine and uh, it's a first step towards your long-term goal." In mobilizing this metaphor of steps, she suggests that employment is not simply an end in itself, but is part of a bigger plan. As such, she presented menial or mundane jobs, such as dishwashing, as opportunities to advance toward employment in which women would find meaning and a sense of purpose, in other words, toward a job with which women associate themselves and their identities. Employment as such is part of personal reformation and identity reconstruction. This framing of employment has a temporal aspect. The rewards are not immediate, or even immediately obvious, but will be attained over time.

Similarly, Susan said that work "gives us our, our step into adulthood, into you know, independence, into, you know, making it, developing our self-worth." The temporality of such promises requires a degree of faith on the part of reintegrating women, faith that the menial will become meaningful. Helen clearly believed in the transformative potential of enacting employment. "Work changes you as a person, right?" she said. "It gives you the financial means 
to be independent. It gives you the confidence. Like I do have a skill set. I am making a difference. I am productive, you know?" Helen was indicating that work has multiple values. It not only provides financial reward; it can increase confidence (which, as noted, is considered foundational to other attributes and potentialities), and offer a sense of accomplishment and productivity. Such descriptions of work's value have been historically mobilized to encourage the on-going labour participation of those whose material rewards are few (Lamont 2000). Jeff also indicated that work has more than monetary value.

Employment is an essential. When we see our work as soul craft, as our life purpose, employment is just like, it's a major component of what we are and who we are and what we do. It gives us a house. It gives us community. It takes up most of the time in our life, more than our family. It often becomes a surrogate family. ... It's so fundamental to the people's well-being. I understand it as fundamental to my well-being.

The notion of work as 'soul craft' and 'surrogate family' is telling of the extent to which Jeff identified with his job as the director of a social enterprise for reintegrating adults. His comments illustrate how work can be described as a vocation, almost like a religious calling that offers spiritual rewards. Susan also expressed beliefs about work that were almost of spiritual significance. She said that work is "everything”, adding "incarcerated and non-incarcerated. It's the most, you know, life-giving source to us, right?"

During our interview Jeff talked at length about both the satisfactions and challenges he had found in his role. As we discussed employability, he reflected on his own approach to labour, "I think work is really, good work, important work, heart-felt work, is so important for everyone. It's important for me. It certainly feels important to me. So, why wouldn't it be important to 
everyone else?" He also commented that it had been a privilege for him to work in this field. "What a great gift it's been for me to help evolve my own vision, and that's, in and of itself, has been amazing success," he said. "I've been so benefitted by being here." Yet even while he recognized the privileges he had in his job, and that he had been fortunate to find his work rewarding, his rhetorical question about 'why wouldn't it be important to everyone else?' implies that he assumed his own motivations and rewards are shared with those of different backgrounds, working in different types of jobs. Are the rewards of making pizzas or cleaning motel rooms likely to evolve women's visions or offer them a soul craft?

In her study of women working minimum wage jobs in America, Jennifer Johnson notes that, given the jobs available to marginalized women, "being paid to do intrinsically rewarding work - much less work you love - was thus another life condition most working-class women were denied" $(2002,97)$. She noted that when working-class women found meaning in their work, it was often the result of repeated efforts to find positive aspects to otherwise dreary tasks, such as by focusing on their positive relationships with co-workers or their chances to apply some creativity to particular tasks. In other words, when work is described as inherently valuable, meaningful and intrinsically beneficial, such descriptions are not necessarily attributable to the actual jobs reintegrating women are offered. Labour scholars like Johnson and Sered and Norton-Hawk (2014) point out that there are few opportunities for working class women to move into careers that offer such intrinsic reward.

Although service providers did not claim that reintegrating women would find intrinsically rewarding vocations, they consistently reiterated claims about work's inherent value. Jessica said that she had seen women in the halfway house she had managed benefitting from these intrinsic rewards. "Work, it was so fulfilling for them," she said. "They had a place to go to spend their 
time. They were making connections outside of their halfway house, they were making connections outside of working professionals. They felt like they had a purpose." I asked her if this applies to those who can only find minimum wage, menial work. "I think they still felt proud of themselves," she said. "Whether there's a sense of purpose in like low-paying, um, service jobs, I don't know. Some got that." Yet as she reflected on the value of work, Jessica noted that given the low wages many women were earning, "the pressure is to pay for things, like housing overweighs that, any purpose you feel."

Jessica noted that the financial pressures of trying to make ends meet on a minimum-wage job can be overwhelming. Similarly, Donna noted that women need to earn a living wage. "The majority of women's crime is related to poverty," she said. "So providing employment that actually provides a living wage would be a huge advantage to women's successful reintegration." Like others, she indicated that women who were unable to get by on their earning from formal employment would be tempted to return to illicit ways of earning money. Nonetheless, service providers like Maria, Helen, Sheila, Kim, Susan, and Patricia insisted that employment could make women independent, and that financial independence was key to helping women address other challenges in their lives. As such, an aspect of the encouragement of women to become employable subjects can be understood as involving a discouragement of dependence or reliance on the state. Sarah noted that there is a stigma associated with social assistance. "It's such a bad thing to be on social assistance," she said, describing what she considered to be a common perception. However, given that it was widely acknowledged that most jobs available to women pay only minimum wage, financial independence seems to be an unrealistic goal.

To further explore how service providers understood the value of employment, I asked them to tell me stories of women who were 'successful'. I was curious to know what kind of jobs 
reintegrating women were able to obtain, but more importantly, I wanted to explore how service providers described 'success', the factors contributing it, and the characteristics of women who achieved it. This was further explored by asking them to tell me a story about someone who had not been successful. How are women who were considered to be successful differentiated from those who were not?

\section{Grit, drive, and other 'determinants of success'}

As I have discussed throughout this work, service providers focused on individual attributes and characteristics when discussing women's employment and employability. The same is true when it comes to discussions of success, which was described as being only available to those

who truly sought it. Success will be found "if someone is determined to succeed," Jeff explained. "That's one of the biggest factors, is this grit." Grit, this elusive combination of passion and perseverance (Hodge, Hong, and Choi 2019; Duckworth 2016), is something that individuals must possess from the outset. It is an individual characteristic, and an individual responsibility to cultivate. As noted above, Sheila said that women were successful if they have "the work ethic and the desire to work." Similarly, when Maria told me about a woman who successfully found a job after months of search, she said this woman had "tenacity". Given the frequently expressed belief that success is attainable through the mobilization of tenacity and grit, it is not surprising that service providers praised women who they considered to demonstrate such qualities. Yet even while service providers emphasized these internal characteristics or aptitudes, when I probed the stories they told me, I found that women who were successful had often been given a significant degree of support. The support they received was exceptional, not in the sense that it 
was unwarranted or disproportionate to their need, but to the extent that such support did not seem available to all women equally.

Elena told me about a young woman who had been heavily drug addicted and ended up in jail. But this woman's mother worked in the field of mental health and understood addiction. When her daughter was released to the halfway house, she provided her with a great deal of support. This family support greatly contributed to the young woman's successful return to the community. Although Elena described some of the steps the young woman took, such as participating in programming and addictions treatment, Elena repeatedly mentioned her family situation, which indicated that it was a key factor in her success. It is not uncommon to find in reintegration literature references to family as key to reintegration success (Davis, Bahr, and Ward 2013; Petersilia 2003; Griffiths, Dandurand, and Murdoch 2007; Morenoff and Harding 2014). However, research that specifically looks at women's reintegration notes that families can be sites of abuse, stress, and negative influence (Maidment 2006; Solinger et al. 2010). Indeed, I frequently heard reference to harmful family dynamics in my interviews with both service providers and reintegrating women. For example, as discussed in the previous chapter, Zahra and Andy told me about parental abuse they had experienced in childhood. Lori mentioned that both her daughter and her husband were in prison, and also described her sister as an addict and added with a tone of resentment that she has “done a lot of crime too, but hasn't got caught for it and never gone to jail. So we don't, we don't really talk and get along." Such comments indicated that families should not be assumed to be sources of support for reintegrating women. Heather commented that at one point, she had "daughter, mother, grandmother, aunt, all in [her halfway house] at the same time. And it's like, no hope in hell sometimes for these girls, right?" She added that women with supportive families were 'anomalies'. It is likely that the young woman 
whom Elena described as receiving extensive support from an informed, sympathetic family was an anomaly among reintegrating women. While her individual commitment to programming and treatment likely contributed to her success, that commitment should not be viewed in isolation from the support she received - and other women who participate in programming but lack supportive family ties may struggle to realize the same results.

It is not only family members who might make exceptional efforts to assist a woman's reintegration. Sometimes service providers themselves invested extra time and resources into assisting an individual. To cite another example from Elena, she described a time at her halfway house when the staff rallied to support a woman was very challenging and aggressive. "It was the staff having to work together to get her basically what she needed. And a lot of the times you wanted to give up because it's like talking to a wall." But staff persisted and eventually this woman found employment and was able to remain in the community. However, Elena talked at length about how she had invested a lot of extra time and energy in working to support this woman, and her co-worker backed up this account by crediting Elena with "being persistent". Jessica, who had experience managing a different halfway house, had described to me the demands placed upon staff in such environments. "The case worker has to balance all of the requirements related more so to risk than to the women's needs, then document all that as per funder standards," she said. "Oftentimes that level of work takes hours because these women are so broken." She added that such requirements were done at the expense of "spending quality time with women to get to know sort of what their strengths are, what sort of, um, what their interests are." This depiction of an under-staffed, over-worked environment, and clients who are "broken" and demanding, was fairly consistent. It suggests that staff are often unable to provide the level of support reintegrating women require, or that staff wish they could give, to adequately 
address all women's challenges. It is a further indication that Elena's story of support for a particularly challenging woman was exceptional. If case workers do not have enough time and resources to invest in all of the women they work with, those who receive such extra support may achieve certain successes that are not available to other women.

Kim also told me a story about a woman who had received exceptional support, in this case from staff inside prison. This young woman had completed the horticulture program at GVI and received significant extra help from the instructor, which included job references and coaching over the phone after her release. Kim described this support as "phenomenal." When she was visiting GVI, she made a point to personally thank the landscaping instructor, which I interpreted as an indication of the infrequency of such additional attention. Not only did this young woman receive special support from her institutional instructor, upon her release, the parole office paid for her to do a landscaping apprenticeship course at the local college. The office then also paid for her driving course and driver's license. Parole offices have funds available to support parolees' employment, and typically such funds are used for purchasing work boots and other necessary work equipment. Although Kim told me about other women who had received funding to complete college courses, it was clear that such funding is only available to those who seem most likely to succeed. When I asked how this likelihood of success was assessed (and thus how funds were distributed), Kim said that willingness to complete programming and participate in employment training inside prison would increase someone's chances of receiving assistance for additional training once released back to the community. She acknowledged that such contingencies are not made clear to women inside. In other words, women who go through the right doors will find others opening for them. Conversely, failing to go through certain doors can have long-term impacts that were not made known at the time. This recalls Sheila's pessimistic 
comment that work-ethic cannot be taught, but rather must be something that women already possess. Those women who are identified as possessing this ethic will be afforded opportunities not available or even made known to women who are seen to be lacking the 'drive to succeed'. The broken psy subjectivity examined in the previous chapter is certainly present here too. As a character unable to work toward her own success, the broken woman is incapable of achieving empowerment, incapable of recognizing the right path to choose, or taking the necessary steps toward it.

Despite that service providers told stories which indicated that successful women had received support above and beyond what was typically offered, they did not identify this external support as the key factor to employment success for reintegrating women. Accounts of additional support women received were off-set with comments about women's personal motivation or drive. For example, the woman who received additional support from her horticulture instructor, and had her college program paid for by the parole office, was identified as successful "because she carried on". In this way, service providers failed to acknowledge the importance of their own role and power. Research on therapeutic support has suggested that some people working in feminist helping professions, such as therapists and social workers, are uneasy about acknowledging the power they have over those they assist. Laura Brown (1994) and Dana Becker (2005) discuss this unease in the context of feminist therapy, arguing that a claim of 'equality' between therapist and client denies the power that therapists have in shaping the experience, process, and outcomes of therapeutic interventions. Similarly, I found that narratives of service providers lacked reference to their own power and authority. By focusing on the behaviours and attitudes of reintegrating women, their narratives shore up the emphasis on the individual responsibility of reintegrating women, while deflecting attention away from the 
responsibility service providers have in shaping women's experiences and even their possibilities for success. The mobilization of the language of agency, by which I mean the focus on women navigating their barriers and making the 'right' decisions, obscures the power of service providers, and the vulnerabilities of women in the relationships with them. It also indicates the limited options available to those disempowered women who are not seen as taking the necessary steps toward their own empowerment. As indicated above, service providers indicate that work is inherently valuable and is something toward which all individuals should strive. Failing to do so can indicate that one has not subscribed to the beliefs about work's value. A lack of 'grit' and 'motivation' may be interpreted as a lack of belief in the fundamental value of work.

\section{Not work-ready: Limitations of the subject position of criminalized women}

In previous chapters, I have examined the commonly identified barriers to women's reintegration and employment, such as the lack of education and employment experience, and lack of services available in the community that specifically address women's needs and interests, as well as the criminal record and its associated stigma. Yet when I asked service providers about women who had not been able to find or maintain employment, they emphasized internal barriers, particularly addictions. They referenced the impacts of trauma and marginalization on women's lives, drawing forth the subject position of the broken criminalized woman. Their narratives demonstrated that the dominant discourses of criminalization and responsibilization limit the possibilities for narratives of change, growth, and personal agency. In particular, as noted in Chapter Five, narratives about addictions suggested that women's agency was restricted by her use of drugs and/or alcohol. "The ones that aren't successful have to do with addiction," Heather said. Like Elena and Jeff, Heather indicated that addiction was a key 
factor in women's inabilities to find work, a factor that they described as both an individual shortcoming and as an illness. Heather gave an example of a woman who had been doing very well in the community and had maintained a job for several months, but after a while she relapsed and "got sent back to GVI."

Other accounts of failures described women as having limited capacities to follow-through with plans or cope with adversity. For example, Jessica suggested women could not handle the "stress" of managing work along with daily tasks and responsibilities. She noted that in prison women do not have to worry about finding a meal or place to sleep, but these become pressing concerns once released. She suggested that some women, unable to cope with the burden of these concerns, were almost willing to be sent back to jail. While sympathetic to the challenges women faced, like other service providers, her narrative indicated that she considered women's 'failures' to be related to individual shortcomings, such as the inability to cope. Indeed, in discussion of agency and responsibility, exhaustion, vulnerability, and failure to act in one's own interests, or even to act at all, are often framed as personal failings (Hemmings and Treacher Kabesh 2013, 34). Similarly, Becker notes that discourses of 'stress' locate women's problems in psychological and medical contexts, rather than in the sociopolitical domain $(2005$, 4). I noticed that service providers often expressed frustrations about the women with whom they worked, particularly if these women were seen to have made wrong decisions and failed to act in their 'own interests'. As noted in the previous chapter, Susan saw women as failing to act in their own best interests when they prioritized romantic relationships instead of focusing on employment and education. Not making the right choices, such as choosing relationships over employment, was framed as "a failure of appropriate subjectivity and affect rather than as a consequence of social stratification" (Hemmings and Treacher Kabesh 2013, 34). If women are to replace their broken psy 
subjectivity with the employable one, they must demonstrate the willingness to make the 'right' choices, and the fortitude to follow through.

Helen told me about a woman who was enjoying her job in construction and restoration, but she added that if she had not found this woman the initial placement, "who knows how long ... she would have taken to actually get that motivation to take the next step." As an employment coordinator, Helen works with both men and women. She remarked that women often required external pressure or a requirement from their parole officer before they made the effort to find work. "There's one woman that I worked with," Helen said, "she wanted to visit family up north, but in order to do that she had to demonstrate [to her PO], she had to get a job. Once that was told to her, this is after like four months, hmm, she got a job quite quickly." Helen laughed and added, "And that's what I've seen," to indicate that this story is illustrative of a pattern she has seen with women coming out of prison.

The expressed belief that some women are not able or willing to find employment complicates the job that service providers must do in supporting them. For example, Kim described one client as being 'all over the map'. "She can't stick to one plan. She just jumps all over. I want to do this, I want to do that. Every week is something different. And I try to bring her back to okay, let's stick to one plan. You're gonna follow through on this one." Kim clearly saw this woman as failing to act in her own best interests, which Kim seemed to experience as making her own job more difficult. Additionally, this story from Kim is illustrative of where a service provider's perception of best interests differs from that of the woman she is helping. In another example, Kim said, 'I've had some clients who think they can do a full-time job, when I know they can't." When I asked how she knows that they cannot work full time, Kim offered an illustration of a conversation with a woman under her supervision. "You can't come and see me 
at nine o'clock because you can't get yourself out of bed. How are you gonna hold a job?" The suggestion that there are reintegrating women who would like to pursue employment, but who are being told by their supervisors that they are not 'work ready' contrasts with the views expressed by Sheila and Helen that reintegrating women lack motivation and are unable to find work because they are unwilling to try. Yet being assessed as 'work ready' requires that women demonstrate more than motivation. Kim's scenario suggests women must also demonstrate things such as punctuality and reliability. This raises questions about whether or not such 'skills' are taught, and how women are being assessed at possessing them.

As discussed in the previous chapter, the over-prescription of medication inside institutions complicates women's reintegration. Psychotropics, which are heavily prescribed to incarcerated women, have common side effects such as drowsiness, memory impairment, and nervousness (Kilty 2014a). Such side-effects can impede women's abilities to take on the multiple tasks associated with finding and maintaining work. As Jessica noted, women who were on psychiatric medications were often prevented "from getting up and being functioning" early enough to make it to work. I soon learned that it was common when visiting halfway houses to find women in their pyjamas at all hours of the day, or meet with women who had only just gotten out of bed. While my research certainly cannot determine the extent to which prescription medication contributed to women's lethargy, it indicates that women's perceived lack of motivation to be out looking for employment should be examined in the context of the suppression and control of incarcerated women through psychiatric medications. ${ }^{52}$ However, as Kim's comment illustrates,

\footnotetext{
52 In my volunteer engagement with community organizations assisting criminalized adults, concerns are often raised about the lack of continuity between prescriptions in the community and in prison. Individuals going in to prison who have a diagnosed mental illness often cannot access their medications, especially in the first few days after their arrest. Similarly, individuals who are prescribed psychotropics and other medication inside institutions
} 
an inability to rise early and be 'work ready' can be interpreted as demonstrative of not being ready for employment.

Elena also suggested that some of the women she worked with were not work ready.

[One woman] had been on the run, used [drugs] a lot, uh, her partner also did the same thing with her. And right now, she wants to work, but she's still not there. She still doesn't trust herself to stay clean in the community uh, around specific people. So what we have her doing is like relapse prevention plans, um selfesteem building which, her self-esteem is very low, so we could see the turnover. But, employment-wise she's pushing for it, but it's recognizing that maybe you're not able to actually be there yet. So it's just taking things one step at a time.

By saying she can see 'the turnover', Elena was referring to an earlier discussion about women who turn back to drug use. Elena associated low self-esteem and lack of forward orientation with addiction. She suggested that addiction needs to be addressed through programming before this woman can be successfully employable. The employable self is not an addicted self. Whether or not the woman agrees with this assessment is a little unclear, Elena suggested she both realizes her vulnerabilities, yet is still 'pushing' for employment. Again, this suggests that those providing employment support may be simultaneously encouraging employment while holding the individual back from employment. Another quote from Elena illustrates how she sometimes discourages women from seeking employment.

will often not have access to these medications, or the same medications and dosages, upon release. This lack of continuity was also referenced by some of the service providers I interviewed, and two made an aside comment about not only the over-prescription of pills, but also the 'watering down' of drugs like methadone. Though assessing the impacts of drug prescription inside institutions, and continuity upon release, is beyond the scope of this project, research on health care and prisoner reentry points to the harmful impacts of lack of continuity (e.g. Begun, Early, and Hodge 2016), which would suggest this could be a factor in being or demonstrating 'work readiness'. 
Once they get out here [to the halfway house] it's okay, programming. Start doing this, start doing that, start working on yourself. And then they go, 'well I want to work.' Where do we fit work in there? And if we can fit work, how are you going to balance that? And that's one of the things we ask them. How are you going to balance it? And that's where they struggle.

The call to 'start working on yourself' reflects the imperative for women to 'work to work'. Women must work on themselves to demonstrate they are ready to work in a job. Such work may include rising on time, or completing prescribed programming. It can also encompass addressing self-esteem, confidence, reliance on relationships, etc., namely the various 'harmful' attitudes and patterns that are traditionally seen as barriers to women's success. As indicated in the previous chapter, the specter of the broken woman which looms large in reintegration discourse is a figure that is fundamentally unemployable. Service providers seemed to struggle in how to transform this broken, addicted woman into an employable subject. The dominant discourses of criminalization and responsibilization do not provide an adequate narrative to explain such a transition or a narrative to chart its course.

\section{Competing temporalities and the steps to success}

As noted above, Helen used the metaphor of steps to suggest that menial jobs were gateways to more rewarding work. The metaphor was mobilized to motivate women who might see little point to taking on an unappealing job. In contrast, Elena's use of the metaphor of steps suggests that women should approach things incrementally and sequentially, and not expect to reach the end goal without first taking the preliminary steps. Her comments, like Kim's scenario noted above, suggest that some service providers are concerned if they perceive women to be skipping 
steps, such as trying to hold down a job before being able to make appointments, or trying to be fully employed before building the capacity to maintain sobriety. Women are expected to demonstrate employability in successfully completing daily tasks (getting up early), in their commitment to addressing personal barriers to employability (addictions), and in their willingness to take on mundane jobs as a means toward the desirable goal of employment. There are competing temporalities here. On one hand, women are directed toward the future, the longterm goal of fulfilling employment. On the other hand, they are directed to the immediate present, told to focus on everyday tasks such as making it to a nine o'clock meeting. They must look to the future, but focus on the present. Yet Jessica suggested that many reintegrating women “end up really not having a future oriented outlook on life." Such perceptions could still be used to justify emphasis on daily tasks and immediate plans, but for reasons counter to those of Kim and Elena. While Kim and Elena are concerned that women are trying to skip steps, Jessica expressed concern that, lacking a long-term goal, women will not take initial steps toward employment, education, or other aspects of reentry. Similarly, Helen suggested that those without long-term career goals did not see the point in taking 'small steps' like acquiring a menial job. Thus, not only are there competing temporalities, but there are contradictory perceptions about women's abilities to articulate, and act toward, future goals.

“They have limited experiences," Helen said. "They don't know what they want to do." She attributed women's lack of motivation to get work to what she perceived as a general lack of awareness of their own skills. She said many women "don't even realize what they're good at. No one's told them, or acknowledged their strengths in the past, right?" Like Jessica, Helen drew connections between women's past experiences, not only of trauma and abuse, but also situations in which they had not had opportunities to discover their passions and interests. Lacking such 
knowledge of self, she said women could imagine few possibilities for success. The subjectivity of the broken woman can be seen in these narratives of women who, because of their past experiences, do not know their own skills and cannot articulate their own interests. The broken woman is focused on the past. In contrast, the employable subject is future-oriented. She is one who can identify steps, or at least is willing to follow those which have been laid out for her by service providers.

However, possessing future goals is not enough for women to break free from the subject position of the broken woman, particularly if their goals are considered to be incompatible with their abilities. In the examples above, Kim and Elena suggested that women were unwilling to take the necessary steps toward their goals. These women had goals, but were seen as trying to skip steps in reaching them. Kim told another story of a woman who had worked in a fairly senior position in government until she was convicted on fraud charges. Upon her release, she wanted to return to the same kind of work, at the same kind of pay. Kim said it took this woman more than two years to come to terms with having to work in minimum-wage jobs. "So, for her to realize um yeah, okay, I'm just a waitress, and that's all I'm ever going to be," was, Kim said, a very bitter pill to swallow. She said this woman resisted employment in the service sector for a long time, even to the point of being forced to declare bankruptcy. This suggests a fascinating tension of temporalities. Kim perceived this woman's future goals as tied to her past, and incompatible with her present. In this case, Kim's narrative suggests that what held this woman back was not trying to skip necessary steps, but not picking the right future toward which she would direct her path.

Additionally, as noted above, service providers focused on employment's abstract value when discussing why women should put themselves on the stepping stones toward 'success'. As 
such, while there is a temporal aspect signified in the metaphor of steps, the future goal is not necessarily tangible, such as a job that pays a living wage. The future goal may be the subject position of a 'worker'. Yet the ways in which women can demonstrate this subject position, and its associated character traits such as diligence, work ethic, and reliability, seem to be confined to the sphere of waged work. As such, it does not allow possibilities for women to demonstrate these character traits in other ways, such as by volunteering in the community, parenting their children, or building a network of social and emotional support. Women are also expected to aim toward the prescribed notions of 'success', namely success as a gainfully employed worker. Yet the 'success' toward which reintegrating women are directed may not actually be experienced by them as 'success'. By this I mean, a service provider may identify a woman who has acquired a job as someone who is successful, but if the job is poorly-paid and boring, the employed woman may have mixed feelings about this apparent 'success'. Johnson (2002) notes that minimum wage work done by vulnerable women, can be exploitative, not empowering. As will be explored in the next section, reintegrating women expressed complicated views about the value of work. For some, employment was an opportunity to achieve and perform redemption; similarly, for others, it was an affirmation of a non-criminalized identity. Yet some expressed ambivalence about employment, and others, clear resistance.

\section{ENGAGEMENT, AMBIVALENCE \& REJECTION}

In Chapter Four, I discussed how some women downplay their criminal conviction and their time spent incarcerated (time spent 'dealing with a situation'). The identity of inmate or offender was not admitted, or acknowledged to me, as part of their self-conception (similarly, most service providers in non-profit, community-based organizations also avoided such terms). The 
narrative of self which downplayed conviction and incarceration was evinced in the way Malone could be 'honest' about her criminal record while distancing herself from being a 'criminal'. Malone is an example of women for whom working seems to have been part of their preincarceration identities, and returning to work was a way to re-establish these identities and distance themselves from the criminalized ones. When she explained that she did not have to fully disclose her criminal past since employers should "know you, not know the inmate", she was making that distinction clear. The 'offender' category is one to which she no longer belongs and thus need not disclose. As discussed previously, the degree to which reintegrating women conceive of their identity in relation to their prior incarceration is highly variable, and likely to continue to change over time. Additionally, the degree to which they conceive of their identity in relation to employment varied significantly among the women I interviewed. Employment was described by reintegrating women as both a possibility for, and a proof of, return to a previous identity. For some, becoming a 'working person' was a way to create a new, reformed identity. Still, there were other women who told me they were open to work opportunities, but who expressed ambivalence about its value or its relevance to their identities. Additionally, there were a few women who indicated that work was not part of who they were or what they were interested in doing. While recognizing that these distinctions are neither static nor clearly demarcated, this general categorization affords an opportunity to probe how reintegrating women describe their engagement with work, and how employment relates to their narratives of self.

\section{Work as meaningful}

Saba Mahmood, in writing about women's participation in the Islamic piety movement, argues that agency exists "not only in those acts that resist norms but also in the multiple ways 
one inhabits norms" (2005, 14-15). Her observation invites exploration of how reintegrating women inhabit the norm of being a 'working person'. As my research demonstrates, there are multiple and even contradictory ways in which reintegrating women do this. Slightly over half of the reintegrating women I interviewed described themselves being 'working persons', 'hardworkers', and other such terms that indicated that they identified work as part of their identity. For most of the women who described themselves as working people, work seems to have been central to their pre-incarceration identity. "When opportunity comes, I get on," Srila said, "cuz, that's, that's always been me." Similarly, Alexa indicated that being a worker was who she was. "I was just never a lazy person," she said. "I’ve always been a working person." Alexa contrasted being a 'working person' with being a 'lazy person', and illustrated how she was the former by telling me how, upon her release, she had applied for fifty jobs before getting hired through a temp agency, and how she had started looking for work almost immediately after she arrived at the halfway house. She got blisters on her feet from walking all over town dropping off her résumé. “I just felt like, it [not having a job] kind of made it look like I wasn’t having no ambition to do anything," she said. On the day of our interview, she had recently started a job at a warehouse and seemed relieved to have finally found employment. I asked if she liked her job. She said it was good, adding that "everyone was friendly." Notably, she emphasized her interpersonal relations rather than the tasks she had to perform (Johnson 2002). The type of job tasks seemed less important than the fact of having a job. "I'm willing to do anything," Alexa said.

Srila expressed a similar ambivalence about the type of job she had. Her job history was varied and mostly in minimum-wage positions. Most of her previous jobs has been found informally, "it was just like, hey can you help me out? Can you stay? You're so good.” Srila 
suggested that her success in finding and keeping work related to her ability to be a good worker, and also to take advantage of opportunities around her. Indeed, as employment options are limited for most reintegrating women, staying open to various opportunities was for many a chance to increase their odds in landing a job. "I'm pretty open to doing anything," Andy said. "I don't really care what I'm doing, as long as I'm making money. I mean, yeah, I used to shovel cow crap, you know, whatever, I bale hay. Like I really don't care what I'm doing as long as I'm making some kind of money." These narratives of work indicated that by having a job, and particularly by being a 'hard worker' or a 'good worker', they saw themselves as being able to demonstrate other positive attributes of self, such as determination and drive.

Like most women convicted of violent crimes, Melody's past violence had been directed at her abusive partner (Hannah-Moffat 2001, 167). She indicated that her long-term, abusive domestic relationship had affected her confidence and perception of self. Additionally, she was incarcerated for almost a decade, which deepened her sense of alienation from a previous identity she had held as a woman who managed a department in a large retail store. After being released to a halfway house, Melody was encouraged to apply for work, but she had many doubts about her ability to find and hold a job. Although her first job did not last, it allowed Melody to experience what it was like to be employed again. "I got a taste of working and I really enjoyed it," she said. This made her decide that it was what she 'wanted to do'. Melody did not directly describe herself to me as a hard worker, but she relayed compliments that others gave her (like that she was a "phenomenal" employee). She had recently put her name forward in an application for a more senior position, which indicated that she felt positively about her performance at work. She was rediscovering abilities she had before, and finding new ways to demonstrate them. Indeed, while women spoke with varying degrees of enthusiasm about their 
jobs and the tasks they performed there, several indicated positive attributes of themselves as workers, such as when Carla described herself as an "asset to a team". Chantell said, "I know what my worth is. I know what I have to contribute." This indicates again that employment can be mobilized either to develop or regain a positive identity.

In her interviews with reintegrating women in the United States, Patricia O'Brien found that reintegrating women who were working at the time of the interview reported that their work was "meaningful" and that it helped them create a new 'life' after incarceration (2001, 290). My findings, however, indicate that these two things should be considered separately and were not always co-existent. Women like Srila seemed to consider work as important in that it demonstrated how her life after incarceration resembled her life prior to incarceration. It allowed a continuity of identity. But with regard to the work itself, making edible arrangements, she spoke of it dismissively. "I'm leaving this job soon," she said. "I'm like out of here." The job paid only minimum wage and was part-time, with hours reduced when business was slow. While Srila said she had a good relationship with her current boss, she clearly did not find the work purposeful and she was frustrated by the low earning potential. She was doing this job because it was the first thing offered to her upon her release, but she did not plan to be there for long.

Lin was also biding time in her current job. A former senior financial advisor and consultant, Lin was studying to write the entrance exam to law school. For now though, she was working part-time in a catering business. "It's exhausting," she said. "But it is something that is safe right now." By 'safe' she meant that her work did not require her to breach any of her parole conditions (such as managing money), and she had been able to avoid the negotiation of disclosing her criminal record since the business was owned by a family member. Yet Lin did not enjoy the actual labour. It was a world away from the professional life she previously held, a 
role in which she was able to travel extensively and earn a good income. "I just love work," Lin said later in the interview. "I love working." But it was clear that when she talked about enjoying work, she was referring to a specific type of work - namely the busy, intellectually demanding work of being a consultant.

Lin seemed frustrated with what she perceived as an expectation that reintegrating women could not aspire to 'meaningful work'. One of the first comments she made during the interview was to criticize the employment support available to women inside federal prison.

The programs that they have [at GVI] consist of things that would um be geared towards landscaping um, construction, um and um, Smart Serve type of, type of. So, I'm not, without diminishing that type of work, you know out in the community, I feel that they're not meaningful employment training. It's, uh, it is disheartening. ... Those are like jobs that are I, you know, again to me they're menial jobs. Like you would be at a café, cleaning and assisting, cooking the muffins, you know? It's not, is it a skill set that you wanted to learn? That you will take with you and take you somewhere when you go out in the community? I don't think so. Um, I think that they're missing the mark.

Lin's remarks clearly indicate that she does not find 'menial' work meaningful, which indicates that she does not see meaning for herself in this kind of work. Johnson (2002), who examined how women found meaning and satisfaction in work, notes that working and middle-class women had different criteria for job satisfaction. Working class women emphasized autonomy, not feeling pressured, and being acknowledged as important for job satisfaction, while middleclass women prioritized autonomy and being challenged. Lin's critique of employment training reflects her experience of her job, and she likely could not imagine finding its same benefits, or 
satisfaction, in the type of job options being offered to her in prison. In contrast, Alexa had commented that she was satisfied with her warehouse job because everyone was friendly and her boss was not 'over her shoulder', which corresponds with Johnson's assessment that not feeling pressured is important for job satisfaction for women who are accustomed to minimum-wage, manual labour jobs. The contrast of expectations or articulations of work satisfaction between Lin and Alexa illustrate how prior experiences shape expectations of what work will be 'meaningful'.

The distinction between those who had 'careers' from those who had jobs or occupations is a relatively modern one (Herr 2001). ${ }^{53}$ Did women like Lin, with experience in business management and finance, hold 'careers' prior to their arrest, while others like Becky, who worked for ten years operating heavy equipment in the Alberta oil sands, and Melody, who had more than twenty years of experience in retail, have 'employment experience'? Indeed, what counts as a 'career' or 'career success' is widely influenced by class, gender, race, age, ability and a host of other intersecting factors. Career scholars note that measures of success include extrinsic outcomes (such as salary and position) as well as intrinsic outcomes (such as feelings of satisfaction and accomplishment), factors which relate to socio-culturally located standards (Seibert, Kraimer, and Liden 2001; Ng et al. 2005; Johnson 2002). The term 'career' came up in only about half of the interviews with reintegrating women, and then it was mostly used in an aspirational context. "Career-wise," Malone said, "I'm looking to get into fashion." She hoped to do this by reconnecting with her former employers and possibly training as a personal stylist. Carla said that right now she was just doing a job now to "get me through", but that down the

\footnotetext{
${ }^{53}$ Edwin Herr notes that the term 'career' was not widely used prior to the 1960s (Herr 2001)
} 
road she planned to "look at my career." Such comments speak to how financial need is often the primary or immediate motivator to work, but also suggest that women differentiate between jobs they do just to 'get through', and jobs that can offer something more. Holly did not suggest she had a career now (with her job in a motel), but indicated that she hoped to find a career when she moved back to her community in order to keep busy and "out of trouble". These perspectives correspond to the notion of career as something which is developed and which is based upon personal interests and goals, not simply immediate need (McDonald and Hite 2016).

Zahra clearly articulated the difference between having a job and having a career when she described the conversation she had with herself during her second stint in jail, a time during which she decided she needed to develop some goals.

This is not your life, just working nine-to-five or just working a cashier job. No, you need to have a career. You need to making something of yourself. That career will grow and you can grow high and above, beyond.

Zahra was inspired by celebrity chefs and people who owned their own restaurants. "So why can't I be one of those persons?" she asked herself. "I mean, it's intimidating, but why can't I do that?" She had a job in a restaurant, and was thinking about pursuing culinary training. She indicated she had a goal of becoming sous-chef within a year. "If I stick to my job, and I do it, and I work those long hours and hard hours, I will eventually get that position.”

Theresa also worked in a restaurant kitchen, although for her this was the continuation of a thirty-year career as a chef and kitchen manager. She was adamant that this was the only kind of work she wanted to do. "On my correctional plan I said I was going to go back to the food industry," she said. "That was my passion, my love. That's what I wanted." She indicated that she was unwilling to take on other work just to pay the bills. "Don't just get a job at anywhere," 
she said in response to being asked what kind of advice she would give to other reintegrating women. "Take the time, rediscover yourself. And do something that makes you happy." Although Theresa was the only woman I talked with who described her work as her "passion", Zahra's comments above suggested she was anticipating that developing her 'job' into a 'career' could bring her satisfaction. While the experience of having a job they loved was rare among the reintegrating women, some of their narratives suggested they knew, or at least imagined, that work could be meaningful if it involved doing enjoyable or stimulating activities.

Nicole did not describe her previous work as her 'passion', but her descriptions of it indicated that she had found it rewarding. Having grown up in a poor neighbourhood in Toronto, Nicole knew first-hand what is was like to not be able to afford to visit a beauty salon. Selftaught, she started offering salon services out of her home, only asking clients to pay "whatever they can come up with, five, ten dollars, whatever." It was clear that the rewards from this work were not simply financial. "I enjoying making people feel good about themselves and look pretty," she said. During her time in jail, Nicole volunteered in the hair salon where she had gained more experience and confidence in her skills. Not only did she have the experience, but she knew that she could do this work independently, without disclosing her criminal record. She was considering going back to hair styling, although she needed to find other work first in order to start saving for supplies. That Nicole could identify herself as a hair-stylist seemed important to her sense of self, even if she was not currently employed as such.

The work and career aspirations expressed by these women contrast from the views articulated by service providers like Helen who suggested that reintegrating women do not know their own abilities, and have no interests on which to build career goals. Yet women's aspirations indicated not only the desire to build a particular career, but also to demonstrate the role of a 
working person. Alexa described the toll on her body from her efforts to find work. Melody mentioned several times that she was "learning everything" in her grocery store department, indicating that her adoption of the employee role involved an expenditure of effort to familiarize herself not just with her required tasks, but with the functioning of the whole department and the roles of those who managed her. Joan talked about how she has shown up for work an hour early ever since her first shift, and how she has had to deal with what she called the 'hazards' of her job such as illness and lice. Such descriptions of how they engage with work demonstrates physical, mental, and emotional resiliency and tenacity. Their stories contradict the figuration of the unmotivated, lost, and broken criminalized woman that is dominates correctional discourses.

\section{Work as redemption}

Not all women had pre-carceral working identities to which they could return. Several women mobilized a narrative about being a working person to claim a reformed identity, and to distinguish themselves from other (non-reformed) criminalized women. This casts work as part of one's possibilities for, and narratives of, redemption (Maruna 2001). Such statements can be interpreted as being a means of preserving a sense of identity beyond that of 'offender' (Burnett 2004). For example, Alexa differentiated herself from other reintegrating women, suggesting she had more drive than those who just 'sat around'. For her, having a job served as proof that she was not lazy and directionless. The job signaled positive identity traits, traits that Alexa indicated she felt challenged to prove when she was not employed. Similarly, Srila suggested that having employment demonstrated that she is not "lazy" like others. She repeatedly differentiated herself from other women in the halfway house, saying that they were "lazy" and that they "want stuff 
given to them". She began telling me what could be interpreted as both advice for other women, and a criticism of what she saw them failing to do.

Just go out there, work for it. Like, you know what I mean? That's the worst part here [at the halfway house] is just waiting for a hand out. You don't want that. Like that's when you start getting lazy. That's when you start falling back. What's the easiest way of making money? That's how you get in trouble again. That's how, you know, cycles repeat themselves. You know? Everything you need, you just have to get up and get it.

Srila described to me how she 'worked for it', how she had reached out to contacts and landed a job shortly after her release. She chafed at the conditions put on her parole, which restricted her from taking advantage of other opportunities she knew about.

"I wasn't one of these people inside that just sit there and do your time, you know?" said Melody about her time at GVI, indicating how she differed from other incarcerated women. She also gave an example of how she thought other women were insincere in their participation in employment programs offered inside. "People want to do programs and their big thing is do you get a certificate for it? Okay, so you're just going through the motions to it make it look good on paper, like you've done these certain things. Like you don't really want to do anything about it." As discussed in Chapter Three, many reintegrating women expressed cynicism about the value of employment programs inside the institutions, but Melody's words illustrate a cynicism about other women's motivations as well. Indeed, as noted in Srila's comments above, reintegrating women at times expressed strong criticism of each other, describing other women as lazy and unmotivated. But they also expressed self-criticism that could be equally exacting. For example, 
Nicole described her inner dialogue about motivating herself to participate in programs and seek employment.

At the end of the day, you're the one that has to look yourself in the mirror. You know, you're only lying to yourself. If you don't do something and then you end up in jail a year later from that and be like holy fuck! Like why didn't I? I could've done this, and I could've done this. You're like, yeah, you could have. Why didn't you? You know, stop being such a dumb ass. Like do it. No one's gonna do shit for you.

Nicole's demand of herself to exert herself reflected the view that if she did not help herself, no one else would. This echoes Srila's criticism above that some women were just waiting around for a 'hand-out'. The demand to not be lazy or idle should always be interpreted within the context of an environment in which reintegrating women may be feeling abandoned and unsupported, even by each other. I wonder if the criticisms expressed toward others reflect a fear that being, or being perceived as, lazy and unmotivated could jeopardize one's freedom. Nicole lamented that in this anxiety-producing environment, women could turn on each other. "As women, we have the power to like bring each other up or we can really tear each other apart," Nicole said. "And like, it would be nice to sort of see that bringing each other up."

Carla also articulated her internal conversation to motivate herself, which included her motivation to assume, and guard, a reformed identity.

I think that you should be busy during the day. Like idle hands, right? I think it's important, just to keep your body healthy too. Like I find it's not just the money, it's like your health. Like, right? It's important to just mentally have something to 
do in your day, you know? Yeah, especially as our kind of women, like after being in jail, you know, to bring us up, just to make yourself feel better too.

Pat O'Malley, in examining the management of risk as a governmental technology, notes that the issue of unemployment can be cast as "a problem of idle individuals" $(2008,454)$. Carla also suggested that employment is a means to avoid idleness when she made reference to the saying that 'idle hands are the devil's plaything, ${ }^{54}$ In other words, the concern is not simply with being idle (or, as Alexa had suggested, with appearing lazy), but that idleness might lead to engagement in other (negative, harmful, or criminal) activities.

Andy also suggested that employment could be a way to ward off harmful activities, but for a reason that differs from Carla's. Andy did not speak critically of people others might call 'lazy' or 'irresponsible', but suggested that people did not value their money if they had not worked hard to earn it.

Sorry but a lot of people that are on ODSP and welfare are addicts. And you know, a lot of them are spending money on drugs. And, I mean, that's, I mean, to each your own, spend your money on what you want. But I think that if they had employment programs and they actually were employed and they made that money, they worked hard for that money, they might be like, hey, you know, I worked really hard for this money. I'm going to do something nice for myself, you know? Like, so I think it would give them more value for themselves.

\footnotetext{
54 The origin of this expression is likely to have been made popular by Chaucer in The Canterbury Tales, though he attributes it to Saint Jerome: "And therfore seith Seint Jerome, 'Dooth somme goode dedes that the devel, which is oure enemy, ne fynde yow nat unoccupied.' For the devel ne taketh nat lightly unto his werkynge swiche as he fyndeth occupied in goode werkes. (The Tale of Melibee VII 1595).
} 
Such descriptions of addicts spending money on drugs because they did not value money they did not earn, or beliefs that boredom and idleness will lead to anti-social and harmful activities, are not uncommon, even among those who have experienced addiction and unemployment. Indeed, keeping 'busy' has been noted as part of a relapse prevention strategy for those dealing with substance abuse (Fox 2013), and was referenced by other women as a way to deal with boredom, particularly when they talked about taking on 'employment' inside institutions. Carla's comment that being occupied during the day is important "especially as our kind of women" suggests that being criminalized has impacted her sense of who she is, and to what group of people she belongs. For 'her group' of reintegrating women, employment can be a way to access improved health and sense of well-being. A 'redeemed' identity, though differentiated from the 'criminalized' identity, still belongs to the same individual. The former has not only a temporal connection to the latter, but an ontological one as well. I wonder if, and at what point, Carla might claim, as Malone did, that she is no longer 'that kind of woman'. Indeed, Holly indicated how the passage of time had changed who she was. "If you would have a met me a year and a half ago compared to now, um, like I still have the same personality but I'm, I'm different." What is required for one to shift one's perception of self, and where is the dividing line between a current and former self?

As these women's narratives suggest, performing employability can be closely related to claiming a redeemed, non-criminal identity. In crafting and embodying a working self, reintegrating adults demonstrate a 'socially acceptable persona', one whose characteristics are informed by normative cultural scripts (Harding 2003). As such, several women drew upon cultural scripts about employability when they intoned the importance of willpower, motivation, 
and work ethic. For example, when I asked Carla what it takes to get back into the workforce, she rattled off several standard motivational phrases.

I think it needs willpower, like you actually have to want to do it. Um, put onehundred percent in, you know? Cuz if you're not really trying, you're not gonna get a job. Like you need to want it, and, trying oh like you're gonna have, you're gonna be disappointed sometimes because you're not always gonna get the job.

So you have to really set your mind to it and know that just because you don't get the first job that comes up, there'll be other opportunities.

Similarly, Melody evoked the adage that looking for work is in itself a full-time job. "People that are complaining that they can't get a job or anything else," she said, "but when you're looking for a job, when you're doing stuff, to me, it's like a full-time job trying to find a job. You know? You just can't go hand out one résumé and say oh well, I applied for all kinds of work, but. You didn't. You gotta put yourself out there, you know?” As such, Melody and Clara's articulations of clichés about 'putting one-hundred percent' and 'looking for work is a full-time job', can be interpreted as their attempts to project a positive self-image that echoes cultural norms (Goffman 1963).

Carla indicated that work can bring women up and make them feel better. Certainly, several women indicated that their jobs were contributing to a positive sense of self, perhaps even boosting their confidence. As discussed in the previous chapter, Donisha expressed pride in the skills she gained at GVI and in a community-based course for youth that provided entry level jobs in the trades. She planned to keep developing her construction skills with the hope that she could become an entrepreneur and flip houses. Zahra was happy with her new restaurant kitchen job and boasted about how quickly she had learned to master new skills. "If I'm not successful, 
I'll try and try." She described how she had to learn to slice ham very thin, and at first, she really struggled to do it right. "But yesterday, I was just flying through it. It was like amazing. They're all like wow, within three days you got the hang of it. It's cool. It's so good. It takes about a month roughly, for someone to learn it. I did within three days."

Zahra did not have culinary ambitions prior to starting this job. She described her precarceral life as one in which she relied on welfare and her abusive partner for any economic support. She was clearly relishing in the opportunity to create her own plans. She also expressed a willingness to engage in the 'stepping stones' toward building a career. "People aim really high, but you gotta start somewhere," she said. Later she again indicated that she was focused on her future. "Yes, I had a miserable life," she said. "I had a bad experience. But I'm moving forward." Such hopeful expressions are a stark contrast to descriptions provided by many service providers of the reintegrating women as crippled by their past. It also contrasts with the views of service providers discussed above with regard to 'steps' and future orientation. Zahra had a plan for her future, and knew the steps she needed to take to realize this plan. Nicole said that she was taking advantage of her time in the halfway house to "take for myself and having that, like you know, stability for myself. It can only mean better stability in the future." Similarly, Ashley noted the importance of learning and practicing "the tedious, mundane things... so that in the future when bigger problems did arise, you would know how to do it. You know how to go through it, and trust yourself." Zahra, Nicole and Ashley were all living in a halfway house when I interviewed them, places which have been identified as those in which residents are more likely to express optimism about their future plans (Sered and Norton-Hawk 2014), optimism which may be dimmed once they are struggling to pay for food and rent. Yet their articulations of hope and ambition certainly indicate that they are capable of demonstrating the characteristics of the 
future-oriented woman. Their recognition of the need to plan and take the necessary steps also indicate self-awareness and agency that challenges the subject position of the broken woman identified in the previous chapter.

Women who had been living longer in the community and were no longer residing in halfway houses still expressed optimism about the future, although it was more tempered with discussions about the realities of delays and of living on a limited income. There are also practical concerns that can make it difficult to move from one stepping stone to the next. Lin, who was studying for the law school entrance exam, was not sure how she would be able to afford to go to school if she were to be accepted. She had also already attempted the exam once and been unsuccessful, further discouraging her about the possibility of realizing her goal, conceived while in prison, of becoming a lawyer and legal advocate for incarcerated women. Chantell was like Lin in that she had a professional college degree and extensive work experience prior to her arrest, but both she and Lin were unable to return to their finance-related professions due to conditions of their parole. Chantell was in the process of completing a college program in event management and was actively developing new career goals. She expressed optimism about her possibilities, but was also aware that she was starting 'at the bottom' in her new field and was not likely to enjoy the same income and title she had previously held. Still, she insisted that in many ways, she was more qualified and experienced than her peers. "I bring a lot more to the table than a lot of them," she said. "I've always been one to kind of take leadership of something, so if I go into a situation and it looks like, oh my gosh, chaotic or whatever, I'm gonna try to bring order to that." While Chantell did not seem to doubt that she would find success, the realization had sunk in that the road ahead was long. Progress often takes longer than hoped. Aspirations have a temporal aspect, one which is often beyond the control of 
individual women. The process of reforming one's identity through employability also has a temporality to it: a transition from past, to present to future.

While several women indicated that they acquired positive feelings about their work, and developed new confidence in their skills, for two research participants in particular, Andy and Joan, work was central to their narrative of redemption. "I wasn't a nice person," Andy said. "I had addictions problems. I had problems with the law." But Andy said the difference now is "black and white" and made multiple references to changing their life, frequently contrasting where they had come from to where they were now. "I'm um, pretty much one of the only people [at the bail house], well I'm the only person that's employed here right now." Being clean from drugs was a big part of Andy's story of personal change, but being employed was also central to their new presentation of self, both as an accomplishment in its own right, but also as an indication of living drug and crime-free.

Andy mentioned several times that their ideal job would be one which recognized the value of previous life experience, such as a peer support position dealing with addiction and exiting the streets. Andy had some experience doing such work as a volunteer, but had not been able to get a paid position, yet indicated several times that such work would be much more meaningful than their current position in environmental clean-up. Similarly, Ashley and Nicole indicated that reintegrating women should have opportunities to help each other. "People who've been through it can help the next person because they know what to do, what not to do," Ashley said. "They have that you know, understanding, that lived experience. And when you're talking to somebody, you know if it's a genuine connection or not. You know when it's bullshit." This suggestion, that some people who claim or try to help are speaking 'bullshit,' recalls another comment from Ashley about therapy inside prison as being a "game." She and others suggested 
that support would be more genuine and meaningful if it came from someone who actually understood what reintegrating women had been through, and the challenges they were experiencing.

Like Andy, Joan had spent most of her life on the street. She had racked up over a hundred convictions, including one for drug trafficking which put her in federal prison. It took four years after her release from GVI to find a job. As noted in the previous chapter, Joan was able to find work in a men's shelter. Her position is noteworthy in that it allowed her to transparently mobilize aspects of her 'criminalized self' into the 'redeemed self', rather than having to demonstrate a complete disconnect. Yet while it sounds ideal that Joan could find a job that recognizes and values her lived experience, I do not want to glamourize her role. As Joan remarked, "this place goes through employees like a meat grinder." She had to deal with overdoses and belligerent clients during her nine-hour long night shifts. On top of this, Joan talked about other 'hazards' of the job: "bed bugs, lice, body lice, every day and in the winter time there's colds, flus, strep throat. And it cycles around, cuz the doors are shut, so you're working in a giant petri dish." For this work, under these conditions, Joan earns nineteen dollars an hour. Yet although she complained about being over-looked for promotions while younger and more-educated staff moved up the ranks, she was clearly proud of her job performance. "It's like a sink or swim thing," she said. "and I swam."

Joan's quip that she was able to swim belies how hard she worked to stay afloat, effort that went perhaps beyond the expectations of her employers but reflected her concern that she needed to prove that she was ready and able to do the job. She described her first months of the job. "I wanted to go gung-ho and show what a good employee I can be," she said. "I knocked myself out. Like burnout was serious.” Joan picked up any extra shifts that were offered, and was 
working up to seven days a week. After a few months, during which she got sick and was physically drained, she realized that she could not maintain this pace. She cut back to three shifts per week. Still, eleven months in, for every shift Joan shows up an hour early "in case someone from the earlier shift blows up." Joan actually receives financial support through the ODSP, support which could be enough to live on. Additionally, the province takes back half of what she earns, ${ }^{55}$ which could understandably be a significant disincentive to work. Nonetheless, Joan insisted she wants to work. "I do get a little bit ahead [financially]," she said, despite the claw back. She added with a husky chuckle "And these are literally the only people that will hire me... So if I blow off this job, I may not ever get another job.”

Joan's employers were willing to recognize her survival skills and street smarts when they offered her the job, but this may be because they know that only the most desperate job-seekers would be willing to work in such conditions. While her employment offers the benefits of increasing her confidence, recognizing her skills, and providing a steady source of income, it also has kept Joan locked into an environment not dissimilar from the one she lived in before. And yet, Joan focused on the bright side.

Even at this point, I'm fifty-two years old, I can still be a part of society. It [the job] helps me feel like a part of society. It's the first time I've ever paid taxes seriously in my life.

\footnotetext{
${ }^{55}$ The Ontario Ministry of Children, Community and Social Services, which oversees distribution of ODSP, allows those receiving ODSP to earn up to $\$ 200$ a month without having income support reduced. Those who earn more than $\$ 200$ in a month will have 50 percent of the net earnings above that deducted from their income support payment (Ontario MCCSS, n.d.)
} 
Joan's cigarette-husky voice rumbled into a chuckle as she commented about paying taxes. This was the first time in her life her labour was officially recognized. Paying taxes has been heralded as a hallmark of 'productive citizenship' (Kaye 2012), and Joan seems to wryly welcome it as proof of her integration into society. She also joked that she could not go back to eking out a living on disability support. "My cats have now become accustomed to the expensive cat food," she said. "They don't like the cheap shit now." While Joan might joke she was doing the job to keep her cats happy, she repeatedly expressed her satisfaction with working, despite claw backs and taxes. Yet for others, paying taxes is one of the reasons for which they resist formal employment.

\section{Employment is 'not a priority'}

"I'm not into tax," Tina said. "I refuse, you know." She insisted that she did not want formal employment because "I have to pay back the government, right?" Repeatedly during our interview, Tina expressed her resistance to 'the system'. Wearing an 'Indigenous Lives Matter' T-shirt, Tina's clearly articulated a narrative of resistance, which included pushing back against the broader colonial political structure. For example, at one point in the interview she said the key question was "how we're gonna address [the issues] on a political level, because you know what I mean? So everything is about a fight when it comes to a person like my, my background and everything." When Carla talked about 'our kind of women', she seemed to be referring to other reintegrating women. Tina's reference to 'a person like me' seemed to be more directly related to her identity as an Indigenous woman. Of the five Indigenous women I interviewed, I've categorized two (Tina and Ashley) as disengaged from work, and two others (Holly and Nicole) as ambivalent about it. For Andy, the only Indigenous participant whom I considered to 
have work as part of the narrative of self, this was part of a redemptive script and had not been part of Andy's previous identity. Colonial policies in Canada have been disastrous to Indigenous communities - politically, economically, and culturally - and have been repeatedly linked with challenging life circumstances including isolation, under-employment, and lack of education (Martel, Brassard, and Jaccoud 2011; Royal Commission on Aboriginal Peoples 1996). Such a context must be acknowledged when considering the expressions of ambivalence and disengagement by reintegrating Indigenous women. Yet as this research shows, it is not only Indigenous women who were disengaged from employment. Employment may be seen to offer few rewards to reintegrating women who have grown up experiencing marginalization and poverty.

Ten women did not have a job when I interviewed them, but eight of these women were either actively pursuing work or were open to the possibility of employment. Certainly, the focus of my interviews and the questions I asked may have elicited a more employment-positive approach than the women might have otherwise expressed; so it is possible more women could be considered to have disengaged from employment. Still, the likelihood that some women told me what they thought I wanted to hear (Sered and Norton-Hawk 2014) makes more significant the narratives of those who expressed resistance to employment and who were pushing back against the imperative to 'work, work, work'. Goffman suggests that stigmatized individuals tend to hold the same beliefs about identity as the general public $(1963,7)$. If this is true, the resistance expressed by some women becomes all the more poignant as it demonstrates a willingness to challenge conventional beliefs, even if such articulations risk augmenting their position as stigmatized outsiders. Reintegrating women are clearly aware of the imperative to work, an imperative that is expressed in their correctional plans, in the discourses of their parole 
or probation officers, and by the various service providers they encounter. Speaking resistance to this imperative is risky in that their vulnerability could be augmented if they lose support from those who view them as non-conforming and non-compliant. This recalls the observation made in chapter three that reintegration women, perceived as 'risks to society', are themselves at risk.

Disengagement and resistance to employment were not always expressed in a straightforward manner, nor without contradictions since "[n]on-conformity can take many forms" (Werth 2012, 337). For example, Ashley said she had participated in prison employment programs at GVI such as sewing, something which she described as "tedious". ${ }^{56}$ And yet, despite the work being dull, Ashley expressed surprise and pleasure in discovering new skills. "Wow, I actually can do this," she said. "I'm actually good at this." Ashley added that by participating in such programs "you learn about yourself." What she learned seemed to be not only that she had certain manual skills, but also that she could find pleasure in this work. Yet she repeatedly insisted that she was not going to be pressured into taking on a job. "Everyone in this world is like work, work, work and then drop, you know?” Ashley said. "Like don’t stop till you drop." She said employment was just not a "priority" anymore, and suggested that she had pursued it in the past out of a desire to prove herself and please others. She suggested this same desire to please others and fulfill their expectations was what got her into "a whole bunch of trouble.” By resisting employment, she was being truer to herself. This corresponds with Werth's finding that some parolees resist rules as part of their assertion of autonomy and self-governance, and even of their reform $(2012,339)$ "So for me, life is way more important. That means my

\footnotetext{
${ }^{56}$ One parole officer told me that in Edmonton's federal women's prison, women were given pillowcases to sew, which seems to me to be the epitome of a tedious sewing task.
} 
interactions with people, my relationships with people. Even if it's for ten minutes, even if, whoever, that's way more valuable than the dollar." Not being an employed subject was, for Ashley, not incompatible with being a reformed subject. She insisted she was doing what was best for herself, claiming full agency in her resistance.

Ashley had enrolled in a trade skills program soon after her release from GVI, and had successfully completed the program. She discussed some of the positive features of this program, particularly its supportive staff, but she had not followed up on their offer to help her find a work placement. Although she said that in the future she may go back to these contacts for help in finding a job, or may pursue other options like massage therapy, any discussion of possible employment goals was followed by statements of resistance, such as insisting that taking on employment was akin to becoming imprisoned again. "You're just like blinded and plugged in and you think that you've escaped this, but you haven't," she said. "You're just a prisoner yourself. You're a prisoner to the system." She acknowledged that if she wanted to regain custody of her nine-year-old son, she needed to have employment and a "solid foundation" to prove she was capable to care for him. But she still resisted this imperative, insisting that the need to find employment “doesn't mean you just have to settle for something that's going to hurt you in the long run."

Yet despite her resistance to formal labour, Ashley discussed her work ethic in the context of assigned chores in the halfway house.

If someone asks me to sweep the floor and I do a good job, that reflects on who I am. And that's the thing, I think people are very lazy, maybe, or they just don't care enough. So if someone asks me to wipe down the couch, why do it half ass? 
Why? Take the time and do it like to the best you can. ... Because it reflects on who you are as an individual, you know?

Ashley's connection of work performance with 'who you are as an individual' is striking given her adamant claims that she did not want employment. It indicates that work ethic can be demonstrated in ways outside of formal employment. In contrast to narratives of wage-earning labour as the dominant expression of "individual moral practice" (Weeks 2011, 11), Ashley indicated that other acts of labour can also provide opportunities to demonstrate integrity and pride. Ashley demonstrates how someone who rejects formal employment might still consider herself to be a 'working person' or may seek other ways to lay claim to the attributes associated with being a worker. This raises the question of whether reintegrating women are provided with sufficient opportunities to express and demonstrate positive attributes, such as diligence, outside of formal employment, and if such efforts are recognized by those who are positions of authority and supervision.

Tina, who also expressed resistance to 'the system', earned a living by working on an honoraria basis for a Native Women's organization: leading ceremonies, drumming, and giving talks. This position allowed her to earn some income, but to not pay taxes. Tina spoke with pride of this role, and expressed satisfaction with the recognition given to her by people she worked for, such that they recognized her cultural knowledge and life experience. "I'm very open with my life and where I'm at at this moment," she said. Janessa was also quite open about her life. Fewer than half of the women I interviewed disclosed to me their criminal charge (I did not ask), but Janessa said with a loud laugh that she had been a drug dealer. She made this statement in the context of boasting that despite her past, she had never had trouble finding employment once she started looking for it. Yet despite her claims that it was easy for her to get work if she wanted, 
she insisted that this was not something she was currently pursuing. "My thing, because I'm done December tenth, this year's my warrant [expiry]. I'm finished with this place," she said. ${ }^{57}$

Once she reached the end of her sentence, she would no longer be required to stay in the halfway house, nor would she be pressured by her PO to find employment. Janessa said her current priority was finding a place where she and her partner could live, something which she hoped to pay for by getting on disability support. "So really my thing is just get on ODSP and get financially set," she said. "But I'll be back to the employment world in five years, after, just not right now." Although she was expressing resistance to employment, there was a temporal element to this resistance. The 'employment world' is a place separate from where she lives now, but it is a place to which some day she may choose to return.

The three women whom I have coded as expressing resistance to employment did not reject completely the character of the employable self. Ashley's resistance was tempered with the recognition that work had been meaningful in the past, and that she still performed work ethic in her daily tasks. She and Janessa both suggested their disengagement with employment might be temporary. Tina had found a way to perform some aspects of the employable self, but on her own terms, allowing her to exert her agency through practices of both resistance and compliance. As Weeks $(2011,99)$ has pointed out, refusal to work is not synonymous with rejection of activity and creativity (such as illustrated by Ashley and Tina), but rather of the centrality and necessity of work as a means of access to rights and belonging. Their narratives indicate the need

\footnotetext{
${ }^{57}$ Warrant expiry refers to the end of a sentence. Often referred to as 'warrant' or WED (warrant expiry date), parolees and parole officers mention this to indicate when a sentence is complete and an individual is no longer under supervision and is free from parole conditions. Warrants do not expire for 'lifers', individuals with life sentences, even when they live in the community.
} 
for more attention to, and validation of, alternative ways of expressing activity, productivity and creativity.

\section{Ambivalence}

When she interviewed incarcerated women, Ros Burnett (2004) found that expressions of ambivalence and uncertainty were common among those who were soon to be released. While the women I interviewed were not incarcerated, seventeen of them were living in halfway houses, which, like parole, is a liminal space between prison and the community (Werth 2012), and six of them had been in this space for a month or less. The perspectives they offer on employment might relate more to their hopes and projections than to their experiences (although some women already had previous experiences of living in the community post-incarceration). Burnett also notes that ambivalence is evident in self-contradictions made during the interview. I noticed such experiences of inner conflict during my interviews, such as discussed above regarding expressions of pride about employment-related accomplishments, and insistence that employment was not worth pursuing. In the narratives of six other women I interviewed, expressions and performances of ambivalence characterized their approach to employment.

Holly, an Indigenous woman from northern Ontario, had recently started a job as a housekeeper in a small inn. Her tasks included cleaning rooms, doing laundry, and helping with the breakfast service. While she said she appreciated some of the positive aspects of her job, such as interactions with co-workers which provided her with a new environment and contacts that were unrelated to incarceration and Corrections, she suggested that she only pursued work because she was pressured to do so by her PO - indeed, she had been told that if she did not get a job, she could not go back home to visit her family. "I guess I needed that little push," Holly said. Like 
Andy, Holly's narrative suggested a process of redemption. She had spent several months focusing on her drug addiction and working to better herself. "I've made a lot of really positive changes in my life," she said, and talked about her renewed interest in diet and health, understanding she had gained about emotions like depression and anxiety, and her new-found calmness and confidence. Employment seemed of little importance in comparison to these other changes. It also seemed clear that she was doing this job to satisfy her parole officer in order to be allowed to attain the more important goal of connecting with her partner and family. Future plans were still unclear and I did not have the impression that she would stay at this job for long. While some women may mobilize employability as part of their demonstration of a reformed character, there are other possibilities for demonstrating redemption. For Holly, this was by living sober and eating a healthy diet.

Some of the women who were looking for work did not seem to expect it would relate to their sense of self. Employment may not offer the same rewards, or path to redemption, that it did for other women. Lori told me she had a job interview the next day, but she seemed to have applied out of boredom and curiosity, and possibly now was regretting her action. She had been browsing the Internet and saw a post for a dishwashing job. She applied online. The restaurant replied with an email inviting her to come for an interview. But Lori had not done a job interview in fifteen years. When I asked her how she felt about it, she ducked her head and whispered "nervous as hell." If it did not go well, she was not sure that she would try again for another job. Even if she would be offered the job, Lori anticipated that it would simply be a way to earn some extra money, and she did not want to have to work more than part-time. "I'd rather not do full-time right now cuz I don't think I could handle that," she said. Although she said the job could be something to 'keep herself busy', she never indicated that she expected anything 
more meaningful from this or any other job. Jock Young argues that when poor and marginalized people are forced to work "at the very lowest level" of jobs, they are receiving messages that not only their labour, but their selves (in capitalist terms) are worth very little $(2007,76)$. In this context, it seems reasonable that Lori would expect to find little meaning and reward in washing dishes. Unlike others like Alexa and Melody, Lori did not seem to consider herself a 'working person.' She had received disability support before, and was focused on getting it again, even as she was aware of the challenges in making ends meet on its paltry income. As noted above, for women who are able to get on ODSP, there is little incentive to work, particularly given that the government will claw back funding if they earn too much.

Tara was also hoping to get back on ODSP, so expressed little interest in finding employment. She had not participated in employment programs at GVI. “I didn't plan on getting a job when I got out. I was just originally going to go right back on ODSP," she explained. "Then I found out the cost of rent here, I was like, yeah, have to get a job to kind of help cover the bills." Still, despite the recognition that she needed an income, and despite pressure from her PO to find work, she was only looking halfheartedly and was discouraged about her chances. She did not describe herself as a hard worker or even as someone interested in work. "I haven't worked since probably 2009," she said, and that had been as a gas station clerk. Tara also emphasized to me that she has physical disabilities that limit what she could do, for example how long she can be on her feet. While I had the impression some of the women, like Andy and Nicole, described their employability to me in possibly exaggerated terms, with Tara I had the impression that she was trying to convince me that she should not be expected to get a job. "I don't think my body would handle an eight-hour shift," she said. 
Becky also expressed indifference and reluctance about working, and had not made much effort to pursue a job. Although she told me she would be interested in working as a truck driver, and talked positively about her experience in the northern Alberta oil sands, she was uncertain about the precise requirements needed to be a driver in Ontario, and did not know where she could obtain the requisite certification. Like Janessa, she referred to the working "world", a place she had once inhabited, and to which she did not seem eager to return. Yet when I asked her if she had children, Becky said she was pregnant with her first child, adding that her pregnancy was another challenge to her employability. “A lot of places wouldn't hire, they won't hire you if they know [you are pregnant]" she said. "But I don't have any money. My boyfriend's not working. He doesn't care to work right now." Because of their lack of money, Becky said she did not have a "choice" about her need to work, adding that she would like to work "until I can't", indicating there was a small window of time in which employment was an option. Her baby was due about a month before her scheduled release from the bail house. Where would she go then? Becky expressed no certainty, and little hope, about what would be next for her and her child. "I have no idea of what's going on yet," she said. She ended this with a low laugh, which sounded more like a 'huh' than a happy chuckle. "I don't know."

Becky's pregnancy clearly added another layer of uncertainty to her future plans. Going into this research project, I had imagined that part of this project would involve exploring how motherhood intersected with employment in women's reintegration priorities and plans. I had expected more women to be ambivalent about employment because of the conflicting demands of childcare. Certainly, this is a struggle commonly found in literature about working women (i.e. Baker 2010; Meers and Strober 2009). There is also a significant body of literature that examines women's criminalization and incarceration with a focus on their roles as mothers, 
particularly with regard to separation from their children (i.e. Golden 2005; Hughes Miller 2015; Eljdupovic, Gordana; Bromwich 2013; Berry and Smith-Mahdi 2006). Yet while thirteen of the women I interviewed told me they had children (and Becky was expecting her first), only one indicated she would rather look after her kids than find a job. Elaine had seven children, ages three to sixteen. She described herself as "a mommy getting paid by love". While she suggested she could work hard if given a job, her priority was returning to her kids and to their full-time care. She also pointed out that she received more in social assistance as a caregiver for her children than she could expect to earn in a job.

In their research on incarcerated and reintegrating women in Canada, Kendra Delveaux, Kelley Blanchette and Jacqueline Wickett found that childcare issues were noted as a barrier to employment by the majority of CSC staff working with reintegrating women, but was raised as an issue by only one of reintegrating women they interviewed $(2005,104)$. My findings are similar in that nine of thirteen service providers I interviewed identified childcare as a barrier to employment, but this was not a concern expressed by the reintegrating women. This may be because the majority of the reintegrating women who were mothers did not have their children living with them. Their children were either grown up or were being raised by someone else. Lin was the only woman I interviewed who was living with, and caring for, her school-age children; but she had other family members who assisted with their care. As noted above, Ashley talked about her son and the pain of being separated from him during her incarceration. But she still resisted the pressure to get a job, even though it was tied to regaining custody. Nicole indicated that finding work was important given the demands of children's expenses, which suggested she expected to be involved in raising her sons who were currently living with their father. She and Zahra told me they were planning to return to their children, but they both appreciated the time 
they had in the halfway house to focus on their own plans. "I think having, well, being [at this halfway house] and having this like time to, I guess, take for myself and having that, like you know, stability for myself, it can only mean better stability in the future," said Nicole. Zahra was adamant that she wanted to do more than return to being a stay-at-home mom. She described her life prior to her incarceration by saying "I didn't get to do anything I wanted to. It was always about [my husband], my family, the kids... I wasn't doing anything with my life. Just sitting on welfare, taking care of my kids" She described her stay in the halfway house as time to re-define herself and build a new way forward. 'Now it's just about me," she said. The 'demands' of motherhood should thus be recognized as more than the tasks of raising children. When service providers discussed how childcare interfered with employability, they seemed to be referring to challenges such as the cost to pay for babysitting or daycare being almost equivalent, or even more, than the income earned at a minimum-wage job, or that women could not work overnight shifts if they had to be home to take care of their children. Yet, as the narratives of reintegrating women suggest, motherhood can also mean losing one's sense of self and ambition, being unable to see oneself as more than a 'mom'. As such, the competing demands of motherhood may relate as much to concepts of self as to demands on time and resources.

\section{EMPLOYMENT'S REINTEGRATIVE VALUE}

This research project was launched by a curiosity about whether the claims about redemptive and restorative effects of employment were, or could be, realized by reintegrating women given their multiple barriers to employment, particularly reliable and well-paid employment. As noted in Chapter Two, employment is held up in reintegration literature, policies and programs as providing structure, routine, a social network, economic value, 
enhanced self-esteem, and personal dignity (Graffam et al. 2004; O'Brien 2001; Ricciardelli, Evans, and Peters 2017). As discussed in this chapter, service providers echoed these claims of employment's value, describing work as transformative, redemptive, and a chance to find and build success. Reintegrating women also indicated the salience of some of these claims. Joan expressed pride in having a job that was recognized by the government, and that allowed her to afford little luxuries unavailable to her when she solely dependent on welfare. Alexa, Andy, and Srila indicated that being employed helped them reclaim a sense of personal dignity as 'working people'. Melody described the supportive network she had at her job, including a manager who encouraged her to apply for a more senior position. Carla indicated that the routine of a job could help avoid idleness and temptation. Thus, in some ways my research confirms commonly expressed views about reintegration and employment.

However, the claims about employment's reintegrative value obscure the ways in which employment is mobilized as a key aspect of women's responsibilization and governance. Discourses which position employment as valuable, life-giving, identity-enriching, etc. make employment seem obvious and necessary, not only to successful reintegration, but to mental and emotional well-being. Such discourses leave little room to discuss other avenues in which women can find, or demonstrate, value, identity and meaning in their lives. For example, that many women are not allowed custody of their own children until they can demonstrate their economic independence clearly demonstrates that employability is a higher priority than motherhood. In other words, this discourages women from prioritizing their reintegrative identity as mothers and care-givers. Those who express skepticism about the value of minimum-wage or menial employment are encouraged to see such jobs as stepping stones to the type of employment that would provide these benefits. 
Claims about employment's value as identity-building (Shivy et al. 2007; Ricciardelli, Evans, and Peters 2017) have been particularly fascinating to me as I questioned the extent to which waged work such as washing dishes, cleaning motel rooms, and scrubbing toilets, offered women an affirming identity that would provide for socio-political inclusion. In this regard, women's discussions of how employment relates to their identity is more complex and dynamic than is currently expressed in literature. To a certain extent, women are instructed to work toward some future, successful self, putting up with menial or mundane work in order to make possible the mobilization of this future possibility. Some women seemed to accept this framing of work as a step toward a future identity, an approach that seemed most clearly articulated by those like Srila who differentiated her current 'job' from a future 'career'. Additionally, women like Malone indicated that employers would get to know her, not the 'inmate', suggesting that through employment she could realize a non-criminalized identity. In these ways, employment can be seen as mobilized by women to create new, future identities distinct from their past.

Other women, like Joan, described employment as opportunities for redemption and as a way achieve a degree of civic belonging, but did not indicate a need or desire to advance toward a different future identity. Joan did not want to work more than three days a week, aware that when she had tried to do this it had taken a toll on her health. Neither did she apply for a similar job in another shelter, even though it paid better, because she was not convinced it was worth the risk of losing the job that she had. She indicated that her current job recognized her skills and abilities, including those which she had gained through lived experiences on the street and in custody. She had found a role that allowed her to express an identity that included her past. As such, does her job offer a 'new' identity, or new expressions of her 'old' identity? 
Additionally, employment was mobilized by some women as a potential to reclaim a past self, not necessarily build toward a future self. Women like Alexa, who prior to their incarceration had been 'workers', immediately sought employment upon release in order to demonstrate something which she saw as a key aspect of herself. It seemed that for some women, like Alexa, the value of embodying a 'working person' transcends the value of the work itself, such that it matters less what type of work one is doing, and more that one is being recognized as a worker. This was sharply contrasted by women like Theresa and Lin, who insisted that there were only certain kinds of work they found valuable. Theresa insisted she would not do work that was not her passion. Lin was currently doing work she found tedious, but made it clear that she aspired to something quite different. These diverse perspectives have made me re-evaluate my assumptions about 'meaningful work' as they open up understanding of the multiple ways in which women find value through employment. 


\section{Irresponsible disempowerment}

You have to believe in yourself. You have to really find that value for yourself first as a human.

- ASHLEY

Thirty years ago, there was a spirit of cautious optimism about women's corrections in Canada. The reforms of the 1990 s sought innovative solutions to pressing problems experienced by women within Canada's prisons, problems not limited to prolonged segregation, stripsearches of female prisoners by male staff, involuntary transfers of women, and the housing of women in men's penitentiaries. Feminists, prisoner advocates, and women with experience within the criminal justice system made numerous recommendations for change in the hope of creating a model of corrections that operated on principles of empowerment, shared responsibility, and respect. They contributed to the 1990 report from the Task Force on Federally Sentenced Women, and endorsed its recommendations. Yet all the good intentions and reform efforts have been unable to undo, and may even have contributed to, the current deeply-flawed reality of women's correctional institutions and associated programs and policies (e.g. HannahMoffat 2001; Comack 1996; Monture-Angus 1999; Hayman 2006). In this dissertation, I offer a contemporary contribution to the scholarship of the past three decades that has queried, monitored and challenged practices and policies relating to women's corrections in Canada, and I demonstrate that the apparatus of women's corrections has failed to honour the spirit and intent of recommendations to which it agreed thirty years ago.

One key reason for this failure, I believe, is the misappropriation of the efforts to emphasize women's lived experiences of trauma, abuse, poverty, racism, and other systemic wrongs. While feminists had emphasized the context of women's criminalization (Comack 1996; Monture- 
Angus 1999), correctional policies and practices emphasize women's individual, emotional, and psychological responses to their context. Efforts to identify women's gender-specific needs were mobilized into strategies of governance that, disguised as 'empowerment' and 'benevolent governance' (Hannah-Moffat 2001), shored up practices of individual responsibilization. Additionally, the subject position of 'responsibilized woman', as expressed through correctional discourses, is conceptually incompatible with that of the criminalized woman. Throughout this dissertation I have demonstrated that the incompatibility of the figuration of the broken psy woman with that of the responsibilized woman creates a tautological tension that is unresolved, and even enhanced, through existing narratives and practices of empowerment.

In drawing this project to a close, I reflect upon the possible repercussions of some of they key claims I have been advancing through this dissertation. In particular, I focus on 1) my concerns about the mobilization of discourses around women's mental illness; 2) the ways in which emphasis on women's responsibilization obscures the roles of community-based service providers; 3) the limitations of employment in offering social belonging; and 4) how women's expressions of ontological distinctions between incarcerated and reintegrating selves invites considerations of our understanding identity and change. I end with some advice given by the reintegrating women I interviewed, advice that was directed at other reintegrating women but which could also apply to those working to improve the supports available to them.

During my field research, I was struck by women's descriptions of their incarceration and the distress, anxiety, and depression it triggered. They talked about the profound sorrow, worry and fear brought on by being separated from their children and loved ones. They mentioned strip searches and seemingly-arbitrary decisions that limited and constrained them. Their emotional responses to such experiences seemed not only understandable, but predictable. Additionally, 
women who have experienced trauma, sexual assault, violence, and intersecting forms of marginalization and oppressions have complex mental and emotional responses to their environment and the people around them (Van der Kolk 2014). It is not uncommon to see statistics about the number of women in federal prisons who have 'mental disorders' (Sapers 2016; Zinger 2018). While I fully agree with the call for more mental health supports for incarcerated women, I wonder if such 'diagnoses' mask the harmful effects of prison by locating the focus on women, not their harmful environment. Certainly, there is a significant and important body of critical legal, criminological, and feminist research documenting and responsibilizing correctional systems for their emotionally and psychologically damaging practices (e.g. Price 2015; Kilty 2012; Hayman 2006; Comack 2018; Hannah-Moffat 2001). Yet I query how discourses about the emotional and psychological impacts of incarceration (and criminalization, separation, trauma, etc.) limit the subject positions available to incarcerated and reintegrating women. As I have demonstrated, the figuration of the broken psy woman pathologizes women's responses to their lived experience. Clearly, this raises serious questions about how women's advocates can discuss the contextual and gender-based needs of women prisoners.

Related to my concerns about how we frame women's experiences and distress, I am concerned about how policies directed at women's 'empowerment' are being realized and mobilized in community-based supports for reintegrating women. Within community-based organizations, narratives about the barriers facing reintegrating women often divides responsibility for these barriers between the institutions (as evidenced in criticisms about the lack of programming and support available to women inside prisons and jail, or in discussions about the burdensome administrative regulations reintegrating women must follow), and reintegrating 
women themselves (as evidenced in comments about the need for women to be more motivated or develop confidence). Expressions about the need for women to embark on the 'steps to success' and to be motivated to improve their circumstances echo the responsibilization discourses of the correctional institution. Similarly, the emphasis I saw within community-based organization on women's experiences of trauma and marginalization supported the subject position of the criminalized and broken-psy woman. Not only does this result in the same tautological incompatibility, but it leaves out of focus the roles and responsibilities of service providers and community-based organizations.

The dual emphasis on the responsibilities of institutions and reintegrating women by those within community-based organizations obscures the power, and arguably even conceptually limits the agency, of service providers. As noted in Chapter Six, some people working in feminist helping professions, such as therapists and social workers, are uneasy about acknowledging the power they have over those they assist (L. S. Brown 1994; Becker 2005). The feminist claims of 'equality' between service providers and clients denies the power that the former have in shaping the experience, process, and outcomes of therapeutic interventions. Similarly, the mobilization of the language of agency directed toward reintegrating women, which I have described as the focus on women's navigation of barriers such as the criminal record and their efforts to find employment, obscures the real or potential vulnerabilities women have in their relationships with service providers. This is especially important to consider in the context of reintegration, where community-based service providers often have the authority to enforce administrative and disciplinary rules governing women's actions (such as curfews, program attendance, and drug and/or alcohol consumption). Service providers are constrained by the disciplinary apparatus of corrections and reintegration. They are also contributing to it. In 
writing this dissertation, I have prioritized the narratives and described experiences of reintegrating women with regard to community-based supports. More research is required to explore more fully how service providers understand their roles and responsibilities. What subject positions, for both reintegrating women and service providers, are created through models such as 'trauma-informed' and 'strength-based' care? Such examinations could not only serve to support the call for more investment in community-based organizations, but also to bring awareness to the dynamics and complexities of power relations within feminist 'empowerment' efforts.

My third closing point relates to employment as the dominant indicator of successful reintegration. Narratives abound in this research, and in the broader literature, about the inherent value of (legitimate) employment, about reintegration as a transition from illegal and illegitimate activities to becoming law-abiding members of the community, and about the centrality of employment as an identity marker. Such discourses about employment reify ideologies about work as meaningful and redemptive, as a 'soul craft'. This has several implications. For workers whose tasks are tedious, or unappealing, how should they interpret the call that this work should be meaningful to their lives? Suggesting that all work is meaningful denies the reality that many people must perform employment tasks that do not correspond with their interests and preferences. I will give an example from my own experience. One summer, when my economic situation was particularly desperate, I took work wherever I could find it. One job involved 'picking chickens' who were destined to become dog food. This meant entering a suffocating barn and grabbing scrawny chickens out of stacked cages. I had been instructed to hold five birds in each hand, dangling them upside-down as they squawked and flapped, covering me with droppings and feathers. I would carry ten birds outside to a trailer, toss them in, then return to the 
barn for more. The only 'meaning' this work had for me was the payment, in cash, at the end of the day. If someone had suggested to me that this work was inherently valuable, or that it would define me, I would have been offended, or discouraged about my prospects. Suggesting that work in inherently valuable and meaningful denies the realities of work that is done, work that is tolerated, because the economic reality is that one must earn an income in order to survive in our capitalist economy.

The narratives of the reintegrating women I interviewed challenged idealizations of work as inherently meaningful, or even as providing economic independence. Many recognized that the opportunities available to them were boring, damaging to their health, or otherwise unappealing. They described such work as a means to an end, the end being the pay-cheque. Thinking about their experiences, and placing that within the current context of the precarious gig economy, I wonder about the ways in which the subject position of the worker, a position which valorizes individual productivity as narrowly conceived with the confines of waged employment, limits our recognition of, and appreciation for, other possibilities for social belonging. Are we not foreclosing other opportunities for belonging that could be more accessible (such that they do not require a criminal record check) and reflective of women's wants and interests? This is not to say that some reintegrating women do not want waged work. This research clearly shows that many do, and they expend significant effort to demonstrate this. But I believe it is important to ask what other possibilities could be made available to women that could allow for, and create, opportunities for inclusion. Indeed, reintegrating women indicate they have other aspects of their identity that could take precedence to being a worker, such as Elaine's prioritization of being a mother, or Holly's interest in diet and healthy living. Our capitalist system, and particularly the high costs of housing and other living expenses in urban areas, certainly requires that 
reintegrating women be given opportunities and supports in finding employment. However, the subject position of the employable woman should not be the only one to which incarcerated and reintegrating women are directed. There is a need to foster more holistic and socially-based conceptions of redemptive subject positions for women who are reintegrating into our communities.

The final point I want to make relates to identity. Reintegrating women expressed in various ways that they were ontologically distinct from incarcerated women. Sometimes this was done through the use of euphemisms to refer to incarceration. Women said they had 'been away' or had been 'dealing with a situation'. Such descriptions of time spent inside prison can be understood as a resistance to the identity of being a criminalized woman. Another frequently used narrative device to indicate separation from the incarcerated identity was the use of temporal distinctions. The incarcerated woman was someone from the past; she was no longer their identity. Such distinctions do not resist the criminalized identity by obscuring it (such as through euphemisms), but rather by placing it outside of the current narrative of self. Even while women described being profoundly marked and impacted by their criminalization and incarceration, indeed even to have had their 'identity' bound up in those experiences, their expressions of temporal distinctions can be understood as efforts to shed that previous identity. Their articulations of distinct identities invite consideration of how we understand the relationship between someone's past and present. Are we ever not who we once were, or more specifically, what we once did? If we are not, what responsibility do we currently have for actions done by the past self? In writing this dissertation, I have been aware of these philosophical questions that are foundational to the rationales of corrections, responsibilization, and reintegration. How we, as individuals and a collective, understand possibilities for internal 
and personal change are at the heart of how we understand reintegration and the opportunities criminalized individuals should be afforded to leave their past behind them. Reintegration is a temporal, geographical, and ontological process. Women transition away from being 'inmates' in the confines of a prison, and enter a new, liminal field of both possibilities and restrictions. Reintegration is thus the construction of a post-carceral identity. My dissertation demonstrates how current conceptions of post-carceral identity are narrowly limited (and particularly focused on employability), suggesting the need for new imaginaries of subject possibilities for reintegrating women.

\section{'DON'T GIVE UP': ADVICE FROM REINTEGRATING WOMEN}

At the close of each interview, I asked reintegrating women if they had any advice, both for service providers in terms of what supports would be effective and meaningful, and to other women. It seems appropriate to end with their words, which demonstrate the tenacity and fierceness of spirit so many of these women expressed within the context of daunting obstacles.

Don't give up. Keep going. It gets better. Um, actually it gets harder, and then it gets better. - Andy

Throughout this dissertation I have articulated my concerns about the ways in which women are responsibilized for their own success. More needs to be done to support them, and to acknowledge both the possibilities and limitations of employment.

Don't give up. That's my advice. Do not give up. You did not give up in jail, right? So don't come out here and give up now, you know? You come this far. Donisha 
The ways in which women have been shaped and harmed by their experiences of trauma and violence needs to be acknowledged, but so too must women's strength and resilience. My hope is that in sharing the narratives of the women who participated in this project, I have reflected both their profound challenges and their remarkable resilience.

I know it's scary. But, you gotta push forward. You gotta get through this. Melody 


\section{Works Cited}

Aboriginal_Justice_Implementation_Committee. 1999. “Final Report: Aboriginal Justice Implementation Commission." Winnipeg.

Adelberg, Ellen, and Claudia Currie. 1987. Too Few To Count: Canadian Women in Conflict with the Law. Vancouver: Press Gang.

Ahmed, Sara. 2017. Living a Feminist Life. Durham \& London: Duke University Press.

Allan, S., D. Bennett, and J. Chettiar. 2014. "My Work Should Not Cost Me My Life: The Case against Criminalizing the Purchase of Sex in Canada." Vancouver.

Angelis, Barbara De. 1995. Confidence: Finding It and Living It. Carlsbad: Hay House Publishing.

Armstrong, Pat, and Hugh Armstrong. 2010. The Double Ghetto: Canadian Women and Their Segregated Work. 3rd editio. Oxford: Oxford University Press.

Backhouse, Constance. 1991. Petticoats and Prejudice. Edited by Women's Press for the Osgoode Society. Toronto.

Backman, Christel. 2011. "Vocabularies of Motive among Employers Conducting Criminal Background Checks." Acta Sociologica 54 (1): 27-44.

https://doi.org/10.1177/0001699310392601.

Baillargeon, Jacques, Ingrid A. Binswanger, Joseph V. Penn, Brie A. Williams, and Owen J. Murray. 2009. "Psychiatric Disorders and Repeat Incarcerations: The Revolving Prison Door." American Journal of Psychiatry 166 (1): 103-9. https://doi.org/10.1176/appi.ajp.2008.08030416.

Baker, Maureen. 2010. "Motherhood, Employment and the 'Child Penalty."' Women's Studies International Forum 33 (3): 215-24.

Balfour, Gillian, and Elizabeth Comack, eds. 2014. Criminalizing Women: Gender and (In)Justice in Neoliberal Times. Winnipeg: Fernwood Publishing.

Barber, James. 1995. Social Work with Addictions. Basingstoke: Macmillan.

Bass, Ellen, and Laura Davis. 1994. The Courage to Heal: A Guide for Women Survivors of Child Sexual Abuse. New York: HarperPerennial.

Beaulaurier, Richard L., and Samuel H. Taylor. 1999. "Self-Determination and Consumer Control: Guiding Principles in the Empowerment Model as Utilized by the Disability Rights Movement." In Empowerment Practice in Social Work: Developing Richer Conceptual Foundations, edited by Lillian M. Wells and Wes Shera, 159-77. Toronto: Canadian Scholars' Press Inc.

Becker, Dana. 2005. The Myth of Empowerment: Women and the Therapeutic Culture in America. New York and London: New York University Press.

Begun, Audrey L, Theresa J Early, and Ashleigh Hodge. 2016. "Mental Health and Substance Abuse Service Engagement by Men and Women During Community Reentry Following Incarceration." Administration and Policy in Mental Health and Mental Health Services Research 43 (2): 207-18. https://doi.org/10.1007/s10488-015-0632-2.

Berk, Sarah Fenstermaker. 1985. The Gender Factory: The Apportionment of Work in American Households. New York: Plenum.

Berry, Phyllis E., and J. Smith-Mahdi. 2006. "Doing Mothering Behind Bars: A Qualitative Study of Incarcerated Mothers." Journal of Crime and Justice 29 (1): 101-21. https://doi.org/10.1080/0735648X.2006.9721219. 
Bodkin, Claire, Lucie Pivnick, Susan J. Bondy, Carolyn Ziegler, Ruth Elwood Martin, Carey Jernigan, and Fiona Kouyoumdjian. 2019. "History of Childhood Abuse in Populations Incarcerated in Canada: A Systematic Review and Meta-Analysis." American Journal of Public Health 109 (3): e1-11. https://doi.org/10.2105/AJPH.2018.304855.

Boehm, Amnon, and Lee H. Staples. 2002. "The Functions of the Social Worker in Empowering: The Voices of Consumers and Professionals." Social Work 47 (4): 449-60.

Bonta, James, and D. Andrews. 1977. "Risk-Need-Responsivity Model for Offender Assessment and Rehabilitation.” Vol. 5. Ottawa. https://doi.org/10.1185/03007997709110168.

Bosworth, Mary, and Emma Kaufman. 2013. "Gender and Punishment.” In Handbook of Punishment and Society, edited by Jonathan Simon and R. Sparks. London: Sage.

Boudon, Raymond. 2003. "Beyond Rational Choice Theory." Annual Review of Sociology 29: 121.

Bouffard, Jeffrey A., and Faye S. Taxman. 2000. "Client Gender and the Implementation of JailBased Therapeutic Community Programs.” Journal of Drug Issues 30 (4): 881-900.

Bourdieu, Pierre. 1977. Outline of a Theory of Practice. Cambridge: Cambridge University Press.

Brennan, Sarah. 2014. "Canada's Mother-Child Program: Examining Its Emergence, Usage and Current State." Canadian Graduate Journal of Sociology and Criminology 3 (1): 11-33.

Brinkman, Svend, and Steinar Kvale. 2015. InterViews: Learning the Craft of Qualitative Interviewing. 3rd ed. Thousand Oaks: SAGE Publications, Inc.

Bromwich, Rebecca Jaremko. 2015. Looking for Ashely: Re-Reading What the Smith Case Reveals about the Governance of Girls, Mothers and Families in Canada. Toronto: Demeter Press.

Brown, Gregory P., John P. Hirdes, and Brant E. Fries. 2015. "Measuring the Prevalence of Current, Severe Symptoms of Mental Health Problems in a Canadian Correctional Population: Implications for Delivery of Mental Health Services for Inmates." International Journal of Offender Therapy and Comparative Criminology 59 (1): 27-50. https://doi.org/10.1177/0306624X13507040.

Brown, Jason, Nancy Higgitt, Christine Miller, Susan Wingert, Mary Williams, and Larry Morrissette. 2006. "Challenges Faced by Women Working in the Inner City Sex Trade." Canadian Journal of Urban Research 15 (1): 36-53.

Brown, Laura S. 1994. Subversive Dialogues: Theory in Feminist Therapy. New York: Basic Books.

Browne, A. 1987. When Battered Women Kill. New York: Free Press.

Burnett, Ros. 2004. "To Reoffend or Not to Reoffend? The Ambivalence of Convicted Property Offenders." In After Crime and Punishment: Pathways to Offender Reintegration, edited by Shadd Maruna and Russ Immarigeon. Taylor \& Francis.

Butler, Judith. 1990. Gender Trouble: Feminism and the Subversion of Identity. New York: Routledge.

Cahn, Naomi R. 2000. "Policing Women : Moral Arguments and the Dilemmas of Criminalization ." DePaul Law Review 49: 817-29.

Canadian_Civil_Liberties_Association. 2014. "False Promises, Hidden Costs: The Case for Reframing Employment and Volunteer Police Record Check Practices in Canada."

Carlton, Bree, and Marie Segrave. 2011. "Women's Survival Post-Imprisonment: Connecting Imprisonment with Pains Past and Present." Punishment \& Society 13 (5): 551-70. 
Chase, Susan E. 1995. "Taking Narrative Seriously: Consequences for Method and Theory in Interview Studies." In Interpreting Experience: The Narrative Study of Lives, edited by Ruthellen Josselson and Amia Lieblich, 1-26. Thousand Oaks: SAGE Publications, Inc.

Chesler, Phyllis. 1972. Women and Madness. Garden City: Doubleday.

Chunn, Dorothy E., and Robert Menzies. 2014. "Producing Feminist Knowledge: Lessons from the Past." In Demarginalizing Voices: Commitment, Emotion, and Action in Qualitative Research, edited by Jennifer M. Kilty, Maritza Felices-Luna, and C. Fabian, Sheryl. Vancouver: UBC Press.

Cobbina, Jennifer E. 2010. "Reintegration Success and Failure: Factors Impacting Reintegration Among Incarcerated and Formerly Incarcerated Women.” Journal of Offender Rehabilitation 49 (3): 210-32.

Code, Lorriane. 1991. What Can She Know? Feminist Theory and the Construction of Knowledge. New York: Cornell University Press.

Cohen, Stanley. 1985. Visions of Social Control. Cambridge: Polity Press.

Colantonio, Angela, Hwan Kim, Stefan Allen, Mark Asbridge, Josian Petgrave, and Serge Brochu. 2014. "Traumatic Brain Injury and Early Life Experiences Among Men and Women in a Prison Population." Journal of Correctional Health Care 20 (4): 271-79. https://doi.org/10.1177/1078345814541529.

Comack, Elizabeth. 1993a. Feminist Engagement with the Law. Ottawa: CRIAW.

- 1993b. Feminist Engagement with the Law. Ottawa: CRIAW. 1996. Women in Trouble: Connecting Women's Laws Violations to Their Histories of Abuse. Halifax: Fernwood Publishing.

- 2018. Coming Back to Jail: Women, Trauma, and Criminalization. Halifax \& Winnipeg: Fernwood Publishing.

Comack, Elizabeth, and Gillian Balfour. 2004. The Power to Criminalize: Violence, Inequality and the Law. Edited by Elizabeth Comack and Gillian Balfour. Halifax: Fernwood Publishing.

Comack, Elizabeth, Cara Fabre, and Shanise Burgher. 2015. "The Impact of the Harper Government's 'Tough on Crime' Strategy: Hearing from Frontline Workers.” Winnipeg. https://www.policyalternatives.ca/sites/default/files/uploads/publications/Manitoba Office/2015/09/Tough on Crime WEB.pdf.

Corbin, Juliet M., and Anselm L. Strauss. 2008. Basics of Qualitative Research: Techniques and Procedures for Developing Grounded Theory. 3rd ed. Los Angeles: Sage Publications.

Correctional_Service_of_Canada. 2007. "A Roadmap to Strengthening Public Safety: Report of the CSC Review Panel, October 2007." Ottawa.

Crawford, Alison. 2016. "Public Safety Minister Vows to Overhaul 'punitive' Criminal Pardons System.” CBC News, January 20, 2016. https://www.cbc.ca/news/politics/liberal-criminaljustice-pardons-1.3412533.

Crenshaw, Kimberle. 1991. "Mapping the Margins : Intersectionality, Identity Politics , and Violence Against Women of Color." Stanford Law Review 43 (6): 1241-99.

Cruikshank, Barbara. 1999. The Will to Empower: Democratic Citizens and Other Subjects. Ithaca: Cornell University Press.

Cubellis, Michelle A, Douglas N Evans, and Adam G Fera. 2019. "Sex Offender Stigma: An Exploration of Vigilantism against Sex Offenders." Deviant Behavior 40 (2).

Davis, Celeste, Stephen J. Bahr, and Carol Ward. 2013. "The Process of Offender Reintegration: 
Perceptions of What Helps Prisoners Reenter Society." Criminology and Criminal Justice 13 (4): 446-69.

Dean, Mitchell. 2010. Governmentality: Power and Rule in Modern Society. 2nd ed. London: Sage.

Delveaux, Kendra, Kelley Blanchette, and Jacqueline Wickett. 2005. "Employment Needs, Interests, and Programming for Women Offenders." Ottawa.

Devault, Marjorie L. 1990. “Talking and Listening from Women's Standpoint: Feminist Strategies for Interviewing and Analysis.” Social Problems 37 (1): 96-116. https://doi.org/10.1525/sp.1990.37.1.03a00070.

DeVault, Marjorie L. 1999. Liberating Method: Feminism and Social Research. Philadelphia: Temple University Press.

Devault, Marjorie L. 1996. "Talking Back to Sociology: Distinctive Contributions of Feminist Methodology." Annual Review of Sociology 22: 29-50.

Dobash, R. Emerson, and Russell Dobash. 1992. Women, Violence and Social Change. London: Routledge.

Dodge, Mary, and Mark R. Pogrebin. 2001. "Collateral Costs of Imprisonment for Women: Complications of Reintegration." The Prison Journal 81 (1): 42-54.

Doucet, Andrea. 2008. “"From Her Side of the Gossamer Wall(s)': Reflexivity and Relational Knowing." Qualitative Sociology 31 (1): 73-87.

Dowden, Craig, and D.A. Andrews. 1999. "What Works for Female Offenders: A Meta-Analytic Review." Crime \& Delinquency 45 (4): 438-52.

Duckworth, Angela Lee. 2016. Grit: The Passion and Power of Perseverance. New York: Scribner.

Dunn, Jennifer L., and Melissa Powell-Williams. 2007. “"Everybody Makes Choices': Victim Advocates and the Social Construction of Battered Women's Victimization and Agency." Violence Against Women 13 (10): 977-1001. https://doi.org/10.1177/1077801207305932.

Duran, Bonnie, Eduardo Duran, and Maria Yellow Horse Brave Heart. 1999. "Native Americans and the Trauma of History." In Studying Native Americans: Problems and Prospects, edited by Russel Thornton, 60-76. Wisconsin: University of Wisconsin Press.

Eagly, Alice H., and Steven J. Karau. 2002. "Role Congruity Theory of Prejudice toward Female Leaders.” Psychological Review 109 (3): 573-98. https://doi.org/10.1037/0033295X.109.3.573.

Eljdupovic, Gordana; Bromwich, Rebecca Jaremko, ed. 2013. Incarcerated Mothers: Oppression and Resistance. Bradford: Demeter Press.

Eljdupovic, Gordana, and Rebecca Jaremko Bromwich. 2013. "Introduction.” In Incarcerated Mothers: Oppression and Resistance, edited by Gordana Eljdupovic and Rebecca Jaremko Bromwich, 1-25. Toronto: Demeter Press.

Everett, Barbara, and Ruth Gallop. 2001. The Link between Childhood Trauma and Mental Illness: Effective Interventions for Mental Health Professionals. Thousand Oaks: Sage.

Ezzy, Douglas. 2002. Qualitative Analysis: Practice and Innovation. London: Routledge.

Faith, Karlene. 1993. Unruly Women: The Politics of Confinement and Resistance. Vancouver: Press Gang.

Farley, Melissa, Jacqueline Lynne, and Ann J. Cotton. 2005. "Prostitution in Vancouver: Violence and the Colonization of First Nations Women." Transcultural Psychiatry 42 (2): 242-71. https://doi.org/10.1177/1363461505052667. 
Feeley, Malcolm, and Jonathan Simon. 1992. "The New Penology: Notes on the Emerging Strategy of Corrections and Its Implications." Criminology 30 (4): 449-74.

Ferrao, Vincent. 2010. "Paid Work." In Women in Canada: A Gender-Based Statstical Report. Ottawa: Stastics Canada.

Fontaine, Jocelyn, and Jennifer Biess. 2012. "Housing as a Platform for Formerly Incarcerated Persons." Washington D.C. http://www.urban.org/sites/default/files/alfresco/publicationpdfs/412552-Housing-as-a-Platform-for-Formerly-Incarcerated-Persons.PDF.

Foran, Caroline. 2019. The Confidence Kit: Your Bullsh*t-Free Guide to Owning Your Fear.

Fortin, Doris. 2004. "Program Strategy for Women Offenders." Ottawa. http://www.cscscc.gc.ca/text/prgrm/fsw/fsw18/fsw18_e.pdf.

Foucault, Michel. 1977. Discipline and Punish. Translated. New York: Vintage Books.

- 1980. The History of Sexuality: Volume One, An Introduction. New York: Vintage Books.

. 1983. "The Subject and Power." In Michel Foucault: Beyond Structuralism and Hermeneutics, edited by Herbert L. Dreyfus and Paul Rabinow, 2nd ed., 208-26. Chicago: University of Chicago Press.

- 1984. The Foucault Reader. Edited by Paul Rabinow. New York: Pantheon. . 1991. "Governmentality.” In The Foucault Effect, edited by Graham Burchell, Colin Gordon, and Peter Miller. Chicago: University of Chicago Press.

Fox, Kathryn J. 2013. "Restoring the Social: Offender Reintegration in a Risky World." International Journal of Comparative and Applied Criminal Justice 00 (3): 1-22. http://www.tandfonline.com/doi/abs/10.1080/01924036.2013.848221.

Francis, Becky. 2002. "Relativism, Realism , and Feminism : An Analysis of Some Theoretical Tensions in Research on Gender Identity." Journal of Gender Studies 11 (1): 39-54.

Freeman, Richard. 2008. "Incarceration, Criminal Background Checks, and Employment in a Low(Er) Crime Society." Criminology \& Public Policy 7 (3): 405-12.

Friedan, Betty. 1965. The Feminine Mystique. Harmondsworth: Penguin.

Garland, David. 1990. Punishment \& Modern Society: A Study in Social Theory. Chicago: University of Chicago Press.

- 1996. "The Limits of the Sovereign State: Strategies of Crime Control in Contemporary Society." The British Journal of Criminology 36 (4): 445-71. https://doi.org/10.1093/oxfordjournals.bjc.a014105.

- 1997. "Governmentality' and the Problem of Crime: Foucault, Criminology, Sociology." Theoretical Criminology 1 (2): 173-214. https://doi.org/10.1177/1056492611432802.

- 2001. The Culture of Control. Oxford: Oxford University Press.

Gatrell, Caroline. 2008. Embodying Women's Work. Maidenhead: Open University Press.

Gatta, Mary. 2014. All I Want Is a Job! Unemployed Women Navigating the Public Workforce System. Stanford: Stanford University Press.

Glaser, Barney G., and Anselm L. Strauss. 1967. The Discovery of Grounded Theory: Strategies for Qualitative Research. Chicago: Aldine.

Glaser, Daniel. 1956. "Criminality Theories and Behavioural Images." The American Journal of Sociology 6 (5): 433-44.

Glick, Peter. 1991. "Trait-Based and Sex-Based Discrimination in Occupational Prestige, Occupational Salary, and Hiring." Sex Roles 25 (5): 351-73. 
Glover, Judith, and Gill Kirton. 2006. Women, Employment and Organization. London: Routledge.

Gobeil, Renee, and Meredith Robeson Barrett. 2007. "Rates of Recidivism for Women Offenders." Corectional Service Canada. https://doi.org/10.1017/CBO9781107415324.004.

Goffman, Erving. 1963. Stigma: Notes on the Management of Spoiled Identity. Englewood Cliffs: Prentice Hall.

Golden, Renny. 2005. War on the Family: Mothers in Prison and the Families They Leave Behind. New York: Routledge.

Gordon, Colin. 1991. "Governmental Rationality: An Introduction." In The Foucault Effect, edited by Graham Burchell, Colin Gordon, and Peter Miler, 1-52. Chicago: University of Chicago Press.

Gorz, Andre. 1999. Reclaiming Work: Beyond the Wage-Based Society. Cambridge, UK: Polity Press.

Gottfredson, Linda S. 1981. "Circumscription and Compromise: A Developmental Theory of Occupational Aspirations.” Journal of Counseling Psychology Monograph 28 (6): 545-79.

Graffam, Joe, Alison Shinkfield, Barbara Lavelle, and Wenda McPherson. 2004. "Variables Affecting Successful Reintegration as Perceived by Offenders and Professionals." Journal of Offender Rehabilitation 40 (1-2): 147-71.

Grant, Melissa Gira. 2014. Playing the Whore: The Work of Sex Work. London \& New York: Verso.

Greiner, Leigh E., Moira A. Law, and Shelley L. Brown. 2015. "Using Dynamic Factors to Predict Recidivism among Women: A Four-Wave Prospective Study." Criminal Justice and Behavior 42 (5): 457-80. http://cjb.sagepub.com/cgi/doi/10.1177/0093854814553222.

Griffiths, Curt T., Yvon Dandurand, and Danielle Murdoch. 2007. "The Social Reintegration of Offenders and Crime Prevention." Ottawa.

Gutierrez, Lorraine M., and Edith Anne Lewis. 1999. Empowering Women of Color. New York: Columbia University Press.

Haan, Willem De, and Ian Loader. 2002. "On the Emotions of Crime, Punishment and Social Control." Theoretical Criminology 6 (3): 243-53.

Hagan, John. 1993. "The Social Embeddedness of Crime and Unemployment." Criminology 31 (4): 465-91.

Hagan, John, and Ronit Dinovitzer. 1999. "Collateral Consequences of Imprisonment for Children, Communities, and Prisoners." In Crime and Justice, Volume 26: Prisons, edited by Michael Tonry and Joan Petersila, Volume 26, 121-62. Chicago: University of Chicago Press.

Hallsworth, Simon, and John Lea. 2011. "Reconstructing Leviathan: Emerging Contours of the Security State." Theoretical Criminology 15 (2): 141-57. https://doi.org/10.1177/1362480610383451.

Haney, Craig. 1982. "Criminal Justice and the Nineteenth-Century Paradigm." Law and Human Behavior 6 (3/4): 191-235.

Haney, Lynne. 2010. Offending Women: Power, Punishment, and the Regulation of Desire. Berkeley: University of California Press.

Hannah-Moffat, Kelly. 1999. "Moral Agent or Actuarial Subject: Risk and Canadian Women's Imprisonment." Theoretical Criminology 3 (1): 71-94.

- 2000. "Re-Forming the Prison - Rethinking Our Ideals." In An Ideal Prison? Critical 
Essays on Women's Imprisonment in Canada2, edited by Kelly Hannah-Moffat and

Margaret Shaw, 30-40. Halifax: Fernwood Publishing.

- 2001. Punishment in Disguise: Penal Governance and Federal Imprisonment of Women

in Canada. Toronto: University of Toronto Press.

. 2002. "Creating Choices: Reflecting on Choices." In Women and Punishment: The

Struggle for Justice, edited by Pat Carlen. Cullompton: Willan Publishing.

_. 2004. "Losing Ground: Gendered Knowledges, Parole Risk, and Responsibility." Social

Politics 11 (3): 363-85.

- 2005. "Criminogenic Needs and the Transformative Risk Subject: Hybridizations of

Risk/Need in Penality." Punishment \& Society 7 (1): 29-51.

- 2008. "Re-Imagining Gendered Penalities: The Myth of Gender Responsivity." In

Imaginary Penalities, edited by Pat Carlen, 193-217. Collumpton: Willan Publishing.

- 2013. "Risk and Punishment." In The Sage Handbook of Punishment and Society, edited

by Jonathan Simon and Richard Sparks. London: Sage.

Hannah-Moffat, Kelly, and Paula Maurutto. 2012. "Shifting and Targeted Forms of Penal

Governance: Bail, Punishment and Specialized Courts." Theoretical Criminology 16 (2):

201-19.

Hannah-Moffat, Kelly, and Margaret Shaw. 2000. An Ideal Prison? Critical Essays on Women's Imprisonment in Canada. Edited by Kelly Hannah-Moffat and Margaret Shaw. Halifax:

Fernwood Publishing.

Hannem, Stacey, and Chris Bruckert. 2014. "Legal Moralism, Feminist Rhetoric, and the Criminalization of Consensual Sex in Canada." In Within the Confines: Women and the Law in Canada, edited by Jennifer M. Kilty. Toronto: Women's Press.

Haraway, Donna. 1996. "Situated Knowledges: The Science Question in Feminism and the Privilege of Partial Perspective." In Feminism and Science, edited by Evelyn Fox Keller and Helen E. Longino. Oxford: Oxford University Press.

Harding, David J. 2003. "Jean Valjean's Dilemma: The Management of Ex- Convict Identity in the Search for Employment.” Deviant Behavior 24 (6): 571-95.

https://doi.org/10.1080/713840275.

Harley, Debra A., Becky Cabe, Ralph Woolums, and Tyra Turner-Whittaker. 2014.

"Vulnerability and Marginalization of Adult Ex-Offenders with Disabilities in Community and Employment Reintegration." Journal of Applied Rehabilitation Counseling 45 (4): 414.

Harner, Holly M., and Suzanne Riley. 2013. "The Impact of Incarceration on Women's Mental Health: Responses from Women in a Maximum-Security Prison." Qualitative Health Research 23 (1): 26-42.

Harrison, Lana D. 2001. "The Revolving Prison Door for Drug-Involved Offenders: Challenges and Opportunities." Crime \& Delinquency 47 (3): 462-84.

Harstock, Nancy. 1987. "The Feminist Standpoint: Developing the Ground for a Specifically Feminist Historical Materialism." In Discovering Reality: Feminist Perspectives on Epistemology, Metaphysics, and Philosophy of Science, edited by Sandra Harding and Merrill Hintikka. Boston: Reidel.

Hartwell, Stephanie. 2001. "Female Mentally Ill Offenders and Their Community Reintegration Needs: An Initial Examination." International Journal of Law and Psychiatry 24 (1): 1-11. Hayman, Stephanie. 2006. Imprisoning Our Sisters: The New Federal Women's Prisons in 
Canada. Montreal: McGill-Queen's University Press.

Heckman, James J., Jora Stixrud, and Sergio Urzua. 2006. "The Effects of Cognitive and Noncognitive Abilities on Labor Market Outcomes and Social Behavior." Journal of Labor Economics 24 (3): 411-82. https://doi.org/10.1086/504455.

Hemmings, Clare, and Amal Treacher Kabesh. 2013. "The Feminist Subject of Agency:

Recognition and Affect in Encounters with 'the Other." In Gender, Agency, and Coercion, edited by Sumi Madhok, Anne Phillips, and Kalpana Wilson, 29-46. Hampshire \& New York: Palgrave Macmillan.

Herr, Edwin L. 2001. “Career Development and Its Practice: A Historical Perspective.” The Career Development Quarterley 49: 196-211.

Hettema, Jennifer, Julie Steele, and William R. Miller. 2004. "Motivational Interviewing." Annual Review of Clinical Psychology 1 (1): 91-111. https://doi.org/10.1146/annurev.clinpsy.1.102803.143833.

Hochschild, Arlie. 1989. The Second Shift: Working Parents and the Revolution at Home. New York: Viking.

Hodge, David R, Philip Young P Hong, and Sangmi Choi. 2019. "Spirituality, Employment Hope, and Grit: Modeling the Relationship among Underemployed Urban African Americans." Social Work Research 43 (1): 43-52. https://doi.org/10.1093/swr/svy034.

Hoff, Lee Ann. 1990. Battered Women as Survivors. London: Routledge.

Holzer, Harry, Steven Raphael, and Michael Stoll. 2007. "The Effect of an Applicant's Criminal History on Employer Hiring Decisions and Screening Practices: Evidence from Los Angeles." In Barriers to Reentry? The Labor Market for Released Prisoners in PostIndustrial America, edited by Shawn Bushway, Michael Stoll, and Weiman. DF, 205-43. New York: Russell Sage Foundation.

Hooks, Bell. 1991. "Sisterhood: Political Solidarity between Women." In A Reader in Feminist Knowledge, edited by S. Gunew. London: Routledge.

Howard Society of Ontario, John, William O'Grady, and Ryan Lafleur. 2016. "Reintegration in Ontario: Practices, Priorities and Effective Models." Toronto.

Hughes Miller, Michelle. 2015. "Mothering Outside-In: Confined Children and Mothering under State Paternalism." In Criminalized Mothers, Criminalizing Mothering, edited by Joanne Minaker and Bryan Hogeveen. Toronto: Demeter Press.

Hurtado, David A., Lisset M. Dumet, Samuel A. Greenspan, Miguel Marino, and Kimberly Bernard. 2018. "Precarious Schedules Linked with Workplace Aggression in a High-Risk Occupation." American Journal of Industrial Medicine 61 (2): 181-85. https://doi.org/10.1002/ajim.22794.

Ibarra, Peter R., and John I. Kitsuse. 2003. "Claims-Making Discourse and Vernacular Resources." In Challenges \& Choices: Constructionist Perspectives on Social Problems, edited by James A. Holstein and Gale Miller, 17-50. New York: Aldine De Gruyter.

Ispa-Landa, Simone, and Charles E. Loeffler. 2016. "Indefinite Punishment and the Criminal Record: Stigma Reports Among Expungement-Seekers in Illinois." Criminology 54 (3): 387-412. https://doi.org/10.1111/1745-9125.12108.

Jeffrey, Leslie Ann, and Gayle MacDonald. 2006. “'It's the Money, Honey': The Economy of Sex Work in the Maritimes." Canadian Review of Sociology 43 (3): 313-27.

John_Howard_Society_of_Ontario. 2018. "The Invisible Burden: Police Records and the Barriers to Employment in Toronto." Toronto. 
Johnson, Jennifer. 2002. Getting By on the Minimum: The Lives of Working-Class Women. New York: Routledge.

Josselson, Ruthellen. 1995. "Imagining the Real: Empathy, Narrative, and the Dialogic Self." In Interpreting Experience: The Narrative Study of Lives, edited by Ruthellen Josselson and Amia Lieblich. Thousand Oaks: Sage Publications.

Josselson, Ruthellen, and Amia Lieblich. 1995. "Introduction." In Interpreting Experience: The Narrative Study of Lives 1, edited by Ruthellen Josselson and Amia Lieblich, ix-xiii. Thousand Oaks: Sage Publications.

Kay, Katty, and Claire Shipman. 2014. The Confidence Code: The Science and Art of SelfAssurance--What Women Should Know. New York: HarperCollins.

Kaye, Kerwin. 2012. "Rehabilitating the 'Drugs Lifestyle': Criminal Justice, Social Control, and the Cultivation of Agency." Ethnography 14 (2): 207-32. https://doi.org/10.1177/1466138112457311.

Kendall, Kathy. 2002. "Time to Think Again about Cognitive Behavioural Programmes." In Women and Punishment: The Struggle for Justice, edited by Pat Carlen, 182-98. Cullompton: Willan Publishing.

Kilty, Jennifer M. 2012a. “'It's like They Don't Want You to Get Better': Psy Control of Women in the Carceral Context." Feminism and Psychology 22 (2): 162-82. https://doi.org/10.1177/0959353512439188.

—. 2014a. "Examining the 'Psy-Carceral' Complex in the Death of Ashley Smith." In Criminalizing Women: Gender and (In)Justice in Neo-Liberal Times, edited by Gillian Balfour and Elizabeth Comack, 2nd ed. Halifax: Fernwood Publishing.

- 2014b. "The Evolution of Feminist Research in the Criminological Enterprise: The Canadian Experience." In Demarginalizing Voices: Commitment, Emotion, and Action in Qualitative Research. Vancouver: UBC Press.

Kilty, Jennifer M. 2012b. "'It's like They Don't Want You to Get Better': Psy Control of Women in the Carceral Context." Feminism and Psychology 22 (2): 162-82. https://doi.org/10.1177/0959353512439188.

Kolk, Bessel Van der. 2014. The Body Keeps the Score: Brain, Mind, and Body in the Healing of Trauma. New York: Viking.

Kornhauser, Arthur. 1965. Mental Health of the Industrial Worker: A Detroit Study. New York: John Wiley \& Sons.

Kvale, Steinar, and Svend Brinkmann. 2008. InterViews: Learning the Craft of Qualitative Research Interviewing. 2nd editio. Los Angeles: SAGE Publications, Inc.

Kwan, Samantha, and Mary Nell Trautner. 2009. "Beauty Work: Individual and Institutional Rewards, the Reproduction of Gender, and Questions of Agency." Sociology Compass 3 (6): 1017-21. https://doi.org/10.1111/j.1751-9020.2009.00243.x.

Lamont, Michele. 2000. The Dignity of Working Men: Morality and the Boundaries of Race, Class, and Immigration. Cambridge: Harvard University Press.

Langer, Neima, Joanne Barton, Donna McDonagh, Christine Noel, and Francoise Bouchard. 2002. "Rates of Prescribed Medication Use by Women in Prison." FORUM on Corrections Research 14 (2).

Lebel, Thomas P. 2012. “Invisible Stripes? Formerly Incarcerated Persons' Perceptions of Stigma." Deviant Behavior 33 (2): 89-107. https://doi.org/10.1080/01639625.2010.538365.

Lee, Judith A. B. 2001. The Empowerment Approach to Social Work Practice. New York: 
Columbia University Press.

Lefèvre-Dognin, C., H. Toure, D. Brugel, A. Laurent-Vannier, V. Verdier, and C Chevignard. 2015. "Childhood Acquired Brain Injury and Subsequent Delinquent Behavior." Annals of Physical and Rehabilitation Medicine 58 (supp 1): e138-39.

Leidner, Robin. 1993. Fast Food, Fast Talk: Service Work and the Routinization of Everyday Life. Berkeley: University of California Press.

Levitas, Ruth. 2005. The Inclusive Society? Social Exclusion and New Labour. 2nd edn. Basingstoke: Palgrave Macmillan.

Li, Spencer De, and Doris Layton Mackenzie. 2003. "The Gendered Effects of Adult Social Bonds on the Criminal Activities of Probationers." Criminal Justice Review 28 (2): 278-98. Loseke, Donileen. 2003. Thinking about Social Problems. New York: Aldine De Gruyter.

Lutz, John. 1992. "After the Fur Trade: The Aboriginal Labouring Class of British Columbia, 1849-1890." Journal of the Canadian Historical Association1 3 (1): 69-93.

Lynch, Mona. 2000. "Rehabilitation as Rhetoric: The Ideal of Reformation in Contemporary Parole Discourse and Practices.” Punishment \& Society 2 (1): 40-65. https://doi.org/0803973233.

Mackenzie, Catriona. 2009. "Personal Identity, Narrative Integration, and Embodiment." In Embodiment and Agency, edited by Sue Campbell, Letitia Meynell, and Susan Sherwin, 100-125. University Park, PA: The Pennsylvania State University Press.

MacKinnon, Shauna. 2015. Decolonizing Employment: Aboriginal Inclusion in Canada's Labour Market. Winnipeg: University of Manitoba Press.

Madhok, Sumi, Anne Phillips, and Kalpana Wilson. 2013. "Introduction.” In Gender, Agency, and Coercion, edited by Sumi Madhok, Anne Phillips, and Kalpana Wilson, 1-13. Hampshire \& New York: Palgrave Macmillan.

Mahmood, Saba. 2005. Politics of Piety: The Islamic Renewal and the Feminist Subject. Princeton: Princeton University Press.

Mahony, Tina Hotton. 2011. "Women and the Criminal Justice System." In Women in Canada: A Gender-Based Statstical Report. Ottawa: Stastics Canada.

Maidment, MaDonna. 2006. Doing Time on the Outside. Toronto: University of Toronto Press.

Malakieh, Jamil. 2018. "Adult and Youth Correctional Statistics in Canada, 2016/2017." Juristat: Canadian Centre for Justice Statistics, no. 85.

Malloch, Margaret S. 1999. "Drug Use, Prison, and the Social Construction of Femininity." Women's Studies International Forum 22 (3): 349-58. https://doi.org/10.1016/S02775395(99)00031-X.

Mangat, Raji. 2014. "More than We Can Afford: The Costs of Mandatory Minimum Sentencing." Vancouver.

March, Miranda. 2010. "Rubrics of Rehabilitation: Gendered Narratives of Selfhood in Court Mandated Treatment Facilities." New York University.

Martel, Joane, Renée Brassard, and Mylène Jaccoud. 2011. "When Two Worlds Collide: Aboriginal Risk Management in Canadian Corrections." British Journal of Criminology 51 (2): $235-55$.

Maruna, Shadd. 2001. Making Good: How Ex-Convicts Reform and Rebuild Their Lives. Washington D.C.: American Psychological Association. . 2011. "Reentry as a Rite of Passage." Punishment \& Society 13 (1): 3-28. https://doi.org/10.1177/1462474510385641. 
Mazzei, Lisa A., and Alecia Youngblood Jackson. 2009. "Introduction: The Limit of Voice." In Voice in Qualitative Inquiry: Challenging Conventional, Interpretive, and Critical Conceptions in Qualitative Research, 1-13. New York: Routledge.

McAleese, Samantha. 2017. "Job Search, Suspended: Changes to Canada's Pardon Program and the Impact on Finding Employment." In After Prison: Navigating Employment and Reintegration, edited by Rose Ricciardelli and Adrienne Peters, 83-104. Waterloo: Wilfrid Laurier University Press.

McAleese, Samantha, and Catherine Latimer. 2017. "Reforming the Criminal Records Act." Toronto.

McConnell, Ashley, Sara Rubenfeld, Jennie Thompson, and Renee Gobeil. 2014. "A Profile of Women under Community Supervision." Ottawa.

McCorkel, Jill. 2004. "Criminally Dependent? Gender, Punishment, and the Rhetoric of Welfare Reform.” Social Politics 11 (3): 386-410. https://doi.org/10.1093/sp/jxh042.

McCoy, Kate. 2010. "Into the Cracks: A Geology of Encounters with Addiction as Disease and Moral Failing.” Journal of Qualitative Studies in Education 23 (5): 615-34. https://doi.org/10.1080/09518398.2010.500632.

McDonald, Kimberly, and Linda Hite. 2016. "An Introduction to Career Development." In Career Development : A Human Resource Development Perspective, 1-14. New York: Routledge.

McInturff, Kate. 2014. “Ontario's Gender Gap: Women and Jobs Post-Recession.” Toronto. https://www.policyalternatives.ca/sites/default/files/uploads/publications/Ontario Office/2014/03/Ontario's Gender Gap FINAL.pdf.

McKim, Allison. 2008. “'Getting Gut-Level': Punishment, Gender, and Therapeutic Governance." Gender \& Society 22 (3): 303-23.

- 2014. "Roxanne's Dress: Governing Gender and Marginality through Addiction Treatment." Signs: Journal of Women in Culture and Society 39 (2): 433-58.

- 2017. Addicted to Rehab: Race, Gender, and Drugs in the Era of Mass Incarceration. New Brunswick: Rutgers University Press.

Meers, Sharon, and Joanna Strober. 2009. Getting to 50/50: How Working Parents Can Have It All. Berkeley: Viva Editions.

Menzies, Robert, and Dorothy E. Chunn. 2014. "The Making of the Black Widow: The Criminal and Psychiatric Control of Women." In Criminalizing Women: Gender and (In)Justice in Neo-Liberal Times, edited by Gillian Balfour and Elizabeth Comack, 2nd ed., 177-96. Halifax: Fernwood Publishing.

Menzies, Robert, Dorothy E. Chunn, and Wendy Chan. 2005. "Introduction." In Women, Madness and the Law: A Feminist Reader, edited by Wendy Chan, Dorothy E. Chunn, and Robert Menzies, 1-18. London: Glasshouse Press.

Meulen, Emily van der. 2010. "Illegal Lives, Loves, and Work: How the Criminalization of Procuring Affects Sex Workers in Canada." Wagadu 8 (Demystifying Sex Work and Sex Workers): 217-40.

Mikkonen, Juha, and Dennis Raphael. 2010. Social Determinants of Health: The Canadian Facts. 3rd editio. Canadian Scholars' Press Inc.

Miller, Leslie J. 2003. "Claims-Making from the Underside: Marginalization and Social Problems Analysis.” In Challenges \& Choices: Constructionist Perspectives on Social Problems, edited by James A. Holstein and Gale Miller, 92-119. Hawthorne: Aldine De 
Gruyter.

Miller, Susan L., and Michelle L. Meloy. 2006. "Women's Use of Force, Voices of Women Arrested for Domestic Violence." Violence against Women 12 (1): 89-115.

Mills, C. Wright. 1959. The Social Imagination. New York: Oxford University Press.

Mills, Sara. 2004. Discourse. London \& New York: Routledge.

Mock, Steven, and Susan Arai. 2011. "Childhood Trauma and Chronic Illness in Adulthood: Mental Health and Socioeconomic Status as Explanatory Factors and Buffers." Frontiers in Psychology 1: 1-6.

Moloughney, Brent. 2004. "A Health Care Needs Assessment of Federal Inmates in Canada." Canadian Journal of Public Health 95.

Monchalin, Lisa. 2016. "The Failed Foreign System of Criminal Justice and the Problem with Canada." In Visions of the Heart: Issues Invovling Aboriginal Peoples in Canada, edited by David Long and Olive Patricia Dickason, 4th edn. Don Mills: Oxford University Press.

Monture-Angus, Patricia. 1999. "Women and Risk: Aboriginal Women, Colonialism, and Correctional Practice." Canadian Woman Studies 19 (1-2).

- 2000. "Aboriginal Women and Correctional Practice: Reflections on the Task Force on Federally Sentenced Women." In An Ideal Prison? Critical Essays on Women's Imprisonment in Canada, edited by Kelly Hannah-Moffat and Margaret Shaw. Black Point: Fernwood Publishing.

Moran, D. 2012. "Prisoner Reintegration and the Stigma of Prison Time Inscribed on the Body." Punishment \& Society 14: 564-83. https://doi.org/10.1177/1462474512464008.

Morash, Merry. 2010. Women on Probation and Parole: A Feminist Critique of Community Programs and Services. Boston: Northeastern University Press.

Morenoff, Jeffrey D., and David J. Harding. 2014. "Incarceration, Prisoner Reentry, and Communities." Annual Review of Sociology 40: 411-29. https://doi.org/10.1146/annurevsoc-071811-145511.

Morse, Janice. 1995. "The Significance of Saturation.” Qualitative Health Research1 5 (2): $147-$ 49.

Moustakas, Clark. 1994. Phenomenological Research Methods. Thousand Oaks: Sage Publications.

Mullany, Jacqueline Marie. 2002. "Special Conditions for Female Probationers: Disparity or Discrimination.” Justice Professional 15 (2): 169-80.

Murphy, Yoko, Jane B Sprott, and Anthony N Doob. 2015. "Pardoning People Who Once Offended." Criminal Law Quarterly 62 (1-2): 209-25.

Murray, Joseph. 2005. "The Effects of Imprisonment on Families and Children of Prisoners." In The Effects of Imprisonment, edited by Alison Liebling and Shadd Maruna, 442-62. Portland: Willan Publishing.

Nelund, Amanda. 2015. "Engendering Alternative Justice: Criminalized Women, Alternative Justice, and Neoliberalism." University of Manitoba.

Ng, Thomas W. H., Lillian T. Eby, Kelly L. Sorensen, and Daniel C. Feldman. 2005. "Pedictors of Objective and Subjective Career Success: A Meta-Analysis." Personnel Psychology 58 (2): 367-408. http://www.redi-

bw.de/db/ebsco.php/search.ebscohost.com/login.aspx?direct=true \&db=buh\&AN=16975646 $\&$ site $=$ ehost-live.

Nietzsche, Friedrich. 1954. Twilight of the Idols. The Portab. New York: Penguin. 
Nolan, Amanda, and Jenelle Power. 2014. "Does the Type of Community Employment Obtained by Offenders on Release Correspond with Their Institional Vocational Certificate?" Correctional Service Canada.

O’Brien, Patricia. 2001. “'Just like Baking a Cake': Women Describe the Necessary Ingredients for Successful Reentry after Incarceration." Families in Society: The Journal of Contemporary Human Services 82 (3): 287-95.

O’Malley, Pat. 1996. "Risk and Responsibility." In Foucault and Political Reason: Liberalism, Neo-Liberalism and Rationalities of Government, edited by Andrew Barry, Thomas Osborne, and Nikolas Rose, 189-208. Chicago: University of Chicago Press.

- 2008. "Experiments in Risk and Criminal Justice." Theoretical Criminology 12 (4): 451-69.

Oakley, Ann. 1974. Housewife: High Value Low Cost. London: Allen Lane.

Pager, Devah. 2007. Marked: Race, Crime and Finding Work in an Era of Mass Incarceration. Chicago: University of Chicago Press.

Parlee, Mary Brown. 1989. "The Science and Politics of PMS Research.” Newport, RI.

Pavao, Jennifer. 2011. "Community-Based Programming for Women in Conflict with the Law : The Perceptions of Staff and Volunteers." University of Waterloo.

Petersen, Ian B. 2015. "Toward True Fair-Chance Hiring: Balancing Stakeholder Interests and Reality in Regulating Criminal Background Checks." Texas Law Review 94 (1): 175-94.

Petersilia, Joan. 2003. When Prisoners Come Home: Parole and Prisoner Reentry. Oxford: Oxford University Press.

Phillips, Nelson, and Cynthia Hardy. 2002. Discourse Analysis: Investigating Processes of Social Construction. Qualitativ. Thousand Oaks: SAGE Publications, Inc.

Pollack, Shoshana. 2005. "Taming the Shrew: Regulating Prisoners through Women-Centered Mental Health Programming." Critical Criminology 13 (1): 71-87.

- 2007. "“'I'm Just Not Good in Relationships": Victimization Discourses and the Gendered Regulation of Criminalized Women.” Feminist Criminology 2 (2): 158-74. https://doi.org/10.1177/1557085106297521.

Price, Joshua M. 2015. "Prison and Social Death: Critical Issues in Crime and Society." In Prison and Social Death. New Brunswick: Rutgers University Press.

Public_Safety_Canada.2019. "2018 Annual Report Corrections and Conditional Release Statistical Overview." Ottawa.

Public Safety Canada. 2017. "Corrections and Conditional Release Statistical Overview." Ottawa. http://www.publicsafety.gc.ca/cnt/rsrcs/pblctns/crrctns-cndtnl-rls-2013/indexeng.aspx.

Raibmon, Paige. 2006. "The Practice of Everyday Colonialism: Indigenous Women at Work in the Hop Fields and Tourist Industry of Puget Sound." Labor: Studies in Working-Class History of the Americas 3 (3): 23-56.

Reasons, Charles, Lois Ross, and Craig Paterson. 1981. Assault on the Worker: Occupational Health \& Safety in Canada. Toronto: Butterworths.

Reinarman, Craig. 2013. "Addiction as Accomplishment: The Discursive Construction of Disease." In Applied Ethics in Mental Health Care: An Interdisciplinary Reader, edited by Dominic Sisti and Hila Rimon-Greenspan, 6359:181-200. Cambridge: MIT Press. https://doi.org/10.1080/16066350500077728.

Reynolds, Tina. 2010. “Glossary of Terms.” In Interrupted Life: Experiences of Incarcerated 
Women in the United States. Berkeley: University of California Press.

Ricciardelli, Rose, Don Evans, and Adrienne Peters. 2017. "Navigating Employment Post-

Release: An Introduction." In After Prison: Navigating Employment and Reintegration, edited by Rose Ricciardelli and Adrienne Peters, 119. Waterloo: Wilfrid Laurier University Press.

Richie, Beth. 1996. Compelled to Crime: The Gender Entrapment of Battered Black Women. New York: Routledge.

Rickard, Diana. 2016. Sex Offenders, Stigma, and Social Control. New Brunswick: Rutgers University Press.

Rinehart, James W. 1996. The Tyranny of Work: Alienation and the Labour Process. 3rd editio. Toronto: Harcourt Brace \& Co.

Roberts, Jenny. 2002. "Women-Centred: The West Mercia Community-Based Programme for Women Offenders." In Women and Punishment: The Struggle for Justice, edited by Pat Carlen, 110-24. Cullompton: Willan Publishing.

Robinson, W. P., A. Shepherd, and J. Heywood. 1998. "Truth, Equivocation/Concealment and Lies, in Job Applications and Doctor-Patient Communication." Journal of Language and Social Psychology 17: 149-55.

Rodgers, Daniel. 1978. The Work Ethic in Industrial America, 1850-1920. Chicago: University of Chicago Press.

Rose, Hilary. 1983. 'Women's Work: Women's Knowledge.” In What Is Feminism?, edited by Juliet Mitchell and Ann Oakley, 161-83. Oxford: Basil Blackwell.

Rose, Nikolas. 1990. Governing the Soul: The Shaping of the Private Self. London: Routledge. . 1996. "The Death of the Social? Re-Figuring the Territory of Government." Economy and Society 25 (3): 327-56.

- 1999a. Governing the Soul: The Shaping of the Private Self. 2nd ed. New York: Free Association Books.

- 1999b. Powers of Freedom: Reframing Political Thought. Cambridge: Cambridge University Press.

- 2000. "Government and Control." British Journal of Criminology 40: 321-39.

Rose, Nikolas, and Mariana Valverde. 1998. “Governed by Law?” Social \& Legal Studies 7 (4): 569-79.

Ross, Lee, and Richard Nisbett. 1991. The Person and the Situation: Perspectives of Social Psychology. Philadelphia: Temple University Press.

Rothman, Robert A. 1987. Working: Sociological Perspectives. Englewood Cliffs: Prentice Hall. Royal_Commission_on_Aboriginal_Peoples. 1996. "Report of the Royal Commission on Aboriginal Peoples." Ottawa.

Rudman, Laurie A., Corinne A. Moss-Racusin, Julie E. Phelan, and Sanne Nauts. 2012. "Status Incongruity and Backlash Effects: Defending the Gender Hierarchy Motivates Prejudice against Female Leaders." Journal of Experimental Social Psychology 48 (1): 165-79. https://doi.org/10.1016/j.jesp.2011.10.008.

Sandberg, Sheryl. 2013. Lean In: Women, Work, and the Will to Lead. New York: Alfred A. Knopf.

Sapers, Howard. 2014. "Annual Report 2013-2014 of the Office of the Correctional Investigator." Ottawa.

- 2016. "Annual Report of the Office of the Correctional Investigator 2015-2016." 
Ottawa.

- 2017. "Corrections in Ontario: Directions for Reform." Toronto.

https://www.mcscs.jus.gov.on.ca/sites/default/files/content/mcscs/docs/Corrections in Ontario\%2C Directions for Reform.pdf.

Sarantakos, Sotirios. 2005. Social Research. 3rd ed. Hampshire \& New York: Palgrave Macmillan.

Savage, Laura. 2019. "Female Offenders in Canada, 2017." https://www150.statcan.gc.ca/n1/en/pub/85-002-x/2019001/article/00001eng.pdf?st $=5 \mathrm{O} 4 \mathrm{CmIhw}$.

Scobie, Olivia, and Amber Gazso. 2013. "It Was Easier to Say I Didn't Have Kids." In Incarcerated Mothers: Oppression and Resistance, edited by Gordana Eljdupovic and Rebecca Jaremko Bromwich, 148-59. Toronto: Demeter Press.

Seabrook, Renita L., and Heather Wyatt-Nichol. 2015. "Marginalization and Hope: Personal Narratives of Previously Incarcerated Mothers." In Criminalized Mothers, Criminalizing Mothering, edited by Joanne Minaker and Bryan Hogeveen, 355-72. Toronto: Demeter Press.

Seibert, Scott, Maria Kraimer, and Robert Liden. 2001. "A Social Capital Theory of Career Success." The Academy of Management Journal 44 (2): 219-37.

Sered, Susan Starr, and Maureen Norton-Hawk. 2014. Can't Catch a Break: Gender, Jail, Drugs, and the Limits of Personal Responsibility. Oakland: University of California Press.

Seshia, Maya. 2005. "The Unheard Speak Out: Street Sexual Exploitation in Winnipeg." Winnipeg.

Settee, Priscilla. 2011. The Strength of Women: Ahkameyimowak. Regina: Coteau Books.

Shivy, Victoria A., J. Juana Wu, Anya E. Moon, Shay C. Mann, Jo G. Holland, and Christine Eacho. 2007. "Ex-Offenders Reentering the Workforce." Journal of Counseling Psychology 54 (4): 466-73.

Sim, Joe. 2005. "At the Centre of the New Professional Gaze: Women, Medicine and Confinement." In Women, Madness and the Law: A Feminist Reader, edited by Wendy Chan, Dorothy E. Chunn, and Robert Menzies, 211-26. London: Glasshouse Press.

Simon, Jonathan. 1994. "In the Place of the Parent: Risk Managment and the Government of Campus Life." Social \& Legal Studies 3: 15-45.

Simpson, Sally S., Jennifer L. Yahner, and Laura Dugan. 2008. “Understanding Women's Pathways to Jail: Analysing the Lives of Incarcerated Women." Australian and New Zealand Journal of Criminology 41 (1): 84-108. https://doi.org/10.1375/acri.41.1.84.

Slaughter, Anne-Marie. 2015. Unfinished Business: Women Men Work Family. New York: Random House.

Smart, Carol. 1992. “The Woman of Legal Discourse.” Social \& Legal Studies 1: 29-44.

-1995. Law, Crime and Sexuality. London: Sage.

Smith, Adam. 1776. The Wealth of Nations. London: Methuen \& Co., Ltd.

Smith, Dorothy E. 1987. The Everyday World as Problematic: A Feminist Sociology. Boston: Northeastern University Press.

Solinger, Rickie, Paula C. Johnson, Martha Raimon, Tina Reynolds, and Ruby Tapia. 2010. Interrupted Life: Experiences of Incarcerated Women in the United States. Edited by Rickie Solinger. Berkeley: University of California Press.

Standing, Guy. 2011. The Precariat: The New Dangerous Class. London: Bloomsbury 
Academic.

Statistics Canada. n.d. "The Surge of Women in the Workforce." Accessed January 4, 2016. http://www.statcan.gc.ca/pub/11-630-x/11-630-x2015009-eng.htm.

- 2015. "Employment by Industry and Sex." 2015. http://www.statcan.gc.ca/tablestableaux/sum-som/101/cst01/labor10a-eng.htm.

Steffensmeier, Darrell, and Emilie Allan. 1996. "Gender and Crime: Toward a Gendered Theory of Female Offending." Annual Review of Sociology 22: 459-87.

Strange, Carolyn E. 1983. "The Velvet Glove: Maternalistic Reform at the Andrew Mercer Reformatory for Females 1874-1927." University of Ottawa.

TFFSW. 1990. "Creating Choices." Ottawa.

Thompson, Jennie, Michael-Anthony Lutfy, and Michelle Bertrand. 2015. "The Needs of Women Offenders under Community Supervision.” Ottawa.

Travis, Jeremy, and Christy Visher. 2005. Prisoner Reentry and Crime in America. Edited by Jeremy Travis and Christy Visher. New York: Cambridge University Press.

Truth and Reconcilliation Commision. 2015. "Truth and Reconciliation Commission: Calls to Action." Winnipeg.

http://www.trc.ca/websites/trcinstitution/File/2015/Findings/Calls_to_Action_English2.pdf.

Tunnell, Kenneth. 1992. Choosing Crime: The Criminal Calculus of Property Offenders. Chicago: Nelson-Hall.

Turnbull, Sarah, and Kelly Hannah-Moffat. 2009. "Under These Conditions: Gender, Parole and the Governance of Reintegration." British Journal of Criminology 49 (4): 532-51.

Uggen, Christopher, Sara Wakefield, and Bruce Western. 2005. "Work and Family Perspectives on Reentry." In Prisoner Reentry and Crime in America, edited by Jeremy Travis and Christy Visher. New York: Cambridge University Press.

Usher, Graham. 1990. “Employment Training: Britain's New Bantustans.” Race and Class 32 (1): 45-56.

Ussher, Jane M. 2005. “Unravelling Women's Madness: Beyond Positivism and Constructivism and towards a Material-Discursive-Intrapsychic Approach." In Women, Madness and the Law: A Feminist Reader, edited by Wendy Chan, Dorothy E. Chunn, and Robert Menzies, 19-40. London: Glasshouse Press.

Vallas, Steven Peter. 2012. Work: A Critique. Cambridge: Polity Press.

Valverde, Mariana, and Michael Mopas. 2004. "Insecurity and Targeted Governance." In Governmentality: Governing International Spaces, edited by Wendy Larner and William Walters, 233-50. London \& New York: Routledge.

Van de Kolk, Bessel. 2014. The Body Keeps the Score: Brain, Mind, and Body in the Healing of Trauma. New York: Viking.

Vis-Dunbar, Megan. 2008. "Child Apprehensions in BC Correctional Facilities."

Vosko, Leah F., and Lisa F. Clark. 2009. "Canada: Gendered Precariousness and Social Reproduction." In Gender and the Countours of Precarious Employment, edited by Leah F. Vosko, Martha MacDonald, and Iain Campbell, 26-42. New York and London: Routledge.

Warner, Tara D., and John H. Kramer. 2009. "Closing the Revolving Door?: Substance Abuse Treatment as an Alternative to Traditional Sentencing for Drug-Dependent Offenders."

Criminal Justice and Behavior 36 (1): 89-109. https://doi.org/10.1177/0093854808326743. Weber, Max. 1922. Economy and Society. 1968th ed. Berkeley: University of California Press. . 1958. The Protestant Ethic and the Spirit of Capitalism. Translated. Mineola: Dover 
Publications, Inc.

Weeks, Kathi. 1998. Constituting Feminist Subjects. Ithaca \& London: Cornell University Press. . 2011. The Problem with Work: Feminism, Marxism, Anitwork Politics, and Postwork Imaginaries. Durham \& London: Duke University Press.

Werth, Robert. 2012. "I Do What I'm Told, Sort of: Reformed Subjects, Unruly Citizens, and Parole." Theoretical Criminology 16 (3): 329-46.

Wesley, Mandy. 2012. "Marginalized: The Aboriginal Women's Experience in Federal Corrections." Ottawa.

Western, Bruce. 2002. "The Impact of Incarceration on Wage Mobility and Inequality." American Sociological Review 67 (4): 526-46.

White, Julie. 1980. "Women and Unions." Ottawa.

Williams, Felisia, Alo Dutta, Madan Kundu, and Michael Welch. 2008. "Vocational Rehabilitation Services Needs of Female Ex-Inmates with Mental Illness: The Perspective of a Southern State." Journal of Applied Rehabilitation Counseling 39 (3): 25-32.

Williams, Jennie, Sara Scott, and Sara Waterhouse. 2001. "Mental Health Services for 'Diffcult' Women: Reflections on Some Recent Developments." Feminist Review, no. 68: 89-104. https://doi.org/10.1080/0141778011004241.

Winnick, Terri A, and Mark Bodkin. 2008. "Anticipated Stigma and Stigma Management Among Those to Be Labeled 'Ex-Con." Deviant Behavior 29 (4): 295-333. https://doi.org/10.1080/01639620701588081.

Withers, Lloyd, and Jean Folsom. 2007. "Incarcerated Fathers: A Descriptive Analysis." Ottawa. Wood, Jennifer, James Schmidtke, and Diane Decker. 2007. "Lying on Job Applications: The Effects of Job Relevance, Commission, and Human Resource Management Experience" 22 (1): $1-9$.

Wotherspoon, Terry. 2007. "Incorporation of Aboriginal Labour." In Race \& Racism in 21st Century Canada: Continuity, Complexity, and Change, edited by Sean P. Hier and B. Singh Bolaria. Toronto: Broadview Press.

Wyse, Jessica J. B. 2013. "Rehabilitating Criminal Selves: Gendered Strategies in Community Corrections." Gender \& Society 27 (2): 231-55.

Young, Iris Marion. 1994. "Punishment, Treatment, Empowerment: Three Approaches to Policy for Pregnant Addicts." Feminist Studies 20 (1): 33-57.

Young, Jock. 2007. The Vertigo of Late Modernity. London \& Los Angeles: Sage.

Zinger, Ivan. 2017. "Issues Facing Federally Sentenced Women: An Ombudsman's Perspective." In Stride Symposium Women in Prison: Building Community for Women Living inside and out of Prison Walls. Kitchener.

—. 2018. "Office of the Correctional Investigator Annual Report 2017-2018." Ottawa. 


\section{PRIMARY SOURCES}

Chu v. Canada (Attorney General), 2017, BCSC 630

Corrections and Conditional Release Act, SC 1992, c. 20

Criminal Records Act, RSC 1985, c. C-47.

Commissioner's Directive 735: Employment and Employability Program, Correctional Service Canada, 2017.

Kelly, Ann. Commissioner of Correctional Service Canada. 2019. The Standing Senate Committee on Human Rights, Evidence. 27 Feb.

Protection of Communities and Exploited Persons Act, SC 2014, c. 25 


\section{APPENDiX A - RECRUITMENT FLYER \\ Non Carleton \\ Canada's Capital University \\ Study on employment programs for women}

Are you looking for work? I am a PhD student studying employment programs and support services for women who have been involved in the criminal justice system and who are trying to find a job.

If you have taken part in employment training or had employment-related support from community organizations, parole officers, or other agencies, I would love to talk to you. Examples of employment support include resume-building, job searches, and skills training.

I want to ask about:

- your experiences with employment training programs and services, in institutions and/or in the community

- challenges or successes you have had in finding work

We can choose where we will do the interview and find a place and time that is convenient for you. Learning from your experience is important to helping understand what works, or doesn't, in helping women find jobs when they have been involved with the criminal justice system.

You can choose to have a Tim Hortons or a grocery store gift card for taking part in this study.

I hope you will participate. If you are interested, please contact me, Anita Grace, by email, phone, or text.

anita.grace@carleton.ca

343.883.7849 


\section{Appendix B - Interview Guide - Service Providers}

1) Information about community organization: Please tell me about your organization and the services you provide to women who have criminal convictions.

a. What is your role? How long have you been in this position? Have you had similar roles in this or other organizations? What training have you done that is related to your role?

2) Information about program participants: Please tell me about who participates in the employment programs you provide.

a. Please tell me about the people who access the services in your organization.

b. What is the process by which women are referred to your organization or access your services? What makes a woman eligible or ineligible to participate in programs? Do women choose to participate in these programs?

3) Information about employment programs/services: Please tell me about your employment-related programs and services and your experiences with these services.

a. What employment-related opportunities are currently available to criminalized women - at your organization and in the community?

b. What employability skills/employment training does your program focus on? How do you teach these skills?

i. What are the jobs you are preparing women for?

ii. What do you think about these programs?

iii. How are these programs evaluated?

c. What kinds of resources do you use in your programs and services (i.e. manuals, handouts, etc.)?

d. What does your average day look like? What is a good day/week for you? What about a bad one?

e. What do you like about this job? Can you give me an example of a positive story? What about one that is not so positive?

f. Do or can women choose to leave the program? Are there consequences for them if they do not complete the program [access to housing or children, parole conditions, etc.]

4) How important do you think employment is for women who have been involved with the criminal justice system?

a. How does the need for employment compare with other needs that reintegrating women have?

b. What challenges does your organization face in helping criminalized women find employment? How do you address those challenges?

5) Is there anything we have not discussed that you think I need to know with regards to employment training for criminalized women? 


\section{APPENDIX C - INTERVIEW GUIDE - REINTEGRATING WoMen}

1) Employment history: Can you tell me about your employment history?

a. Are you currently employed? If not, are you looking for work?

b. What kind of job would you like to have?

c. Can you tell me about jobs you've had?

d. Can you tell me a story about an experience you have had when applying for jobs?

e. What do you think are the biggest challenges you have faced in trying to find employment? How do you respond to these challenges?

2) Information about employment programs: Please tell me about the types of employment training you have participated in.

a. Are you currently in any program/receiving employment-related services?

i. What skills/ training does the program focus on?

ii. What resources are you given?

iii. What kinds of jobs are you being trained for?

iv. Can you describe an average day of training?

b. Have you done employment training in the past [in institutions and/or in community]? Please describe these.

i. How were you referred to these programs?

ii. Did you choose to participated in these programs or were you required to participate? What kind of choices were available to you within these programs?

iii. How did you feel about participating in these programs?

c. Can you give me a comparison between a program or training that you found helpful, and one that you did not?

d. How do you know if you are doing well in a program [feedback process/grades/certificates]?

e. Have you ever quit an employment program? If so, why? What happened then?

f. Have you ever felt pressured to take a program or stay in a program even if it was not helpful?

g. If you could give advice to people who design or run employment programs for women, what would you say?

3) How important do you think employment is for women who have been involved with the criminal justice system?

4) Is there anything we have not discussed that you think I need to know with regards to employment training for criminalized women?

5) Information about participant: Can you please tell me your age? Race/ethnicity? Disabilities/barriers to employment? 